\title{
Molecular analysis of importin- $\alpha$-mediated nucleocytoplasmic signaling in plant innate immunity
}

\author{
Dissertation zur Erlangung des Doktorgrades \\ der Mathematisch-Naturwissenschaftlichen Fakultäten \\ "Doctor rerum naturalium" \\ der Georg-August-Universität Göttingen \\ im Promotionsprogramm Biologie \\ der Georg-August University School of Science (GAUSS) \\ vorgelegt von \\ Charlotte Roth \\ aus Hildesheim
}

Göttingen 2015 


\section{Promovierenden-Erklärung}

1. Die Gelegenheit zum vorliegenden Promotionsvorhaben ist mir nicht kommerziell vermittelt worden. Insbesondere habe ich keine Organisation eingeschaltet, die gegen Entgelt Betreuerinnen und Betreuer für die Anfertigung von Dissertationen sucht oder die mir obliegenden Pflichten hinsichtlich der Prüfungsleistungen für mich ganz oder teilweise erledigt.

2. Hilfe Dritter wurde bis jetzt und wird auch künftig nur in wissenschaftlich vertretbarem und prüfungsrechtlich zulässigem Ausmaß in Anspruch genommen. Insbesondere werden alle Teile der Dissertation selbst angefertigt; unzulässige fremde Hilfe habe ich dazu weder unentgeltlich noch entgeltlich entgegengenommen und werde dies auch zukünftig so halten.

3. Die Ordnung zur Sicherung der guten wissenschaftlichen Praxis an der Universität Göttingen wird von mir beachtet.

4. Eine entsprechende Promotion wurde an keiner anderen Hochschule im In- oder Ausland beantragt; die eingereichte Dissertation oder Teile von ihr wurden nicht für ein anderes Promotionsvorhaben verwendet.

Mir ist bekannt, dass unrichtige Angaben die Zulassung zur Promotion ausschließen bzw. später zum Verfahrensabbruch oder zur Rücknahme des erlangten Grades führen. 


\section{Betreuungsausschuss}

1. Betreuer: Prof. Dr. Volker Lipka

Zellbiologie der Pflanze, Albrecht-von-Haller Institut für Pflanzenwissenschaften

2. Betreuer: PD Dr. Thomas Teichmann

Zellbiologie der Pflanze, Albrecht-von-Haller Institut für Pflanzenwissenschaften

Anleiter: Dr. Marcel Wiermer

Zellbiologie der Pflanze, Albrecht-von-Haller Institut für Pflanzenwissenschaften

\section{Mitglieder der Prüfungskommission}

\section{Referent: Prof. Dr. Volker Lipka}

Zellbiologie der Pflanze

Albrecht-von-Haller Institut für Pflanzenwissenschaften

Korreferent: PD Dr. Thomas Teichmann

Zellbiologie der Pflanze

Albrecht-von-Haller Institut für Pflanzenwissenschaften

\section{Weitere Mitglieder der Prüfungskommission}

Prof. Dr. Ivo Feußner

Biochemie der Pflanze

Albrecht-von-Haller Institut für Pflanzenwissenschaften

Prof. Dr. Christiane Gatz

Molekularbiologie und Physiologie der Pflanze

Albrecht-von-Haller Institut für Pflanzenwissenschaften

Prof. Dr. Cynthia Gleason

Molekulare Pflanzenwissenschaften

Albrecht-von-Haller Institut für Pflanzenwissenschaften

Prof. Dr. Andrea Polle

Forstbotanik und Baumphysiologie

Fakultät für Forstwissenschaften und Waldökologie 

Für meine Familie 



\section{List of publications}

Wirthmueller, L., Roth, C., Fabro, G., Caillaud, M.-C., Rallapalli, G., Asai, S., Sklenar, J., Jones, A.M.E., Wiermer, M., Jones, J.D.G., and Banfield, M.J. (2015). Probing formation of cargo/importin- $\alpha$ transport complexes in plant cells using a pathogen effector. Plant Journal 81(1): 40-52.

Jessen, D., Roth, C., Wiermer, M., and Fulda, M. (2015). Two activities of long-chain acylcoenzyme A synthetase are involved in lipid trafficking between the endoplasmic reticulum and the plastid in Arabidopsis. Plant Physiology 167(2): 351-66.

Huang, Y., Minaker, S., Roth, C., Huang, S., Hieter, P., Lipka, V., Wiermer, M., and Li, X. (2014). An E4 ligase facilitates polyubiquitination of plant immune receptor resistance proteins in Arabidopsis. Plant Cell 26 (1): 485-496.

Wirthmueller, L., Roth, C., Banfield, M.J., and Wiermer, M. (2013). Hop-on hop-off: importin- $\alpha$-guided tours to the nucleus in innate immune signaling. Frontiers in Plant Science 4: 149.

Huang, Y., Chen, X., Liu, Y., Roth, C., Copeland, C., McFarlane, H.E., Huang, S., Lipka, V., Wiermer, M., and Li, X. (2013). Mitochondrial AtPAM16 is required for plant survival and the negative regulation of plant immunity. Nature Communications 4: 2558.

Schön, M., Töller, A., Diezel, C., Roth, C., Westphal, L., Wiermer, M., and Somssich, I.E. (2013). Analyses of wrky18 wrky40 plants reveal critical roles of SA/EDS1 signaling and indole-glucosinolate biosynthesis for Golovinomyces orontii resistance and a loss-of resistance towards Pseudomonas syringae pv. tomato AvrRPS4. MolecularPlant Microbe Interactions 26 (7): 758-767.

Roth, C., and Wiermer, M. (2012). Nucleoporins Nup160 and Seh1 are required for disease resistance in Arabidopsis. Plant Signaling and Behavior 7 (10): 1212-1214. 


\section{Abstract}

IMPORTIN- $\alpha$ s are a family of nuclear transport receptors that mediate the translocation of nuclear localization signal (NLS)-containing cargo proteins from the cytoplasm into the nucleus through nuclear pores. The IMPORTIN- $\alpha 3$, MOS6 (MODIFIER OF SNC1, 6), is one of nine putative IMPORTIN-as encoded by the Arabidopsis genome. MOS6 was identified as an essential component of auto-immune responses and related growth inhibition caused by the constitutively active TIR-NB-LRR Resistance protein variant, snc1 (suppressor of npr1-1, constitutive 1). In addition, MOS6 is required for basal resistance. This suggests that MOS6 is required for specific or preferential nuclear import of unknown cargo proteins involved in defense signaling.

In this study, the contribution of the nine IMPORTIN- $\alpha$ family members to basal resistance and snc1-mediated auto-immunity was investigated and potential functional redundancies within the nuclear import receptor family in plant defense signaling were addressed. For reverse-genetic analyses, a collection of importin- $\alpha$ single, double and triple mutant combinations was generated and a prominent role of MOS6 in plant immunity and snc1 auto-immunity could be demonstrated.

To identify defense-related cargo substrates and interaction partners of MOS6, in planta affinity purification of functional epitope-tagged MOS6 coupled with mass spectrometry was performed in addition to analyses of an established Arabidopsis interactome database. From these approaches, thirteen candidate MOS6 interactors were selected for further characterization. Transient expression in Nicotiana benthamiana and subsequent co-immunoprecipitation was used to validate these interactions. Several interactors were shown to selectively bind MOS6 as they did not interact with its closest homolog IMPORTIN- $\alpha 6$, reinforcing the idea of MOS6 substrate specificity. T-DNA insertion mutants of MOS6-interactor candidates were isolated and subjected to functional analyses. Interestingly, a mutation in the gene encoding the TIRNBS protein TN13 leads to impaired resistance against Pseudomonas syringae pv. tomato DC3000 with an incomplete effector repertoire ( $\triangle$ AvrPto/AvrPtoB). This finding demonstrates a so far unknown involvement of the novel MOS6-interacting protein TN13 in plant innate immunity. Confocal laser scanning microscopy revealed that TN13 localizes to the endoplasmic reticulum when transiently expressed in $N$. benthamiana. This may suggest release of TN13 from the ER-membrane upon pathogen attack and subsequent MOS6-mediated nuclear translocation for maintenance of basal resistance. 


\section{Zusammenfassung}

IMPORTIN-as bilden eine Familie von Kernimport-Rezeptoren. Sie vermitteln die Translokation von Proteinen, die ein Kernlokalisationssignal enthalten, vom Zytoplasma in den Zellkern. Dies geschieht durch Kernporen, die die Doppelmembran des Zellkerns durchspannen. IMPORTIN- $\alpha 3 /$ MOS6 (MODIFIER OF SNC1, 6) ist eines von neun im Arabidopsis Genom kodierten IMPORTIN- $\alpha$ s. MOS6 wurde als eine wesentliche Komponente von Auto-Immunantworten, die durch die konstitutiv aktive TIR-NB-LRR Proteinvariante, snc1 (suppressor of npr1-1, constitutive 1) verursacht werden, identifiziert. Zusätzlich ist MOS6 für die basale pflanzliche Resistenz in Arabidopsis erforderlich. Dies deutet darauf hin, dass MOS6 spezifisch oder präferentiell Komponenten der pflanzlichen Immunität in den Zellkern transportiert.

Im Rahmen dieser Arbeit wurden zunächst der Beitrag der neun IMPORTIN- $\alpha$ s in der basalen Resistenz und der snc1-vermittelten Auto-Immunität analysiert sowie mögliche funktionelle Redundanzen innerhalb der Kernimport-Rezeptor-Familie während pflanzlicher Immunantworten untersucht. Dabei konnte mittels revers-gentechnischer Analysen von importin- $\alpha$ Einzel-, Doppel- und Dreifachmutantenkombinationen gezeigt werden, dass MOS6 innerhalb der Arabidopsis IMPORTIN- $\alpha$ Familie eine vorrangige Funktion in basaler Resistenz und snc1-vermittelter Auto-Immunität hat.

Für die Identifizierung immunrelevanter Cargo-Substrate und Interaktionspartner von MOS6 wurde parallel zur Nutzung einer etablierten Arabidopsis Interaktom Datenbank Epitop-markiertes MOS6 stabil in transgenen mos6-1 Pflanzen exprimiert, die nach Pathogeninokulation zur Affinitätsreinigung gekoppelt mit Massenspektrometrie genutzt wurden. Dreizehn Interaktionspartner-Kandidaten wurden für die weitere Charakterisierung ausgewählt. Mittels Co-Immunopräzipitation nach transienter Expression in Nicotiana benthamiana wurden diese Interaktionen mit MOS6 überprüft. Mehrere der Kandidaten interagierten spezifisch mit MOS6 und nicht mit dessen nächstem Verwandten IMPORTIN- $\alpha 6$, wodurch die Hypothese der Substrat-Spezifität von MOS6 untermauert wird. T-DNA-Insertionslinien der MOS6 InteraktionspartnerKandidaten wurden isloliert und in Bezug auf die pflanzliche Abwehr funktionell untersucht. Dies führte zu der Entdeckung von TN13, einem TIR-NBS (TN) Protein, das mit MOS6 aber nicht mit dessem nächstverwandten Homolog IMP- $\alpha 6$ interagiert und in der Abwehr gegen Pseudomonas syringae pv. tomato DC3000 ( $\triangle$ AvrPto/AvrPtoB) beteiligt ist. Zudem wurde durch transiente Expression in $N$. benthamiana und konfokaler Fluoreszenzmikroskopie gezeigt, dass TN13 im endoplasmatischen Retikulum (ER) lokalisiert. Dies könnte bedeuten, dass TN13 nach Pathogenbefall vom ER abgespalten und für die Aufrechterhaltung basaler Resistenzantworten durch MOS6 vermittelt in den Zellkern transportiert wird. 


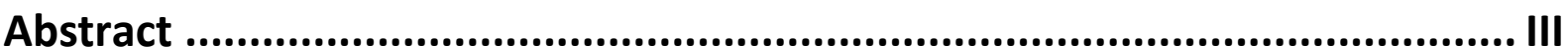

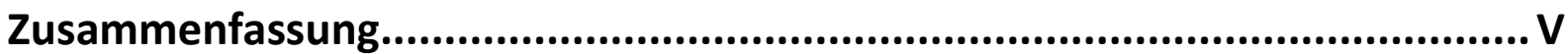

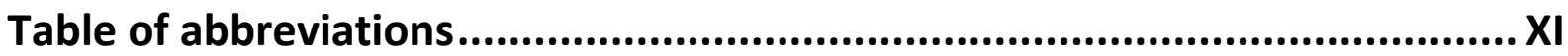

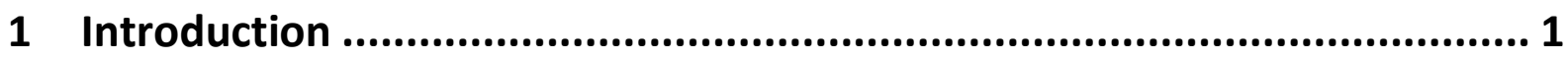

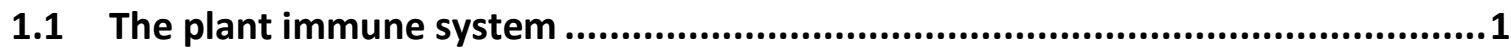

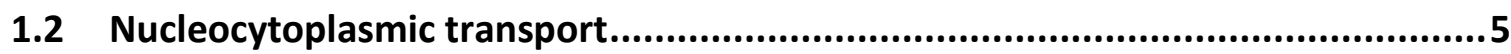

1.3 Dynamic nucleocytoplasmic responses in plant immunity...............................8

1.4 The role of the nuclear transport machinery in plant immunity ........................12

1.5 The IMPORTIN- $\alpha$ family in animal and plant immunity ................................ 15

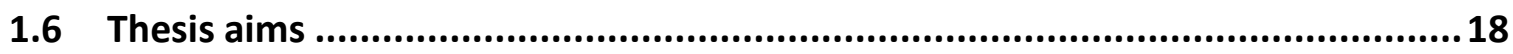

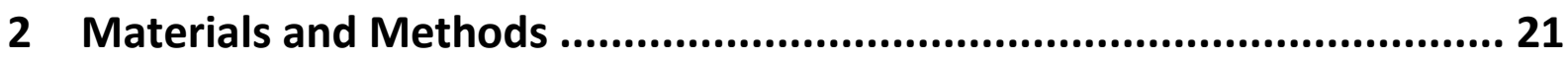

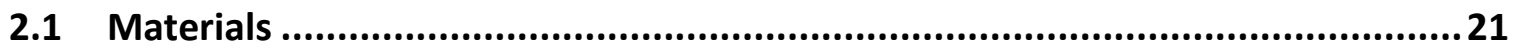

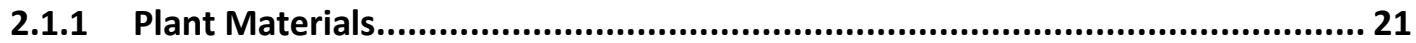

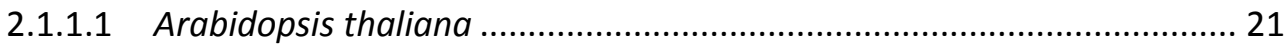

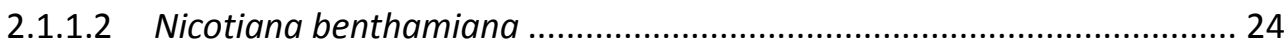

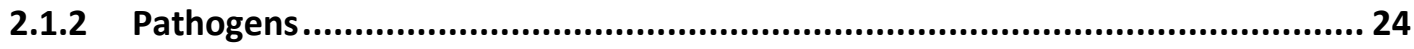

2.1.2.1 Hyaloperonospora arabidopsidis ........................................................ 24

2.1.2.2 Pseudomonas syringae pv. tomato........................................................ 24

2.1.3 Bacterial strains used for cloning and transient expression............................. 25

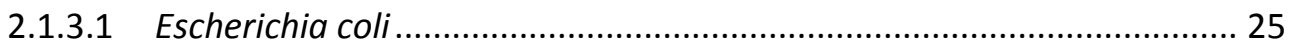

2.1.3.2 Agrobacterium tumefaciens.......................................................... 25

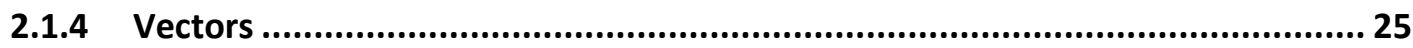

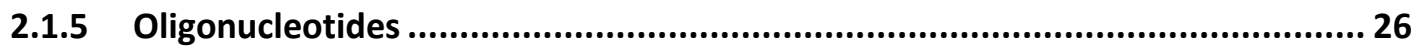

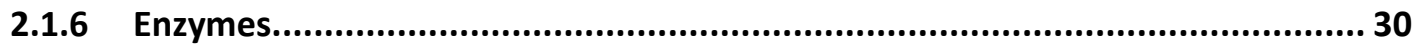

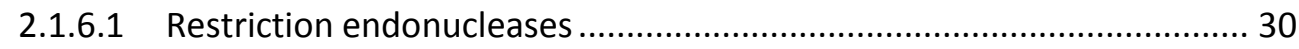

2.1.6.2 Nucleic acid modifying enzymes ....................................................... 30

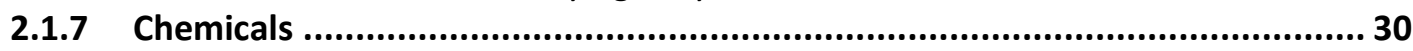

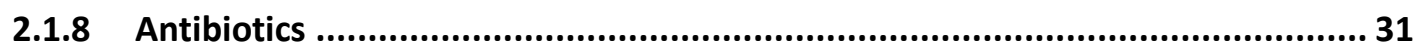

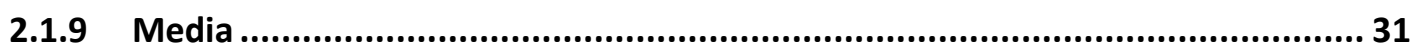

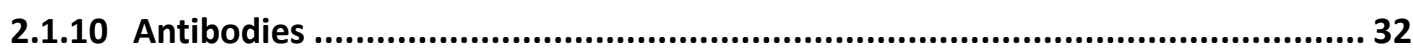

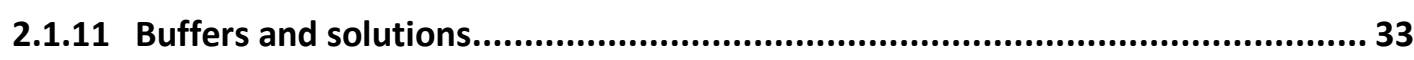

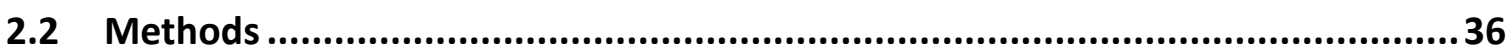

2.2.1 Maintenance and cultivation of plant material........................................ 36

2.2.1.1 Generation of Arabidopsis F1 and F2 progeny ............................... 36

2.2.1.2 Arabidopsis seed sterilisation ................................................. 37

2.2.1.3 Agrobacterium-mediated stable transformation of Arabidopsis .......... 37

2.2.1.4 Glufosinate selection of Arabidopsis transformants on soil.................. 38

2.2.2 Inoculation and maintenance of Hyaloperonospora arabidopsidis ................... 38

2.2.2.1 Quantification of Hyaloperonospora arabidopsidis sporulation............ 38 
2.2.3 Maintenance of Pseudomonas syringae pv. tomato cultures ........................ 39

2.2.3.1 Pseudomonas syringae pv. tomato growth assay................................. 39

2.2.4 Biochemical methods ........................................................................... 40

2.2.4.1 Total protein extraction for immunoblot analysis .............................. 40

2.2.4.2 Strepll affinity purification ........................................................... 40

2.2.4.3 Co-immunoprecipitation......................................................... 41

2.2.4.4 Denaturing SDS-polyacrylamide gel electrophoresis (SDS-PAGE) ......... 42

2.2.4.5 Immunoblot analysis.............................................................. 43

2.2.4.6 Silver staining of SDS-PAGE gels.................................................. 43

2.2.4.7 Tryptic in-gel-digestion ............................................................... 44

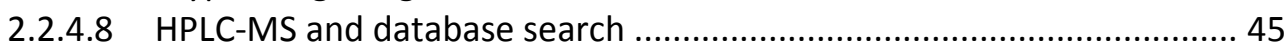

2.2.5 Molecular biological methods................................................................. 46

2.2.5.1 Preparation of genomic DNA from Arabidopsis with FTA paper ........... 46

2.2.5.2 Polymerase chain reaction (PCR) .................................................... 46

2.2.5.3 Isolation of total RNA from Arabidopsis ........................................... 47

2.2.5.4 DNase-digestion of total RNA from Arabidopsis................................. 47

2.2.5.5 Reverse transcription-polymerase chain reaction (RT-PCR) ................. 47

2.2.5.6 Plasmid DNA isolation from Escherichia coli ...................................... 48

2.2.5.7 Restriction endonuclease digestion of DNA ...................................... 48

2.2.5.8 Agarose gel electrophoresis of DNA ............................................... 48

2.2.5.9 Isolation of DNA fragments from agarose gel................................... 49

2.2.5.10 Site specific recombination of DNA in Gateway ${ }^{\circledR}$-compatible vectors ... 49

2.2.5.11 DNA sequencing and sequence analysis ........................................ 49

2.2.5.12 Preparation of chemically competent E.coli cells ................................ 50

2.2.5.13 Transformation of chemically competent $E$. coli cells ............................ 50

2.2.5.14 Preparation of electro-competent $A$. tumefaciens cells ......................... 51

2.2.5.15 Transformation of electro-competent $A$. tumefaciens cells .................. 51

2.2.6 Agrobacterium-mediated transient transformation of $\boldsymbol{N}$. benthamiana leaves. 51

2.2.7 Localization studies using confocal laser scanning microscopy (CLSM) ............ 52

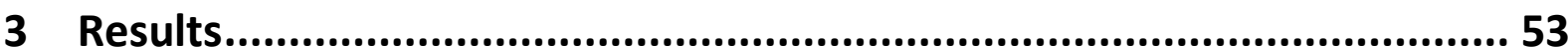

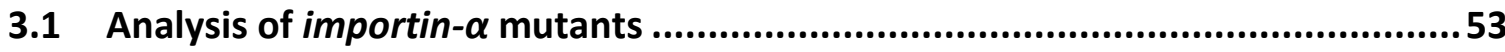

3.1.1 Mutants lacking functional MOS6 are more susceptible against Pseudomonas bacteria with incomplete effector repertoire .......................................... 54

3.1.2 The Arabidopsis IMPORTIN- $\alpha$ family ....................................................... 56

3.1.3 Characterization of importin- $\alpha$ mutant lines.......................................... 58

3.1.3.1 Importin- $\alpha$ T-DNA insertion lines used in this study ............................. 58

3.1.3.2 Phenotypic characterization of $i m p$ - $\alpha$ single mutants.......................... 61

3.1.3.3 mos6 alleles but no other imp- $\alpha$ mutants are impaired in resistance against $H$. a. NOCO2 and Pst DC3000 ( $\triangle$ AvrPto/AvrPtoB) .....................63 63

3.1.3.4 Only mutant alleles of mos6 but not of other imp-as suppress the

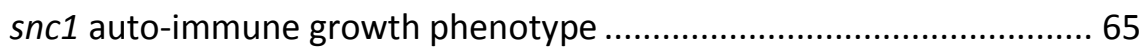

3.1.4 Characterization of imp- $\alpha$ double and triple mutants .............................. 67

3.1.4.1 Higher order mutant combinations containing imp- $\alpha 1$ show reduced growth

3.1.4.2 Susceptibility of triple mutant lines containing mos 6 is not further increased as compared to the mos6-1 single mutant

3.2 Identification and characterization of defense-related cargo proteins and interaction partners of the IMPORTIN- $\alpha 3$, MOS6 .........................................72

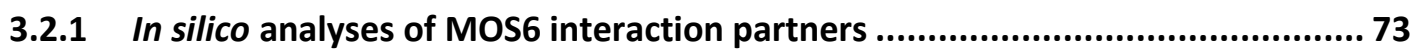


3.2.2 Generation and characterization of stable transgenic Arabidopsis plants expressing 3xHA-Strepll tagged MOS6 .......................................................... 75

3.2.3 In planta affinity purification of MOS6 interacting proteins ........................... 77

3.2.4 Validation of MOS6 interactions via Agrobacterium-mediated transient expression in $\mathbf{N}$. benthamiana and Co-immunoprecipitation ......................... 83

3.2.5 Reverse genetic analysis of candidate MOS6 interactors in pathogen defense .85 3.2.5.1 A T-DNA insertion in the TIR-NBS gene TN13 is more susceptible to Pst DC3000 ( $\triangle$ AvrPto/AvrPtoB) but does not suppress the snc1

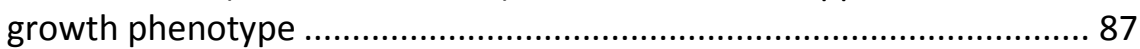

3.2.5.2 TN13-cCFP localizes in the ER in N. benthamiana .................................. 89

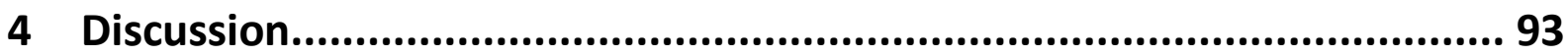

4.1 Selective roles of Arabidopsis IMP- $\alpha$ proteins in plant growth and defense.......93

4.1.1 Regulation of IMP- $\alpha$ expression and function ...............................................94 94

4.1.2 MOS6 is selectively required for plant defense............................................... 96

4.1.3 IMP- $\alpha 1, I M P-\alpha 2$ and MOS6 have partially redundant functions in plant growth regulation ......................................................................................... 97

4.2 Identification and characterization of MOS6 cargo proteins and interaction partners

4.2.1 Exclusive and redundant functions of MOS6 and its closest homolog IMP- $\alpha 6$ in nuclear transport complex formation

4.2.1.1 NUP1/NUP136 and NUP155 selectively interact with MOS6 while NUP50 interacts with both, MOS6 and IMP- $\alpha 6 \ldots \ldots \ldots \ldots \ldots \ldots \ldots \ldots \ldots \ldots . . . . . . . . . . . . . . . . .100$

4.2.1.2 MOS6 and IMP- $\alpha 6$ interact with karyopherins of the IMP- $\beta$ family..... 103

4.2.1.3 MYB70, ORS1 and WRKY60 interact with MOS6 but not with IMP- $\alpha 6107$

4.2.1.4 MOS6 but not its closest homolog IMP- $\alpha 6$ interacts with the TIR-NBS protein TN13 which is involved in plant innate immunity.

4.3 Possible roles for the TIR-NBS protein TN13 in plant defense signaling ..........111

4.3.1 The TIR-NBS protein TN13 localizes to the endoplasmic reticulum when expressed transiently in $N$. benthamiana

4.4 Outlook

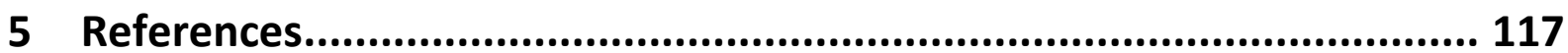

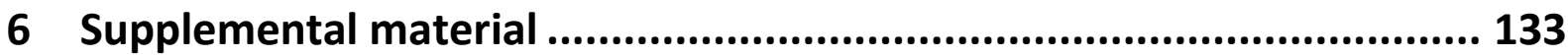

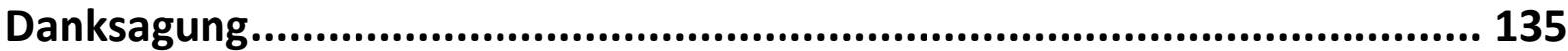

Curriculum Vitae .............................................. Error! Bookmark not defined. 


\section{Table of abbreviations}

\begin{tabular}{|c|c|}
\hline$::$ & fused to (in the context of gene fusion constructs) \\
\hline${ }^{\circ} \mathrm{C}$ & degree Celsius \\
\hline Abbr & abbreviation \\
\hline avr & avirulence \\
\hline$b p$ & base pair(s) \\
\hline $\mathrm{C}$ & carboxy-terminal \\
\hline CALA2 & Hyaloperonospora arabidopsidis isolate CALA2 \\
\hline CaMV & cauliflower mosaic virus \\
\hline $\mathrm{CC}$ & coiled-coil \\
\hline CDNA & complementary DNA \\
\hline CFP & cyan fluorescent protein \\
\hline cfu & colony forming unit \\
\hline CLSM & confocal laser scanning microscopy \\
\hline$d$ & $\operatorname{day}(s)$ \\
\hline $\mathrm{dH}_{2} \mathrm{O}$ & deionised water \\
\hline DMSO & dimethylsulfoxide \\
\hline DNA & deoxyribonucleic acid \\
\hline DNase & deoxyribonuclease \\
\hline dNTP & deoxynucleosidetriphosphate \\
\hline DTT & dithiothreitol \\
\hline EDS1 & ENHANCED DISEASE SUSCEPTIBILITY 1 \\
\hline EDTA & ethylenediaminetetraacetic acid \\
\hline EMWA1 & Hyaloperonospora arabidopsidis isolate EMWA1 \\
\hline $\mathrm{EtOH}$ & ethanol \\
\hline Fig. & Figure \\
\hline g & gram \\
\hline gDNA & genomic DNA \\
\hline GFP & green fluorescent protein \\
\hline GUS & $\beta$-glucuronidase \\
\hline $\mathrm{h}$ & hour(s) \\
\hline HR & hypersensitive response \\
\hline HRP & horseradish peroxidase \\
\hline IMP- $\alpha$ & IMPORTIN- $\alpha$ \\
\hline IMP- $\beta$ & IMPORTIN- $\beta$ \\
\hline kb & kilobase(s) \\
\hline
\end{tabular}


$\mathrm{kDa}$

L

$\log$

LRR

m

M

$\mu$

$\min$

$\mathrm{mM}$

MOS

mRNA

$\mathrm{N}$

NBS

ng

$\mathrm{nm}$

$\mathrm{NOCO} 2$

NPC

NUP

OD

ORF

P35SS

PAMP

PCR

PAGE

$\mathrm{pH}$

PR

Pst

pv.

$\mathrm{R}$

RNA

ROI

rpm

RPM

RPP

RPS

RT

RT-PCR

SA
kiloDalton(s)

litre

decimal logarithm

leucine-rich repeats

milli

molar (mol/L)

micro

minute(s)

millimolar

MODIFIER OF SNC1

messenger ribonucleic acid

amino-terminal

nucleotide binding site

nanogram

nanometer

Hyaloperonospora arabidopsidis isolate $\mathrm{NOCO} 2$

nuclear pore complex

nucleoporin

optical density

open reading frame

double $35 \mathrm{~S}$ promoter of CaMV

pathogen-associated molecular pattern

polymerase chain reaction

polyacrylamide gel-electrophoresis

negative decimal logarithm of the $\mathrm{H}+$ concentration

pathogenesis related

Pseudomonas syringae pv. tomato

pathovar

resistance

ribonucleic acid

reactive oxygen intermediates

rounds per minute

resistance to Pseudomonas syringae pv. maculicola

resistance to Peronospora parasitica

resistance to Pseudomonas syringae

room temperature

reverse transcription-polymerase chain reaction

salicylic acid 


\begin{tabular}{ll} 
SAR & systemic acquired resistance \\
SDS & sodium dodecyl sulphate \\
Sec & second(s) \\
SNC1 & SUSCEPTIBLE TO NPR1 CONSTITUTIVE 1 \\
TBS & Tris buffered saline \\
T-DNA & transfer DNA \\
TIR & Drosophila Toll and mammalian interleukin-1 receptor \\
TLR & Toll-like receptor \\
Tris & Tris-(hydroxymethyl)-aminomethane \\
U & unit \\
V & Volt \\
vir & virulence \\
V/v & volume per volume \\
WT & wild-type \\
W/v & weight per volume \\
YFP & yellow fluorescent protein \\
& \\
\hline
\end{tabular}




\section{Introduction}

Plants need to adapt to their surroundings to be able to cope with abiotic and biotic stresses. Environmental changes as well as above- and below-ground attack by a diverse range of potential pathogens are perceived by individual plant cells and need to be integrated into appropriate cellular responses. In the course of evolution, plants acquired a sophisticated multi-layered system of innate immunity. The efficiency of the plant innate immune system is illustrated by the fact that disease is only an exception while immunity against an enormous number of diverse pathogens is the rule (Jones and Dangl, 2006). The induction of defense responses resulting from recognition of conserved microbial molecular structures represents a first layer of immunity (Gomez-Gomez and Boller, 2000; Zipfel et al., 2006; Miya et al., 2007; Petutschnig et al., 2010). Suppression of this layer of defense by highly specialized pathogens results in host susceptibility (Hemetsberger et al., 2012; Stegmann et al., 2012; Caillaud et al., 2012a). This in turn can be overcome by a second level of immunity that acts largely intracellularly (Narusaka et al., 2009; Rehmany et al., 2005; Shen et al., 2007). Importantly, communication between the cytoplasm and the nucleus is indispensable for all these cellular defense responses and signal transduction processes (Cheng et al., 2009; Wiermer et al., 2012; Wirthmueller et al., 2007; Caillaud et al., 2012b). Understanding the contribution of the nuclear import receptor MOS6/IMPORTIN- $\alpha 3$ and the potential involvement of additional nuclear transport receptors to plant immune signaling is the focus of this work.

\subsection{The plant immune system}

In contrast to animals, plants lack specialized mobile cells that can be readily produced when required for defense and an adaptive immune system that creates immunological memory. To fight pathogens, plants must therefore rely on a combination of germ-line encoded cellular innate immunity and the generation of mobile signals that travel from the infection site to prime resistance in systemic tissues. Microbial pathogens able to pass preformed structural and chemical barriers in the plants' cell periphery as for example the 
cell wall, deposition of cutin and suberin in the cuticle or constitutively produced antimicrobial substances face two layers of inducible defense responses (Nürnberger and Brunner, 2002; Heath, 2000; Veronese et al., 2003). Typically, activated defense responses require an enhanced need for energy and therefore induction is strictly regulated and takes place only upon pathogen attack (Boller and $\mathrm{He}, 2009$ ). Prerequisite for efficient defense reactions is the recognition of potential pathogens by the plants' surveillance system. A crucial first step in non-self recognition that contributes to plant non-host resistance is the perception of pathogens at the cell surface by specialized pattern recognition receptors (PRRs) at the plasma membrane that perceive so called PAMPs (pathogen-associated molecular patterns), leading to the activation of defense signaling cascades and subsequent initiation of PAMP-triggered immunity (PTI, Figure 1.1 (1). PAMPs are slowly evolving molecules that are indispensable for microbial life but are not present in the host organism. Thus, PAMPs usually are structurally conserved within a class of microbes. Prominent examples for PAMPs are the epitope flg22 of bacterial flagellin which is recognized by the receptor FLAGELLIN SENSITIVE 2 (FLS2), the elongation factor thermo unstable (EF-Tu) peptide elf18 which is recognized by the EF-Tu receptor (EFR) and the fungal cell wall component chitin which is recognized by the CHITIN RECEPTOR KINASE 1 (CERK1, Gomez-Gomez and Boller, 2000; Zipfel et al., 2006; Miya et al., 2007; Petutschnig et al., 2010; Zipfel et al., 2004). PAMP-recognition by PRRs typically triggers the production of reactive oxygen species (ROS), changes in ion fluxes at the plasma membrane, activation of calcium-dependent protein kinases (CDPKs) and mitogen-activated protein kinase (MAPK) cascades among other responses (Boller and Felix, 2009; Dodds and Rathjen, 2010; Schwessinger and Zipfel, 2008). For example, perception of flg22 by FLS2 results in activation of the MAP kinases MPK3 and MPK6 and subsequent activation of downstream WRKY-type transcription factors for increased expression of defense genes (Asai et al., 2002).

PAMP-triggered basal immune responses usually serve as a sufficient protection against non-adapted pathogens. Host-adapted pathogens, however, evolved effector molecules (also called virulence (vir) factors) that are secreted by the pathogen to evade recognition by the host or to suppress host defense responses in order to circumvent PTI, resulting in effector-triggered susceptibility (ETS, Boller and He, 2009; Panstruga and 
Dodds, 2009). Interaction of effectors with host proteins can take place at various locations including the host cell cytoplasm (Figure 1.1 (2). However, several effector proteins are targeted to host cell nuclei (Caillaud et al., 2012a; Caillaud et al., 2012b; Rivas and Deslandes, 2013; Deslandes et al., 2003; Schornack et al., 2010). The presence of predicted NLS motifs in some of these effectors indicate that the host cells' nuclear import machinery is exploited for nuclear translocation (Chisholm et al., 2006; Schornack et al., 2010; Boch and Bonas, 2010).

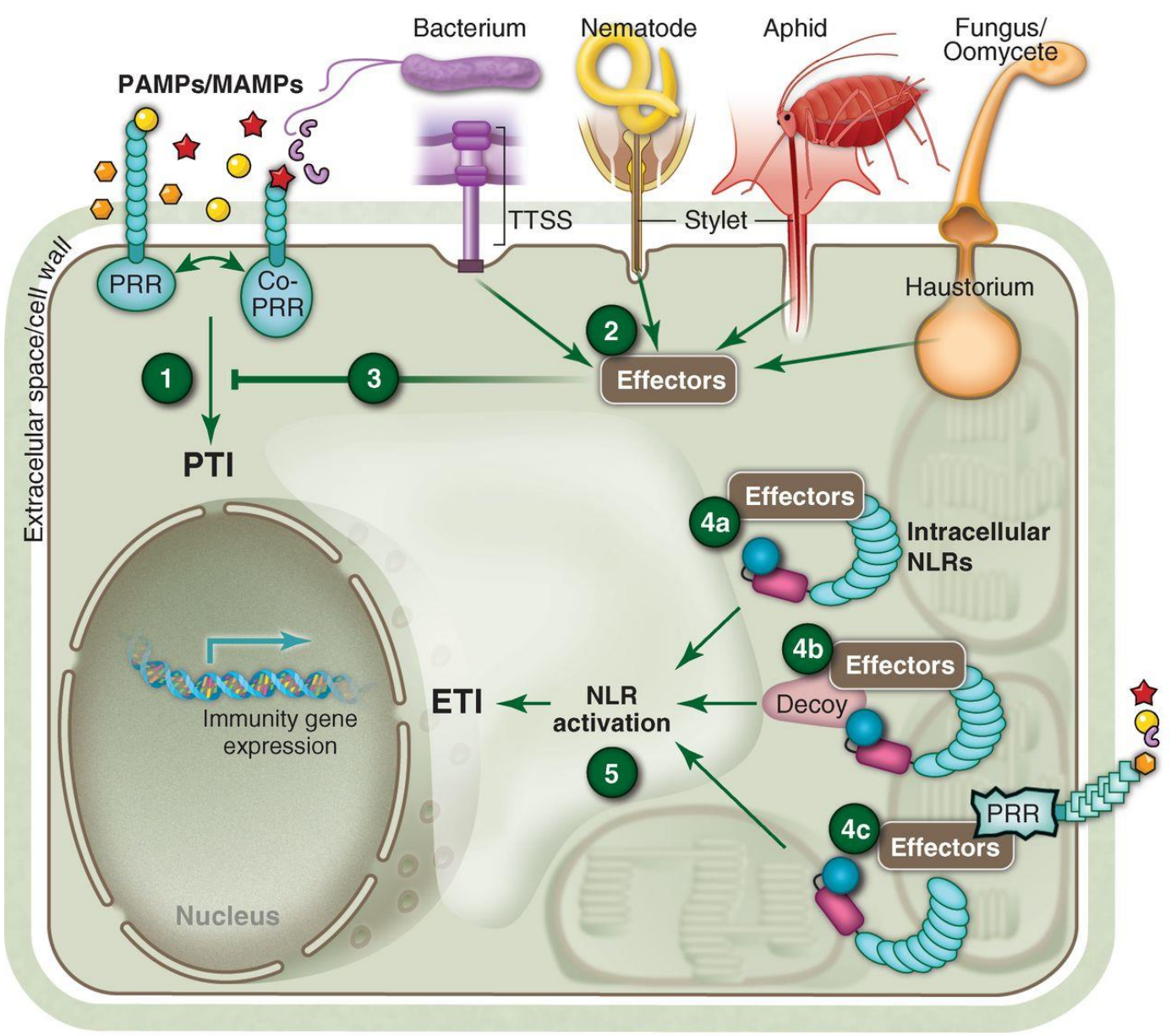

Figure 1.1 Schematic illustration of the plant immune system. All pathogens expose PAMPs to their surroundings. 1) Plants perceive PAMPs via membrane bound Pattern Recognition Receptors (PRRs) and initiate PAMP triggered immunity (PTI). To counteract PTI, pathogens deliver virulence effectors (2) to the plant cell cytoplasm. Effector proteins translocate to specific subcellular locations where they can suppress PTI (3). This results in effector triggered susceptibility (ETS). 4) Intracellular R proteins (NLRs) can recognize effectors by direct interaction ( 4 a), by interaction with a decoy ( 4 b) or by guarding an effector target (4 c). $\mathrm{R}$ protein activation leads to strong induction of defense responses and thus effector triggered immunity (ETI, 5). Notably, all layers of immunity require nucleocytoplasmic transport across the nuclear envelope through nuclear pore complexes. Figure from Dangl et al. (2013). 
To counteract ETS, plants have evolved intracellular Resistance (R) proteins, most of which are nucleotide-binding/leucine-rich repeat immune sensors NB-LRRs (or NLRs) to directly or indirectly recognize the presence of effector molecules (Figure 1.1 (4). Effector recognition leads to a strong defense response termed effector triggered immunity (ETI) that typically involves a ROS burst and local cell death execution in form of a hypersensitive response (HR). ETI and the HR are effective against biotrophic pathogens that depend on living tissue. Necrotrophic pathogens, in contrast, kill and feed on the dead host plants' tissue in the course of infection. Because of the contribution of $\mathrm{R}$ proteins, ETI is also called R protein-mediated resistance. Effector recognition can take place via direct interaction (Figure 1.1 (4), Ueda et al., 2006; Dodds et al., 2006) or indirectly through a mechanism where the $\mathrm{R}$ protein guards the host cell effector target or a decoy protein (Mackey et al., 2002; Van Der Biezen, Erik A. and Jones, 1998; Dangl and Jones, 2001).

NB-LRR receptors are the most common R protein variants and are related to NLRs known from the animal immune system (Kanneganti et al., 2007b; Ronald and Beutler, 2010). NB-LRR-type R proteins usually contain three distinct domains: a central nucleotide-binding (NB) domain, C-terminal leucine-rich-repeats (LRRs) and either a coiled-coil (CC) or toll interleukin-1 receptor (TIR) domain at the N-terminus (Dangl and Jones, 2001). The two subclasses usually employ different downstream signaling components. Signals from TIR-NB-LRRs (TNLS) converge on the lipase-like protein EDS1 (ENHANCED DISEASE SUSCEPTIBILITY 1), whereas CC-NB-LRRS (CNLS) signaling requires the plasma membrane localized NDR1 (NON-RACE SPECIFIC DISEASE RESISTANCE 1, García et al., 2010; Aarts et al., 1998). Interestingly, the balance of EDS1 proteins present in the cytosol and nucleus is important for efficient immunity (García et al., 2010). Notably, several R proteins have also been shown to be nuclear localized. One example is the EDS1-dependent nucleocytoplasmic TNL Rprotein RPS4 (RESISTANCE TO PSEUDOMONAS SYRINGAE 4), which accumulates in the nucleus after perception of its corresponding effector avrRps4 (Wirthmueller et al., 2007; Heidrich et al., 2011).

The local defense responses described above also confer elevated resistance of distal, uninfected tissues against subsequent attack by a broad spectrum of pathogens in a process called systemic acquired resistance (SAR, Durrant and Dong, 2004). Importantly, 
both, PRR and R protein activation results in transcriptional reprogramming of host cells that depends on defense signal transduction into the nucleus and nuclear export of defense-related mRNAs. Hence, communication between the cytoplasm and the nucleus is required for both, PTI and ETI.

\subsection{Nucleocytoplasmic transport}

The separation of genetic material from the cytoplasm by the double membrane of the nuclear envelope (NE) is the major characteristic of all eukaryotic organisms. The inner nuclear membrane and the outer nuclear membrane of the NE are separated by the perinuclear space. The outer nuclear membrane forms a continuum with the endoplasmic reticulum (ER). The exchange of macromolecules such as proteins or RNA across the nuclear envelope depends on highly regulated import and export processes (Meier and Somers, 2011). For this, nuclear pore complexes (NPC) represent tunnels that span the nuclear envelope (Figure 1.1). NPCs have an eightfold-symmetry and are composed of numerous nucleoporin proteins that form distinct sub-complexes (Suntharalingam and Wente, 2003; Hoelz et al., 2011). Nucleoporins either belong to the central FG nucleoporins (named after hydrophobic phenylalanine-glycine (FG)-rich motifs) located in the central channel or build the cytoplasmic filaments, cytoplasmic ring, nuclear ring and nuclear basket. (Cronshaw et al., 2002; Tamura and Hara-Nishimura, 2011). Selective transport through the NPCs is regulated by the FG nucleoporins that represent docking sites for transport receptors (Hoelz et al., 2011). These proteins limit the diffusion of molecules into the nucleus by engaging in low-affinity and high-specificity interactions with transport factors (Alber et al., 2007; Ryan and Wente, 2000; Cronshaw et al., 2002; Strawn et al., 2004). Although the general structure is highly conserved in eukaryotes, number and size of NPCs are variable between different organisms cell types and even the developmental stage of a given cell type influences NPC composition (Fiserova et al., 2009; Maul, 1977; Goldberg et al., 1997; Reichelt, 1990; Rout, 1993; Kiseleva et al., 2001; Winey et al., 1997; Capelson and Hetzer, 2009). For Arabidopsis 30 putative nucleoporins (NUPs) that are conserved among yeast, vertebrates and plants have been identified (Tamura et al., 2010; Tamura and Hara-Nishimura, 2011; Neumann et al., 2010). 
Due to the action of FG nucleoporins only small soluble molecules and proteins with a molecular weight of less than $40-60 \mathrm{kDa}$ can translocate into the nucleus by passive diffusion (Stewart, 2007a; Wang and Brattain, 2007). Hence, an additional set of proteins is involved in transport of larger proteins across the NE: the nuclear transport receptors (NTRs) of the karyopherin family. NTRs mediate both, nuclear import and export and the respective receptors are thus categorized into importins and exportins (Meier, 2007). Nucleocytoplasmic translocation usually requires the presence of a nuclear localization signal (NLS) for nuclear destination or leucine-rich nuclear export signal (NES) for cytoplasmic destination on the cargo substrate (Figure 1.2, Görlich and Kutay, 1999; Terry et al., 2007; Stade et al., 2002). The most abundant NLS motifs are basic Lys/Arg-rich sequences that can be monopartite with the consensus sequence $(K[K / R] X] K / R])$ or bipartite $\left([K / R][K / R] X_{10-12}[K / R]_{3 / 5}\right.$, Chang et al., 2013; Marfori et al., 2011; Marfori et al., 2012).

Asymmetrical distribution of the small GTPase Ran (Ras-related nuclear protein) between the nucleus and the cytoplasm is the driving force of nucleocytoplasmic

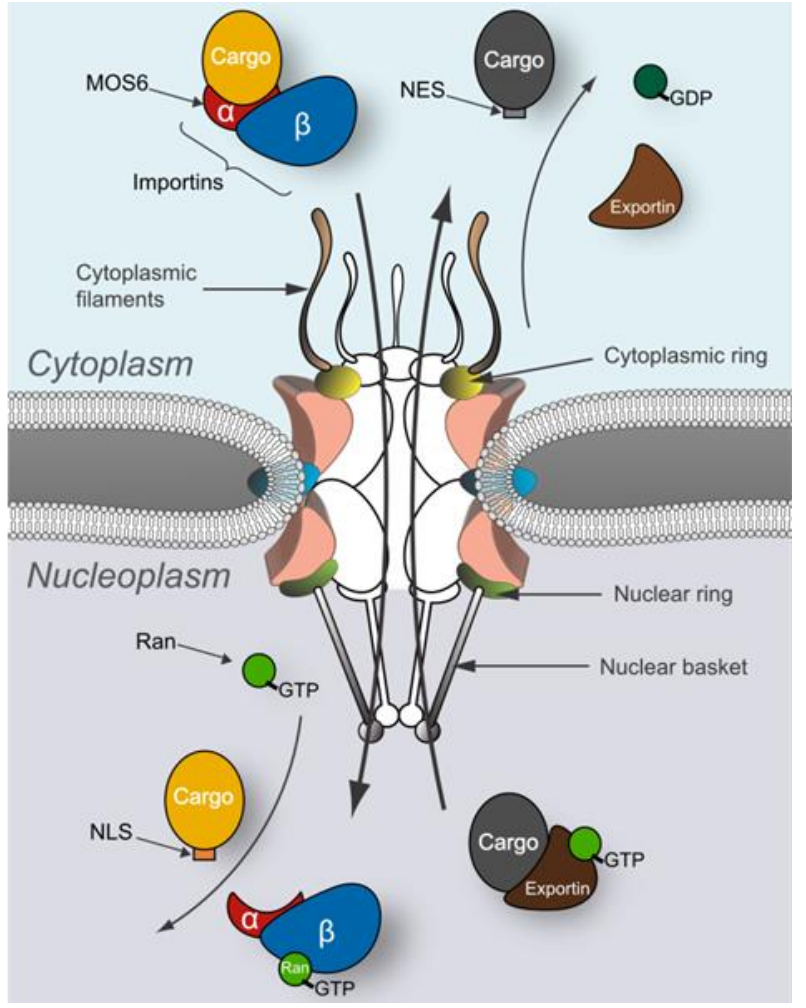

Figure 1.1 Schematic overview of karyopherinmediated protein transport through a nuclear pore complex. In the cytoplasm, a trimeric complex of the two import receptor subunits IMP- $\alpha$ and IMP- $\beta$ with an NLS containing cargo protein is formed. IMP- $\alpha$ directly binds to the NLS and thereby bridges the interaction of cargo to IMP- $\beta$. One of the Arabidopsis IMP- $\alpha$ proteins is MOS6 (MODIFIER OF SNC1 6). IMP- $\beta$ mediates interaction with nucleoporins in the nuclear pore complex for translocation into the nucleoplasm. The nuclear pore complex consists of distinct sub-complexes: the cytoplasmic filaments, cytoplasmic ring, nuclear ring, nuclear basket and the core/central channel. The trimeric transport complex dissociates in the nucleus by action of Ran in its GTP-bound form. Cargo export is mediated by exportin together with Ran in its GTP-bound form along the concentration gradient for Ran-GTP. In the Cytoplasm, cargo and exportin dissociate after GTP hydrolysis. Figure adapted from Wiermer et al. (2007). 
transport (Görlich and Kutay, 1999; Terry et al., 2007; Meier and Somers, 2011). The Ran guanine nucleotide exchange factor (RanGEF) is bound to chromatin and thus restricted to the nucleus, which leads to a higher concentration of Ran-GTP in the nucleus (Merkle, 2011). In contrast, the Ran GTPase-activating protein (RanGAP) leads to a higher concentration of Ran-GDP in the cytoplasm due to its cytoplasmic localization (Xu et al., 2007). Interestingly, many small proteins as for example many transcription factors and pathogenic effector proteins also contain NLS and rely on active nucleocytoplasmic transport to ensure efficient import, although they could freely diffuse through NPCs (Krebs et al., 2010; Ballesteros et al., 2001; Caillaud et al., 2012b; Deslandes et al., 2003; Schornack et al., 2010; Weinthal et al., 2011).

For classical nuclear import, the NLS-containing cargo protein is bound by the receptor protein IMPORTIN- $\alpha$ (IMP- $\alpha$ ) in the cytoplasm via its armadillo (ARM) repeat domains (Cook et al., 2007; Marfori et al., 2011; Chang et al., 2013). IMP- $\alpha$ proteins have a N-terminal auto-inhibitory IMPORTIN- $\beta$-binding (IBB) domain, ten armadillo (ARM) repeats that form two NLS-binding pockets and a C-terminal acidic patch that interacts with the CAS export protein (Conti and Kuriyan, 2000; Goldfarb et al., 2004). The Arabidopsis genome encodes nine IMP- $\alpha$ proteins (Wirthmueller et al., 2013). Upon cargo binding, the IBB domain of the IMP- $\alpha$ protein is exposed and interacts with IMPORTIN- $\beta$ (IMP- $\beta$, Figure 1.2, Kobe, 1999; Harreman et al., 2003). In the nucleus, Ran-GTP binding to IMP- $\beta$ causes conformational changes that result in dissociation of the trimeric complex (Gilchrist et al., 2002). The exportin CAS in its Ran-GTP bound form then interacts with IMP- $\alpha$, which results in release of the cargo. IMP- $\alpha$ bound to CAS-Ran-GTP, as well as IMP- $\beta$-Ran-GTP are exported to the cytoplasm along the Ran-GTP gradient (Kutay et al., 1997). In the cytoplasm, Ran-GTP is hydrolyzed to Ran-GDP, which leads to the release of IMP- $\alpha$ and IMP- $\beta$, respectively (Stewart, 2007b). Ran-GDP is returned to the nucleus by the NUCLEAR TRANSPORT FACTOR 2 (NTF2), where it is converted back to Ran-GTP by Ran-GEF (Ribbeck et al., 1998; Bhattacharya and Steward, 2002; Zhao et al., 2006).

The Arabidopsis karyopherin EXPORTIN 1 (XPO1) mediates export of NES-motif containing cargo proteins out of the nucleus (Haasen et al., 1999; La Cour et al., 2003; Stade et al., 1997). XPO1 interacts with Ran-GTP for nuclear export. Ran-GTP is hydrolyzed in the cytoplasm for subsequent cargo-release (Haasen et al., 1999). 
In addition to the classical NLS presented above, atypical nuclear localization signals have been described. A number of cargo proteins with atypical NLS can directly bind to and thus be imported by IMP- $\beta$ alone. Usually, these sequences are basic and structurally more complex than classical NLS (Lam et al., 1999; Lee et al., 2003; Nagoshi and Yoneda, 2001; Jakel and Görlich, 1998; Zehorai and Seger, 2014; Palmeri and Malim, 1999). Additional non-canonical NLS are the Mata2 NLS found in yeast and maize (Hall et al., 1984; Hicks et al., 1995) and the non-canonical M9 NLS whose nuclear import is mediated by TRANSPORTIN 1 (TRN1) without involvement of IMP- $\alpha$ (Michael et al., 1995; Bogerd et al., 1999; Pollard et al., 1996; Lee et al., 2006). PY-NLS that contain a characteristic proline/tyrosine sequence were identified by characterization of NLSs recognized by human TRN1 (Marfori et al., 2011; Lee et al., 2006). Interestingly, Arabidopsis TRN1 is the transport receptor for two small RNA-binding proteins, AtGRP7 and AtGRP8 (GLYCINERICH RNA-BINDING PROTEIN 7 and 8), that are involved in plant immunity (Ziemienowicz et al., 2003).

\subsection{Dynamic nucleocytoplasmic responses in plant immunity}

Plant immune responses rely on stimulus-induced nuclear translocation of signaling molecules such as defense regulators and transcription factors (TF) that regulate the transcription of immunity-related genes in the nucleus. In analogy to NF-KB (Nuclear Factor $\kappa$-light-chain-enhancer of activated B-cells) signaling in animal immunity, where nuclear localization and accumulation of NF-KB TFs is induced in response to biotic stress by release from inhibitory $\mathrm{I}-\mathrm{KB}$ proteins, components of plant defense are dynamically transported across the NE (Huang et al., 2000; Johnson et al., 1999; Malek et al., 2001; García and Parker, 2009). This holds true for processes leading to PTI as well as for certain regulators involved in ETI, in which the expression of defense-related genes is adapted to the respective pathogenic threat. Additionally, a number of pathogen-derived effector proteins use the nucleocytoplasmic transport machinery to translocate to the nucleus in order to manipulate the host cell and stimulate infection. Several examples for regulated nucleocytoplasmic partitioning in response to biotic stress have been described and are summarized below. 
An example for dynamic nuclear localization in PTI is the rice PRR XA21 which confers resistance to the bacterium Xanthomonas oryzae pv. oryzae (Song et al., 1995). The plasma membrane resident XA21 contains an intracellular kinase domain that is cleaved off when activated (Park and Ronald, 2012). This kinase domain carries a functional NLS and is transported to the nucleus, where it presumably regulates the transcription of defense-related genes (Park and Ronald, 2012).

The ankyrin-repeat protein NPR1 (NONEXPRESSER OF PATHOGENESIS-RELATED GENES 1) is a prominent example for the importance of nucleocytoplasmic partitioning in SAR that is triggered after local R protein activation (Kinkema et al., 2000; Zhang et al., 1999). In its inactive state, NPR1 forms oligomers that are stabilized via disulfide bridges and resides in the cytoplasm. When SA is produced during plant defense reactions, NPR1 disulfide bridges are reduced due to changes in the redox status of the cell (Tada et al., 2008). This leads to monomerization and probably to unmasking of a NLS sequence in NPR1 (Tada et al., 2008). Monomeric NPR1 is able to accumulate in the nucleus where it can execute its function as transcriptional co-activator. NPR1 induces expression of defense genes via interaction with TGA transcription factors of the basic region leucine zipper (bZIP) family (Mou et al., 2003; Tada et al., 2008; Zhang et al., 1999; Kinkema et al., 2000; Després et al., 2003). SA signaling, induction of $P R$ genes and SAR are impaired in the npr1-1 mutant (Cao et al., 1994; Zhang et al., 1999). Another example for stress induced conformational change that leads to exposure of an NLS motif is found in the Arabidopsis transcription factor bZIP10 (Kaminaka et al., 2006). In uninduced cells, bZIP10 is bound by the Arabidopsis zinc finger protein LSD1. In this complex the bZIP10 NLS is masked and the transcription factor is sequestered in the cytoplasm. Cytoplasmic retention of bZIP10 by LSD1 prevents activation of a cell death pathway (Kaminaka et al., 2006). Nuclear localization of Pisum sativum LSD1 in Arabidopsis protoplasts suggests that PsLSD1 alone is able to localize to the nucleus (He et al., 2011). PsLSD1 does not harbor a NLS and nuclear transfer is reported to be mediated by its zinc finger motifs that interact with several Arabidopsis IMP-as and may constitute a novel NLS (He et al., 2011).

EDS1 (ENHANCED DISEASE SUSCEPTIBILITY 1) is a central regulator of basal and TNL R protein mediated resistance and harbors predicted canonical NLS and NES motifs for coordination of nuclear and cytoplasmic activities (García et al., 2010; Heidrich et al., 
2011). EDS1 forms molecularly and spatially distinct nucleocytoplasmic complexes with PAD4 (PHYTOALEXIN DEFICIENT 4) and SAG101 (SENESCENCE-ASSOCIATED GENE 101) and associates with several TNLs (Feys et al., 2005; García et al., 2010; Wagner et al., 2013). The Arabidopsis TNL receptor RPS4 requires EDS1 nuclear accumulation for transcriptional reprogramming (García et al., 2010). RPS4 and EDS1 both recognize the Pseudomonas syringae effector AvrRps4 (Gassmann et al., 1999; Heidrich et al., 2011; Bhattacharjee et al., 2011) and EDS1 may act as signal transducer between RPS4 and defense gene expression (Feys et al., 2005; Wirthmueller et al., 2007; García et al., 2010; Heidrich et al., 2011). Consistent with these findings, transport of EDS1 through NPCs is necessary for TNL mediated immunity (Cheng et al., 2009; Heidrich et al., 2011; Wiermer et al., 2010), further underlining the significance of dynamic nucleocytoplasmic distribution for defense signaling upon pathogen recognition.

The activation of NLR proteins typically leads to transcriptional reprograming and consistent with this, several plant NLRs accumulate in the nucleus upon effector-induced activation (Shen et al., 2007; Wirthmueller et al., 2007; Cheng et al., 2009; Caplan et al., 2008a; Tameling et al., 2010). For example upon recognition of the cognate powdery mildew effector $A v r A_{10}$, the barley CNL receptor MLA10 (MILDEW LOCUS A) interacts with WRKY1/2 transcriptional repressors of PTI in the nucleus to derepress defense gene expression (Shen et al., 2007). The WRKY zinc-finger motifs are characteristic for WRKY TFs that recognize $W$-box sequences in promoter regions (Eulgem et al., 2000). Interestingly, expression of a number of WRKY TFs is induced in response to pathogen challenge or after PAMP perception and promoters of numerous defense related genes contain W-boxes (Dong et al., 2003; Yu et al., 2001; Eulgem and Somssich, 2007). In addition to these findings, some WRKY proteins have been proven to be directly involved in plant defense. For example WRKY33 plays a role in regulation of defense pathways against necrotrophic fungal pathogens downstream of MAPK cascades and WRKY18, WRKY40 and WRKY60 interact for plant defense regulation in the nucleus (Zheng et al., 2006; Birkenbihl et al., 2012; Xu et al., 2006). The importance of the WRKY domain in plant immunity is further illustrated by the Arabidopsis TNL protein RRS1-R (RESISTANT TO RALSTONIA SOLANACEARUM 1-Recessive) that mediates resistance to Ralstonia solanacearum bacteria expressing the effector protein PopP2 (Deslandes et al., 2002; 
Deslandes et al., 2003; Tasset et al., 2010). RRS1-R contains a WRKY domain in addition to the TIR, NBS and LRR domains and an NLS motif (Deslandes et al., 2002). RRS1-R and PopP2 interact in the nucleus (Deslandes et al., 2003). The Arabidopsis nucleocytoplasmic TNL protein SUPPRESSOR OF npr1-1, CONSTITUTIVE 1 (SNC1) also activates immune responses by association with a transcriptional regulator (Zhu et al., 2010). The transcriptional corepressor TOPLESS-RELATED 1 (TPR1) was shown to localize to the nucleus and target negative regulators of immunity (Zhu et al., 2010). Recently, it was demonstrated that SNC1 can oligomerize in both the nucleus and the cytosol and activates immunity in the nucleus (Xu et al., 2014).

Further findings that link $\mathrm{R}$ protein function to the transcriptional machinery in the nucleus come from the tobacco TNL R protein $\mathrm{N}$. $\mathrm{N}$ was shown to recognize tobacco mosaic virus (TMV) and to interact with Squamosa Promoter-like (SPL) TFs (Caplan et al., 2008a; Whitham et al., 1994). While nuclear localization of $\mathrm{N}$ is required for defense response, the recognition of the TMV p50 replicase by $\mathrm{N}$ occurs in the cytoplasm where $\mathrm{N}$ binds a pre-recognition complex containing the TMV p50 effector and the host chloroplastic sulfotransferase NRIP1 (N RECEPTOR-INTERACTING PROTEIN 1, Burch-Smith et al., 2007; Caplan et al., 2008b). The function of the Solanum tuberosum CNL R protein $\mathrm{Rx}$ is also linked to nucleocytoplasmic trafficking. This immune receptor has been shown to be required for resistance to Potato Virus X (PVX, Slootweg et al., 2010; Sacco et al., 2007). Rx is sequestered and stabilized by Ran-GTPase activating protein 2 (RanGAP2) in the cytoplasm (Tameling et al., 2010; Tameling and Baulcombe, 2007; Sacco et al., 2007). Importantly, RanGAP2 is involved in generating the RanGTP-RanGDP gradient across the NE which directly links Rx protein function to nucleocytoplasmic trafficking ( $\mathrm{Xu}$ et al., 2007; Tameling et al., 2010; Sacco et al., 2007).

In addition to host defense related proteins that are regulated by dynamic nuclear and cytoplasmic partitioning, several pathogenic effector proteins might use the plant nucleocytoplasmic transport machinery for virulence. Consistent with this, several of these proteins are translocated to the host cell cytoplasm in the course of infection (Dou and Zhou, 2012; Petre and Kamoun, 2014). Evolution of NLS motifs in a high number of pathogen effectors suggests that these proteins exploit the host nuclear import machinery to efficiently execute their functions inside the nucleus (Caillaud et al., 2012b; 
Kanneganti et al., 2007b; Bai et al., 2009; Sugio et al., 2014; Wirthmueller et al., 2015). Interestingly, the molecular weight of effector proteins usually is below the molecular weight exclusion limit of NPCs, so that they in principle could enter the host nucleus by passive diffusion even without a NLS motif (Wang and Brattain, 2007). However, exclusive nuclear localization indicates the involvement of active nuclear transport. This could be shown for the effectors HaRxL106 (from Hyaloperonospora arabidopsidis (H. a.), 27 kDa), NUK7 (from P. infestans, $47 \mathrm{kDa}$ ) and SAP11 (from Aster Yellows phytoplasma strain Witches' Broom, $11 \mathrm{kDa}$ ) that co-opt the nucleocytoplasmic transport machinery for efficient nuclear import (Wirthmueller et al., 2015; Kanneganti et al., 2007a; Bai et al., 2009; Sugio et al., 2014).

The examples described above illustrate that transport between the cytoplasm and the nucleus is crucial for all layers of plant immunity. Cytosolic signaling events are targeted towards regulation of gene expression that ultimately takes place in the nucleus and export of defense-related transcripts into the cytoplasm for translation also has to be fine-tuned. Consistent with this, mutations in genes encoding components of the nucleocytoplasmic trafficking machinery display defects in pathogen resistance (Palma et al., 2005; Zhang and Li, 2005; Cheng et al., 2009; Wiermer et al., 2012; Roth and Wiermer, 2012). However, the detailed mechanisms that contribute to nuclear transport of specific host defense proteins in response to biotic stress are still not well understood.

\subsection{The role of the nuclear transport machinery in plant immunity}

As elaborated above, dynamic signaling events across the NE are necessary for plant immunity but how changes in nuclear translocation rates are regulated is just beginning to emerge. Notably, several proteins that were found to be involved in autoimmune responses activated in the deregulated TNL mutant snc1 (suppressor of npr-1, constitutive 1) encode components of the plant nucleocytoplasmic trafficking machinery (Zhang et al., 2003; Johnson et al., 2012).

The gain-of-function mutant snc1 was discovered in a genetic screen for suppressors of the npr1-1 mutant (Li et al., 2001; Zhang et al., 2003). SNC1 encodes a TNL R protein which signals through PAD4 and EDS1 when activated (Zhang et al., 2003; Li et 
al., 2001). SNC1 is closely related to the TNL R proteins RPP4 and RPP5 (with over 70\% similarity of amino acid sequence) and its cognate effector protein is not yet known. The snc1 mutation results in a glutamic acid to lysine substitution in the linker region between the NBS and LRR domains and renders the protein constitutively active (Zhang et al., 2003). Therefore snc1 mutant plants display phenotypes associated with constitutive activation of defense responses even without pathogen interaction. The auto-immune activity results in retarded plant growth and dark leaves with curly morphology. Basal levels of SA are increased which is accompanied with constitutive expression of $P R$ genes, and increased resistance against virulent pathogens such as Pseudomonas syringae pv. maculicola (Psm) ES4326 bacteria and the oomycete Hyaloperonospora arabidopsidis (H. a.) isolate NOCO2 (Zhang et al., 2003).

A genetic screen to identify suppressors of the snc1 auto-immune mutant phenotype led to the isolation of modifier of snc1 (mos) mutants based on suppression of the snc1 growth phenotype back to wild-type like morphology and suppression of enhanced resistance in snc1. Subsequently, suppression of the other snc1 autoimmune phenotypes was assessed (Johnson et al., 2012). The mos genes characterized so far encode proteins involved in diverse functions such as: nucleocytoplasmic trafficking, RNA processing, protein modification, and epigenetic control of gene expression (Palma et al., 2005; Zhang and Li, 2005; Zhang et al., 2005; Goritschnig et al., 2007; Wiermer et al., 2007; Goritschnig et al., 2008; Cheng et al., 2009; Germain et al., 2010; Li et al., 2010; Xu et al., 2012; Xu et al., 2011).

Notably, five of the MOS genes identified in the snc1 suppressor screen are involved in nucleocytoplasmic trafficking. MOS3 is a nucleoporin homolog of vertebrate NUP96. MOS11 is a homolog of a human RNA binding protein (Sugiura et al., 2007; Dufu et al., 2010; Germain et al., 2010). In vertebrates, NUP96 is part of the NUP107-160 nuclear pore sub-complex that is involved in mRNA export (Fabre et al., 1994; Vasu et al., 2001) and MOS3 and MOS11 are both required for mRNA export from the nucleus to the cytoplasm (Zhang and Li, 2005; Parry et al., 2006; Germain et al., 2010). Other components of a putative complex similar to the NUP107-160 nuclear pore sub-complex that contains MOS3 have been found to be involved in basal and $R$ protein mediated defense as well (Wiermer et al., 2012; Roth et al., 2003). The single copy gene MOS7 
codes for a protein homolog to NUP88 in animals. This nucleoporin is involved in attenuating protein export from the nucleus to the cytoplasm (Uv et al., 2000). In line with this, the nuclear accumulation of NPR1, EDS1, and SNC1 proteins is reduced in mos7-1 mutants due to enhanced export (Cheng et al., 2009; Wiermer et al., 2010). These defects in protein export in mos7-1 result in compromised SAR, basal defense and $R$ protein mediated resistance. The findings summarized above illustrate the crucial importance of nucleoporins in regulating the nuclear pore permeability for defense regulatory proteins and mRNAs in plant immunity.

Nuclear transport receptors represent another level of nuclear translocationregulation and IMP- $\alpha$ and IMP- $\beta$-like proteins were also identified from the mos screen. MOS14 is a member of the IMP- $\beta$ super-family and nuclear localized (Xu et al., 2011). It is encoded by a single copy gene in Arabidopsis. MOS14 was shown to be involved in nuclear localization of proteins that function in splicing and altered splicing patterns of SNC1 were found in mos14 mutants (Long and Caceres, 2009; Xu et al., 2011). MOS6 was identified from the mos screen and codes for IMP- $\alpha 3$, one of nine predicted IMP- $\alpha$ s in Arabidopsis (Palma et al., 2005; Wirthmueller et al., 2013). Different mos6 alleles were shown to partially suppress the snc1 auto-immune phenotypes and loss of MOS6 results in enhanced disease susceptibility towards the virulent $H$. $a$. isolate NOCO2 (Palma et al., 2005). It was shown that GFP-tagged snc1-4 accumulates in the nucleus of wild-type Arabidopsis protoplasts whereas this fusion protein is present in the cytosol and in the nucleus in mos6 mutant protoplasts (Zhu et al., 2010). However, snc1-4 harbors a glutamic acid to lysine exchange in the second LRR motif in addition to the snc1 mutation responsible for auto-immunity. Although this suggests that MOS6 could be responsible for appropriate snc1-4 nuclear import, it remains to be tested whether SNC1 is a direct cargo substrate of MOS6. The identification of MOS6 as a genetic suppressor of snc1 auto-immune phenotypes together with the pathogen-phenotypes of mos 6 single mutants suggest that MOS6 may specifically or preferentially import unknown cargo proteins involved in defense signaling into the nucleus. This also raises the question whether MOS6 is the only IMP- $\alpha$ in Arabidopsis that is required for plant immunity. 


\subsection{The IMPORTIN- $\alpha$ family in animal and plant immunity}

Together with MOS6, the Arabidopsis genome contains nine IMP- $\alpha$ paralogs (Wirthmueller et al., 2013). The genome of the single cellular eukaryote Saccharomyces cerevisiae only encodes one IMP- $\alpha$ whereas several paralogs have been identified in higher eukaryotes. The genomes of humans, mice, rice or Drosophila melanogaster, contain seven, six, five or three IMP- $\alpha$ s, respectively (Merkle, 2001; Ouyang et al., 2007; Ratan et al., 2008; Hu et al., 2010; Kelley et al., 2010; Wirthmueller et al., 2013). The relatively high number of IMP- $\alpha$ s in higher eukaryotes indicates specialization of IMP- $\alpha$ family members in nuclear protein import or might be explained by possibly redundant roles of different IMP-as. The complexity of higher eukaryotic organisms demands for regulation of nuclear import in order to meet the specific requirements of different tissues, developmental or physiological stages and stimulus-specific nucleocytoplasmic dynamics. Research from the mammalian field provides important insights into regulation of IMP- $\alpha$ activities via tissue-specific expression patterns (Köhler et al., 1997; Tsuji et al., 1997; Yasuhara et al., 2007). Another way to allow for complex regulation is the specialization of NTRs to import a specific group of cargos. In fact, several examples from the mammalian field show the preferential nuclear import of cargo proteins by specific IMP- $\alpha$ adapters (Köhler et al., 1999; Melen et al., 2003; Miyamoto et al., 1997; Nadler et al., 1997; Quensel et al., 2004).

The nuclear import of NF-kB TFs (1.3, Huang et al., 2000; Malek et al., 2001) following $I \kappa B$ degradation in human cells is a well-studied example for IMP- $\alpha$ specificity. Here, human IMP- $\alpha 3$ and IMP- $\alpha 4$ are mainly responsible for import of NF- $\kappa B$ p50/p65 heterodimers although at least seven different IMP- $\alpha$ isoforms are present in the human genome (Pemberton and Paschal, 2005; Fagerlund et al., 2005). During this process, IMP- $\alpha 3$ binds to NF-KB p50 with its major NLS binding pocket while the minor pocket mediates binding to NF-KB p65 (Fagerlund et al., 2005). Another example for IMP- $\alpha$ specificity in human cells is the import of the nuclear protein Ran guanine nucleotide exchange factor wich selectively depends on IMP- $\alpha 3$ (RCC1, Quensel et al., 2004).

Like in mammals, Drosophila melanogaster immune responses also depend on the action of NF-KB proteins whose activity is controlled at the level of nuclear transport (Bhattacharya and Steward, 2002). Translocation to the nucleus is stimulus-dependent 
and occurs after activation of the Toll signaling cascade. The nuclear transport receptor specifically involved in transport of NF-KB transcription factors is NTF2 (NUCLEAR TRANSPORT FACTOR 2). NTF2 is usually involved in importing Ran-GDP back to the nucleus after a round of nucleocytoplasmic transport (Bhattacharya and Steward, 2002; Ribbeck et al., 1998). Direct binding of NTF2 to NF-אBs, however, has not been shown and the possibility that NTF2 indirectly influences import of these proteins by regulating the function of IMPs or Ran must be considered as well. Another group of transcription factors whose activity is regulated on a spatial level are the mammalian signal transducers and activators of transcription (STAT). STAT proteins dimerize and cross the nuclear envelope upon activation of the canonical STAT-signaling pathway. Stimulus induced signaling leads to phosphorylation which in turn results in homo- or hetero-dimerization (Lim and Cao, 2006). STAT1 homodimers and STAT1/STAT2 heterodimers specifically interact with IMP- $\alpha 5$ (Melen et al., 2001; Fagerlund et al., 2002) and loss of IMP- $\alpha 3$ via RNAi leads to impaired nuclear translocation of STAT3, but not of STAT1 (Liu et al., 2005). This finding leads to the conclusion that STAT3 specifically interacts with IMP- $\alpha 3$ and corroborates the notion that some IMP-as preferentially bind to particular STAT transcription factors. In addition to transcription factors that use the nucleocytoplasmic transport system to enter the nucleus in a biotic stress induced manner, the vertebrate NLRs CIITA and NLRC5 (CLASS II TRANSACTIVATOR and NLR CASPASE RECRUITMENT DOMAIN (CARD) CONTAINING PROTEIN 5) both contain NLS motifs and ultimately regulate gene expression via interaction with DNA-binding proteins inside the nucleus (Meissner et al., 2012b; Meissner et al., 2012a; Cressman et al., 2001; Spilianakis et al., 2000). However, exclusive binding to a specific IMP- $\alpha$ or a subset of IMP- $\alpha$ proteins has not yet been shown.

Only few examples for IMP- $\alpha$ cargo selectivity exist in plants. In the following, examples are summarized where pathogen effector proteins were found to preferentially bind to certain IMP- $\alpha$ proteins. The Agrobacterium tumefaciens Vir proteins are a prominent example for pathogen derived proteins that take advantage of the plant nucleocytoplasmic transport machinery to promote infection (Durrenberger et al., 1989; Shurvinton et al., 1992; Howard et al., 1992; Ballas and Citovsky, 1997; Bhattacharjee et al., 2008). For transformation, the Agrobacterium derived transfer DNA (T-DNA) needs to 
be transported into the host nucleus. For this, a T-DNA/protein complex (T-complex) is formed in the cytoplasm of infected host cells. The effectors VirD2 and VirE2 form a covalently linked complex with the T-DNA (Durrenberger et al., 1989). Both VirD2 and VirE2 harbor bipartite NLS (Gelvin, 2010; Pitzschke and Hirt, 2010). Several Arabidopsis IMP-as interact with these NLS motifs and subsequently mediate transfer of the T-complex to the nucleus (Ballas and Citovsky, 1997; Bhattacharjee et al., 2008). Knock-out of IMP- $\alpha 4$ alone, however, has been shown to be sufficient to reduce A. tumefaciens transformation rates in Arabidopsis root tissue. Interestingly, this phenotype can be complemented by ectopic overexpression of other IMP- $\alpha$ paralogs (Bhattacharjee et al., 2008). IMP- $\alpha 4$ is the predominantly expressed IMP- $\alpha$ in Arabidopsis root tissue. This indicates that the specialized function of IMP- $\alpha 4$ in the transport of the T-complex in roots may be explained by its tissue-specific expression. Hence, tissuespecific expression rates of IMP- $\alpha$ s add an additional level of regulation for cargo selectivity in nucleocytoplasmic transport. It could be shown that the rate of NLS-cargo/NTR complex formation is an important factor for efficiency of nuclear import. This implies that nuclear import rates can be elevated by either increasing protein levels of the cargo or IMP- $\alpha$, or by increasing the affinity of the NLS for the NTR (Riddick and Macara, 2005; Hodel et al., 2006; Timney et al., 2006; Wirthmueller et al., 2015).

Additional examples for preferential binding to IMP- $\alpha$ s by effector proteins were found in a directed yeast two hybrid screen aimed to search for interactions between 83 effectors from H. a. and Pseudomonas syringae pv. tomato (Pst) with numerous Arabidopsis proteins (Mukhtar et al., 2011). In this screen two interactions between plant IMP-as and effectors were detected (Mukhtar et al., 2011). The H. a. effector HaRxLL445 was shown to interact with MOS6 while the effector HaRxL106 interacted with MOS6, IMP- $\alpha 1$, IMP- $\alpha 2$ and IMP- $\alpha 4$ (Mukhtar et al., 2011). Specific interaction of MOS6, IMP- $\alpha 1$, IMP- $\alpha 2$ and IMP- $\alpha 4$ with HaRxL106 could be verified in ColP experiments (Wirthmueller et al., 2015). Selective interaction with IMP- $\alpha$ proteins was also reported for effectors from the oomycete pathogen Phytophthora infestans and the Phytoplasma asteris effector SAP11 (SECRETED AY-WB protein). Nuclear import of these effectors could be attenuated by silencing of NbIMP- $\alpha 1$ or NbIMP- $\alpha 2$ in $N$. benthamiana (Kanneganti et al., 2007a; Bai et al., 2009). SAP11 contains an eukaryotic bipartite NLS which probably is 
involved in IMP- $\alpha$ binding (Bai et al., 2009). Nuclear import of the bipartite NLS-containing P. infestans effectors Nuk6 and Nuk7 is also specifically inhibited by silencing of NbIMP- $\alpha 1$ and NbIMP- $\alpha 2$ while nuclear localization of another Nuk effector (Nuk12) was not affected (Kanneganti et al., 2007a).

The examples above illustrate that selective binding of cargo proteins to a specific IMP- $\alpha$ or a subset of IMP- $\alpha$ proteins occurs in animals and could be demonstrated for some effector proteins in plant-pathogen interactions. However, besides these reports little is known about nuclear transport mechanisms that mediate exchange of proteins between the cytoplasm into the nucleoplasm in plant cellular immune responses. To date no plant host defense regulator has been reported as cargo substrates of any IMP- $\alpha$. Therefore, it is feasible to postulate that the identification and analysis of defense-related cargo proteins could provide important insights in plant immune responses.

\subsection{Thesis aims}

A central regulatory node in plant cellular immunity is the dynamic translocation of defense signal transducers and immune regulatory proteins between the cytoplasm and the nucleus. The underlying mechanisms and processes specifically regulating nucleocytoplasmic signaling in plant defense, however, are still poorly understood. The Arabidopsis nuclear transport receptor MOS6/IMPORTIN- $\alpha 3$ was identified in a forward genetic screen for suppressors of auto-immune responses activated in the deregulated TIR-NB-LRR $R$ gene mutant, snc1. In addition, MOS6 was found to be involved in basal resistance against the virulent oomycete pathogen Hyaloperonospora arabidopsidis NOCO2 (Palma et al., 2005). However, defense-regulatory cargo proteins of MOS6 that mediate pathogen resistance have not been described. Also, whether other Arabidopsis IMP- $\alpha$ paralogs are required for plant disease resistance is not known.

The first aim of this work was to isolate and functionally characterize a collection of imp- $\alpha$ single, double and triple mutant combinations in order to elucidate the involvement of the nine Arabidopsis IMP- $\alpha$ family members in plant growth and basal disease resistance. Additionally, potential functional redundancies between MOS6 and 
other nuclear protein import receptors in snc1-mediated auto-immunity and basal defense signaling should be addressed.

MOS6-mediated resistance has so far only been characterized genetically (Palma et al., 2005). Therefore, the second aim of this work was to identify and subsequently characterize MOS6 defense-related cargo proteins and interaction partners. In combination with analyses of an established Arabidopsis interactome database that is based on yeast two-hybrid assays (Mukhtar et al., 2011), an in planta affinity purification approach should be conducted using stable transgenic mos6 plants expressing functional epitope-tagged MOS6. Analysis of affinity-purified MOS6 transport complexes in plant cells responding to pathogen challenge by mass spectrometry should allow identification of MOS6 specific cargo proteins and novel components of nucleocytoplasmic transport that are engaged in plant defense signaling. After independent validation of MOS6interactions in planta, reverse-genetic analyses should be used to assess the involvement of MOS6-interactors in plant immunity. 


\section{Materials and Methods}

The materials and methods section is divided into two parts. First, information on the organisms, materials, chemicals and equipment used in this study is provided. The second part describes the methods employed.

\subsection{Materials}

\subsubsection{Plant Materials}

\subsubsection{Arabidopsis thaliana}

Arabidopsis wild-type (Table 2.1), mutant lines (Table 2.2) and transgenic plant lines (Table 2.3) used in this study are listed below.

Table 2.1 Wild-type Arabidopsis accessions used in this study

\begin{tabular}{lll}
\hline Accession & Abbr. & Original source \\
\hline Columbia & Col-0 & J. Dangl \\
Landsberg-erecta & Ler & Nottingham Arabidopsis Stock Centre ${ }^{\mathrm{b}}$ \\
Wassilewskija & Ws-0 & K. Feldmann ${ }^{\mathrm{c}}$
\end{tabular}

aniversity of North Carolina, Chapel Hill, NC, USA

${ }^{\mathrm{b}}$ Nottingham, UK

'University of Arizona, Tucson, AZ, USA

Table 2.2 Mutant Arabidopsis lines used in this study

\begin{tabular}{|c|c|c|c|c|}
\hline Abbr. & $\begin{array}{l}\text { AGI locus } \\
\text { identifier }\end{array}$ & Accession & Mutagen/T-DNA & Reference/Source \\
\hline
\end{tabular}

\section{Single mutants}

\begin{tabular}{lllll}
\hline snc1 & AT4G16890 & Col-0 & EMS & (Li et al., 2001) \\
eds1-2 & AT3G48090 & Col-0 & FN & (Bartsch et al., 2006) \\
mos6-1 & AT4G02150 & Col-0 & FN & (Palma et al., 2005) \\
mos6-2 & AT4G02150 & Col-0 & FN & (Palma et al., 2005) \\
mos6-4 & AT4G02150 & Col-0 & SALK_025919 & (Alonso et al., 2003)
\end{tabular}




$\begin{array}{lllll}i m p-\alpha 1 & \text { At3G06720 } & \text { Col-0 } & \text { SALK_001092 } & \text { (Alonso et al., 2003) } \\ i m p-\alpha 2 & \text { At4G16143 } & \text { Col-0 } & \text { SALK_099707 } & \text { (Alonso et al., 2003) } \\ i m p-\alpha 3 & \text { At4G02150 } & \text { Col-0 } & \text { SALK_025191 } & \text { (Alonso et al., 2003) } \\ i m p-\alpha 4 & \text { At1G09270 } & \text { Col-0 } & \text { SALK_203869 } & \text { (Alonso et al., 2003) } \\ i m p-\alpha 5 & \text { At5G49310 } & \text { Col-0 } & \text { SALK_023989 } & \text { (Alonso et al., 2003) } \\ i m p-\alpha 6 & \text { At1G02690 } & \text { Col-0 } & \text { GABI_435H12 } & \text { (Kleinboelting et al., 2012) } \\ i m p-\alpha 7 & \text { At3G05720 } & \text { Col-0 } & \text { SALK_020428 } & \text { (Alonso et al., 2003) } \\ i m p-\alpha 8 & \text { At5G52000 } & \text { Col-0 } & \text { SAIL_08I405 } & \text { (Alonso et al., 2003) } \\ i m p-\alpha 9 & \text { At5G03070 } & \text { Col-0 } & \text { SALK_085535 } & \text { (Alonso et al., 2003) }\end{array}$

Double and higher order mutants containing imp- $\alpha$ alleles

\begin{tabular}{|c|c|c|}
\hline$i m p-\alpha 1 i m p-\alpha 2$ & Col-0 & line was generated by crossing in this work \\
\hline$i m p-\alpha 5 \operatorname{mos} 6-4$ & Col-0 & line was generated by crossing in this work \\
\hline$i m p-\alpha 5 i m p-\alpha 7$ & Col-0 & line was generated by crossing in this work \\
\hline$i m p-\alpha 8 i m p-\alpha 7$ & Col-0 & line was generated by crossing in this work \\
\hline mos6-4 imp- $\alpha 1$ & Col-0 & line was generated by crossing in this work \\
\hline mos6-4 imp- $\alpha 2$ & Col-0 & line was generated by crossing in this work \\
\hline mos6-4 imp- $\alpha 5$ & Col-0 & line was generated by crossing in this work \\
\hline mos6-4 imp- $\alpha 7$ & Col-0 & line was generated by crossing in this work \\
\hline mos6-4 imp- $\alpha 8$ & Col-0 & line was generated by crossing in this work \\
\hline mos6-1 imp- $\alpha 1$ & Col-0 & line was generated by crossing in this work \\
\hline mos6-1 imp- $\alpha 2$ & Col-0 & line was generated by crossing in this work \\
\hline mos6-1 imp- $\alpha 5$ & Col-0 & line was generated by crossing in this work \\
\hline mos6-1 imp- $\alpha 6$ & Col-0 & line was generated by crossing in this work \\
\hline $\operatorname{mos} 6-1$ imp- $\alpha 7$ & Col-0 & line was generated by crossing in this work \\
\hline $\operatorname{mos} 6-4 i m p-\alpha 1 i m p-\alpha 2$ & Col-0 & line was generated by crossing in this work \\
\hline $\operatorname{mos} 6-4 i m p-\alpha 1 i m p-\alpha 5$ & Col-0 & line was generated by crossing in this work \\
\hline $\operatorname{mos} 6-4$ imp- $\alpha 1$ imp- $\alpha 7$ & Col-0 & line was generated by crossing in this work \\
\hline $\operatorname{mos} 6-4$ imp- $\alpha 2$ imp- $\alpha 5$ & Col-0 & line was generated by crossing in this work \\
\hline $\operatorname{mos} 6-4$ imp- $\alpha 2$ imp- $\alpha 7$ & Col-0 & line was generated by crossing in this work \\
\hline $\operatorname{mos} 6-4$ imp- $\alpha 5$ imp- $\alpha 7$ & Col-0 & line was generated by crossing in this work \\
\hline snc1 imp- $\alpha 1$ & Col-0 & line was generated by crossing in this work \\
\hline snc1 imp- $\alpha 2$ & Col-0 & line was generated by crossing in this work \\
\hline
\end{tabular}




\begin{tabular}{|c|c|c|c|c|}
\hline snc1 imp- $\alpha 3$ & & Col-0 & \multicolumn{2}{|c|}{ line was generated by crossing in this work } \\
\hline snc1 imp- $\alpha 4$ & & Col-0 & \multicolumn{2}{|c|}{ line was generated by crossing in this work } \\
\hline snc1 imp- $\alpha 5$ & & Col-0 & \multicolumn{2}{|c|}{ line was generated by crossing in this work } \\
\hline snc1 imp- $\alpha 6$ & & Col-0 & \multicolumn{2}{|c|}{ line was generated by crossing in this work } \\
\hline snc1 imp- $\alpha 7$ & & Col-0 & \multicolumn{2}{|c|}{ line was generated by crossing in this work } \\
\hline snc1 imp- $\alpha 8$ & & Col-0 & \multicolumn{2}{|c|}{ line was generated by crossing in this work } \\
\hline \multicolumn{5}{|c|}{ Candidate mutant lines } \\
\hline nup155 & AT1G14850 & Col-0 & GABI_306C07 & (Kleinboelting et al., 2012) \\
\hline nup50 & AT1G52380 & Col-0 & SAIL_84_H08 & (Alonso et al., 2003) \\
\hline nup1/nup136 & AT3G10650 & Col-0 & SALK_020221 & (Alonso et al., 2003) \\
\hline $\operatorname{trn} 1$ & AT2G16950 & Col-0 & SALK_003127 & (Alonso et al., 2003) \\
\hline imp-6, put. & AT3G08943 & Col-0 & SALK_105245 & (Alonso et al., 2003) \\
\hline imp-6, put. & AT3G08947 & Col-0 & SALK_095888 & (Alonso et al., 2003) \\
\hline$n t f 2$ & AT5G43960 & Col-0 & SALK_011708 & (Alonso et al., 2003) \\
\hline kpnb1/impB2 & AT5G53480 & Col-0 & GABI_180F05 & (Kleinboelting et al., 2012) \\
\hline myb70 & AT2G23290 & Col-0 & GABI_350C10 & (Kleinboelting et al., 2012) \\
\hline wrky60 & AT2G25000 & Col-0 & SALK_120706 & (Alonso et al., 2003) \\
\hline ors1 & AT3G29035 & Col-0 & GABI_778C04 & (Kleinboelting et al., 2012) \\
\hline $\operatorname{tn} 13$ & АT3G04210 & Col-0 & GABI_154D04 & (Kleinboelting et al., 2012) \\
\hline$t n l$ & АT3G44670 & Col-0 & SALK_029707 & (Alonso et al., 2003) \\
\hline snc1 $\operatorname{tn} 13$ & & Col-0 & line was gener & ed by crossing in this work \\
\hline
\end{tabular}

Table 2.3 Transgenic Arabidopsis lines used in this study

\begin{tabular}{|c|c|c|c|}
\hline Abbr. & Background & Construct & Reference/Source \\
\hline MW39_a & $\operatorname{mos} 6-1$ & $\begin{array}{l}\text { pXCG } \\
\text { pMOS6::gMOS6-3xHA-Strepll }\end{array}$ & $\begin{array}{l}\text { Quathamer, } \\
\text { Master thesis, } 2011\end{array}$ \\
\hline MW39_b & snc1 mos6-1 & $\begin{array}{l}\text { pXCG } \\
\text { pMOS6::gMOS6-3xHA-Strepll }\end{array}$ & this work \\
\hline MW40_a & $\operatorname{mos} 6-1$ & $\begin{array}{l}\text { pXCSG } \\
\text { gMOS6-3xHA-Strepll }\end{array}$ & $\begin{array}{l}\text { Quathamer, } \\
\text { Master thesis, } 2011\end{array}$ \\
\hline MW40_b & snc1 mos6-1 & $\begin{array}{l}\text { pXCSG } \\
\text { gMOS6-3xHA-Strepll }\end{array}$ & this work \\
\hline
\end{tabular}




\subsubsection{Nicotiana benthamiana}

$N$. benthamiana seeds were obtained from T. Romeis (Max-Planck-Institute for Plant Breeding Research (MPIZ, Cologne, Germany) and were used for transient expression studies mediated by Agrobacterium tumefaciens.

\subsubsection{Pathogens}

The three isolates of the oomycete pathogen Hyaloperonospora arabidopsidis (H. a.) used in this work are listed in Table 2.4. The different strains of the bacterial pathogen Pseudomonas syringae pv. tomato (Pst) are summarized in section 2.1.2.2. Both pathogens were used for infections of Arabidopsis plants.

\subsubsection{Hyaloperonospora arabidopsidis}

The three H. a. isolates used in this study vary in their ability to infect certain Arabidopsis ecotypes. The NOCO2 isolate is virulent on Col-0 plants, whereas CALA2 and EMWA1 isolates are incompatible with Col-0 due to RPP2 and RPP4 mediated resistance, respectively. These isolates are able to grow on the Ler and the Ws-0 ecotypes, respectively.

Table 2.4 Hyaloperonospora arabidopsidis isolates used in this study

\begin{tabular}{lll}
\hline Isolate & Original source & Reference \\
\hline CALA2 & Oospore infection of a single seedling & (Holub et al., 1994) \\
EMWA1 & Oospore infection of a single seedling & (Holub et al., 1994) \\
NOCO2 & Conidia isolated from a single seedling & (Parker et al., 1993) \\
\hline
\end{tabular}

\subsubsection{Pseudomonas syringae pv. tomato}

The Pseudomonas syringae pv. tomato (Pst) strain DC3000 ( $\triangle$ AvrPto/AvrPtoB) strain that lacks the type three secreted effectors AvrPto and AvrPtoB was used. AvrPto and AvrPtoB 
interfere with signaling from MAMP-activated receptor kinases (Torres et al., 2006; He et al., 2006). Pst DC3000 ( $\triangle$ AvrPto/AvrPtoB) was described by Lin and Martin (2005).

\subsubsection{Bacterial strains used for cloning and transient expression}

\subsubsection{Escherichia coli}

The chemically competent Escherichia coli strain TOP10 was obtained from Invitrogen ${ }^{\mathrm{TM}}$ (Karlsruhe, Germany). It was used for plasmid amplification and harbors the following

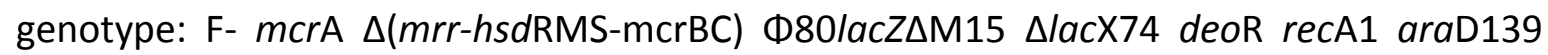
$\Delta$ (ara-leu)7697 ga/U ga/K rpsL (StrR) endA1 nupG.

\subsubsection{Agrobacterium tumefaciens}

For stable transformation of Arabidopsis and transient transformation of $N$. benthamiana plants, the electro competent Agrobacterium tumefaciens strain GV3101 was used (Koncz and Schell, 1986). The strain used in this study carries the helper-plasmid pMP9ORK and is resistant against rifampicin, kanamycin and gentamycin (Koncz and Schell, 1986).

\subsubsection{Vectors}

The vectors used or generated in this study are listed below (Table 2.5).

Table 2.5 Vectors

\begin{tabular}{|c|c|c|}
\hline Abbr. & Construct name & Use and Description \\
\hline & $\mathrm{pENTR}^{\mathrm{TM}} / \mathrm{D}-\mathrm{TOPO}^{\circledR}$ & $\begin{array}{l}\text { Entry vector for the Gateway }{ }^{\circledR} \\
\text { system that allows directional } \\
\text { TOPO }^{\circledR} \text { cloning of blunt-end PCR } \\
\text { products (Invitrogen }{ }^{\mathrm{TM}} \text { ) }\end{array}$ \\
\hline MW09 & pXCSG-cCFP & $\begin{array}{l}\text { Binary Gateway }{ }^{\circledR} \text { destination } \\
\text { vector for expression of fusion } \\
\text { proteins under control of P35SS } \\
\text { with a C-terminal cCFP tag } \\
\text { (Witte et al., 2004) }\end{array}$ \\
\hline
\end{tabular}




\begin{tabular}{|c|c|c|}
\hline MW19 & pXCSG gIMP- $\alpha 6:: 3 x H A-S t r e p \mid l$ & $\begin{array}{l}\text { Vector for expression of gIMP-a6 } \\
\text { under control of P35SS with a C- } \\
\text { terminal 3xHA-Strepll tag } \\
\text { (Witte et al., 2004) }\end{array}$ \\
\hline MW33 & pXCG p+gMOS6::3xHA-Strepll & $\begin{array}{l}\text { Vector for expression of gMOS6 } \\
\text { under control of its native } \\
\text { promoter with a C-terminal 3xHA- } \\
\text { Strepll tag (Witte et al., 2004) }\end{array}$ \\
\hline MW34 & pXCSG gMOS6::3xHA-StrepII & $\begin{array}{l}\text { Vector for expression of gMOS6 } \\
\text { under control of P35SS with a C- } \\
\text { terminal 3xHA-Strepll tag } \\
\text { (Witte et al., 2004) }\end{array}$ \\
\hline MW36 & pXCSG mYFP::mYFP & $\begin{array}{l}\text { Vector for expression of tandem } \\
\text { mYFP::mYFP }\end{array}$ \\
\hline CR48 & pXCSG gIMP $\beta$,put.(AT3G08943)::cCFP & \multirow{12}{*}{$\begin{array}{l}\text { Vectors for expression of } \\
\text { candidate MOS6 interactors } \\
\text { under control of P35SS } \\
\text { with a C-terminal cCFP tag }\end{array}$} \\
\hline CR49 & pXCSG gIMPß,put.(AT3G08947)::cCFP & \\
\hline CR50 & pXCSG gTIR-NB-LRR(AT3G44670)::CCFP & \\
\hline CR61 & pXCSG gMYB70(AT2G23290)::cCFP & \\
\hline CR62 & pXCSG gWRKY60(AT2G25000)::CCFP & \\
\hline CR63 & pXCSG gORS1(AT3G29035)::cCFP & \\
\hline CR68 & pXCSG gNTF2(AT5G43960)::cCFP & \\
\hline CR69 & pXCSG gNUP155(AT1G14850)::cCFP & \\
\hline CR70 & pXCSG gTN13(AT3G04210)::cCFP & \\
\hline CR71 & pXCSG CDS-TRN1(AT2G16950)::cCFP & \\
\hline CR72 & pXCSG gNup1(AT3G10650)::cCFP & \\
\hline CR73 & pXCSG gAtKPNB1(AT5G53480)::cCFP & \\
\hline
\end{tabular}

\subsubsection{Oligonucleotides}

Oligonucleotides were designed with the Geneious ${ }^{\circledR}$ software (V.7.1.5) and ordered from Invitrogen ${ }^{\mathrm{TM}}$ (Karlsruhe, Germany). Lyophilized primers were resuspended and diluted with nuclease-free $\mathrm{H}_{2} \mathrm{O}$ to a concentration of $100 \mu \mathrm{M}(100 \mathrm{pmol} / \mu \mathrm{l})$ for storage and $10 \mu \mathrm{M}(10 \mathrm{pmol} / \mu \mathrm{l})$ for working stocks. The oligonucleotides were stored at $-20^{\circ} \mathrm{C}$. Table 2.6 lists the primers used in this study. Start codons are highlighted in red and CACC sequences for $\mathrm{pENTR} \mathrm{T}^{\mathrm{TM}} / \mathrm{D}-\mathrm{TOPO}^{\circledR}$ cloning are shown in blue. 
Table 2.6 Oligonucleotides

\begin{tabular}{|c|c|c|}
\hline Abbr. & Sequence $\left(5^{\prime} \rightarrow 3^{\prime}\right)$ & Characteristics/Use \\
\hline \multicolumn{3}{|c|}{ Primers for cloning } \\
\hline CR230 & GAAGGAGAATGGACTTAAGAG & $\begin{array}{l}\text { Amplification of gAT1G14850 } \\
\text { (NUP115) from Col-0 gDNA for } \\
\text { cloning into pENTR }{ }^{\mathrm{TM}} / \mathrm{D}-\mathrm{TOPO}^{\circledR}\end{array}$ \\
\hline CR234 & $\begin{array}{l}\text { CACCATGGGTGACTCGGAAAACG } \\
\text { AGTATCTGTAGCTGTTGGAG }\end{array}$ & $\begin{array}{l}\text { Amplification of } \text { gAT1G52380 } \\
\text { (NUP50) from Col-0 gDNA for } \\
\text { cloning into pENTR }{ }^{\text {TM }} / \mathrm{D}-\mathrm{TOPO}^{\circledast}\end{array}$ \\
\hline CR237 & CACCATGGCGGCGACGGCGGTGG & $\begin{array}{l}\text { Amplification of gAT2G16950 } \\
\text { (TRN1) from Col-0 cDNA for cloning } \\
\text { into pENTR }{ }^{\text {TM }} / \mathrm{D}-\mathrm{TOPO}^{\circledR}\end{array}$ \\
\hline $\begin{array}{l}\text { CR239 } \\
\text { CR240 }\end{array}$ & $\begin{array}{l}\text { CACCATGGCTATGGAGATCACAC } \\
\text { GAGCACGAGTCTTGCG }\end{array}$ & $\begin{array}{l}\text { Amplification of gAT3G08943 } \\
\text { (IMPb,put) from Col-0 gDNA for } \\
\text { cloning into pENTR }{ }^{\text {TM }} / \mathrm{D}-\mathrm{TOPO}^{\circledR}\end{array}$ \\
\hline $\begin{array}{l}\text { CR242 } \\
\text { CR243 }\end{array}$ & $\begin{array}{l}\text { CACCATGGCGATGGAGATCACAC } \\
\text { TGATGGGTGCATGAGCCTTG }\end{array}$ & $\begin{array}{l}\text { Amplification of gAT3G08947 } \\
\text { (IMPb,put) from Col-0 gDNA for } \\
\text { cloning into pENTR }{ }^{\text {TM }} / \mathrm{D}-\mathrm{TOPO}^{\circledR}\end{array}$ \\
\hline CR245 & $\begin{array}{l}\text { CACCATGGCGAGCGCGGCACGG } \\
\text { TTTCTTCCTGGTGGATTTC }\end{array}$ & $\begin{array}{l}\text { Amplification of gAT3G10650 } \\
\text { (NUP1) from Col-0 gDNA for cloning } \\
\text { into pENTR }{ }^{\text {TM }} / \mathrm{D}-\mathrm{TOPO}^{\circledR}\end{array}$ \\
\hline CR251 & $\begin{array}{l}\text { CACCATGGCGACTCCTTATCCTG } \\
\text { GCGACCACCACCGCGGTAG }\end{array}$ & $\begin{array}{l}\text { Amplification of gAT5G43960 } \\
\text { (NTF2) from Col-0 gDNA for cloning } \\
\text { into pENTR }{ }^{\mathrm{TM}} / \mathrm{D}-\mathrm{TOPO}^{\circledR}\end{array}$ \\
\hline CR257 & CACCATGTCTGGTTCGACCCGG & $\begin{array}{l}\text { Amplification of } \text { gAT2G23290 } \\
\text { (MYB70) from Col-0 gDNA for } \\
\text { cloning into } \mathrm{pENTR}{ }^{\mathrm{TM}} / \mathrm{D}-\mathrm{TOPO}^{\circledR}\end{array}$ \\
\hline CR260 & $\begin{array}{l}\text { CACCATGGACTATGATCCCAAC } \\
\text { TGTTCTTGAATGCTCTATC }\end{array}$ & $\begin{array}{l}\text { Amplification of } \text { gAT2G25000 } \\
\text { (WRKY60) from Col-0 gDNA for } \\
\text { cloning into pENTR }{ }^{\text {TM }} / \mathrm{D}-\mathrm{TOPO}^{\circledR}\end{array}$ \\
\hline CR263 & CACCATGGATTCTTATTTTTTTCC & $\begin{array}{l}\text { Amplification of gAT3G04210 } \\
\text { (TN13) from Col-0 gDNA for cloning } \\
\text { into } p \text { ENTR }^{\text {TM }} / \mathrm{D}-\mathrm{TOPO}^{\circledR}\end{array}$ \\
\hline CR266 & CACCATGGATTACAAGGTATCAAG & $\begin{array}{l}\text { Amplification of gAT3G29035 } \\
\text { (ORS1) from Col-0 gDNA for cloning } \\
\text { into pENTR }{ }^{\text {TM }} / \text { D-TOPO }^{\circledR}\end{array}$ \\
\hline CR270 & CACCATGGGTTCTGTAATGAGC & $\begin{array}{l}\text { Amplification of gAT3G44670 (TNL) } \\
\text { from Col-0 gDNA for cloning into } \\
\text { pENTR }^{\text {TM }} / \mathrm{D}-\mathrm{TOPO}^{\circledR}\end{array}$ \\
\hline CR284 & $\begin{array}{l}\text { CACCATGGCAATGGAGGTTACGC } \\
\text { AACAGATATGGCACGGGTTATG }\end{array}$ & $\begin{array}{l}\text { Amplification of gAT5G53480 } \\
\text { (AtKPNB1/IMP-B2) from Col-0 gDNA } \\
\text { for cloning into } p \text { ENTR }{ }^{\text {TM }} / \mathrm{D}-\mathrm{TOPO}^{\circledR}\end{array}$ \\
\hline
\end{tabular}


Primer for sequencing

\begin{tabular}{|c|c|c|}
\hline MW6 & GTAAAACGACGGCCAG & $\begin{array}{l}\text { M13 fwd. for sequencing and } \\
\text { colony-PCR }\end{array}$ \\
\hline MW7 & CAGGAAACAGCTATGAC & $\begin{array}{l}\text { M13 rev. for sequencing and } \\
\text { colony-PCR }\end{array}$ \\
\hline CR287 & CCGCGAACACCAGCGGGATT & AT5G43960/NTF2 sequencing \\
\hline CR288 & GGCTCTCGGATTCGCCCAAGC & \multirow{2}{*}{$\begin{array}{l}\text { AT5G53480/AtKPNB1/IMP- } \beta 2 \\
\text { sequencing }\end{array}$} \\
\hline CR289 & CAGCTCCAGCCGAGTGAGCA & \\
\hline CR290 & AGTGTGCTGCACTGAAGGAC & \multirow{6}{*}{ AT1G14850/NUP155 sequencing } \\
\hline CR291 & CCAGGCCATCTCCTCCATTG & \\
\hline CR292 & ACGAAGGGCTCTGCCTTTGC & \\
\hline CR293 & CGATATTAGCCCGCGACTAC & \\
\hline CR294 & CAGAGCGTTCCGAGAGTACC & \\
\hline CR295 & ACTCGCAGTTCTTCAGTTCC & \\
\hline CR296 & CAAGGAGGACGTCTCTAATG & \multirow{5}{*}{ AT3G10650/NUP1 sequencing } \\
\hline CR297 & CCTACAATGTCGCTGGTAAC & \\
\hline CR298 & AGAATGTAGAGGCGCCAAAG & \\
\hline CR299 & GCCAACCTCAGAAGAGAAAC & \\
\hline CR300 & GAGGTATGGCTTCAGCAGAC & \\
\hline CR306 & GTAAGTCGATCGGTCATGAG & \multirow{3}{*}{ AT3G44670/TNL sequencing } \\
\hline CR307 & TTAGGAGTGGCTCAAGAACG & \\
\hline CR308 & CGAGAATGCGACTAATCTCC & \\
\hline CR322 & TGCAGATCCTAGGCAAGAAC & \multirow{7}{*}{ AT2G16950/TRN1 sequencing } \\
\hline CR323 & GAAGCTTGCCCTGGGTTCTG & \\
\hline CR324 & CTCAGCTACCTCCAGAGAAC & \\
\hline CR325 & GATGAGGCCTGGAAACAAAG & \\
\hline CR326 & CACACCTGGGTGTAATACTG & \\
\hline CR327 & GATTCGCTCCATTTGCTCAG & \\
\hline CR328 & CCGCCTGCTTGATTTCCTTG & \\
\hline CR329 & GACCGTCAAGAGTATGACAG & AT3G08943/IMP- $\beta$ put. sequencing \\
\hline
\end{tabular}


Primer for genotyping

\begin{tabular}{|c|c|c|c|}
\hline MW10 & & ATTTTGCCGATTTCGGAAC & T-DNA primer SALK-LBb1.3 for PCR \\
\hline MW11 & & CGTCCGCAATGTGTTATTAAG & T-DNA primer SAIL.1F for PCR \\
\hline UU41 & & CCCATTTGGACGTGAATGTAGACAC & T-DNA primer GABI-KAT for PCR \\
\hline CR349 & LP & GCTGATGCTATTTGGTGCTTC & $\begin{array}{l}\text { genotyping of } \\
\text { GABI 154D04/tn13 }\end{array}$ \\
\hline CR350 & $\mathrm{RP}$ & CTGATGTAAGGAAGCAGACCG & (AT3G04210) \\
\hline CR337 & LP & CATTGTTCCACATGTCATGC & $\begin{array}{l}\text { genotyping of } \\
\text { GABI 180F05/Atkpnb1/imp-62 }\end{array}$ \\
\hline CR338 & $\mathrm{RP}$ & CCTTCTCGGCAACATTAGGC & (AT5G53480) \\
\hline CR339 & LP & TTAAGTTCCGAGGAGACCTCC & $\begin{array}{l}\text { genotyping of } \\
\text { GABI_306C07/nup155 }\end{array}$ \\
\hline CR340 & $\mathrm{RP}$ & ATGAAGCTGTTGTCTGCTTGC & (AT1G14850) \\
\hline CR50 & LP & TGAAAAAGGTTTGCATTTATAATTTG & $\begin{array}{l}\text { genotyping of } \\
\mathrm{GABI} 350 \mathrm{C} 10 / \mathrm{myb} 70\end{array}$ \\
\hline CR51 & $\mathrm{RP}$ & GAGCGTGCGCTAGTATAATCG & (AT2G23290) \\
\hline CR355 & LP & TTTAGGGAAGGCTAAGCTTGG & $\begin{array}{l}\text { genotyping of } \\
\text { GABI_778C04/ors1 }\end{array}$ \\
\hline CR356 & $\mathrm{RP}$ & ATGCAAACACAATTCAGCATG & (AT3G29035) \\
\hline CR144 & LP & TTTCCСTCTCTGCTACTGCTG & $\begin{array}{l}\text { genotyping of } \\
\text { SAIL } 84 \mathrm{H} 08 / \text { nup } 50\end{array}$ \\
\hline CR145 & $\mathrm{RP}$ & TTACTGTCAACTTCATCGCCC & (AT1G52380) \\
\hline CR345 & LP & CATTGGCAAGAACTAGCCTTG & genotyping of \\
\hline CR346 & $\mathrm{RP}$ & TACTGGTTCACAGAACCCAGG & (AT2G16950) \\
\hline CR188 & LP & AAATGACAAGACCGGATCATG & $\begin{array}{l}\text { genotyping of } \\
\text { SALK } 011708 / n t f 2\end{array}$ \\
\hline CR189 & $\mathrm{RP}$ & TTGGCTAAGTGATTGAATCGG & (AT5G43960) \\
\hline CR353 & LP & TACCTTGTTGCGTTCAAAAGC & genotyping of \\
\hline CR354 & $\mathrm{RP}$ & ATTCTGGAGGCTTTTGAGAGC & $\begin{array}{l}\text { SALK_020221/nup1/nup136 } \\
\text { (AT3G10650) }\end{array}$ \\
\hline CR66 & LP & AAAAGAGGGAAGCTCCACAAG & $\begin{array}{l}\text { genotyping of } \\
\text { SALK } 029707 / t n l\end{array}$ \\
\hline CR67 & $\mathrm{RP}$ & TCAGCTTTTGGTTGGTGAAAG & (AT3G44670) \\
\hline CR96 & LP & TCTCGAGAGCAAACAGAAACC & genotyping of \\
\hline CR97 & $\mathrm{RP}$ & TGGTCGAATTGCTTATTAAACG & $\begin{array}{l}\text { SALK_095888/imp-6, put. } \\
\text { (AT3G08947) }\end{array}$ \\
\hline CR158 & LP & GGCAAATATAAGGGGGTTACG & genotyping of \\
\hline CR159 & $\mathrm{RP}$ & CCTGAGCTGAAGTATGCCTTG & (AT3G08943) \\
\hline CR114 & LP & GCCAACAAATTTAATCCAACG & $\begin{array}{l}\text { genotyping of } \\
\text { SALK_120706/wrky60 }\end{array}$ \\
\hline CR115 & $\mathrm{RP}$ & TATTGCACACCAAAGTGTTCG & (AT2Ḡ 25000$)$ \\
\hline
\end{tabular}

LP : left border primer; RP : right border primer 


\subsubsection{Enzymes}

\subsubsection{Restriction endonucleases}

Restriction enzymes were purchased either from New England BioLabs (NEB; Frankfurt am Main, Germany) or Fermentas (St. Leon-Rot, Germany) and were used with the supplied 10x reaction buffers according to the manufacturer's instructions.

\subsubsection{Nucleic acid modifying enzymes}

Homemade Taq DNA polymerase was used for standard polymerase chain reactions (PCR, see 2.2 .5 .4$)$. PCR products for cloning were amplified by the proofreading iProof ${ }^{\mathrm{TM}} \mathrm{High}$ Fidelity DNA polymerase (Bio-Rad, Munich, Germany). For the LR recombination reaction between entry and destination vectors compatible for the Gateway system the Gateway LR Clonase ${ }^{\mathrm{TM}}$ enzyme mix (Invitrogen ${ }^{\mathrm{TM}}$, Karlsruhe, Germany) was used. The following table lists nucleic acid modifying enzymes used in this study.

Table 2.7 Nucleic acid modifying enzymes

\begin{tabular}{lll}
\hline Enzymes & Supplier & Purpose \\
\hline iProof ${ }^{\mathrm{TM}}$ High-Fidelity DNA polymerase & Bio-Rad & Cloning PCR \\
LR clonase & Invitrogen & LR reaction \\
Taq DNA polymerase & homemade & Standard PCR \\
RevertAidTM H Minus M-MulVRT & Fermentas & Reverse transcriptase \\
DNAse I & Fermentas & Digest of extracted RNA \\
\hline
\end{tabular}

\subsubsection{Chemicals}

Laboratory grade chemicals and reagents were purchased from AppliChem (Darmstadt, Germany), Bio-Rad (Munich, Germany), BD Clontech GmbH (Heidelberg, Germany), BD (Franklin Lakes, NJ, USA), Difco (Heidelberg, Germany), Duchefa (Biochemie Haarlem, Netherlands), Fermentas (St. Leon-Rot, Germany), Finnzymes (Espoo, Finland), Fluka (Buchs, Switzerland), GE Healthcare (Munich, Germany), Invitrogen ${ }^{\mathrm{TM}}$ (Karlsruhe, Germany), Macherey Nagel (Düren, Germany), Merck (Darmstadt, Germany), New 
England BioLabs (NEB) (Frankfurt/Main, Germany), Roche (Mannheim, Germany), Roth (Karlsruhe, Germany), Serva (Heidelberg, Germany), Sigma-Aldrich (Deisenhofen, Germany) or VWR ${ }^{\mathrm{TM}}$ (Darmstadt, Germany) unless otherwise stated.

\subsubsection{Antibiotics}

Ampicillin (Amp) $\quad 100 \mathrm{mg} / \mathrm{mL}$ in $\mathrm{H}_{2} \mathrm{O}$

Carbenicillin (Carb) $50 \mathrm{mg} / \mathrm{mL}$ in $\mathrm{H}_{2} \mathrm{O}$

Gentamycin (Gent) $15 \mathrm{mg} / \mathrm{mL}$ in $\mathrm{H}_{2} \mathrm{O}$

Kanamycin (Kan) $50 \mathrm{mg} / \mathrm{mL}$ in $\mathrm{H}_{2} \mathrm{O}$

Rifampicin (Rif) $\quad 100 \mathrm{mg} / \mathrm{mL}$ in DMSO

Aqueous solutions were sterile filtrated. Stock solutions $(1000 \mathrm{x})$ were stored at $-20^{\circ} \mathrm{C}$.

\subsubsection{Media}

Media were sterilized by autoclaving at $121^{\circ} \mathrm{C}$ for $20 \mathrm{~min}$. Before addition of antibiotics, the respective media were cooled down to $55^{\circ} \mathrm{C}$. Heat labile compounds were sterilized using filter sterilization units prior to addition.

Escherichia coli medium

LB (Luria-Bertani) broth

$\begin{array}{lll}\text { Peptone } & 10.0 & \mathrm{~g} / \mathrm{L} \\ \text { Yeast extract } & 5.0 & \mathrm{~g} / \mathrm{L} \\ \mathrm{NaCl} & 10.0 & \mathrm{~g} / \mathrm{L} \\ \mathrm{pH} 7.0 & & \end{array}$

For LB agar plates $1.5 \%(\mathrm{w} / \mathrm{v})$ agar was added.

Pseudomonas syringae medium

NYG broth

$\begin{array}{lll}\text { Peptone } & 5.0 & \mathrm{~g} / \mathrm{L} \\ \text { Yeast extract } & 3.0 & \mathrm{~g} / \mathrm{L} \\ \text { Glycerol } & 20 & \mathrm{~mL} / \mathrm{L} \\ \text { pH 7.0 } & & \end{array}$

For NYG agar plates $1.5 \%(\mathrm{w} / \mathrm{v})$ agar was added. 
Agrobacterium tumefaciens medium

DYT

$\begin{array}{lcc}\text { Yeast extract } & 10.0 & \mathrm{~g} / \mathrm{L} \\ \text { Peptone } & 16.0 & \mathrm{~g} / \mathrm{L} \\ \mathrm{NaCl} & 10.0 & \mathrm{~g} / \mathrm{L}\end{array}$

For DYT agar plates $1.5 \%(\mathrm{w} / \mathrm{v})$ agar was added.

Arabidopsis thaliana medium

$1 / 2$ MS (Murashige and Skoog) agar plates (Murashige and Skoog, 1962)

$\begin{array}{lll}\text { MS powder including vitamins and MES buffer } & 2.2 & \mathrm{~g} / \mathrm{L} \\ \text { Sucrose } & 5.0 & \mathrm{~g} / \mathrm{L} \\ \text { Plant agar } & 4.5 & \mathrm{~g} / \mathrm{L}\end{array}$

$\mathrm{pH}$ was adjusted to 5.7 with $\mathrm{KOH}$

For selection of transgenic Arabidopsis plants carrying the phosphinothricin acetyltransferase (PAT) gene that confers Basta ${ }^{\circledR}$ (glufosinate-ammonium) resistance, DL-Phosphinothricin (PPT) was added to the agar plates: DL-Phosphinothricin $(10 \mathrm{mg} / \mathrm{mL})$ 1:1000. Also, $100 \mu \mathrm{g} / \mathrm{mL}$ Amp were added to prevent growth of bacteria in agar plates.

\subsubsection{Antibodies}

Primary and secondary antibodies used for immunoblot detection are listed below. The antibodies used in this study were aliquoted and stored at $-80{ }^{\circ} \mathrm{C}$. Primary and secondary antibodies ready for use were kept at $4{ }^{\circ} \mathrm{C}$.

Table 2.8 Antibodies

\begin{tabular}{|c|c|c|c|c|}
\hline Primary antibodies & Source & Dilution & Milk & Reference \\
\hline$\alpha-G F P$ & $\begin{array}{l}\text { mouse } \\
\text { monoclonal }\end{array}$ & $1: 5000$ & $0 \%$ & $\begin{array}{l}\text { Roche } \\
\text { (Mannheim, Germany) }\end{array}$ \\
\hline$\alpha-H A$ & $\begin{array}{l}\text { mouse } \\
\text { monoclonal }\end{array}$ & $1: 10000$ & $2 \%$ & $\begin{array}{l}\text { Sigma-Aldrich } \\
\text { (Deisenhofen, Germany) }\end{array}$ \\
\hline Secondary antibodies & Source & Dilution & Milk & Reference \\
\hline$\alpha$-mouse IgG-HRP* & goat polyclonal & $1: 5000$ & $2 \%$ & $\begin{array}{l}\text { Thermo Scientific } \\
\text { (Waltham, MA, USA) }\end{array}$ \\
\hline$\alpha$-mouse IgG-poly HRP* & goat polyclonal & $1: 5000$ & $2 \%$ & $\begin{array}{l}\text { Thermo Scientific } \\
\text { (Waltham, MA, USA) }\end{array}$ \\
\hline
\end{tabular}

* HRP: Horseradish peroxidase 


\subsubsection{Buffers and solutions}

The buffers and solutions used in this work are listed in the following section. All buffers and solutions were prepared with ultra-pure $\mathrm{H}_{2} \mathrm{O}$. Sterilization was carried out for 20 min at $121{ }^{\circ} \mathrm{C}$. Buffers and solutions not displayed in this listing are specified with the corresponding methods.

\begin{tabular}{|c|c|c|c|}
\hline \multicolumn{4}{|c|}{ AGAROSE GEL ELECTROPHORESIS AND PCR } \\
\hline \multirow[t]{2}{*}{ Agarose solution } & Agarose & 1 & $\%(w / v)$ \\
\hline & TAE Buffer & 1 & $x$ \\
\hline \multirow{4}{*}{$\begin{array}{l}\text { DNA gel loading buffer } \\
(6 x)\end{array}$} & Xylene xyanole & 0.01 & $\%(w / v)$ \\
\hline & Orange-G & 0.01 & $\%(w / v)$ \\
\hline & Bromophenol blue & 0.01 & $\%(w / v)$ \\
\hline & Glycerol & 30 & $\%(w / v)$ \\
\hline \multirow{4}{*}{$\begin{array}{l}\text { FTA buffer for punch-PCR } \\
(50 x)\end{array}$} & Tris & 10 & $\mathrm{mM}$ \\
\hline & EDTA & 2 & $\mathrm{mM}$ \\
\hline & Tween 20 & 0.1 & $\%(w / v)$ \\
\hline & $\mathrm{pH} 7.5 \mathrm{HCl}$ & & \\
\hline \multirow{5}{*}{$\begin{array}{l}\text { PCR reaction buffer for Taq } \\
(10 x)\end{array}$} & Tris & 100 & $\mathrm{mM}$ \\
\hline & $\mathrm{KCl}$ & 500 & $\mathrm{mM}$ \\
\hline & $\mathrm{MgCl}_{2}$ & 15 & $\mathrm{mM}$ \\
\hline & Triton X-100 & 1 & $\%(w / v)$ \\
\hline & $\mathrm{pH} 9.0 \mathrm{KOH}$ & & \\
\hline \multirow{3}{*}{$\begin{array}{l}\text { TAE-buffer } \\
(50 x)\end{array}$} & Tris & 2 & M \\
\hline & Glacial acetic acid & 57.1 & $\mathrm{~mL} / \mathrm{L}$ \\
\hline & EDTA (pH 8.0) & 50 & $\mathrm{mM}$ \\
\hline \multirow{3}{*}{$\begin{array}{l}\text { TE buffer for } \\
\text { primer/plasmids }(1 x)\end{array}$} & Tris & 10 & $\mathrm{mM}$ \\
\hline & EDTA & 1 & $\mathrm{mM}$ \\
\hline & $\mathrm{pH} 8.0 \mathrm{HCl}$ & & \\
\hline \multirow[t]{2}{*}{ TE-1 buffer for punch-PCR } & Tris & 10 & $\mathrm{mM}$ \\
\hline & EDTA & 0.1 & $\mathrm{mM}$ \\
\hline
\end{tabular}




\begin{tabular}{|c|c|c|c|}
\hline \multicolumn{4}{|c|}{ HISTOCHEMICAL STAINING FOR MICROSCOPY } \\
\hline \multirow[t]{3}{*}{ Coomassie staining solution } & Methanol & 45 & $\%(w / v)$ \\
\hline & Acetic acid & 10 & $\%(w / v)$ \\
\hline & Coomassie R-250 & 0.05 & $\%(w / v)$ \\
\hline \multirow{6}{*}{$\begin{array}{l}\text { Lactophenol trypan } \\
\text { blue solution }\end{array}$} & Lactic acid & 10 & $\mathrm{~mL}$ \\
\hline & Glycerol & 10 & $\mathrm{~mL}$ \\
\hline & $\mathrm{H}_{2} \mathrm{O}$ & 10 & $\mathrm{~mL}$ \\
\hline & Phenol & 10 & $\mathrm{~mL}$ \\
\hline & Trypan blue & 10 & $\mathrm{mg}$ \\
\hline & Before use dilute $1: 1$ in ethanol. & & \\
\hline \multirow{2}{*}{$\begin{array}{l}\text { Propidium iodide } \\
\text { staining solution }\end{array}$} & Propidium iodide & 0.05 & $\%(w / v)$ \\
\hline & Silwet L-77 & 0.01 & $\%(w / v)$ \\
\hline \multicolumn{4}{|c|}{ BUFFERS USED FOR INFILTRATION WITH BACTERIA } \\
\hline \multirow{2}{*}{$\begin{array}{l}\text { Agrobacterium } \\
\text { infiltration medium }\end{array}$} & $\mathrm{MgCl}_{2}$ & 10 & $\mathrm{mM}$ \\
\hline & Acetosyringone & 150 & $\mu \mathrm{M}$ \\
\hline \multirow{2}{*}{$\begin{array}{l}\text { Pseudomonas } \\
\text { infiltration medium }\end{array}$} & $\mathrm{MgCl}_{2}$ & 5 & $\mathrm{mM}$ \\
\hline & Sylvet & 0,002 & $\%$ \\
\hline \multicolumn{4}{|l|}{ SDS-PAGE AND WESTERN BLOT } \\
\hline \multirow{6}{*}{$\begin{array}{l}\text { Laemmli sample buffer } \\
(2 x)\end{array}$} & Tris & 0.125 & M \\
\hline & SDS & 4 & $\%(w / v)$ \\
\hline & Glycerol & 20 & $\%(w / v)$ \\
\hline & Bromophenol blue & 0.02 & $\%(w / v)$ \\
\hline & DTT & 0.2 & $M$ \\
\hline & $\mathrm{pH} 6.8 \mathrm{HCl}$ & & \\
\hline \multirow[t]{2}{*}{ Ponceau S solution } & Ponceau S & 0.2 & $\%(w / v)$ \\
\hline & Acetic acid & 5 & $\%$ \\
\hline $\begin{array}{l}\text { Resolving gel buffer } \\
(4 x)\end{array}$ & $\begin{array}{l}\text { Tris } \\
\mathrm{pH} 8.8 \mathrm{HCl}\end{array}$ & 1.5 & $M$ \\
\hline
\end{tabular}




\begin{tabular}{|c|c|c|c|}
\hline \multirow{6}{*}{$\begin{array}{l}\text { Resolving gel } \\
(7.5 \%)\end{array}$} & $\mathrm{H}_{2} \mathrm{O}$ & 4.82 & $\mathrm{~mL}$ \\
\hline & Resolving gel buffer (4x) & 2.5 & $\mathrm{~mL}$ \\
\hline & $10 \%$ SDS & 0.1 & $\mathrm{~mL}$ \\
\hline & $30 \%$ Acrylamide/Bis solution, 29:1 & 2.5 & $\mathrm{~mL}$ \\
\hline & TEMED & 5.0 & $\mu \mathrm{L}$ \\
\hline & $10 \%$ APS & 75 & $\mu \mathrm{L}$ \\
\hline \multirow{6}{*}{$\begin{array}{l}\text { Resolving gel } \\
(10 \%)\end{array}$} & $\mathrm{H}_{2} \mathrm{O}$ & 4.1 & $\mathrm{~mL}$ \\
\hline & Resolving gel buffer $(4 \mathrm{x})$ & 2.5 & $\mathrm{~mL}$ \\
\hline & $10 \%$ SDS & 0.1 & $\mathrm{~mL}$ \\
\hline & $30 \%$ Acrylamide/Bis solution, 29:1 & 3.3 & $\mathrm{~mL}$ \\
\hline & TEMED & 5.0 & $\mu \mathrm{L}$ \\
\hline & $10 \%$ APS & 75 & $\mu \mathrm{L}$ \\
\hline \multirow{2}{*}{$\begin{array}{l}\text { Stacking gel buffer } \\
(4 \mathrm{x})\end{array}$} & Tris & 0.5 & M \\
\hline & $\mathrm{pH} 6.8 \mathrm{HCl}$ & & \\
\hline \multirow{6}{*}{$\begin{array}{l}\text { Stacking gel } \\
(4 \%)\end{array}$} & $\mathrm{H}_{2} \mathrm{O}$ & 6.1 & $\mathrm{~mL}$ \\
\hline & Resolving gel buffer & 2.5 & $\mathrm{~mL}$ \\
\hline & $10 \%$ SDS & 0.1 & $\mathrm{~mL}$ \\
\hline & $30 \%$ Acrylamide/Bis solution, 29:1 & 1.3 & $\mathrm{~mL}$ \\
\hline & TEMED & 10 & $\mu \mathrm{L}$ \\
\hline & $10 \%$ APS & 100 & $\mu \mathrm{L}$ \\
\hline \multirow{5}{*}{$\begin{array}{l}\text { Transfer buffer } \\
(1 x)\end{array}$} & Tris & 250 & $\mathrm{mM}$ \\
\hline & Glycine & 40 & $\mathrm{mM}$ \\
\hline & SDS & 0.0125 & $\%(w / v)$ \\
\hline & $\mathrm{pH} 9.2 \mathrm{HCl}$ & & \\
\hline & Before use add $20 \%(\mathrm{v} / \mathrm{v})$ methanol. & & \\
\hline
\end{tabular}

The $\mathrm{pH}$ of Tris buffers was adjusted with $\mathrm{HCl}$ or $\mathrm{NaOH}$ if not otherwise stated. 


\subsection{Methods}

\subsubsection{Maintenance and cultivation of plant material}

For vernalization and elimination of potential contamination by pests such as thrips Arabidopsis thaliana seeds were frozen $\left(-20^{\circ} \mathrm{C}\right.$, overnight) and subsequently thawed at room temperature in airtight plastic bags. The seeds were sown directly on damp soil (Frühstorfer Erde, Type T25, Str1, Archut). For germination, the plant trays were covered with transparent lids and transferred to short day (SD) growth conditions in an environmental growth chamber (8h photoperiod at $22^{\circ} \mathrm{C}$, light intensity of approximately $200 \mu$ Einsteins $\mathrm{m}^{-2} \mathrm{sec}^{-1}$ and $65 \%$ rel. humidity; Johnson Controls, Milwaukee, WI, USA). After germination the lids were removed. For early induction of bolting, flower development and subsequent seed set the plants were transferred to long day (LD) conditions (16h photoperiod at $22^{\circ} \mathrm{C}$, light intensity of approximately $200 \mu$ Einsteins $\mathrm{m}^{2}$ $\sec ^{-1}$ and $65 \%$ rel. humidity). Aerial plant tissue was encased with a paper bag prior to silique opening to collect seeds. Plants were watered every 2 to 3 days with tab water.

Nicotiana benthamiana seeds were treated in the same way as described above. Two week old $N$. benthamiana plants were transferred to LD conditions ( $16 \mathrm{~h}$ photoperiod at $25^{\circ} \mathrm{C}$, light intensity of approximately $200 \mu$ Einsteins $\mathrm{m}^{-2} \mathrm{sec}^{-1}$ and $65 \%$ rel. humidity) for rapid plant growth. 4 to 6 weeks old plants were used for transient expression studies.

\subsubsection{Generation of Arabidopsis F1 and F2 progeny}

For crossing of different Arabidopsis lines fine tweezers and a binocular were used. Three to four inflorescences of the line chosen to be pollinated were selected. The meristems, buds and flowers that were younger or older than flower developmental stage 10-12 according to Smyth et al. (1990) were removed. For dissection of the stigmas all other parts of the remaining flowers were removed. Fresh pollen from the donor line was applied by dapping the anthers several flowers onto the dissected stigmas. Crosses were done on both directions to rule out possible effects of the chosen parental genotypes (House et al., 2010). The treated stigmas were tagged with colored tape. Elongated 
siliques were enveloped in small paper bags before ripening. Mature siliques were harvested and five plants of the F1 generation were grown as described in 2.2.1. After testing for heterozygosity by genotyping (2.2.5.2) plants were allowed to self-pollinate. F2 seeds were collected and used for further analysis.

\subsubsection{Arabidopsis seed sterilisation}

For in vitro culture, Arabidopsis seeds were sterilized with $\mathrm{Cl}_{2}$-gas. Therefore, seeds were transferred to paper bags that were labeled with pencil, so that the labeling could not bleach during the procedure. In an desiccator, the seed bags were arranged around a beaker containing $15 \mathrm{~mL}$ of Sodium-hypochloride solution (chlorine bleach). $5 \mathrm{~mL}$ of $37 \%$ $\mathrm{HCl}$ were directly pipetted into the hypochloride solution and the desiccator lid was closed immediately. The seeds were incubated in the forming $\mathrm{Cl}_{2}$-gas for 4 to $5 \mathrm{~h}$ and left for ventilation overnight in the opened desiccator under the fume hood. Sterilized seeds were directly sown on suitable culture media.

\subsubsection{Agrobacterium-mediated stable transformation of Arabidopsis}

The Agrobacterium-mediated stable transformation of Arabidopsis described in the following is based on the floral dip method reported previously (Clough and Bent, 1998). Plants germinated under SD conditions were transferred to LD conditions for bolting and flowering. The first developed shoot apical meristems were cut in order to induce growth of additional shoots. Agrobacterium strains were grown in $20 \mathrm{~mL}$ selective DYT medium (overnight, $28^{\circ} \mathrm{C}, 180 \mathrm{rpm}$ ). With this overnight culture, $400 \mathrm{~mL}$ selective DYT medium were inoculated. The culture was grown under the same conditions until $\mathrm{OD}_{600}>1.6$. After pelleting (1200 g, $15 \mathrm{~min}$ at room temperature), the Agrobacteria cells were resuspended in $5 \%$ sucrose with $0.05 \%$ Sylvet- 77 to $\mathrm{OD}_{600} \sim 0.8$. The plants were dipped by submerging all inflorescences and gently rotating the plants in the solution. The plants were then covered with a plastic lid and kept in the laboratory overnight. After one day, the plants were transferred back to LD conditions and allowed to set seeds. 


\subsubsection{Glufosinate selection of Arabidopsis transformants on soil}

T1 seeds were sown densely on damp soil and allowed to germinate as described in 2.2.1. After circa 1 week, the seedlings were evenly sprayed with the herbicide Basta ${ }^{\circledR}(200 \mathrm{~g} / \mathrm{L}$ glufosinate ammonium solution, Bayer, Leverkusen, Germany) diluted 1:1000 in $\mathrm{H}_{2} \mathrm{O}$. This treatment was repeated 3 to 4 times in two day intervals. Seedlings that were successfully transformed with the phosphinothricin acetyltransferase (PAT) gene survived this treatment whereas non-transformed seedlings died. Maximal 38 seedlings were transplanted to single-plant-pots and cultivated for further analyses.

\subsubsection{Inoculation and maintenance of Hyaloperonospora arabidopsidis}

H. a.s isolates were propagated on their respective compatible Arabidopsis host ecotypes (see 2.1.2.1) as mass conidiosporangia cultures over a 7 day cycle. For infection, conidiospores were collected by harvesting leaf tissue from infected plants ( $7 \mathrm{dpi}$ ) into $50 \mathrm{~mL}$ falcon tubes and subsequent vortexing in $\mathrm{dH}_{2} \mathrm{O}$. After filtering through fine tissue to remove plant material a Neubauer improved counting cell chamber was used to adjust the spore suspension to a concentration of $4 \times 10^{4}$ spores $/ \mathrm{mL} \mathrm{dH}_{2} \mathrm{O}$. Plants used for infection were grown under SD conditions as described above (2.2.1). Two weeks old seedlings were inoculated by spraying with spore suspension. The plants were transferred to a growth chamber $\left(18^{\circ} \mathrm{C}\right.$ and $10 \mathrm{~h}$ light period) and were covered with a propagator lid taped to the tray for high humidity. Stocks of $H$. $a$. isolates were kept as mass conidiosporangia cultures on leaf tissue at $-80^{\circ} \mathrm{C}$.

\subsubsection{Quantification of Hyaloperonospora arabidopsidis sporulation}

For the quantification of $H$. a. sporulation on Arabidopsis leaf tissue, the conidiospores were counted 6 days post inoculation. For each Arabidopsis line, at least 2 pots with 30 to 40 seedlings were inoculated. The harvesting of leaf tissue from infected plants was performed as described above (2.2.2). In order to be able to calculate the number of spores per g plant tissue, the weight of the harvested leaf material was determined before vortexing the material in a certain volume of $\mathrm{dH}_{2} \mathrm{O}$. The number of spores in this 
spore suspension was determined by counting the spores repeatedly with a Neubauer improved counting chamber.

\subsubsection{Maintenance of Pseudomonas syringae pv. tomato cultures}

The Pseudomonas syringae pv. tomato strain used in this study (2.1.2.2) was grown on selective NYG agar plates containing rifampicin $(50 \mu \mathrm{g} / \mathrm{mL})$ and kanamycin $(50 \mu \mathrm{g} / \mathrm{mL})$. Plates were incubated at $28{ }^{\circ} \mathrm{C}$ for two days and stored at $4{ }^{\circ} \mathrm{C}$. Plates were refreshed every two to three weeks.

\subsubsection{Pseudomonas syringae pv. tomato growth assay}

The plants used for the Pst vacuum-infiltration assay were grown for 4 weeks under SD conditions on soil that was covered with a fine mesh prior to seed germination. This mesh prevented the soil from falling into the cell-suspension during the infiltration process. A $50 \mathrm{~mL}$ selective NYG liquid culture containing $50 \mu \mathrm{g} / \mathrm{mL}$ rifampicin and kanamycin was inoculated with a small amount of plate-grown cells of one of the Pst strains described above (2.1.2.2 and 2.2.3). This liquid culture was incubated overnight on a rotary shaker at $28{ }^{\circ} \mathrm{C}$ and $180 \mathrm{rpm}$. Of this culture, $3 \mathrm{~mL}$ were used to inoculate $50 \mathrm{~mL}$ of selective liquid NYG (50 $\mathrm{gg} / \mathrm{mL}$ rifampicin and kanamycin). This culture was incubated for circa $3 \mathrm{~h}$ as described before. After pelleting the cells (1200 g, $10 \mathrm{~min}, \mathrm{RT})$, the supernatant was discarded and the cells were resuspended in $50 \mathrm{~mL} 5 \mathrm{mM} \mathrm{MgCl}$. For vacuum-infiltration, the cell-suspension was diluted to a concentration of $1 \times 10^{5} \mathrm{cfu}$ (colony forming units) $/ \mathrm{mL}$. Circa $1 \mathrm{~L}$ of suspension was needed to infiltrate 2 pots. Two pots with plants were inverted and put into a plastic desiccator. The desiccator was filled with the suspension until the plants' leaves were submerged. A vacuum was applied for 1:15 min and maintained for 1:30 min and then slowly released. The plants were removed from the desiccator and rinsed gently with water. Non-infiltrated leaves were removed.

For day zero $\left(d_{0}\right)$ samples, 4 leaf discs from 4 independent plants were harvested with a cork borer $\left(\varnothing 0.55 \mathrm{~cm}\right.$; total area of $1 \mathrm{~cm}^{2}$ ) and transferred to 2 microcentrifuge tubes. After adding $50 \mu \mathrm{L}$ of $10 \mathrm{mM} \mathrm{MgCl}_{2}$, the leaf material was macerated. For a 10:1 
dilution, $450 \mu \mathrm{L} 10 \mathrm{mM} \mathrm{MgCl}$ were added. $50 \mu \mathrm{L}$ of each sample were plated on selective NYG agar plates (50 $\mathrm{gg} / \mathrm{mL}$ rifampicin and kanamycin).

Infiltrated plants were transferred to a growth chamber (8h photoperiod at $22^{\circ} \mathrm{C}$, $65 \%$ rel. humidity) and kept well watered. Day three $\left(d_{3}\right)$ samples were taken similarly to $d_{0}$ samples. For $d_{3}$ samples, 4 leaf discs from 4 independent plants were harvested in nine repetitions and macerated in $10 \mathrm{mM} \mathrm{MgCl}_{2}$. A dilution series $\left(10^{-1}\right.$ to $\left.10^{-7}\right)$ was pipetted using a microtiter plate and $5 \mu \mathrm{L}$ from each dilution were pipetted on a NYG agar plate (50 $\mu \mathrm{g} / \mathrm{mL}$ rifampicin and kanamycin). After incubation at $28^{\circ} \mathrm{C}$ for $2 \mathrm{~d}$ the numbers of cfu were counted.

\subsubsection{Biochemical methods}

\subsubsection{Total protein extraction for immunoblot analysis}

For total protein extraction, at least 4 leaf discs from 3 to 5 week old Arabidopsis or $N$. benthamiana plants were harvested with a cork borer $(\varnothing 0.55 \mathrm{~cm})$. The leaf discs were put into a $2 \mathrm{~mL}$ centrifuge tube together with two $1.2 \mathrm{~mm}$ stainless steel beads and frozen in $\mathrm{N}_{2}{ }^{(I)}$ immediately. The samples were homogenized by use of a bead mill (Tissuelyser LT, Quiagen). Homogenates of 4 leaf discs were combined with $80 \mu \mathrm{L}$ of $2 x$ SDS-PAGE sample buffer and subsequently boiled for $8 \mathrm{~min}$. The samples were cooled on ice before being centrifuged at $21.000 \mathrm{~g}$ and $4{ }^{\circ} \mathrm{C}$ for at least $15 \mathrm{~min}$. Supernatants were transferred to new centrifuge tubes and loaded directly on SDS-PAGE gels or stored at $-20^{\circ} \mathrm{C}$.

\subsubsection{Strepll affinity purification}

In order to identify cargo proteins and interaction partners of the Strepll-tagged MOS6 protein the Strepll affinity purification was carried out based on the method reported previously (Witte et al., 2004). For each purification, $0.75 \mathrm{~g}$ fresh leaf material of 3 to 4 week old transgenic Arabidopsis plants was ground in $1.5 \mathrm{~mL}$ extraction buffer $(0.1 \mathrm{M}$ HEPES, $0.02 \mathrm{M} \mathrm{NaCl}, 5$ mM EDTA, 15 mM DTT, 0.025 \% Triton X-100, 1 x protease inhibitor mix $(5 \mathrm{mg} / \mathrm{mL}$ 4-2-Aminoethyl-Benzene-Sulfonyl-Fluoride, $0.0025 \mathrm{mg} / \mathrm{mL}$ BestatinHydochloride, $0.005 \mathrm{mg} / \mathrm{mL}$ Pepstatin A, $0.5 \mathrm{mg} / \mathrm{mL}$ Leupeptin-hemisulfate, 0.005 
mg/mLE-64, Trans-Epoxysuccinyl-L-Leucylamido-(4-Guanidino)-Butane, 50 mg/mL 1-10Phenanthroline-Monohydrate in DMSO) using mortar and pestle. The resulting slurry were transferred into $2 \mathrm{~mL}$ centrifuge tubes and centrifuged at $21.000 \mathrm{~g}, 4^{\circ} \mathrm{C}$ for $20 \mathrm{~min}$. The supernatants were transferred to fresh $2 \mathrm{~mL}$ centrifuge tubes and $100 \mu \mathrm{L}$ were used as input samples. $25 \mu \mathrm{L}$ Strep-Tactin ${ }^{\circledR}$ MacroPrep (50 \% suspension, IBA, Göttingen, Germany) were added to each extract. The samples were incubated for 30 min at $4{ }^{\circ} \mathrm{C}$ on a rotation wheel $(4 \mathrm{rpm})$. Subsequently, the affinity matrix was pelleted by centrifugation for $30 \mathrm{~s}$ at $700 \mathrm{~g}$ and the supernatant was removed carefully. At this point $100 \mu \mathrm{L}$ of the supernatant were used as unbound samples. The affinity matrix was washed five times with $500 \mu \mathrm{L}$ wash buffer (0.1 M HEPES, $0.02 \mathrm{M} \mathrm{NaCl}, 5 \mathrm{mM}$ EDTA, $2 \mathrm{mM} \mathrm{DTT}$, $0.025 \%$ Triton $X-100$ ) by gently inverting the tubes followed by centrifugation for $30 \mathrm{~s}$ at $700 \mathrm{~g}$. Finally, the affinity matrix was incubated twice with $75 \mu \mathrm{L}$ elution buffer $(7,5 \mu \mathrm{L}$ biotin $(500 \mathrm{mg} / \mathrm{mL}$ ) added to $67,5 \mu \mathrm{L}$ washing buffer) for $5 \mathrm{~min}$ in a thermomixer (1.000 rpm, room temperature). The supernatants resulting from the two elution steps were pooled to yield a total of circa $150 \mu \mathrm{L}$ elution sample per extraction. $60 \mu \mathrm{L}$ of the elution samples each were combined with $15 \mu \mathrm{L} 4 \mathrm{x}$ SDS-PAGE sample buffer. The remaining affinity matrix was incubated with $60 \mu \mathrm{L} 4 \mathrm{x}$ SDS-PAGE sample buffer to yield the boil-off sample. $25 \mu \mathrm{L}$ 4x SDS-PAGE sample buffer were added to the input and unbound samples. The different extracts were all boiled for $8 \mathrm{~min}$ and loaded directly on SDS-PAGE gels or stored at $-20^{\circ} \mathrm{C}$.

\subsubsection{Co-immunoprecipitation}

Co-immunoprecipitation (ColP) was carried out with transiently transformed $N$. benthamiana (2.2.6) leaf material that was harvested 2 to $3 \mathrm{dpi}$, frozen in $\mathrm{N}_{2}{ }^{(1)}$ and stored at $-80^{\circ} \mathrm{C}$. For each ColP $5 \mu \mathrm{L}$ GFP-Trap ${ }^{\circledR} \_$M beads (GFP-Trap ${ }^{\circledR}$ coupled to magnetic particles (Chromotec) were washed with $500 \mu \mathrm{L}$ extraction buffer $(50 \mathrm{mM}$ Tris- $\mathrm{HCl}$, pH 8.0, $150 \mathrm{mM} \mathrm{NaCl} 1 \mathrm{mM}$ EDTA, $5 \mathrm{mM}$ DTT, 0.2 \% NP40, 1 x protease inhibitor mix) by use of a magnetic rack and stored on ice. For each ColP $1 \mathrm{~g}$ leaf material was ground to fine powder in $\mathrm{N}_{2}{ }^{(I)}$ using a mortar and pestle. Two $\mathrm{mL}$ extraction buffer were added to each of the frozen samples. The mixtures were further homogenized on ice and subsequently allowed to thaw. $2 \mathrm{~mL}$ of the resulting extracts were transferred to $2 \mathrm{~mL}$ 
centrifuge tubes and centrifuged at $21.000 \mathrm{~g}, 4^{\circ} \mathrm{C}$ for $30 \mathrm{~min}$. The supernatants were transferred to new tubes and the centrifugation was repeated for an additional $15 \mathrm{~min}$. After this step, $60 \mu \mathrm{L}$ were taken from the supernatants as input samples and the rest of the extracts were combined with the washed GFP-Trap ${ }^{\circledR} \_\mathrm{M}$ beads. After an incubation step of 1 to 2 hours at $4{ }^{\circ} \mathrm{C}$ on a rotation wheel $(4 \mathrm{rpm})$, the samples were placed in a magnetic rack. The supernatants were removed by use of a vacuum pump after the magnetic beads were clearly visible at the back of the tubes where the magnet was located. Samples were washed with $1 \mathrm{~mL}$ wash buffer $(50 \mathrm{mM}$ Tris- $\mathrm{HCl}, \mathrm{pH}$ 8.0, $150 \mathrm{mM}$ $\mathrm{NaCl}, 1 \mathrm{mM}$ EDTA, $5 \mathrm{mM}$ DTT, $0.2 \% \mathrm{NP} 40$ ). The washing step was repeated 3 to 4 times. The purified GFP-Trap ${ }^{\circledR} \_M$ beads were combined with $45 \mu \mathrm{L}$ 4x SDS-PAGE sample buffer. The input samples were combined with $40 \mu \mathrm{L} 4 \mathrm{x}$ SDS-PAGE sample buffer. All samples were boiled for $8 \mathrm{~min}$ and loaded directly on SDS-PAGE gels or stored at $-20^{\circ} \mathrm{C}$.

\subsubsection{Denaturing SDS-polyacrylamide gel electrophoresis (SDS-PAGE)}

The Mini-PROTEAN ${ }^{\circledR}$ system (BioRad) was used to cast discontinuous polyacrylamide gels according to the manufacturer's instructions. In this study, $7.5 \%$ and $10 \%$ resolving gels were used that were overlaid with $4 \%$ stacking gels. After pouring the resolving gel between two glass plates spaced $1.5 \mathrm{~mm}$ it was overlaid with isopropanol and left at room temperature for polymerization. The isopropanol was removed when the gel was completely polymerized and the stacking gel was poured on top of the resolving gel. A comb suitable for $1.5 \mathrm{~mm}$ spaced glass plates was inserted and the gel was left at room temperature for polymerization. After polymerization, gels were used directly for SDSPAGE or stored at $4{ }^{\circ} \mathrm{C}$. For storage, the gels were wrapped in wet paper towels to prevent drying out.

Polyacrylamide gels were placed in the Mini-PROTEAN ${ }^{\circledR}$ Tetra Cell electrophoresis tank (BioRad) and after submerging in 1x SDS-running buffer the combs were removed. Denatured protein samples (10 to $60 \mu \mathrm{L}$ of total extracts or 5 to $10 \mu \mathrm{L}$ of affinity purified or immuno precipitated extracts) were loaded on the gel together with a pre-stained molecular weight marker (PageRuler Plus Prestained Protein Ladder, Thermo Scientific). Gels were run at 100 to $150 \mathrm{~V}$. Resolving of the marker bands was used as indicator for sufficient resolution. 


\subsubsection{Immunoblot analysis}

Proteins from sufficiently resolved SDS-PAGE gels were blotted onto Hybond ${ }^{\mathrm{TM}}-\mathrm{ECL}^{\mathrm{TM}}$ nitrocellulose membrane (Amersham Biosciences) using the Mini Trans-Blot ${ }^{\circledR}$ system (BioRad) assembled according to the manufacturer's instruction. After SDS-PAGE, the glass plates holding the gels were disassembled and the stacking gels were removed. After equilibrating the gels as well as the nitrocellulose membrane in $1 \times$ transfer buffer, the gels and membranes were assembled in the transfer cassettes. The transfer was carried out for $80 \mathrm{~min}$ at $100 \mathrm{~V}$. The transfer cassettes were disassembled, the gels discarded and the membranes incubated with Ponceau S (PonS) solution for $5 \mathrm{~min}$. The Pons was used to monitor equal loading. The membranes were scanned and subsequently washed in TBS-T before being blocked for circa $1 \mathrm{~h}$ at room temperature. Blocking was carried out with TBS-T containing $3 \%$ milk powder (Roth, Karlsruhe). After blocking, the membranes were incubated with the primary antibody solution by slowly shaking overnight at $4{ }^{\circ} \mathrm{C}$ or for at least $90 \mathrm{~min}$ at room temperature. The antibodies used in this study were either $\alpha \mathrm{HA}$ or $\alpha$ GFP (see 2.1.10 for details). The primary antibody solution was removed and the membranes were washed at least 4 times for $10 \mathrm{~min}$ at room temperature by shaking in TBS-T. Afterwards, the membranes were incubated with the secondary antibody solution by slowly shaking for at least $90 \mathrm{~min}$ at room temperature. The secondary antibody used to detect primary antibody-antigen conjugates was horseradish peroxidase (HRP)-conjugated goat anti-mouse (see 2.1.10 for details). After incubation with the secondary antibody solution the membranes were washed as described above. Chemiluminescence detection was carried out using a 5:1 to 1:1 mixture of the SuperSignal ${ }^{\circledR}$ West Pico Chemiluminescence- and SuperSignal ${ }^{\circledR}$ West Femto Maximum Sensitivity-kits (Pierce) according to the manufacturer instructions. Chemiluminescence resulting from incubating the membranes with substrate solutions was detected by exposing the membrane to X-Ray Screen Film Blue Sensitive (CEA).

\subsubsection{Silver staining of SDS-PAGE gels}

The silver staining protocol used in this study was carried out based on the method reported previously (Shevchenko et al., 1996) and is compatible with mass spectrometry 
analysis. The solutions were always prepared freshly. $50 \mathrm{~mL}$ solution per SDS-PAGE gel was used. First, the proteins in the SDS-PAGE gel were fixed by incubating the gel for $\geq 15 \mathrm{~min}$ in solution 1 ( $15 \mathrm{~mL}$ ethanol, $5 \mathrm{~mL}$ acetic acid, $30 \mathrm{~mL} \mathrm{ddH20).} \mathrm{This} \mathrm{step} \mathrm{can} \mathrm{be}$ prolonged overnight. Next, the gel was impregnated by incubation in solution 2 (15 mL ethanol, $1.25 \mathrm{~mL} 4 \mathrm{M}$ sodium acetate $(\mathrm{pH} 6), 0.05 \mathrm{~g}$ sodium thiosulfate $\left(\mathrm{Na}_{2} \mathrm{~S}_{2} \mathrm{O}_{3}\right)$, $33.75 \mathrm{~mL} \mathrm{ddH} \mathrm{H}_{2} \mathrm{O}$ ) for $30 \mathrm{~min}$. After washing three times for $10 \mathrm{~min}$ in $\mathrm{dH}_{2} \mathrm{O}$ the gel was

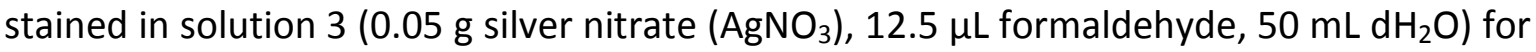
30 min. Brief washing in $\mathrm{dH}_{2} \mathrm{O}$ for maximum 1 min was followed by developing the gel in

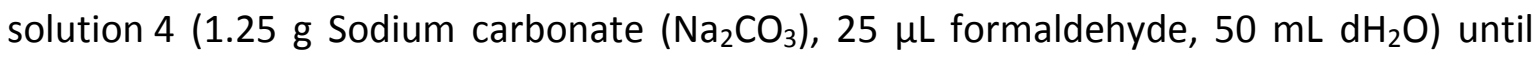
protein bands were visible. After 5 to $10 \mathrm{~min}$ the reaction was stopped by replacing solution 4 with the stop-Solution ( $1 \%$ acetic acid). The gel was then scanned and stored in $\mathrm{dH}_{2} \mathrm{O}$ at $4{ }^{\circ} \mathrm{C}$.

\subsubsection{Tryptic in-gel-digestion}

After Strepll affinity purification, extracts were loaded on SDS-PAGE gels that were then subjected to silver staining (2.2.4.6). Lanes on these gels were cut into 3 to 5 pieces with a clean scalpel. These gel-pieces were covered individually with water (Lichrosolv, Merck) in centrifuge tubes and stored at $4{ }^{\circ} \mathrm{C}$ until used for tryptic digestion. The tryptic in-geldigest protocol used in this study was carried out based on the method reported previously (Shevchenko et al., 1996).

The water in which the gel-pieces were stored was exchanged with $30 \mu \mathrm{L}$ acetonitrile or more (Rotisolv HPL, Carl Roth $\mathrm{GmbH}$ ), until the gel pieces were covered and then incubated at room temperature for $10 \mathrm{~min}$. Excess acetonitrile was removed and the gel-pieces were dried in a speedvac at medium temperature level $\left(45^{\circ} \mathrm{C}\right.$, circa $10 \mathrm{~min}$ ). The samples were reduced by adding $150 \mu \mathrm{L} 10 \mathrm{mM}$ DTT (BioChemica, Applichem) in $100 \mathrm{mM}$ ammonium hydrogencarbonate (99\% p.a. (Carl Roth $\mathrm{GmbH}$ ) and incubation for $1 \mathrm{~h}$ at $56{ }^{\circ} \mathrm{C}$. The DTT solution was removed and the samples were alkylated by adding $150 \mu \mathrm{L} 55 \mathrm{mM}$ iodoacetamide (Sigma Ultra, Sigma) in $100 \mathrm{mM}$ ammonium hydrogencarbonate and incubation at room temperature for $45 \mathrm{~min}$ in the dark. The iodoacetamide solution was removed. The gel-pieces were washed with $150 \mu \mathrm{L}$ $100 \mathrm{mM}$ ammonium hydrogencarbonate for $10 \mathrm{~min}$ at room temperature. After removal 
of the ammonium hydrogencarbonate, $150 \mu \mathrm{L}$ acetonitrile were added to the gel-pieces and incubated at room temperature for $10 \mathrm{~min}$. This washing step was repeated with 150 $\mu \mathrm{L} 100 \mathrm{mM}$ ammonium hydrogencarbonate and $150 \mu \mathrm{L}$ acetonitrile. The gel-pieces were dried again in a speedvac centrifuge ( $45^{\circ} \mathrm{C}$, circa $10 \mathrm{~min}$ ). $30 \mu \mathrm{L}$ trypsin digestion buffer (25 $\mathrm{mg}$ Trypsin (sequencing grade modified, Promega), resolved in $80 \mu \mathrm{L}$ Promega Resuspension Buffer, diluted 1:20 with $50 \mathrm{mM}$ ammoniumhydrogencarbonate) was added to the dry gel pieces and left to soak on ice for $45 \mathrm{~min}$. Remainders of unsoaked trypsin digestion buffer were removed and $30 \mu \mathrm{L} 50 \mathrm{mM}$ ammonium hydrogencarbonate were added for overnight incubation at $37^{\circ} \mathrm{C}$. The samples were centrifuged $(21000 \mathrm{~g}$, room temperature) and the supernatants were collected in fresh centrifuge tubes. $30 \mu \mathrm{L}$ $20 \mathrm{mM}$ ammonium hydrogencarbonate were added to the gel pieces and the samples were incubated for $10 \mathrm{~min}$ at room temperature. The supernatants were combined with the previous eluate. $30 \mu \mathrm{L} 50 \%$ acetonitrile / 5\% formic acid (98-100\%, Merck) were added to the gel pieces and the samples were incubated for $20 \mathrm{~min}$ at room temperature. After that, the samples were centrifuged at $21000 \mathrm{~g}$, room temperature and the supernatants were combined with the previous eluates. This step was repeated once. The combined supernatants were dried in the speedvac. The dried peptide pellets were resuspended in $10 \mu \mathrm{L}$ sample buffer (95\% LC-water / 5 \% LC-acetonitrile / $0.1 \%$ formic acid) or stored at $4^{\circ} \mathrm{C}$ until high performance liquid chromatography-mass spectrometry (HPLC-MS) analysis.

\subsubsection{HPLC-MS and database search}

HPLC-MS analyses and database search was carried out by Dr. Oliver Valerius, (Department of Molecular Microbiology and Genetics, University Göttingen) according to the protocol described by Hillebrand et al., (2012). Therefore, the ultimate HPLC system (Dionex, Amsterdam, Netherlands) was used to separate tryptic peptides. The LCQ DecaXP machine (Thermo Electron Corp., San Jose, CA, USA) was used to subject tryptic peptides to electrospray ionization mass spectrometry. 


\subsubsection{Molecular biological methods}

\subsubsection{Preparation of genomic DNA from Arabidopsis with FTA paper}

This method can be used with plant material from very young as well as old plants and was adapted from Tsukaya et al., (2005) and Ndunguru et al., (2005). After labeling the plants, one small leaf was cut of each plant and put on the surface of a FTA ${ }^{\circledR}$ Classic Card (fast technology for analysis of nucleic acids, Whatman). The leaf samples were covered with a piece of parafilm (Bemis) and pressed with the round end of a test tube onto the $\mathrm{FTA}^{\circledR}$ card. These prints were labeled and allowed to dry for at least $60 \mathrm{~min}$. For use as template in a PCR, a small piece of the leaf-sample was punched out with a micro punch (1.2 mm, Harris) and put directly into a PCR-reaction tube. The leaf-punch was incubated in $50 \mu \mathrm{L}$ FTA buffer for 5 min. The FTA buffer was exchanged with $50 \mu \mathrm{L} \mathrm{TE}-1$ buffer and the sample was incubated again for $5 \mathrm{~min}$. After removal of the TE-1 buffer the PCR-mix was added to the leaf-punch. This mixture was subjected to PCR as described in 2.2.5.2.

\subsubsection{Polymerase chain reaction (PCR)}

For cloning, the proofreading iProof polymerase (BioRad) was used for PCR according to the manufacturer's instructions. Standard genotyping PCR reactions were carried out using the home made Taq polymerase (see 2.1.6.2 for details). The 96-well MyCycler thermal cycler (BioRad) was used to carry out all PCR reactions. Usually, the PCR mix consisted of 0.1 to $20 \mathrm{ng}$ template DNA or a leaf-punch (2.2.5.1), $2 \mu \mathrm{L} 10 \times \mathrm{PCR}$ reaction buffer, $0.5 \mu \mathrm{L}$ dNTP mix (10 mM), $1 \mu \mathrm{L}$ forward primer $(10 \mu \mathrm{M}), 1 \mu \mathrm{L}$ reverse primer $(10 \mu \mathrm{M})$ and $0.5 \mu \mathrm{L}$ Taq DNA polymerase ad $20 \mu \mathrm{L}$ with $\mathrm{dH}_{2} \mathrm{O}$. The usual thermal profile of the reaction included one step for initial denaturation $\left(94{ }^{\circ} \mathrm{C}\right.$ for $3 \mathrm{~min}$ ) followed by 25 to 50 cycles of denaturation $\left(94{ }^{\circ} \mathrm{C}\right.$ for $30 \mathrm{~s}$ ), annealing (50 to $60{ }^{\circ} \mathrm{C}$ for $30 \mathrm{sec}$ ), extension ( $72{ }^{\circ} \mathrm{C}$ for $1 \mathrm{~min}$ per $\mathrm{kbp}$ (homemade Taq polymerase) or $30 \mathrm{~s}$ per kbp (iProof polymerase) and a final extension $\left(72^{\circ} \mathrm{C}\right.$ for $\left.3 \mathrm{~min}\right)$. 


\subsubsection{Isolation of total RNA from Arabidopsis}

For total RNA extraction, 80 to 100 mg leaf material of 3 to 6 weeks old plants was harvested and put into a $2 \mathrm{~mL}$ centrifuge tube together with two $1.2 \mathrm{~mm}$ stainless steel beads (Roth). The sample was frozen in $\mathrm{N}_{2}{ }^{(I)}$ immediately and homogenized by use of a bead mill (TissueLyser LT, Quiagen). According to the manufacturer's instructions (Quiagen) the homogenate was combined with $1 \mathrm{~mL}$ Quiazol (Quiagen) and vortexed until dissolved before being shaken vigorously for $10 \mathrm{~min}$ at room temperature. The sample was centrifuged for $1 \mathrm{~h}$ at $21000 \mathrm{~g}$ and $4{ }^{\circ} \mathrm{C}$. About $600 \mu \mathrm{L}$ of the supernatant was transferred to new centrifuge tubes and combined with $440 \mu \mathrm{L}$ ice cold isopropanol. The tube was gently inverted and allowed to incubate for $10 \mathrm{~min}$ at room temperature. The sample was centrifuged for $15 \mathrm{~min}$ at $21000 \mathrm{~g}$ and $4{ }^{\circ} \mathrm{C}$. The supernatant was discarded and $500 \mu \mathrm{L} 70 \% \mathrm{EtOH}$ were used to wash the pellet by vortexing. The sample was centrifuged for $15 \mathrm{~min}$ at $21000 \mathrm{~g}$ and $4{ }^{\circ} \mathrm{C}$ before the EtOH was discarded completely. The pellet was allowed to dry for circa $10 \mathrm{~min}$ at room temperature before being dissolved in $50 \mu \mathrm{L} \mathrm{dH_{2 }} \mathrm{O}$. The samples were stored at $-80^{\circ} \mathrm{C}$.

\subsubsection{DNase-digestion of total RNA from Arabidopsis}

RNA samples were digested with DNase I (Fermentas) prior to reverse transcriptionpolymerase chain reaction (RT-PCR, 2.2.5.5) according to the manufacturer's instructions (Fermentas). After adjusting the RNA samples to $1 \mu \mathrm{g}$ RNA in a final volume of $8 \mu \mathrm{L}$ in $\mathrm{dH}_{2} \mathrm{O}, 1 \mu \mathrm{L} 10 \times$ DNase I buffer with $\mathrm{MgCl}_{2}$ (Fermentas) and $1 \mu \mathrm{L}$ DNase I $(1 \mathrm{u} / \mu \mathrm{L}$ ) were added. The mixture was incubated at $37{ }^{\circ} \mathrm{C}$ for $30 \mathrm{~min}$ and then $1 \mu \mathrm{L} 25 \mathrm{mM}$ EDTA was added. This was followed by a further incubation at $65^{\circ} \mathrm{C}$ for $10 \mathrm{~min}$ and finally at $4{ }^{\circ} \mathrm{C}$ for 2 min. The DNase I digested samples were either used directly for RT-PCR or stored at $-80^{\circ} \mathrm{C}$.

\subsubsection{Reverse transcription-polymerase chain reaction (RT-PCR)}

DNase I digested RNA samples (2.2.5.4) were directly used for cDNA synthesis according to the manufacturer's instructions (Fermentas). Total RNA samples $(1 \mu \mathrm{g})$ were combined 
with $2 \mu \mathrm{L}$ oligo $\mathrm{dT}_{18}$ primer $(100 \mu \mathrm{g} / \mu \mathrm{l})$ and incubated at $70{ }^{\circ} \mathrm{C}$ for $10 \mathrm{~min}$. After cooling down to $4{ }^{\circ} \mathrm{C}$, the samples were combined with $4 \mu \mathrm{L}$ M-MulVRT $5 \times$ buffer (Fermentas), $2 \mu \mathrm{L}$ dNTPs $(10 \mathrm{mM}), 0.3 \mu \mathrm{L}$ reverse transcriptase (RevertAid ${ }^{\mathrm{TM}} \mathrm{H}$ Minus M-MulVRT, $200 \mathrm{u} / \mu \mathrm{L}$, Fermentas) and $0.7 \mu \mathrm{L} \mathrm{dH}_{2} \mathrm{O}$. This was followed by incubation at $42{ }^{\circ} \mathrm{C}$ for $70 \mathrm{~min}$, incubation at $70{ }^{\circ} \mathrm{C}$ for $10 \mathrm{~min}$ and finally at $4{ }^{\circ} \mathrm{C}$ for $2 \mathrm{~min}$. For use in semi quantitative real time PCR (2.2.5.2), the samples were diluted 1:5. Diluted samples were stored at $-20^{\circ} \mathrm{C}$.

\subsubsection{Plasmid DNA isolation from Escherichia coli}

Escherichia coli TOP10 cells (2.1.3.1) were used to amplify plasmid DNA. E. coli cells were cultivated in selective LB medium at $37^{\circ} \mathrm{C}$ and $180 \mathrm{rpm}$ overnight. According to the manufacturer's instructions, $4 \mathrm{~mL}$ overnight culture was used to extract plasmids via standard alkaline lysis with the GeneJET ${ }^{\mathrm{TM}}$ Plasmid Miniprep kit (Fermentas).

\subsubsection{Restriction endonuclease digestion of DNA}

According to the manufacturer's instructions (Fermentas), restriction digests were carried out using $0.1 \mu \mathrm{L}$ of restriction enzyme per $19 \mu \mathrm{L}$ reaction. Digests were carried out with buffers appropriate for the respective enzymes and incubated at $37^{\circ} \mathrm{C}$ for circa $1 \mathrm{~h}$.

\subsubsection{Agarose gel electrophoresis of DNA}

DNA-fragments resulting from PCR or digestion of plasmids were separated by agarose gel electrophoresis. Agarose gels usually consisted of 0.8 to $2 \%(\mathrm{w} / \mathrm{v})$ UltraPure ${ }^{\mathrm{TM}}$ Agarose (Biozym) in 1x TAE buffer (Mülhardt, 2009). The agarose was dissolved completely by heating the mixture in a microwave. Prior to pouring the gel into a gel casting device the agarose solution was cooled down and one droplet (circa $40 \mu \mathrm{L}$ ) of ethidiumbromide solution (10 mg/mL Roth) per $50 \mathrm{~mL}$ gel was added. A comb was pushed into the gel and it was allowed to solidify at room temperature. The solid gel was placed in a gel electrophoresis tank filled with 1x TAE buffer. The comb was removed and DNA-samples mixed with 6 x loading dye were loaded. The GeneRuler ${ }^{\mathrm{TM}} 1 \mathrm{~kb}$ DNA ladder (Fermentas) 
was used as size standard. Electrophoretic separation was carried out for 10 to $120 \mathrm{~min}$ at 90 to $120 \mathrm{~V}$ depending on size and purpose of the DNA-fragments. A gel documentation system (G:Box, Genoplex Transilluminator, VWR) was used with the GeneSnap software (SynGene) to visualize and photograph separated DNA fragments with UV-light.

\subsubsection{Isolation of DNA fragments from agarose gel}

Specific DNA-fragments amplified for digestion or cloning were separated on agarose gels by electrophoresis (2.2.5.8), visualized under UV-light and excised from the gel with a clean scalpel. The NucleoSpin ${ }^{\circledR}$ Extract II kit (Macherey-Nagel) was used according to the manufacturer's instructions for extraction of DNA from these gel pieces.

\subsubsection{Site specific recombination of DNA in Gateway ${ }^{\circledR}$-compatible vectors}

Directional cloning of blunt end PCR products into the vector $\mathrm{PENTR}{ }^{\mathrm{TM}} / \mathrm{D}-\mathrm{TOPO}^{\circledR}$ (Invitrogen) was carried out with the $\mathrm{PENTR}^{\mathrm{TM}} / \mathrm{D}^{-\mathrm{TOPO}^{\circledR}}{ }^{\circledR}$ cloning kit according to the manufacturer's instructions. Thereby, entry clones suitable for further recombination into the Gateway ${ }^{\circledR}$ system (Invitrogen) were assembled. The Gateway ${ }^{\circledR}$ LR Clonase $^{\circledR}$ enzyme kit (Invitrogen) was used according to the manufacturer's instructions to transfer the fragments of interest from pENTR $^{\mathrm{TM}} / \mathrm{D}-\mathrm{TOPO}^{\circledR}$-constructs to gene expression vectors (destination vectors). The LR reaction was composed of $0.5 \mu \mathrm{L}$ LR-buffer, $0.4 \mu \mathrm{L}$ entry clone plasmid prep, $0.4 \mu \mathrm{L}$ destination vector plasmid prep, $0.7 \mu \mathrm{L}$ TE-buffer and $0.5 \mu \mathrm{L}$ LR- Clonase ${ }^{\circledR}$. After an incubation time of $1 \mathrm{~h}$ at room temperature, $0.5 \mu \mathrm{L}$ proteinase $\mathrm{K}$ solution $(2 \mu \mathrm{g} / \mu \mathrm{l})$ were added and the reaction was incubated at $37^{\circ} \mathrm{C}$ for $10 \mathrm{~min}$. The whole reaction was used to transform E. coli TOP10 cells (see 2.2.5.13).

\subsubsection{DNA sequencing and sequence analysis}

Single sequencing reactions on purified plasmids were performed by SeqLab (Göttingen) using the Barcode Economy Run Service. $2 \mu \mathrm{L}$ extracted plasmid DNA (2.2.5.6) were combined with $1 \mu \mathrm{L}$ primer $(10 \mu \mathrm{M})$ and $12 \mu \mathrm{L} \mathrm{dH}_{2} \mathrm{O}$ to yield a $15 \mu \mathrm{L}$ sequencing mix. 
Sequence data was analyzed with Geneious ${ }^{\mathrm{TM}}$ Pro software version 7.1.5 (Biomatters Ltd., Kearse et al., 2012).

\subsubsection{Preparation of chemically competent E.coli cells}

E. coli TOP10 cells (2.1.3.1) were grown as overnight culture in $5 \mathrm{~mL} \mathrm{LB}$ media $\left(37^{\circ} \mathrm{C}\right.$, $180 \mathrm{rpm})$. This culture was used to inoculate the main culture of $500 \mathrm{~mL}$ LB media. The main culture was incubated for circa $3 \mathrm{~h}\left(37^{\circ} \mathrm{C}, 180 \mathrm{rpm}\right)$ until bacterial growth reached $\mathrm{OD}_{600}=0.5$. The culture was transferred into a centrifuge beaker that had been cleaned previously by incubation in $0.25 \mathrm{M} \mathrm{HCl}$ for $3 \mathrm{~h}$. After cooling on ice for $15 \mathrm{~min}$, the cells were centrifuged for $10 \mathrm{~min}$ at $4{ }^{\circ} \mathrm{C}$ and $1200 \mathrm{~g}$. The supernatant was discarded and the cells were resuspended in $80 \mathrm{~mL}$ ice cold TFB1 buffer ( $30 \mathrm{mM} \mathrm{KAc}, 50 \mathrm{mM} \mathrm{MnCl}, 100 \mathrm{mM}$

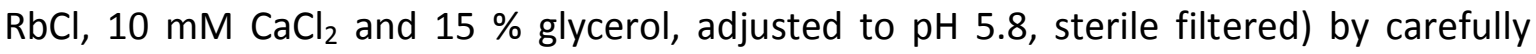
pipetting. The cells were cooled again on ice for $15 \mathrm{~min}$ prior to centrifugation for $5 \mathrm{~min}$ at $1200 \mathrm{~g}, 4^{\circ} \mathrm{C}$. After the supernatant was discarded, the cells were resuspended in $8 \mathrm{~mL}$ ice cold TFB2 buffer (10 mM MOPS, $75 \mathrm{mM} \mathrm{CaCl}, 10 \mathrm{mM} \mathrm{RbCl}$ and $15 \%$ glycerol, adjusted to $\mathrm{pH} 7.0$, sterile filtered). $50 \mu \mathrm{L}$ aliquots were frozen in $\mathrm{N}_{2}{ }^{(\text {l) }}$ and stored at $-80^{\circ} \mathrm{C}$.

\subsubsection{Transformation of chemically competent $E$. coli cells}

The heat shock method (Inoue et al., 1990) was used for transformation of chemically competent E. coli TOP10 (2.1.3.1) cells. A $50 \mu \mathrm{L}$ aliquot of chemically competent $E$. coli cells was thawed before plasmid DNA was added. In case of PENTR $^{\mathrm{TM}} / \mathrm{D}-\mathrm{TOPO}^{\circledR}$ cloning reactions and LR reactions, whole reactions were transformed. After incubation on ice for $10 \mathrm{~min}$, the cells were heat shocked at $42^{\circ} \mathrm{C}$ for $1 \mathrm{~min}$. This was followed by incubation on ice for $2 \mathrm{~min}$ and addition of $750 \mu \mathrm{LLB}$ media. The cells were incubated at $37^{\circ} \mathrm{C}$ for 30 to $60 \mathrm{~min}$. The cells were centrifuged at $600 \mathrm{~g}$ for $5 \mathrm{~min}$ at room temperature. Most of the supernatant was discarded and the cells were resuspended gently in circa $100 \mu \mathrm{L} L B$ media that were left in the tube. Thereby, the whole transformation could be plated onto selective media plates. 


\subsubsection{Preparation of electro-competent A. tumefaciens cells}

A.tumefaciens GV3101 pMP90RK cells (2.1.3.2) were grown as overnight culture in $5 \mathrm{~mL}$ DYT media containing $50 \mu \mathrm{g} / \mathrm{mL}$ rifampicin, $50 \mu \mathrm{g} / \mathrm{mL}$ kanamycin and $15 \mu \mathrm{g} / \mathrm{mL}$ gentamycin $\left(28^{\circ} \mathrm{C}, 180 \mathrm{rpm}\right)$. The whole overnight culture was used to inoculate the main culture of $200 \mathrm{~mL}$ DYT media without antibiotics. The main culture was incubated for circa $3 \mathrm{~h}\left(28{ }^{\circ} \mathrm{C}, 180 \mathrm{rpm}\right)$ until bacterial growth reached $\mathrm{OD}_{600}=0.6$. The culture was split and transferred to four sterile $50 \mathrm{~mL}$ falcon tubes. After cooling on ice for 15 to $30 \mathrm{~min}$, the cells were centrifuged for $15 \mathrm{~min}$ at $4{ }^{\circ} \mathrm{C}$ and $6000 \mathrm{~g}$. The supernatant was discarded and the cells were resuspended in $200 \mathrm{~mL}$ ice cold $\mathrm{dH}_{2} \mathrm{O}$. The centrifugation was repeated and the cells were resuspended in $100 \mathrm{~mL}$ ice cold $\mathrm{dH}_{2} \mathrm{O}$ before being centrifuged again. After the supernatant was discarded, the cells were resuspended in $5 \mathrm{~mL}$ ice cold $10 \%$ glycerol. The previously split cell suspension was now recombined before being centrifuged as described above. The pellet was resuspended in $1 \mathrm{~mL}$ of ice cold $10 \%$ glycerol. $50 \mu \mathrm{L}$ aliquots were frozen in $\mathrm{N}_{2}{ }^{(1)}$ and stored at $-80^{\circ} \mathrm{C}$. Prior to transformation, the cells were diluted $1: 3$ with $\mathrm{dH}_{2} \mathrm{O}(2.2 .5 .15)$.

\subsubsection{Transformation of electro-competent $A$. tumefaciens cells}

Electro-competent A.tumefaciens GV3101 pMP90RK cells $(2.1 .3 .2,2.2 .5 .14)$ were transformed by electroporation (Koncz and Schell, 1986). A $50 \mu \mathrm{L}$ aliquot of competent cells was thawed and diluted 1:3 with $\mathrm{dH}_{2} \mathrm{O}$ before $50 \mathrm{ng}$ of plasmid DNA were added. After incubation on ice for $10 \mathrm{~min}$, the cells were transferred to a pre-cooled electroporation cuvette $(0.1 \mathrm{~cm}$ electrode distance). The electroporation apparatus MicroPulser ${ }^{\mathrm{TM}}$ (Bio-Rad) was used with the Agr program (25 $\mu \mathrm{F}, 2.5 \mathrm{kV}$ and $400 \Omega$ ). Each transformation was pulsed once and placed back on ice immediately. This was followed by addition of $750 \mu \mathrm{LLB}$ media. The cells were incubated at $28^{\circ} \mathrm{C}$ for 60 to $120 \mathrm{~min} .50 \mu \mathrm{L}$ of the transformation were plated onto a selective DYT media plate.

\subsubsection{Agrobacterium-mediated transient transformation of $\boldsymbol{N}$. benthamiana leaves}

For transient transformation of N. benthamiana, A.tumefaciens GV3101 pMP90RK strains carrying the desired expression constructs (2.1.4) were grown as overnight culture in $5 \mathrm{~mL}$ 
DYT media containing the appropriate antibodies $\left(28{ }^{\circ} \mathrm{C}, 180 \mathrm{rpm}\right)$. The cells were centrifuged for $10 \mathrm{~min}$ and $1200 \mathrm{~g}$ at room temperature and the pellet was resuspended in $5 \mathrm{ml}$ infiltration medium (10 mM MgCl, $150 \mu \mathrm{g} / \mathrm{ml}$ acetosyringone). The concentration of the bacterial solution was measured from a 1:10 dilution and adjusted to $O D_{600}=0.3$. The bacterial solution was then left at room temperature without agitation for 1 to $3 \mathrm{~h}$. Two hours before infiltration, 4 weeks old $N$. benthamiana plants were placed on the bench and watered. Young leaves were infiltrated with a $1 \mathrm{ml}$ syringe without needle. Whole leaves were infiltrated and then marked with a colored tape at the petioles. After 2 days samples for protein extracts were taken (2.2.4.1) and the leaves were analyzed by confocal laser scanning microscopy (2.2.7).

\subsubsection{Localization studies using confocal laser scanning microscopy (CLSM)}

Confocal laser-scanning microscopy after transient expression of fluorescence-tagged proteins in $N$. benthamiana ( 2 to $3 \mathrm{dpi}, 2.2 .6$ ) was performed on a Leica SP5-DM6000 (Leica $\mathrm{GmbH}$ ) equipped with an argon ion laser as excitation source and Leica LAS AF software (v.2.6.7266.0). Excitation wavelengths of $514 \mathrm{~nm}$ for YFP (detection at 525 to $600 \mathrm{~nm}$ ), $485 \mathrm{~nm}$ for ECFP (detection at 465 to $485 \mathrm{~nm}$ ) and $561 \mathrm{~nm}$ for chlorophyll autofluorescence (detection at 680 to $700 \mathrm{~nm}$ ) were used. 


\section{Results}

The result section of this work is subdivided into two parts. The first part focuses on the analysis of imp- $\alpha$ mutants. After corroborating the previously described phenotypes of imp- $\alpha 3 / \operatorname{mos} 6$ mutants in plant immunity (Palma et al., 2005) and discovery of a novel disease susceptibility phenotype against weakly virulent Pseudomonas syringae pv. tomato (Pst) bacteria (Pst DC3000 ( $\triangle$ AvrPto/AvrPtoB)), a collection of imp- $\alpha$ T-DNA insertion mutants was established and used for functional analyses. By use of these and higher order imp- $\alpha$ mutant combinations the genetic requirement of the nine Arabidopsis IMP-as in plant growth, snc1-mediated auto-immunity and defense against virulent and avirulent isolates of Hyaloperonospora arabidopsidis (H.a.) and Pst DC3000 ( $\triangle$ AvrPto/AvrPtoB) was analyzed.

The identification and characterization of defense-related cargo proteins and interaction partners of the IMP- $\alpha$ MOS6 was the second objective of this work. For this purpose, an in planta affinity purification approach of functional epitope-tagged MOS6 coupled with mass spectrometry was conducted. This approach was combined with in silico analyses of the immune related Arabidopsis interactome database PPIN-1 (Mukhtar et al., 2011). Identified interactions were validated by use of the wellestablished Nicotiana benthamiana transient expression system and subsequent co-immunoprecipitation analysis. T-DNA insertion mutants of MOS6-interactors were subsequently isolated and functionally analyzed in pathogen interaction assays.

\subsection{Analysis of importin- $\alpha$ mutants}

The Arabidopsis genome contains nine IMP- $\alpha$ paralogs. This comparably high number suggests either specialization or redundant functions of members of the IMP- $\alpha$ family. The following section describes the reverse-genetic dissection of the role of different IMP-as for plant growth and immunity. For this purpose single as well as double and triple mutants of closely related IMP-as were functionally characterized. 


\subsubsection{Mutants lacking functional MOS6 are more susceptible against Pseudomonas bacteria with incomplete effector repertoire}

Plants carrying the auto-immune snc1 mutation show constitutive resistance to virulent pathogens and severely stunted growth under most growth conditions (Alcázar and Parker, 2011). The partial suppression of the snc1 auto-immune phenotype by mutations in MOS6 as well as the enhanced susceptibility of mos 6 single mutants to virulent $H$. $a$. NOCO2 demonstrates the important role of MOS6 in plant immunity (Palma et al., 2005).

In this study, it was initially analyzed whether the published snc1 growth and pathogen phenotypes are reproducible under the available growth conditions (2.2.1) and whether mos6-1 partially suppresses the stunted growth of snc1. Figure 3.1 shows the size and morphological differences between Col-0, snc1, mos6-1 and snc1 mos6-1 plants grown under short day growth conditions (2.2.1). The snc1 mutant plants have the typical morphology characterized by stunted growth and dark, curly leaves (Zhang et al., 2003). Size and morphology of mos6-1 single mutants do not differ from the wild-type Col-0 plants. The snc1 mos6-1 double mutant plants, however, grow to an intermediate size compared to Col-0 and snc1 but develop curly leaves more similar to snc1 mutants than to Col-0. These results show that the mutant plants presented above could be cultivated in a way that allowed them to exhibit their previously published specific phenotypes (Palma et al., 2005).
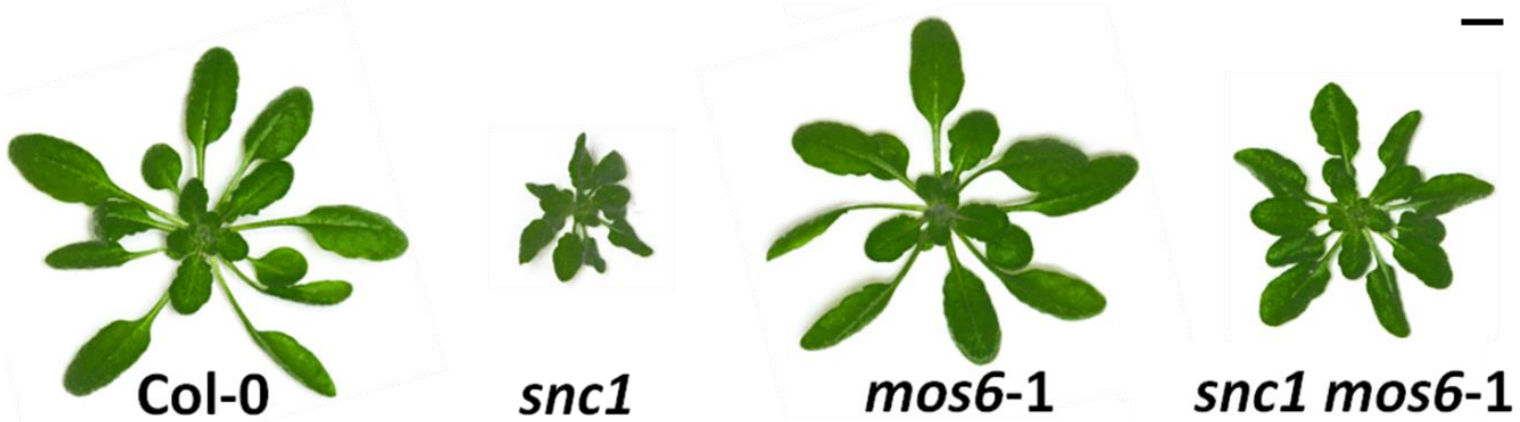

Figure 3.1 Suppression of the snc1-associated stunted growth morphology by mos6-1. Morphology of Col-0, snc1, mos6-1 and snc1 mos6-1. Plants are four-week-old and were grown in parallel on soil under short day growth conditions. Scale bar: $1 \mathrm{~cm}$.

In addition to suppression of the snc1 growth phenotype, loss of mos6-1 results in enhanced susceptibility to the virulent oomycete pathogen $H$. a. NOCO2 whereas snc1 mutants show enhanced resistance due to constitutive defense activation (Palma et al., 
2005). These phenotypes were reproducible for snc1 and mos6-1 as well as for two additional mos6 mutant alleles, mos6-2 (Palma et al., 2005) and mos6-4 (SALK_025919; Figure 3.2 A, Wirthmueller et al., 2015). Although mos6 mutants are impaired in basal resistance to $H$. a. NOCO2, it was reported previously that mos6 plants display no significant increase in susceptibility against the virulent bacterial pathogen Pseudomonas syringae pv. maculicola ES4326 (Palma et al., 2005). To test if mos6 mutants are impaired in basal resistance against less aggressive Pst bacteria, susceptibility of the three mos 6 mutant alleles towards the weakly virulent Pst DC3000 ( $\triangle$ AvrPto/AvrPtoB) strain was analyzed (Figure 3.2 B). This Pst strain lacks the secreted effectors AvrPto and AvrPtoB that have been shown to interfere with signaling from MAMP-activated receptor kinases (Torres et al., 2006; He et al., 2006).

mos6 mutants are more susceptible to infection by Pst DC3000 ( $\triangle$ AvrPto/AvrPtoB,

Figure 3.2 B). Together, these analyses show that the published suppression of

A

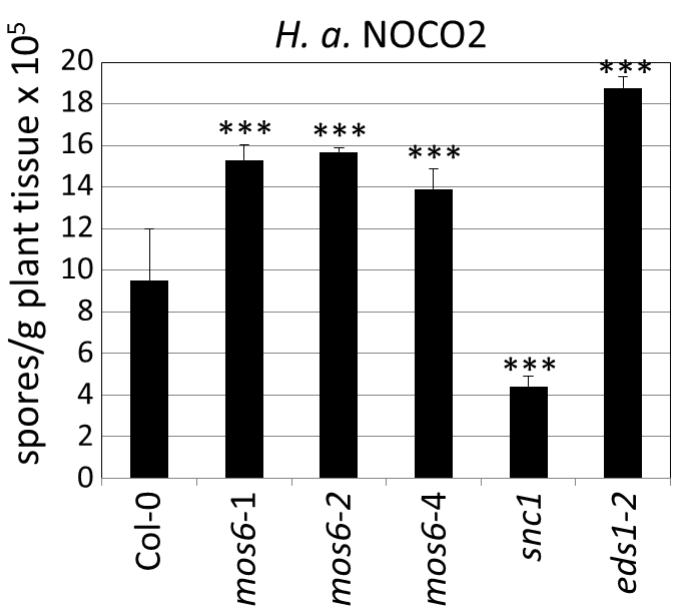

B

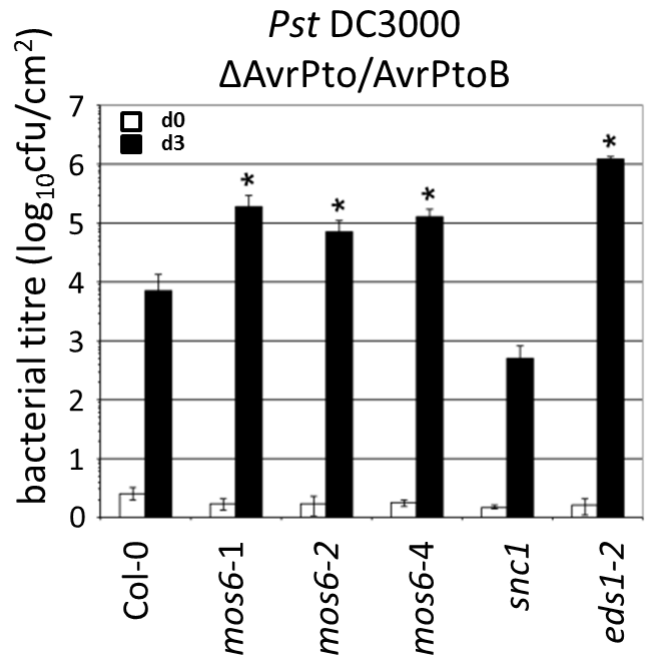

Figure 3.2 mos6 mutants show enhanced susceptibility to virulent $H$. a. NOCO2 and Pst DC3000 ( $\triangle$ AvrPto/AvrPtoB). A) Sporulation levels of $H$. a. NOCO2. Two-week-old seedlings of the indicated genotypes were spray-inoculated with a conidiospore suspension of $4 \times 10^{4}$ spores per $\mathrm{mL} \mathrm{H}_{2} \mathrm{O}$. Conidiophores were counted $6 \mathrm{dpi}$. Bars represent means. Error bars show standard deviation and asterisks indicate statistical significance ( $t$-test for pairwise comparison between Col-0 and mutant, $p<0.0001$ ). B) Growth of Pst DC3000 ( $\triangle$ AvrPto/AvrPtoB). Leaves of four-week-old plants were vacuum-infiltrated with a bacteria suspension of $1 \times 10^{5} \mathrm{cfu} / \mathrm{mL}$. To quantify bacterial growth, leaf discs within the inoculated areas were taken immediately (d0) and three days after inoculation (d3). Bars represent means from two replicate samplings for $\mathrm{d} 0$ (white bars) and three replicate samplings for $d_{3}$ (black bars). Error bars show standard deviation and asterisks indicate statistical significance ( $t$-test, $\mathrm{p}<0.05)$. snc1 and eds1-2 (Col eds1-2) are resistant and susceptible controls, respectively. This Figure was recently published in Wirthmueller et al. (2015). Cfu=colony-forming units. All experiments were repeated at least three times with similar results. 
snc1-associated stunted growth morphology by mos6 and the impaired resistance of mos6 mutants to virulent $H$. a. NOCO2 (Palma et al., 2005) can be reproduced under the plant growth and pathogen infection conditions available for this work. Importantly, the infection assays presented here also revealed increased susceptibility of mos 6 mutants to the weakly virulent Pst DC3000 ( $\triangle$ AvrPto/AvrPtoB). This robust pathogen interaction assay can now be used to analyze the genetic requirement of additional IMP- $\alpha$ s for basal resistance against this hemi-biotroph bacterial pathogen.

\subsubsection{The Arabidopsis IMPORTIN- $\alpha$ family}

The size of the IMP- $\alpha$ gene family has undergone considerable expansion during eukaryotic evolution. Several paralogs have been identified in higher eukaryotes whereas the genome of the single cellular eukaryote Saccharomyces cerevisiae only encodes one single IMP- $\alpha$. The genomes of humans, mice, rice or Drosophila melanogaster contain seven, six, five or three IMP- $\alpha$ s, respectively, and nine IMP- $\alpha$ paralogs have been reported for Arabidopsis (Merkle, 2001; Ouyang et al., 2007; Ratan et al., 2008; Hu et al., 2010;

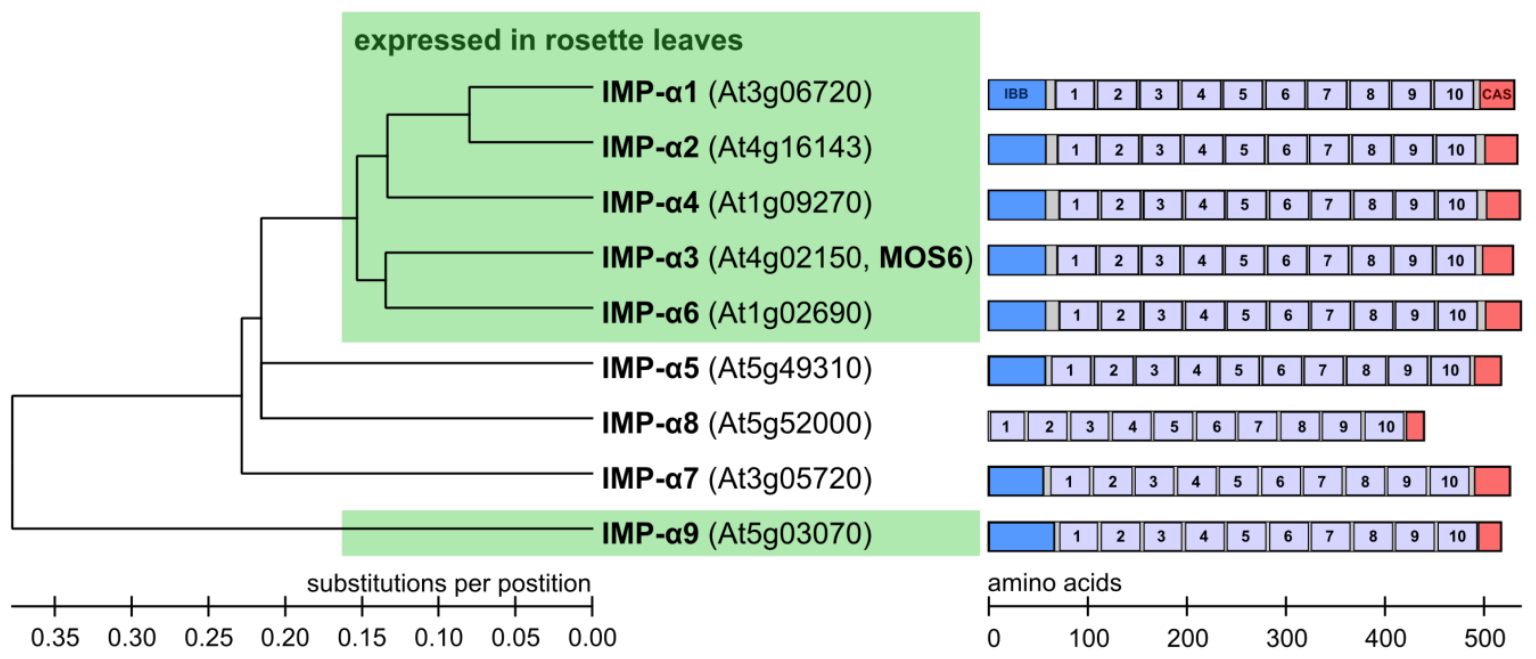

Figure 3.3 Phylogenetic tree and protein domain structure of IMP- $\alpha$ proteins in Arabidopsis. The phylogenetic tree was constructed using neighbor joining in Molecular Evolutionary Genetics Analysis (MEGA) v4.0 (Tamura et al., 2007). IMP- $\alpha 9$ was used to root the tree. Scale bar represents amino acid substitutions per position. IMP- $\alpha$ s that are expressed in rosette leaves are highlighted in green. Schematic representation: The different protein domains are depicted as boxes within the full length protein sequence. IMP- $\beta$-binding domains (IBB) are shown in dark blue, the ten Armadillo repeat domains are shown in light blue and the domains responsible for binding the export receptor CAS are shown in red. Scale bar shows number of amino acids. A modified version of this Figure has been published in Wirthmueller et al. (2013). 
Kelley et al., 2010; Wirthmueller et al., 2013). Figure 3.3 shows the phylogeny of the nine Arabidopsis IMP-as. The phylogenetic tree was constructed with full length amino acid sequences using neighbor joining in Molecular Evolutionary Genetics Analysis (MEGA) v4.0 (Tamura et al., 2007) and has recently been published in Wirthmueller et al. (2013). Most IMP- $\alpha$ s showing the highest gene expression levels in rosette leaves are closely related (highlighted in green in Figure 3.3). MOS6/IMP- $\alpha 3$ is most closely related to IMP- $\alpha 6$ and both are expressed in leaf tissue as can also be seen in Figure 3.4. All Arabidopsis IMP-as contain ten armadillo repeat domains (ARM) that form the NLS binding sites and one domain responsible for binding to the export receptor protein CAS for cycling back to the cytoplasm (Figure 3.3, Goldfarb et al., 2004; Matsuura and Stewart, 2004). In contrast to all other IMP- $\alpha$ s, IMP- $\alpha 8$ lacks the IMP- $\beta$-binding domain (IBB, Figure 3.3). The IBB has been described as an internal nuclear localization signal that acts as an

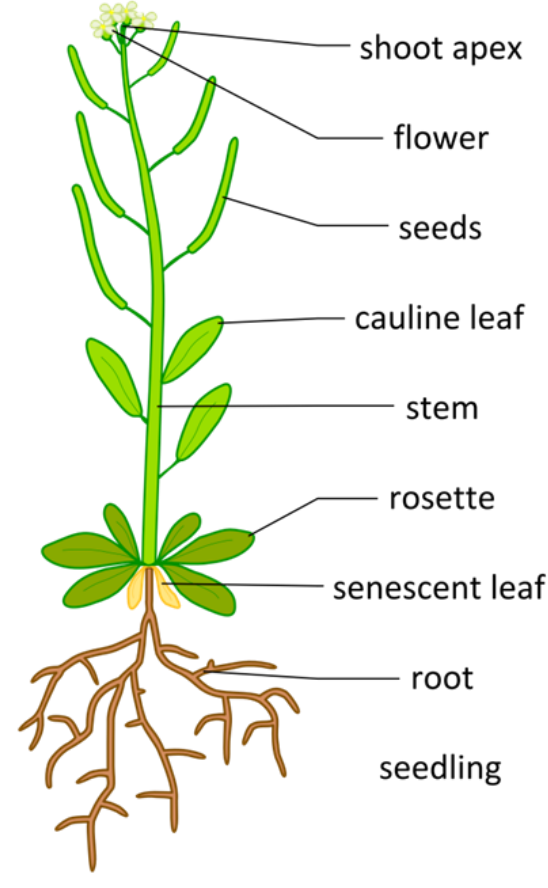

\begin{tabular}{|l|l|l|l|l|l|l|l|l|l|}
\hline \\
$\mid 4031$ & 6167 & 9117 & 6010 & 331 & 7732 & 232 & 126 & 1989 \\
\hline 3923 & 4394 & 5550 & 5525 & 412 & 2925 & 659 & 200 & 2401 \\
\hline 5539 & 6062 & 5284 & 5307 & 376 & 3362 & 619 & 196 & 3522 \\
\hline 3756 & 6573 & 2335 & 4873 & 334 & 631 & 154 & 129 & 1471 \\
\hline 5347 & 6281 & 4632 & 5729 & 391 & 1741 & 204 & 162 & 1472 \\
\hline 3652 & 6173 & 3055 & 5638 & 330 & 1106 & 199 & 175 & 1414 \\
\hline 6106 & 9245 & 4301 & 6201 & 315 & 951 & 156 & 141 & 1540 \\
\hline 5411 & 4428 & 5916 & 7601 & 295 & 3981 & 176 & 145 & 1799 \\
\hline 4654 & 5698 & 4441 & 5566 & 288 & 1948 & 198 & 167 & 1426 \\
\hline low expression & & & & & & & \\
\hline
\end{tabular}

Figure 3.4 Gene expression profile of Arabidopsis IMP-as. Gene expression data were gathered from the Genevestigator database (https://www.genevestigator.com; Hruz et al., 2008). Data referring to whole tissues were chosen for comparison of expression levels. Numbers represent linear signal intensity values of the given gene in the indicated tissues. Heat map indicates low signal intensity (green) to high signal intensity (red). The Figure was recently published in Wirthmueller et al. (2013). 
auto-inhibitory domain and competes with NLS-cargos for binding to the ARM-repeats (Görlich et al., 1996; Kobe, 1999; Stewart, 2007a). Apart from the missing IBB in IMP- $\alpha 8$, all IMP- $\alpha$ s are highly homologous with regard to their amino acid sequences.

Figure 3.4 shows the gene expression profiles of Arabidopsis IMP- $\alpha$ s. Data referring to whole tissues were chosen for comparison of gene expression levels and were gathered from the Genevestigator database (Hruz et al., 2008). IMP- $\alpha 1, I M P-\alpha 2$, MOS6/IMP- $\alpha 3, I M P-\alpha 4$ and IMP- $\alpha 6$ are not only closely related in regard to amino acid sequence but are expressed in the same tissues. These five IMP- $\alpha$ s together with IMP- $\alpha 9$ are ubiquitously expressed whereas IMP- $\alpha 5, I M P-\alpha 7$ and IMP- $\alpha 8$ are only weekly expressed. Additionally, expression of IMP- $\alpha$ s was not obviously altered after treatment with pathogens in any of the datasets available via the Genevestigator or the Bar Expression Browser tools (Toufighi et al., 2005; Hruz et al., 2008).

\subsubsection{Characterization of importin- $\alpha$ mutant lines}

As demonstrated above, the nine Arabidopsis IMP- $\alpha$ s do not show striking differences in their protein domain structure with the exception of IMP- $\alpha 8$, which lacks the IBB domain responsible for IMP- $\beta$-binding. Taken together with the highly similar expression pattern of IMP- $\alpha 1, I M P-\alpha 2, I M P-\alpha 4, I M P-\alpha 6, I M P-\alpha 9$ and $M O S 6 / I M P-\alpha 3$ the structural similarity leads to the assumption that at least the IMP- $\alpha$ s co-expressed in leaf tissue may act redundantly. The identification of mos 6 as a genetic suppressor of snc1-related autoimmunity and the findings that the mos6 single mutants alone are more susceptible to virulent H. a. NOCO2 and mildly virulent Pst (Figures 3.1, 3.2 and Palma et al., 2005), suggest that MOS6 plays a prominent role in plant immunity. In order to analyze a possible contribution of the other IMP- $\alpha$ s in plant defense, a collection of imp- $\alpha$ T-DNA insertion lines was established for all nine Arabidopsis IMP- $\alpha$ s.

\subsubsection{Importin- $\alpha$ T-DNA insertion lines used in this study}

The T-DNA insertion mutant lines used in this work were obtained from the European Arabidopsis Stock Centre (NASC, Scholl et al., 2000). Homozygous plants were isolated via PCR-based genotyping. The schematic gene structures of the nine Arabidopsis IMP- $\alpha$ s are 
depicted in Figure 3.5. Initially, two independent T-DNA insertion lines for each IMP- $\alpha$ gene were ordered if available. Homozygous lines were tested for disruption of functional transcripts via RT-PCR using cDNA-specific primers flanking the T-DNA insertion sites. Of these, only the lines with no residual transcripts detectable by RT-PCR were subsequently used for further functional analyses. In Figure 3.5 the RT-PCRs confirming absence of functional transcripts are shown next to the corresponding gene structures. The newlyestablished mutant lines are named imp- $\alpha 1, \operatorname{imp}-\alpha 2, \operatorname{imp}-\alpha 4, \operatorname{imp}-\alpha 5, i m p-\alpha 6, i m p-\alpha 7$, imp- $\alpha 8$ and imp- $\alpha 9$ throughout this study. For MOS6, in addition to the previously

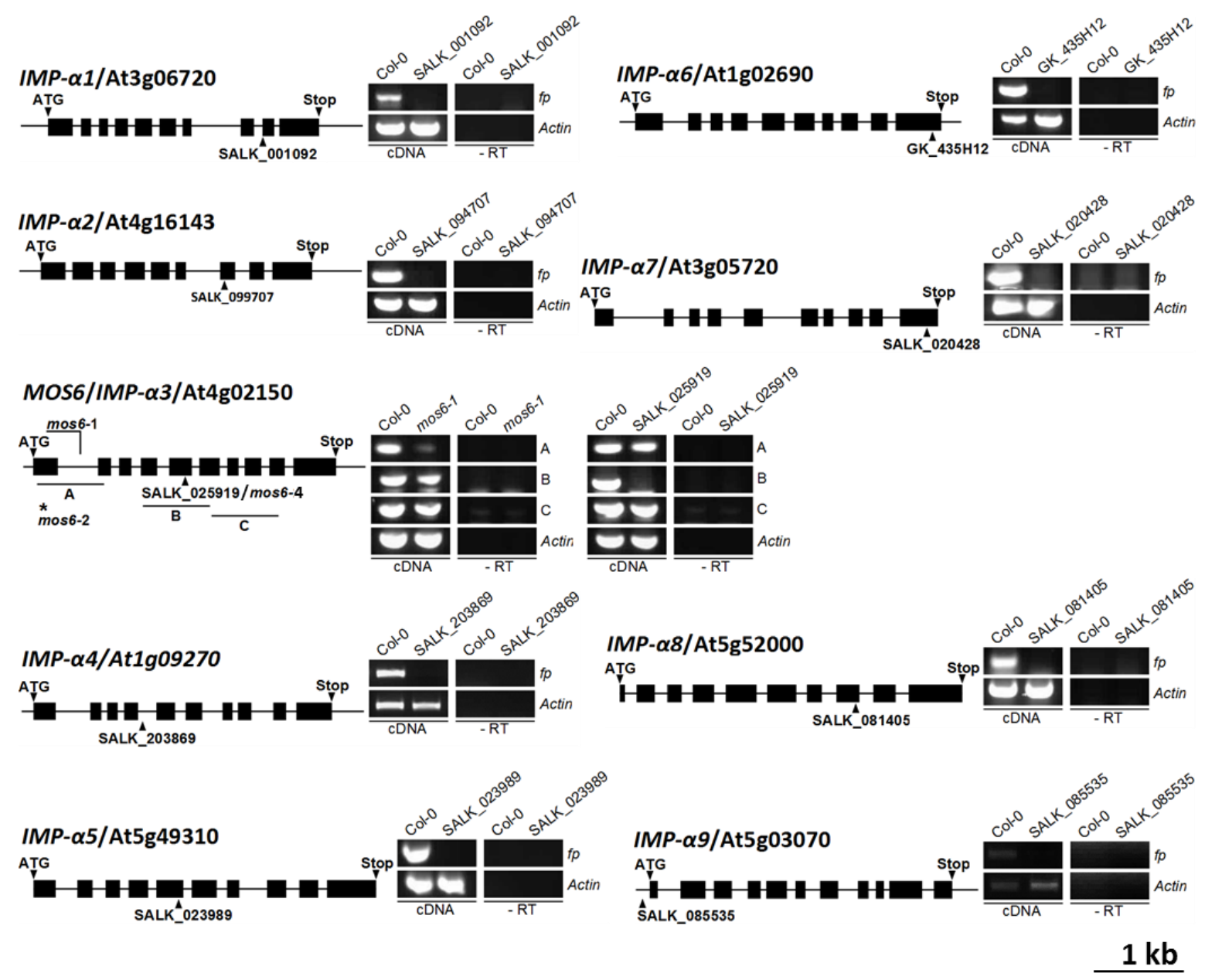

Figure 3.5 Schematic gene structures of Arabidopsis IMP- $\alpha$ s. Exons are represented as black boxes, introns as solid lines. Start and Stop codons are labeled as ATG or Stop above the gene structures. Positions of T-DNA insertions are indicated as triangles below the gene structures. Asterisk marks the 1 bp deletion in mos6-2. Semi-quantitative RT-PCRs for the respective genes are shown next to the gene structures. Col-0 was used as wild-type control. Flanking primers $(\mathrm{fp})$ were used to amplify fragments from cDNA, confirming disruption of functional transcripts. Primer combinations used for analysis of mos6 transcripts are labeled as A, B and C. -RT samples were used as controls for gDNA contamination. PCR products were analyzed by agarose gel electrophoresis and ethidium bromide staining. 
described mos6-1 and mos6-2 mutant alleles (Palma et al., 2005), the T-DNA insertion line SALK_025919 was used and is named mos6-4 for the remainder of this work. This mos6 mutant allele was recently published (Lukhovitskaya et al., 2015; Wirthmueller et al., 2015). For detection of partial transcripts of MOS6, three different cDNA-specific primer pairs were used. In Figure 3.5, the fragment resulting from amplification with primers flanking the site of the mos6-1 mutation is marked as " $A$ ". Fragment " $B$ " was amplified with primers flanking the site of the SALK_025919 T-DNA insertion. Fragment " $C$ " was amplified with primers $3^{\prime}$ of this insertion site. Figure 3.5 shows that mos6-1 mutants still contain transcripts $3^{\prime}$ of the mutation, whereas in mos6-4 partial transcripts $5^{\prime}$ as well as 3 ' of the T-DNA insertion were detectable. The part of the transcript missing in mos6-1 mutants codes for the IBB-domain of the protein. However, the presence of a truncated MOS6 protein in mos6-1 cannot be deduced from these data.

To assess a potential compensatory up-regulation of the gene expression of the remaining functional IMP $\alpha$ s in the different imp- $\alpha$ single mutants, semi-quantitative RT-PCRs were performed. Figure 3.6 shows the RT-PCR analysis for the nine IMP- $\alpha$ s as well as for SNC1 on CDNA transcribed from RNA that was extracted from rosette leaves of

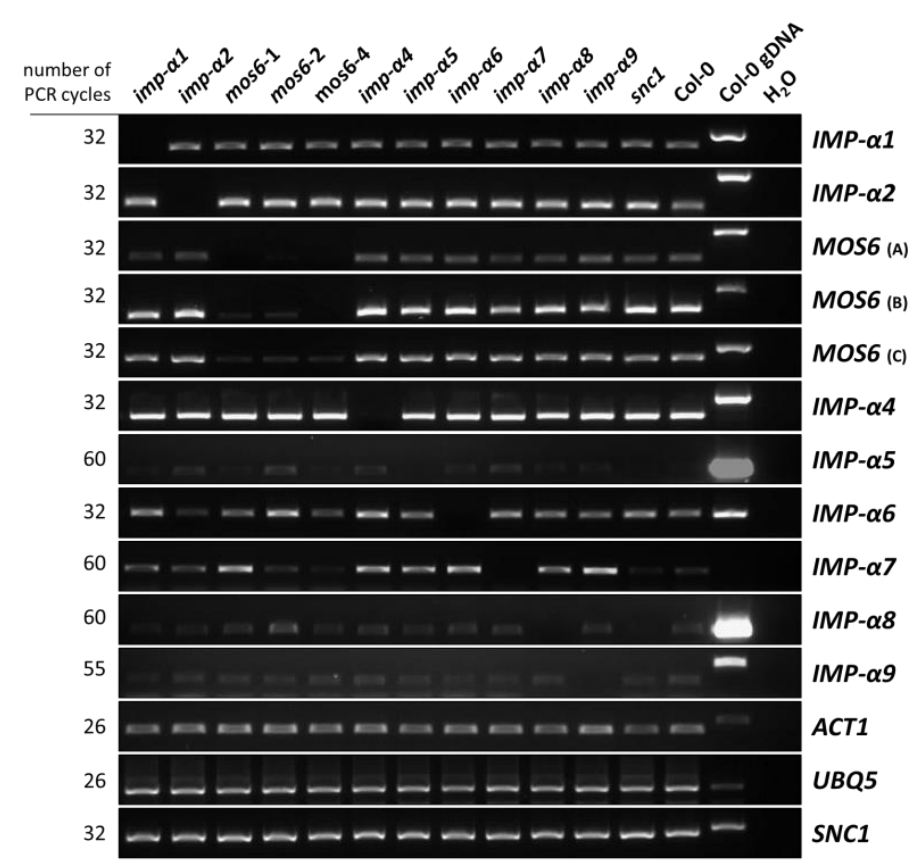

Figure 3.6 Expression of remaining functional IMPas in impa single mutants is not obviously altered. Semiquantitative RT-PCR analysis for expression of the nine Arabidopsis IMP- $\alpha$ S and SNC1 on CDNA transcribed from total RNA that was extracted from four-weekold unchallenged plants of the indicated genotypes. ACT1 and UBQ5 expression were used as controls. Where possible, primer combinations were designed to be located in exons and span at least one intron of the tested gene to monitor potential contamination by genomic DNA based on the size of PCR-fragments. Note that bands corresponding to IMP- $\alpha 5$, $I M P-\alpha 6, I M P-\alpha 7$ and IMP- $\alpha 8$ are the same size as Col-0 gDNA bands due to the primer combinations not spanning introns. Numbers of PCR cycles are depicted on the left. See Figure 3.5 for position of $A$ ), B) and C) fragments in MOS6. PCR products were analyzed by agarose gel electrophoresis and ethidium bromide staining. 
four-week-old imp- $\alpha$ mutant lines. ACTIN1 (ACT1, AT2G37620) and UBIQUITIN5 (UBQ5, AT3G62250) expression were used as controls. As had been deduced from the gene expression data available via the Genevestigator database (Figure 3.4), expression levels

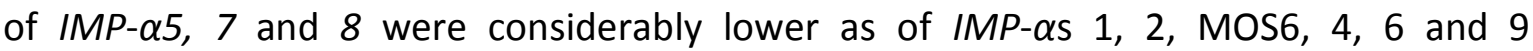
(Figure 3.4). IMP- $\alpha 5, I M P-\alpha 7$ and IMP- $\alpha 8$ expression shows some fluctuation that might be attributed to low expression levels. Accordingly, 55 to 60 PCR cycles had to be used for amplification of IMP- $\alpha 5,7,8$ and 9. However, it can be concluded from three independent biological replicates that the expression of remaining IMPas in the different imp-a single mutants was not considerably altered. In addition to IMP-as, SNC1 expression was analyzed as well. There were no significant differences with regard to SNC1 expression in the single imp- $\alpha$ mutant lines and vice versa there was no obvious compensatory upregulation in the expression of any IMP- $\alpha$ in the snc1 auto-immune mutant. Similarly, IMP- $\alpha$ expression levels are not considerably altered after infection with pathogens in any of the datasets available via the Genevestigator or the Bar Expression Browser tools (Toufighi et al., 2005; Hruz et al., 2008).

\subsubsection{Phenotypic characterization of imp- $\alpha$ single mutants}

One prominent phenotype of the snc1 auto-immune mutant is the stunted growth morphology. Beside the smaller statue, snc1 plants have dark and curly leaves (Li et al., 2001). In the genetic suppressor screen that aimed to identify modifiers of snc1 (mos) mutations based on suppression of this growth phenotype, the mos6-1 mutation was identified (Palma et al., 2005). Loss of mos6-1 alone, does not cause a growth phenotype different from the wild-type Col-0 (Figure 3.1, Palma et al., 2005), suggesting that loss of MOS6 function does not have an impact on regular plant growth and development. In order to assess whether this also holds true for other imp- $\alpha$ single mutants, growth phenotypes of the imp- $\alpha$ mutant collection introduced in 3.1.3.1 (Fig. 3.5) were analyzed. Plants were grown in parallel on soil under short day ( $8 \mathrm{~h}$ light) and long day (16 h light) conditions and photographed (Figure 3.7). Col-0 plants were used as wild-type and snc1 mutant plants as control for severely stunted growth. Pictures of whole rosettes were 
taken of five-week-old short day and three-week-old long day grown plants. Plants grown in the long day chamber were allowed to bolt and flower and pictures were taken of five-week-old flowering plants. The imp- $\alpha$ single mutant plants were not obviously different from the Col-0 wild-type in three independent experiments. Neither rosette size, morphology, plant size, bolting nor flowering times of the mutant plants differed from

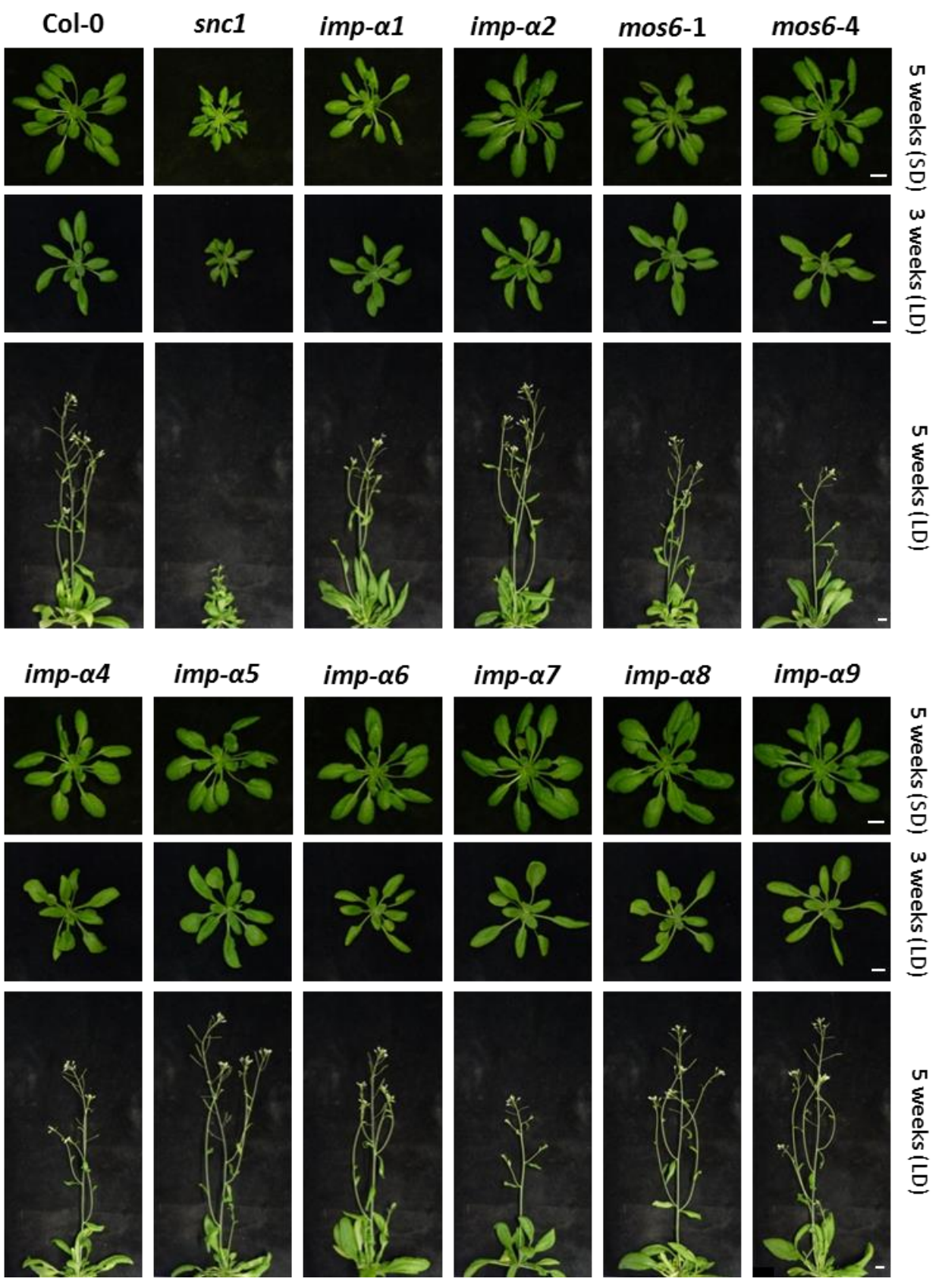

Figure 3.7 Growth phenotypes of imp- $\alpha$ single mutants. Morphology of Col-0, snc1 and imp- $\alpha$ single mutants. Plants were grown in parallel on soil for five weeks under short day (SD) conditions and three or five weeks under long day (LD) conditions. Scale bar $=1 \mathrm{~cm}$. The experiments were repeated three times with similar results. 
Col-0. No other morphological defects could be observed for any of the imp- $\alpha$ single mutants.

\subsubsection{3 mos 6 alleles but no other imp- $\alpha$ mutants are impaired in resistance against H. a. NOCO2 and Pst DC3000 (DAvrPto/AvrPtoB)}

Loss of mos6 results in susceptibility towards the virulent oomycete strain H. $a$. NOCO2 and mildly virulent Pst (Figure 3.2; Wirthmueller et al., 2015; Palma et al., 2005). In order to assess a possible involvement of other IMP- $\alpha$ s in immunity against these pathogens, the collection of imp- $\alpha$ T-DNA insertion lines was analyzed for defense phenotypes

A

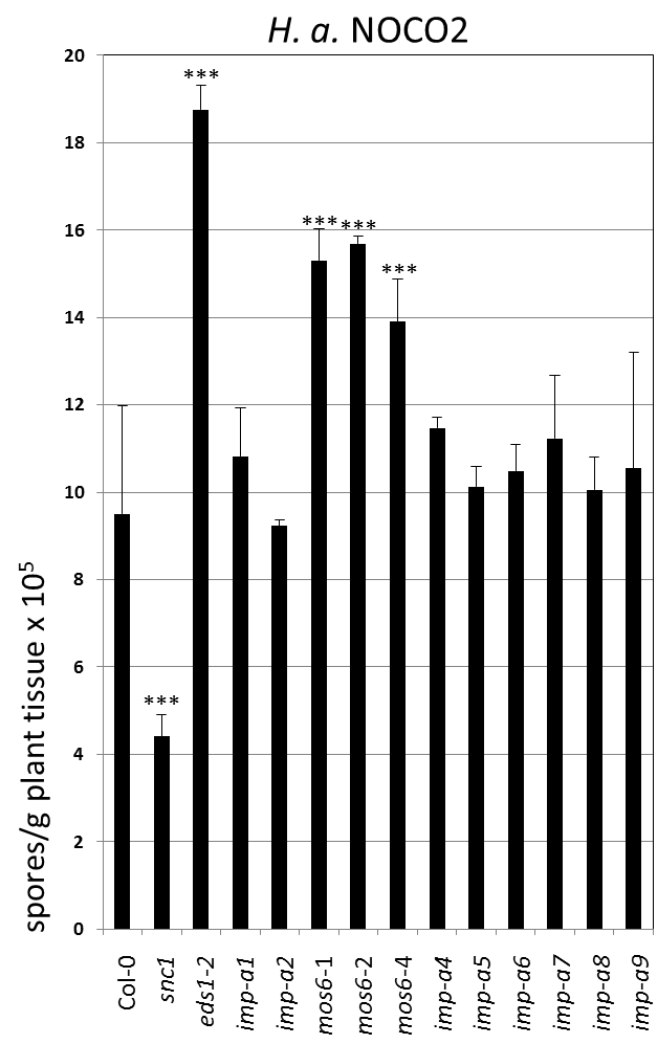

B
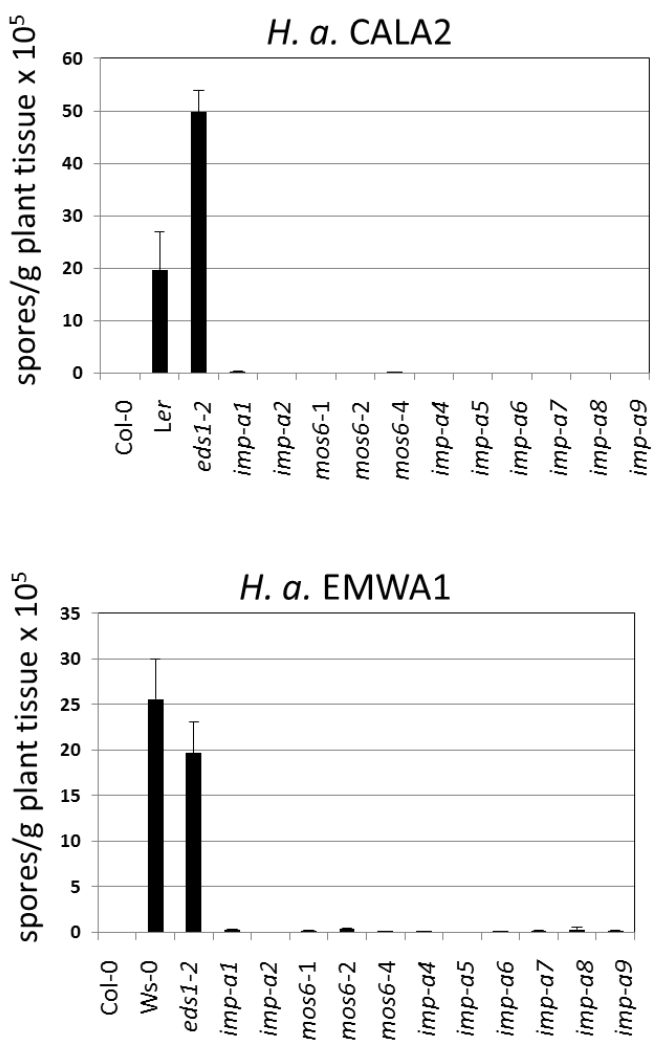

Figure 3.8 mos6 alleles but no other imp- $\alpha$ mutants are more susceptible to H.arabidopsidis NOCO2. Twoweek-old seedlings of the indicated genotypes were sprayed with a conidiospore suspension of $4 \times 10^{4}$ spores per $\mathrm{mL} \mathrm{H}_{2} \mathrm{O}$. Conidiophores were counted 6 dpi. Bars represent means. Error bars show standard deviation and asterisks indicate statistical significance (t-test for pairwise comparison between wild-type and mutant, $\mathrm{p}<0.0001)$. snc1 and eds1-2 (Col eds1-2) are resistant and susceptible controls, respectively. A) Growth of the virulent $H$. a. NOCO2 for which Col-0 is a susceptible host ecotype. B) Growth of the avirulent $H$. $a$. isolates CALA2 (top) and EMWA1 (bottom) that are recognized in Col-0 by RPP2 and RPP4, respectively. Ler (lacking functional RPP2) and Ws-0 (lacking functional RPP4) were used as susceptible wildtype ecotypes for the respective $H$. $a$. isolate. Part of this Figure was shown in Figure 3.2.(A). The experiments were repeated three times with similar results. 
(Figures 3.8 and 3.9). Basal resistance against H. a. NOCO2 is significantly compromised in mos6-1, mos6-2 and mos6-4 compared to Col-0 wild-type plants but not in the other imp- $\alpha$ mutants (Figure 3.8). The higher susceptibility observed for the three mos 6 mutant alleles was less strong as the total breakdown of resistance in hyper-susceptible Col eds1-2 control plants.

The $H$. $a$. isolates CALA2 and EMWA1 are avirulent on Col-0 due to effector triggered immunity mediated by the R proteins RPP2 and RPP4, respectively (Botella et al., 1998; Caillaud et al., 2012b). To test whether this layer of resistance is compromised by loss of a certain IMP- $\alpha$, the imp- $\alpha$ mutant collection was inoculated with these pathogens. CALA2 and EMWA1 were able to grow and sporulate on their susceptible

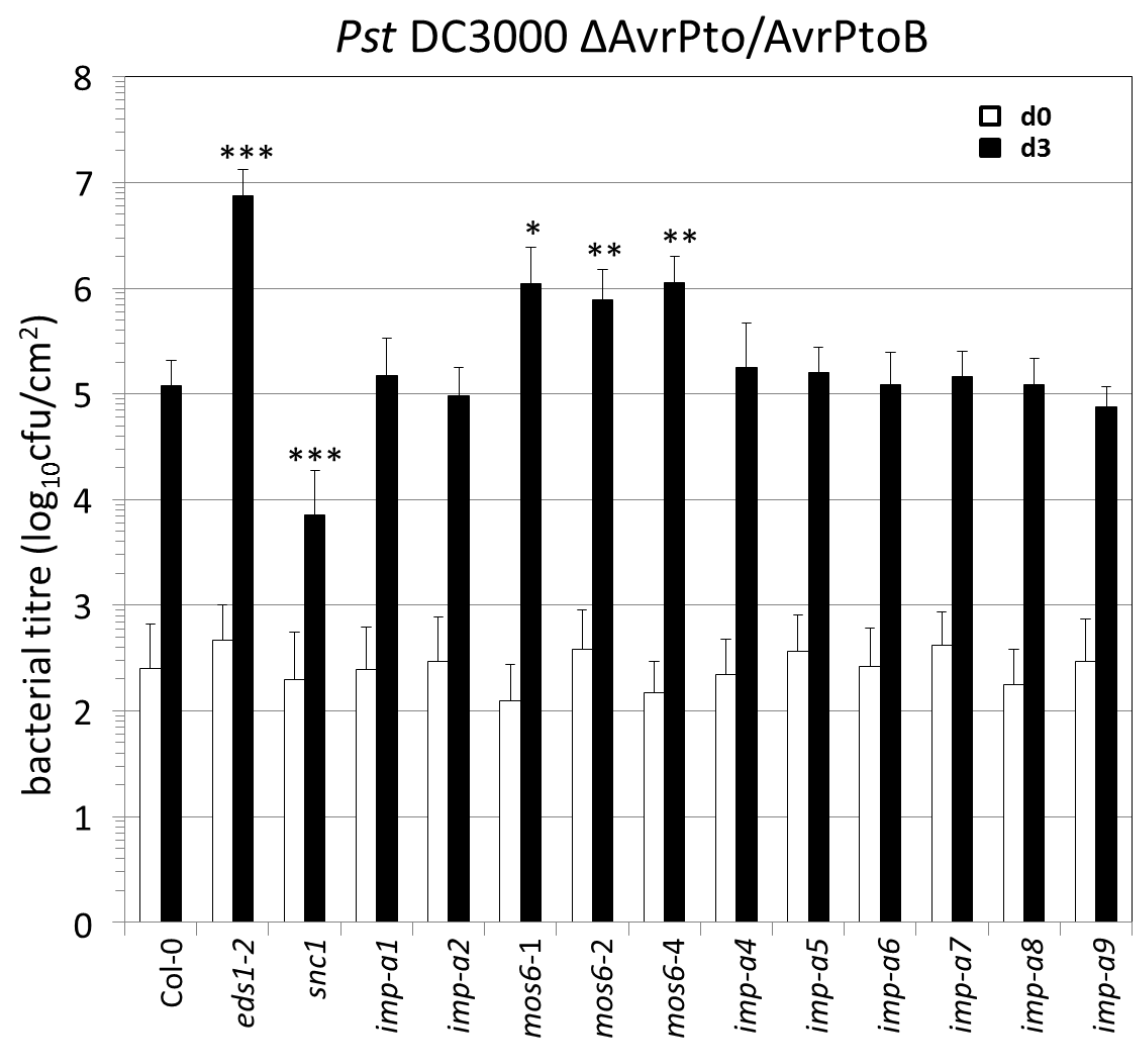

Figure 3.9 mos6 alleles but no other imp- $\alpha$ mutants are more susceptible to Pst with incomplete effector repertoire. Growth of Pst DC3000 ( $\triangle$ AvrPto/AvrPtoB). Leaves of four-week-old plants of the indicated genotypes were vacuum-infiltrated with a bacterial suspension of $1 \times 10^{5} \mathrm{cfu} / \mathrm{mL}$. To quantify bacterial growth, leaf discs within the inoculated areas were taken immediately (d0) and three days after infection (d3). Bars represent means from two replicate samplings for do (white bars) and nine replicate samplings for $\mathrm{d}_{3}$ (black bars). Error bars show standard deviation and asterisks indicate statistical significance (t-test for pairwise comparison between Col-0 and mutant, $\left.{ }^{*} \mathrm{p}<0.05, * * \mathrm{p}<0.01, * * * \mathrm{p}<0.001\right)$. snc1 and eds $1-2$ (Col eds1-2) are resistant and susceptible controls, respectively. Cfu = colony-forming units. The experiment was repeated three times with similar results. 
host-ecotypes Ler (lacking functional RPP2) and Ws-0 (lacking functional RPP4), respectively, and on the susceptible Col eds1-2 control (Figure 3.8 B). No spore development was detected on any of the imp- $\alpha$ mutants including the three mos 6 alleles.

In this work it was shown that loss of MOS6 results in enhanced disease susceptibility against the mildly virulent Pseudomonas strain Pst DC3000 ( $\triangle$ AvrPto/AvrPtoB, Figure 3.2). To analyze a potential genetic requirement for additional members of the IMP- $\alpha$ family in resistance against Pst DC3000 ( $\triangle$ AvrPto/AvrPtoB), the whole set of imp- $\alpha$ mutants, including the mos6 alleles, was inoculated with this pathogen strain. Resistance against Pst DC3000 ( $\triangle$ AvrPto/AvrPtoB) was significantly compromised in mos6-1, mos6-2 and mos6-4 but not in the other imp- $\alpha$ mutants (Figure 3.9). As observed for the NOCO2 defense phenotype (Figure 3.8), the enhanced susceptibility of the three mos6 alleles was less pronounced as the total breakdown of resistance in the hyper-susceptible Col eds1-2 control.

Together, these infection studies demonstrate that only mos6 mutant plants are impaired in basal resistance against virulent $H$. a. NOCO2 and Pst DC3000 with reduced effector repertoire ( $\triangle$ AvrPto/AvrPtoB) whereas the other analyzed imp- $\alpha$ mutants are not compromised in this resistance layer. $R$ gene-mediated resistance conferred by RPP 2 and RPP4 remains intact in all of the tested imp-a mutants, including mos6-1, mos6-2 and mos6-4. These data suggest that MOS6 is specifically involved in basal resistance with no other IMP- $\alpha$ family member acting redundantly.

\subsubsection{Only mutant alleles of mos6 but not of other imp-as suppress the snc1 auto-immune growth phenotype}

Mutations in MOS6 suppress the stunted growth phenotype of the snc1 auto-immune mutant (Figure 3.1; Palma et al., 2005). Combined with the enhanced disease susceptibility phenotypes of mos6 mutants against H. a. NOCO2 and Pst DC3000 ( $\triangle$ AvrPto/AvrPtoB, Figures 3.2, 3.8 and 3.9), this strongly suggests that this IMP- $\alpha$ homolog selectively contributes to plant immunity, since mutations in the other eight IMP- $\alpha$ genes do not compromise resistance to these pathogens (Figures 3.8 and 3.9). To test whether the remaining eight IMP- $\alpha$ s encoded by the Arabidopsis genome are 
required genetically for manifestation of the snc1 auto-immune phenotype, all imp- $\alpha$ single mutant lines (Figure 3.5) were crossed with snc1 to produce snc1 imp- $\alpha$ double mutants. Figure 3.10 shows plants grown in parallel on soil under short day (SD, $8 \mathrm{~h}$ light)
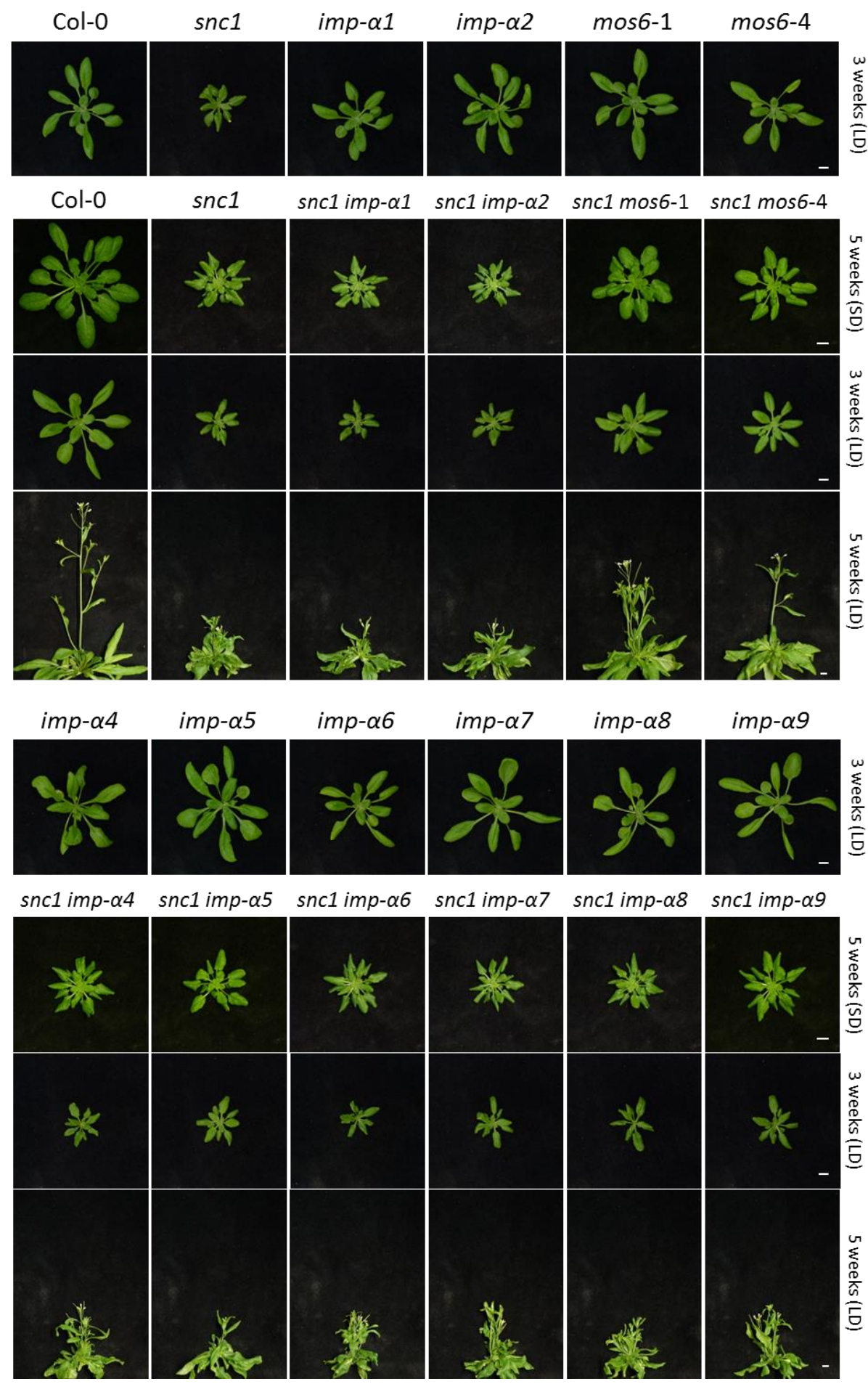

snc1 imp- $\alpha 9$

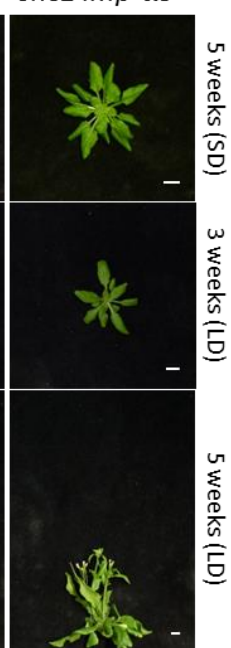

Figure 3.10 Phenotypic analysis of snc1 imp- $\alpha$ double mutants. All plants were grown in parallel on nutrient deficient soil for five weeks under short day (SD) conditions and three or five weeks under long day (LD) conditions. For comparison the corresponding single mutants (also depicted in Figure 3.7) which were grown together with the snc1 imp- $\alpha$ double mutant plants are shown above the respective double mutant plants. Scale bar $=1 \mathrm{~cm}$. 
and long day (LD, $16 \mathrm{~h}$ light) growth conditions. Col-0 plants were used as wild-type and snc1 single mutant plants as control for the typical snc1 growth phenotype. Shown above the pictures of snc1 imp- $\alpha$ double mutant plants are pictures of corresponding single mutant plants from Figure 3.7 that were grown in parallel with the double mutants under long day conditions. Whole rosettes of five-week-old short day and three-week-old long day grown plants were photographed. Plants grown under LD conditions were allowed to bolt and flower and pictures were taken of five-week-old flowering plants. The snc1 mutants clearly showed the typical stunted growth morphology reported previously (Li et al., 2001). All snc1 imp- $\alpha$ double mutant plants were undistinguishable from snc1 plants, except for the lines containing one of the mos6 alleles. snc1 mos6-1 as well as snc1 mos6-4 plants were larger than the original snc1 mutant plants and showed the typical partial suppression of snc1-related growth retardation (Figure 3.1; Palma et al., 2005).

In summary, the reverse-genetic analyses of imp- $\alpha$ single and snc1 imp- $\alpha$ double mutants indicate that, among the nine IMP- $\alpha$ s in Arabidopsis, IMP- $\alpha 3$ MOS6 is selectively required for basal plant defense responses against the oomycete pathogen $\mathrm{H}$. $a$. NOCO2 and the bacterial pathogen Pst DC3000 ( $\triangle$ AvrPto/AvrPtoB) as well as for manifestation of the stunted growth morphology of the auto-immune mutant snc1.

\subsubsection{Characterization of imp- $\alpha$ double and triple mutants}

In the previous sections, it has been shown that of the nine Arabidopsis IMP- $\alpha$ s apparently only MOS6 is genetically required for immune responses against virulent $H$. $a$. NOCO2 and Pst DC3000 ( $\triangle$ AvrPto/AvrPtoB) and growth inhibition caused by autoactivated snc1. However, it is important to note that the loss of MOS6 does not result in complete breakdown of basal resistance and only partial suppression of the snc1mediated growth phenotype. This could be explained by partially overlapping functions of IMP- $\alpha$ family members. The possibility of redundancy was addressed by crossing imp- $\alpha$ single mutant lines to produce imp- $\alpha$ double and triple mutants that subsequently were characterized. mos6 mutants were combined with mutants of the other IMP- $\alpha$ s except imp- $\alpha 4$ and imp- $\alpha 9$ for which mutant lines were not available when double mutants were generated. Additionally, several other double mutant combinations were generated, e.g. between the closely related $i m p-\alpha 1$ and $i m p-\alpha 2$ that are highly expressed in leaves. For 
the generation of mos 6 containing triple mutants, the different mos 6 imp- $\alpha$ double mutants were combined.

\subsubsection{Higher order mutant combinations containing imp- $\alpha 1$ show reduced growth}

In order to assess whether the generated imp- $\alpha$ double mutants show any growth phenotypes, plants were grown in parallel on soil under short day and long day conditions and photographed (Figure 3.11). Col-0 plants were used as wild-type controls. Pictures of
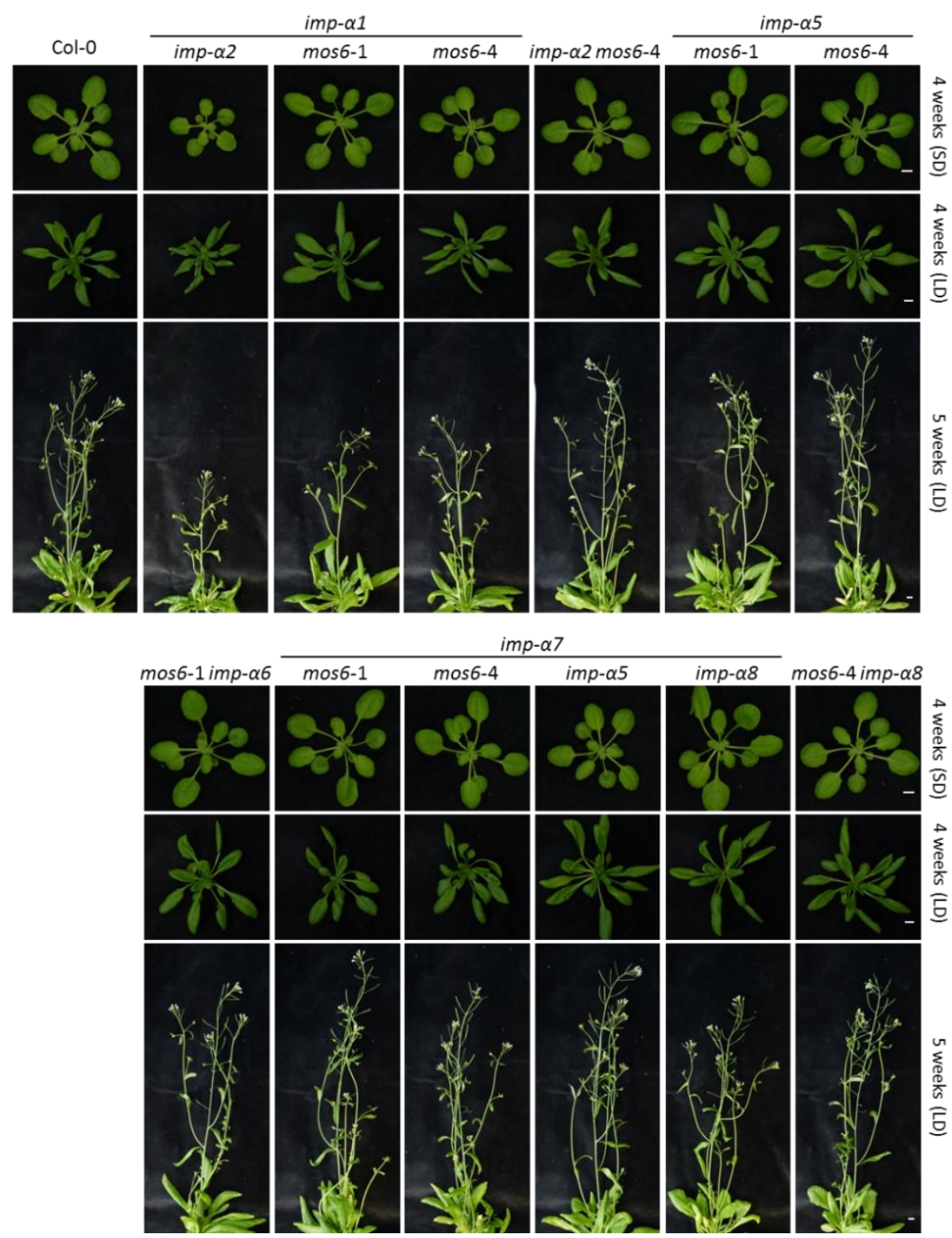

Figure 3.11 Phenotypic analysis of imp- $\alpha$ double mutants. Plants were grown in parallel on soil for four weeks under short day (SD) conditions and four or five weeks under long day (LD) conditions. Scale bar $=1 \mathrm{~cm}$. 
whole rosettes were taken of four-week-old short day and four-week-old long day grown plants. Plants grown in the long day chamber were allowed to bolt and flower and pictures were taken of five-week-old flowering plants. Generally, growth of imp- $\alpha$ double mutants was indistinguishable from Col-0 wild-type plants that were grown under the same conditions. However, double mutants containing the imp- $\alpha 1$ allele were smaller than wild-type plants (Figure 3.11) although imp- $\alpha 1$ single mutants do not show a growth phenotype different from Col-0 (Figure 3.7). This was true for the imp- $\alpha 1$ imp- $\alpha 2$, imp- $\alpha 1$ mos6-1 and imp- $\alpha 1$ mos6-4 double mutant plants. The phenotype was most pronounced in the double mutant of the closely related imp- $\alpha 1$ and imp- $\alpha 2$. For the mos 6 imp- $\alpha 1$ combinations this weak reduction was most clearly seen for full grown plants after five weeks growth under LD conditions rather than for rosette sizes. Aside from this no other obvious morphological defects could be observed for any of the imp- $\alpha$ double mutants (Figure 3.11). In addition to double mutants, phenotypes of the generated triple mutant combinations were characterized. Figure 3.12 shows growth phenotypes of the imp- $\alpha$

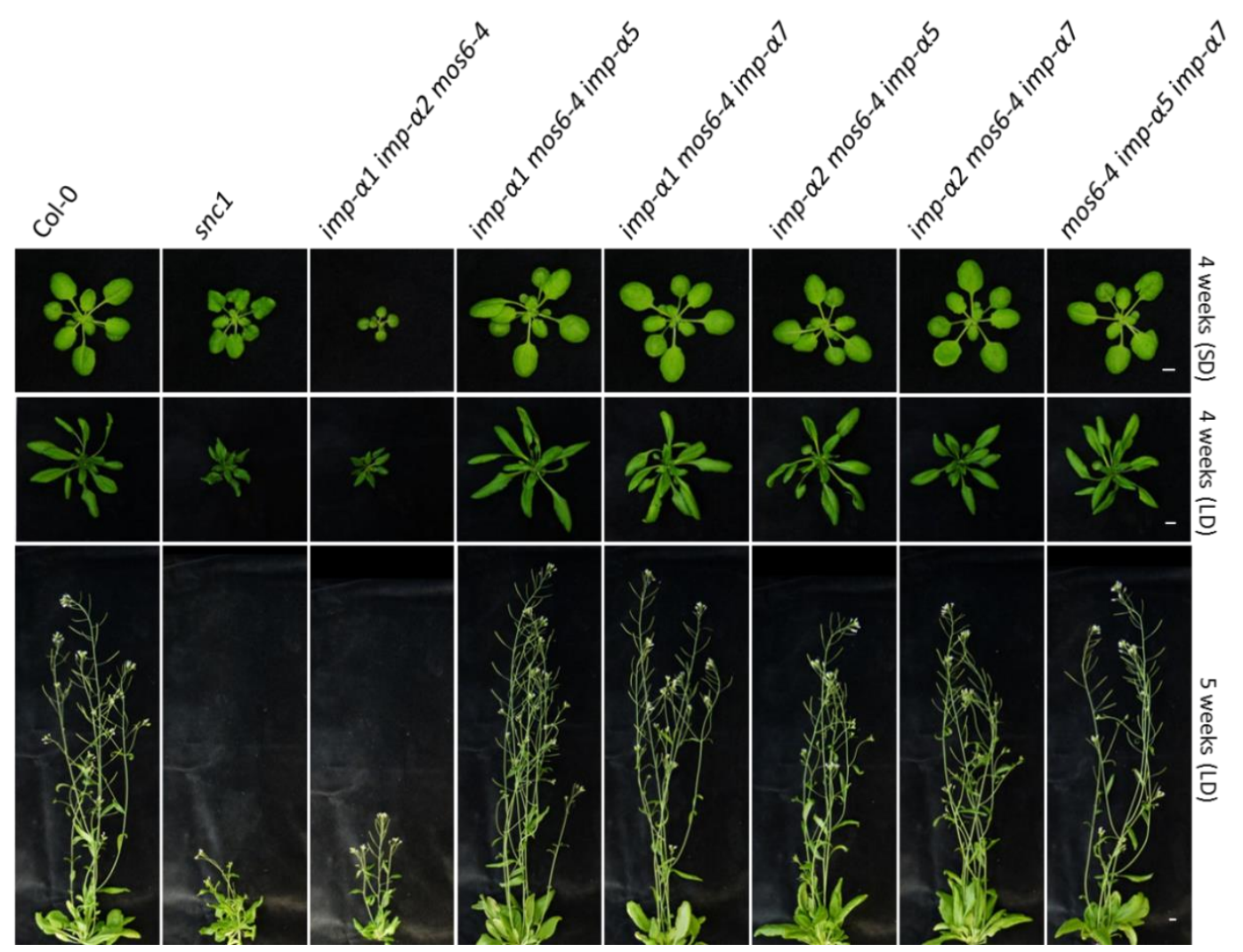

Figure 3.12 Phenotypic analysis of imp- $\alpha$ triple mutants. Plants were grown in parallel on soil for four weeks under short day (SD) conditions and four or five weeks under long day (LD) conditions. Scale bar $=1 \mathrm{~cm}$. 
triple mutant lines. snc1 mutants were used as control for reduced growth. The imp- $\alpha 1$ imp- $\alpha 2$ mos6-4 mutant plants were severely stunted in comparison to the imp- $\alpha 1$ imp- $\alpha 2$ and imp- $\alpha 1$ mos 6 double mutants and Col-0. In particular, when grown under short day conditions, these plants were even smaller than the growth retarded snc1 plants (Figure 3.12). Aside from this, no other morphological defects could be observed for any of the imp- $\alpha$ triple mutants.

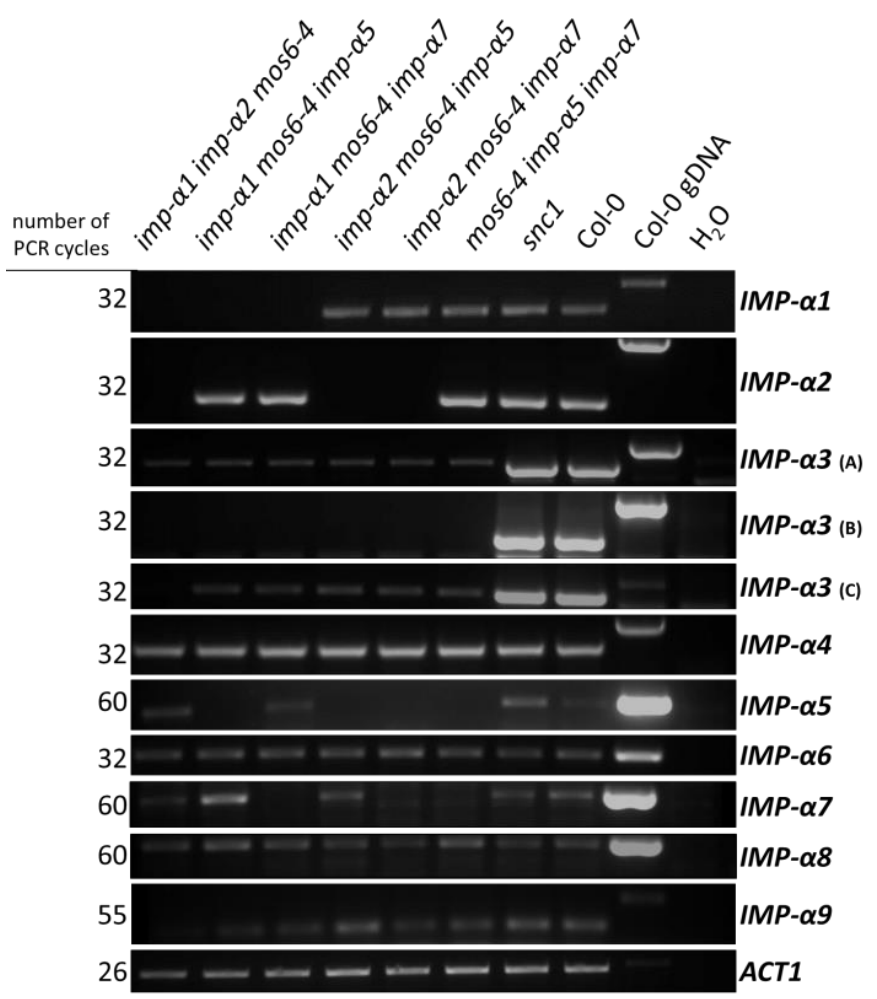

Figure 3.13 Expression of remaining functional IMP- $\alpha$ s in imp-a triple mutants is not obviously altered. Semi-quantitative RT-PCR analysis of IMP- $\alpha$ s on CDNA transcribed from total RNA extracted from leaves of four-week-old plants of the indicated genotypes. ACTIN1 expression was used as control. When possible, primer combinations were designed to be located in exons and span at least one intron of the tested genes to monitor contamination by genomic DNA based on the size of PCRfragments. Note that bands corresponding to IMP- $\alpha 5, I M P-\alpha 6, I M P-\alpha 7$ and $I M P-\alpha 8$ are the same size as Col-0 gDNA bands due to the primer combinations not spanning introns. Numbers of PCR cycles are depicted on the left. PCR products were analyzed by agarose gel electrophoresis and ethidium bromide staining.

To also assess a possible compensatory up-regulation in the expression of the remaining functional IMP $\alpha$ s in the triple mutants, semi-quantitative RT-PCRs were performed. Figure 3.13 shows the RT-PCR analysis for IMP- $\alpha$ s on cDNA transcribed from RNA extracted from leaves of four-week-old imp- $\alpha$ triple mutant lines. ACTIN1 (ACT1) expression was used as control. This gene expression study shows that there were no significant differences in regard to IMP- $\alpha$ expression in the triple imp- $\alpha$ mutant lines as compared to the wild-type control Col-0. 


\subsubsection{Susceptibility of triple mutant lines containing mos6 is not further increased as compared to the mos6-1 single mutant}

This work revealed that loss of MOS6 function in mos6-1, mos6-2 and mos6-4 results in enhanced susceptibility against mildly virulent Pst DC3000 ( $\triangle$ AvrPto/AvrPtoB) whereas all other imp- $\alpha$ single mutants did show wild-type like susceptibility against this pathogen strain (Figure 3.2, Figure 3.9). To analyze the genetic relationship between MOS6 and other IMP-as in response to Pst DC3000 ( $\triangle$ AvrPto/AvrPtoB) the triple mutants were inoculated with this pathogen. The susceptibility of triple mutants containing mos6-4 is similar to that of the mos6-1 single mutant and no additive effects of additional imp- $\alpha$ mutant alleles on susceptibility were observed (Figure 3.14).

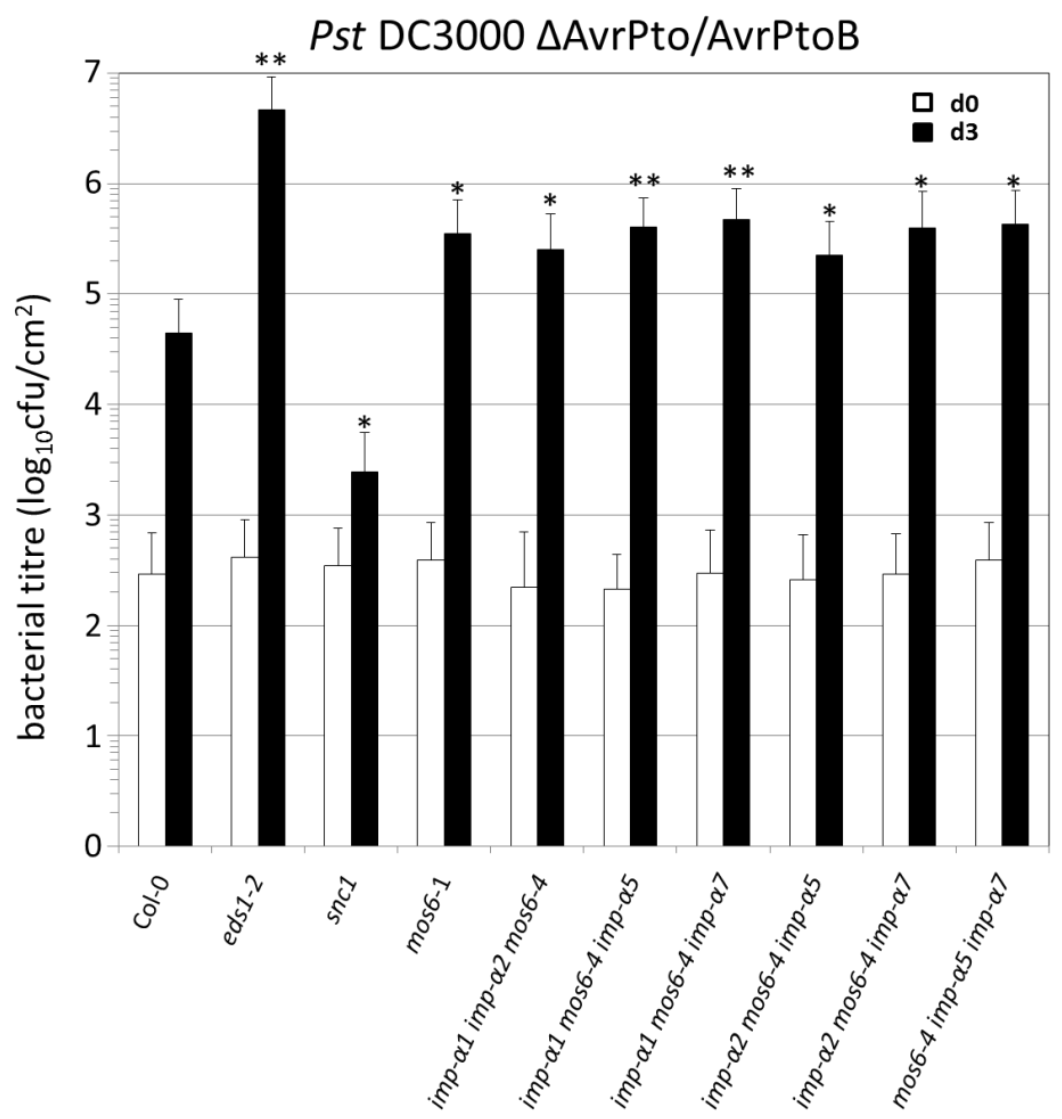

Figure 3.14 Triple mutant lines containing mos6 show susceptibility against mildly virulent Pst DC3000 ( $\triangle$ AvrPto/AvrPtoB) to an extent comparable to mos6-1. Growth of Pst DC3000 ( $\triangle$ AvrPto/AvrPtoB). The leaves of four-week-old plants of the indicated genotypes were infiltrated with a bacterial suspension of $1 \times 10^{5} \mathrm{cfu} / \mathrm{mL}$. To quantify bacterial growth, leaf discs within the inoculated areas were taken immediately (d0) and three days after infection (d3). Bars represent means from two replicate samplings for d0 (white bars) and nine replicate samplings for $d_{3}$ (black bars). Error bars show standard deviation and asterisks indicate statistical significance (t-test for pairwise comparison of wild-type and mutants, * $p<0.05$, ** $\mathrm{p}<0.01$ ). snc1 and eds1 (Col eds1-2) are resistant and susceptible controls, respectively. Cfu = colonyforming units. All experiments were repeated twice with similar results. 
Together, the analyses of imp- $\alpha$ triple mutant combinations show that IMP- $\alpha 1, I M P-\alpha 2$ and MOS6/IMP- $\alpha 3$ have partially redundant functions that are important for regular plant growth and development. In contrast, MOS6 appears to be selectively required for maintaining the basal resistance layer against Pst DC3000 ( $\triangle$ AvrPto/AvrPtoB) as the susceptibility of the triple mutants containing mos6-4 was not further increased as compared to the mos6-1 single mutant.

\subsection{Identification and characterization of defense-related cargo proteins and interaction partners of the IMPORTIN- $\alpha 3$, MOS6}

The nuclear protein import receptor MOS6/IMP- $\alpha 3$ has partially redundant functions with IMP- $\alpha 1$ and IMP- $\alpha 2$ in plant growth (Figure 3.12 ) but is selectively required for basal plant immunity and the constitutive disease resistance phenotype activated in the autoimmune mutant snc1 (Figures 3.8 - 3.10 and Palma et al., 2005). This suggests that MOS6 may specifically or preferentially import unknown cargo proteins involved in plant defense signaling into the nucleus. Several examples from the mammalian field show the preferential nuclear import of cargo proteins by specific IMP- $\alpha$ adapters (Miyamoto et al., 1997; Nadler et al., 1997; Köhler et al., 1999; Melen et al., 2003; Quensel et al., 2004; Fagerlund et al., 2005; Fagerlund et al., 2002; Liu et al., 2005). In plants, only very few examples of IMP- $\alpha$ cargo specificity are known (Bhattacharjee et al., 2008; Kanneganti et al., 2007a; Wirthmueller et al., 2015). Defense-related cargo proteins or interaction partners that are transported by a specific IMP- $\alpha$ protein have not been described so far. Therefore, the second objective of this work was to identify and characterize MOS6 defense-related cargo proteins and interaction partners. For this purpose, the yeast twohybrid based Plant-Pathogen Immune Network (PPIN-1, Mukhtar et al., 2011) was used to search for MOS6 interaction candidates in an in silico approach. In parallel, in planta affinity purification of epitope-tagged MOS6 coupled with subsequent analysis by mass spectrometry was carried out. From both approaches, candidates were selected for

validation of the interaction by transient expression in $N$. benthamiana and co-immunoprecipitation (CoIP). To investigate whether MOS6 interaction candidates are 
involved in plant immunity, T-DNA insertion mutants were isolated and inoculated with Pst DC3000 (AAvrPto/AvrPtoB).

\subsubsection{In silico analyses of MOS6 interaction partners}

The Arabidopsis Interactome and Plant-Pathogen Immune Network (PPIN-1) generated via high throughput yeast two-hybrid analyses by the Arabidopsis Interactome Mapping Consortium (2011; Mukhtar et al., 2011, http://signal.salk.edu/interactome/ index.html) was used to search for putative MOS6 interaction partners. This search yielded 73 proteins. MOS6-interacting candidates were selected for further analyses based on the following criteria: i) selective interaction with MOS6 and no other IMP- $\alpha$ family member in PPIN-1, ii) presence of a predicted nuclear localization signal (NLS) in the amino acid sequence, iii) prediction of subcellular localization in the nucleus and/or cytoplasm, iv) transcription in rosette leaf tissue and v) indication for involvement in plant immune responses.

First, proteins were identified that specifically interacted with MOS6 in the yeast two-hybrid analyses of the PPIN-1 network. Proteins that solely interacted with MOS6 and not with other IMP- $\alpha$ family members were selected. Testing the candidates for presence of a predicted mono- or bipartite NLS motif allowed selection of proteins that are possible cargos for IMP- $\alpha$ mediated nuclear transport. For this, the online available NLS-mapper tool was used (http://nls-mapper.iab.keio.ac.jp/cgi-bin/NLS_Mapper_form. cgi, Kosugi et al., 2009a; Kosugi et al., 2008; Kosugi et al., 2009b). Proteins that did not contain a NLS motif were excluded from the list. To test whether MOS6-interaction partners were predicted to localize to the same subcellular compartments as MOS6, the subcellular localization database for Arabidopsis proteins SUBA3 (http://suba3. plantenergy.uwa.edu.au/, Heazlewood et al., 2007; Tanz et al., 2013; Heazlewood et al., 2005) and the subcellular localization prediction tool Yloct (http://abi.inf.unituebingen.de/Services/ YLoc/webloc.cgi, Briesemeister et al., 2010a, 2010b) were used. MOS6 localizes to the nucleus and the cytoplasm (Palma et al., 2005). Therefore, candidates that were predicted by bioinformatic analyses to be localized in the cytoplasm and/or nucleus were selected. To assess whether MOS6 interactor candidates are expressed in rosette leaves, the eFP-browser (http://bar.utoronto.ca, Winter et al., 2007) 
and the Genevestigator database (https://genevestigator.com/gv/plant.jsp, Hruz et al., 2008) were used to analyze expression profiles of these proteins. MOS6 is involved in defense against the foliar pathogens Pst DC3000 ( $\triangle$ AvrPto/AvrPtoB) and $H$. $a$. NOCO2 (Figure 3.2). This suggests that presence of MOS6 in rosette leaf tissue is required for its function in plant immunity against these pathogens. Consistent with this, MOS6 is transcribed in leaf tissue (Figure 3.4). Hence, only proteins that were also expressed in rosette leaf tissue were selected. Finally, the candidates were assessed based on putative or reported involvement in plant immune responses. For this, if available, previously published data on the remaining candidates were gathered and evaluated. Among the 73 proteins from the PPIN-1 in silico analysis, three transcription factors (MYB70, WRKY60 and ORS1) and two TIR-NBS proteins (a TNL and TN13) were chosen for further analysis according to the selection criteria described above.

MYB70 is a MYB family transcription factor (Jung et al., 2008). Interestingly, MYB70 is targeted by various $H$. $a$. effector proteins but has not been further characterized so far (Weßling et al., 2014; Mukhtar et al., 2011). Based on these data MYB70 was chosen for further analysis. WRKY60 was selected because of its involvement in defense against various pathogens such as virulent and avirulent strains of Pst and the necrotrophic fungal pathogen Botrytis cinerea (Dong et al., 2003; Xu et al., 2006). WRKY60 functions partially redundant in pathogen resistance together with WRKY18 and WRKY40 (XU et al., 2006; Schön et al., 2013; Chen et al., 2010). Both, WRKY18 and WRKY40 did not interact with MOS6 in PPIN-1. The NAC transcription factor ORS1 (ORESARA1 SISTER1) regulates senescence in Arabidopsis and its transcription is strongly induced by $\mathrm{H}_{2} \mathrm{O}_{2}$ treatment (Balazadeh et al., 2011; Matallana-Ramirez et al., 2013). Due to its role in regulating the expression of WRKY40 (Balazadeh et al., 2011), ORS1 was selected from the PPIN-1 dataset for further analysis.

Two members of the TIR-NBS protein class were selected based on presence of conserved cytoplasmic TIR (Toll/IL-1 receptor homologous region) and NBS (nucleotide-binding site) domains. These domains together with the LRR (leucine-rich repeat) domain are found in one of the two major classes of disease resistance proteins in plants (Meyers, 2003). The yet uncharacterized TIR-NBS-LRR protein encoded by AT3G44670 is named TNL in the following. The MOS6-interactor candidate TN13 harbors the TIR and NBS domains but no 
LRR domain and was shown to associate with the Pst DC3000 effector HopY (Nandety et al., 2013). For both TIR-NB-type proteins no function in plant immunity has yet been shown. The candidates selected from the PPIN-1 analysis are summarized in Table 3.2 (page 84) together with MOS6-interactors found in in planta affinity purification experiments described in the following (3.2.3).

\subsubsection{Generation and characterization of stable transgenic Arabidopsis plants expressing 3xHA-Strepll tagged MOS6}

In parallel to in silico analysis of the Arabidopsis Interactome and Plant-Pathogen Immune network database (Mukhtar et al., 2011), an in planta affinity purification approach was conducted to identify new MOS6 cargo proteins and interaction partners involved in nucleocytoplasmic defense signaling and transport. For this, the mos6-1 mutant line was stably transformed with genomic MOS6 (ATG to Stop) fused to a C-terminal 3xHA-Strepll affinity-purification tag (MOS6-3xHA-SII). Transgenic expression was driven by either the endogenous MOS6 promoter (Np::MOS6, $1 \mathrm{~kb}$ upstream from the transcription start site) or the constitutively active Cauliflower Mosaic Virus double 355 promoter. The small eight amino acid Strepll-tag allows rapid one-step affinity purification of protein complexes from crude leaf extracts under very mild conditions (Witte et al., 2004). The triple HA epitope tag allows detection of the fusion protein via immunoblot analysis and can therefore be used to monitor interaction in co-immunoprecipitation experiments. Immunoblot analyses of total protein leaf extracts were used to verify expression of fulllength MOS6-3xHA-SII fusion proteins in multiple independent stable transgenic lines that were confirmed to be homozygous and to contain a single T-DNA insertion (Figure 3.15 A).

To test whether the full length MOS6-3xHA-SII fusion protein is functional, transgenic Arabidopsis lines were analyzed for their defense phenotype against Pst DC3000 ( $\triangle$ AvrPto/AvrPtoB). The increased susceptibility of the mos6-1 mutant could be complemented by transgenic expression of MOS6-3xHA-SII (Figure 3.15 B). This was true for both, lines that transgenically expressed MOS6::3xHA-SII under control of the native MOS6 promoter and lines expressing MOS6 under control of the 355 promoter. To obtain additional proof for the functionality of the MOS6-3xHA-SII fusion protein constructs, snc1 mos6-1 double mutants were transformed with Np::MOS6-3xHA-SII and 
A

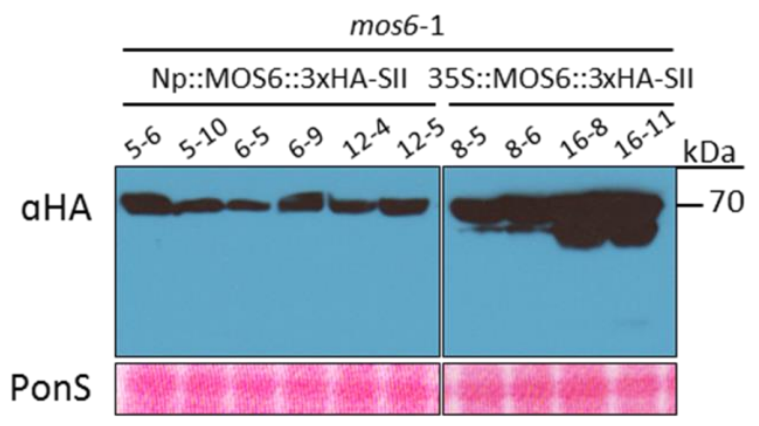

C
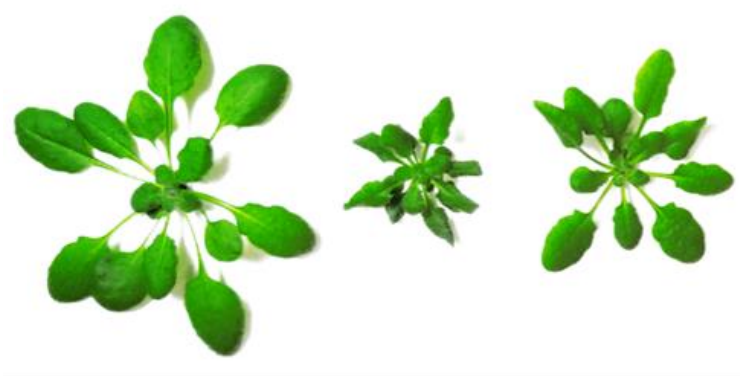

Col-0
B

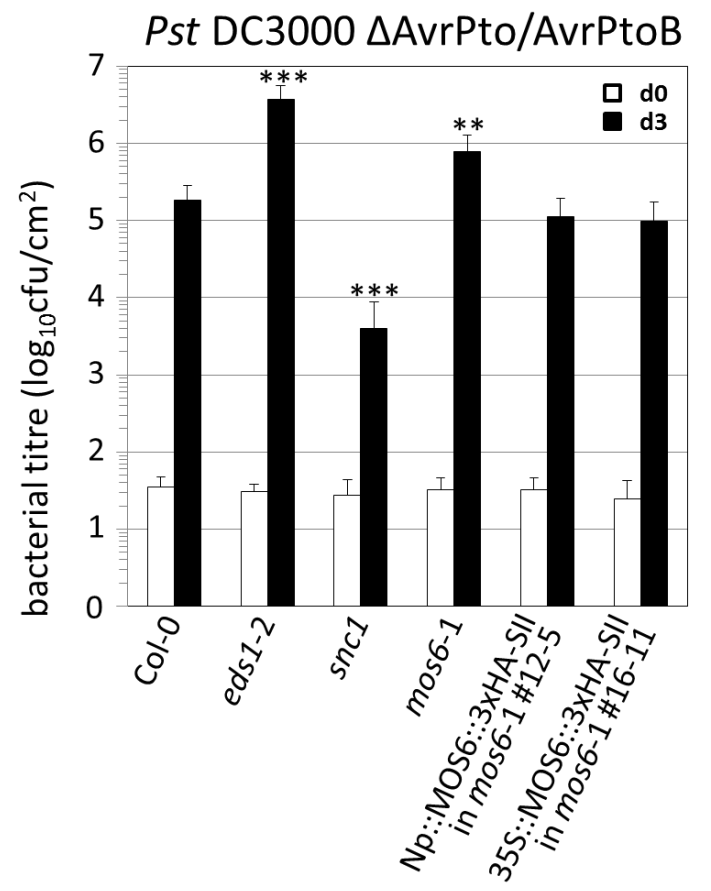

Figure 3.15 MOS6 fused to a 3xHA-SII tag complements mos6-1 susceptibility and phenotype in the snc1 auto-immune background. A) Immunoblot analyses of homozygous single insertion transgenic lines expressing MOS6::3xHA-SII in the mos6-1 background. Total protein extracts from leaf tissues of four-weekold T4 transgenic plants expressing either Np::MOS6::3xHA-SII or 35S::MOS6::3xHA-SII in mos6-1 background were used for immunoblot analysis. Proteins were separated on $10 \%$ SDS polyacrylamide gels and blotted onto nitrocellulose membranes. Membranes were probed with $\alpha \mathrm{HA}$ antibodies. Equal loading was monitored by staining the membrane with PonceauS (PonS). $\mathrm{Np}=$ native MOS6 promoter, $35 \mathrm{~S}=$ constitutive $35 \mathrm{~S}$ promoter. B) Transgenic expression of MOS6::3xHA-SII in mos6-1 background complements the mos6-1 phenotype of enhanced susceptibility towards mildly virulent Pst DC3000 $(\triangle$ AvrPto/AvrPtoB). The leaves of four-week-old T4 transgenic plants were vacuum-infiltrated with a bacteria suspension of $1 \times 10^{5} \mathrm{cfu} / \mathrm{mL}$. To quantify bacterial growth, leaf discs within the inoculated areas were taken immediately ( $d 0$ ) and three days after infection (d3). Bars represent means from two replicate samplings for $\mathrm{d} 0$ (white bars) and nine replicate samplings for $\mathrm{d}_{3}$ (black bars). Error bars show standard deviation and asterisks indicate statistical significance (t-test, $* * \mathrm{p}<0.01, * * * \mathrm{p}<0.001)$. snc1 and eds1-2 (Col eds1-2) are resistant and susceptible controls, respectively. Cfu = colony-forming units. This experiment was repeated twice with similar results. C) MOS6::3xHA-SII complements mos6-1 in the snc1 auto-immune background. Morphology of Col-0, snc1, snc1 mos6-1 and T4 transgenic plants expressing MOS6::3xHA-SII under control of the native MOS6 promoter (Np) in the snc1 mos6-1 background. Plants are four weeks old and were grown in parallel on soil. Scale bar $=1 \mathrm{~cm}$. 
35S::MOS6-3xHA-SII. Stable transgenic lines were generated and the plants growth phenotype was analyzed. The wild-type like growth of the snc1 mos6-1 double mutant was fully reverted back to snc1-like stunted morphology by expression of MOS6-3xHA-SII (Figure $3.15 \mathrm{C}$ ). This is true for Np::MOS6-3xHA-SII as well as for 35S::MOS6-3xHA-SII in snc1 mos6-1 (Figure 3.15, 35S::MOS6-3xHA-SII in snc1 mos6-1 not shown).

The fact that expression of MOS6-3xHA-SII re-established the snc1 mos6-1 double mutant phenotype back to the original snc1 auto-immune morphology indicates that this fusion protein is fully functional. Consistent with this, MOS6-3xHA-SII expression under control of the native promoter or the 355 promoter complemented the enhanced disease susceptibility of the mos6-1 single mutant against Pst DC3000 ( $\triangle$ AvrPto/AvrPtoB).

\subsubsection{In planta affinity purification of MOS6 interacting proteins}

To identify MOS6 cargo proteins and interaction partners involved in nucleocytoplasmic defense signaling, an in planta affinity purification approach was conducted. First, both stable transgenic Arabidopsis lines expressing MOS6-3xHA-SII under control of the native promoter (line \#12-5) or the 355 promoter (line \#16-11) in the mos6-1 background (Figure 3.15) were used to test efficiency of the Strepll-affinity purification protocol. Col-0 wildtype plants served as controls. StrepTactin ${ }^{\circledR}$-Sepharose beads (IBA, Göttingen) were used for Strepll-affinity purification according to Witte et al., (2004). The efficiency of MOS6-3xHA-SII purification from both transgenic lines was compared by SDS-PAGE and silver staining of the SDS gel (Figure 3. $16 \mathrm{~A}$ ). MOS6-3xHA-SII (circa $70 \mathrm{kDa}$ ) was purified from the MOS6-3xHA-SII over-expressing line but was barely detectable in extracts from the native promoter line and Col-0 in initial experiments (Figure 3. $16 \mathrm{~A}$ ). Because of efficient purification of MOS6-3xHA-SII from the over-expressing plants, this line was used for further optimization of the affinity purification. The binding yield of MOS6-3xHA-SII could be improved by using a StrepTactin ${ }^{\circledR}$ Macroprep resin (IBA, Göttingen).

Three-week-old MOS6-3xHA-SII over-expressing plants and Col-0 controls (expressing untagged MOS6) were inoculated with $H$. a. NOCO2 to induce interaction between MOS6 and potential defense-related interaction partners. Strepll-affinity purification was carried out 8 days post inoculation. Separation by SDS-PAGE and analysis by silver staining of SDS gels revealed several differential bands in the MOS6-3xHA-SII 
A

B

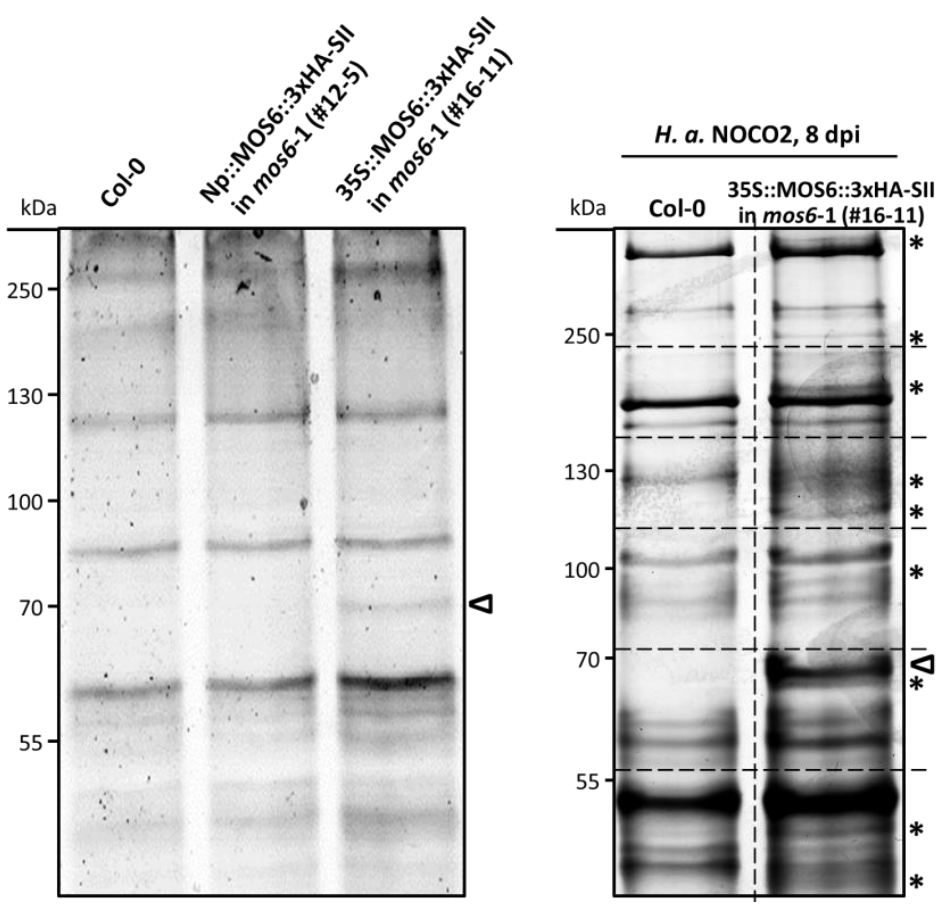

Figure 3.16 Identification of MOS6 associated proteins. A) Affinity-purification from a transgenic line expressing MOS6-3xHA-SII under control of the native MOS6 promoter ( $\mathrm{Np}, \# 12-5)$ was compared to a transgenic line over-expressing MOS6-3xHA-SII under control of the 35 S promoter (35S, \#16-11) and the wild-type control Col-0. StrepTactin ${ }^{\circledR}$ Sepharose was used for affinity purification from extracts from 4-week-old plants. Eluted proteins were separated by SDS-PAGE and silver stained. MOS6-3xHA-SII could be purified from plant line \#16-11 to amounts visible by silver-staining of the SDS gel. Arrow indicates MOS6-3xHA-SII containing band. Molecular weight markers in kilo Dalton (kDa) are shown left. B) MOS6$3 \times$ HA-SII-interacting proteins were efficiently isolated by StrepTactin Macroprep ${ }^{\circledR}$ affinity-purification from protein extracts derived from three-week-old leaf tissue of Hyaloperonospora arabidopsidis NOCO2 infected plants ( $8 \mathrm{dpi}$ ). Interacting proteins were eluted, separated by SDS-PAGE and silver stained. Shown are silver stained extracts from Col-0 control plants and 3xHA-SII tagged MOS6 overexpressing mos6-1 plants. Several differential bands were identified (marked by asterisks). Arrow indicates MOS6-3xHA-SII containing band. Lanes of silver stained extracts were cut into 6 pieces (dashed lines) for tryptic digestion. Digested samples were analyzed by LC-MS/MS. Molecular weight markers in kilo Dalton (kDa) are shown left.

over-expressing line that were absent in the Col-0 control (Figure $3.16 \mathrm{~B}$ ). Whole lanes of the silver-stained gel were cut into six pieces for tryptic in-gel digestion and subsequent LC-MS/MS analysis. Subtraction of peptide hits derived from LC-MS/MS-analyses of corresponding Col-0 samples from peptides purified from MOS6-3xHA-SII over-expressing plants yielded the proteins that putatively interacted with MOS6-3xHA-SII.

As expected, peptides corresponding to transgenically expressed MOS6-3xHA-SII were found in all extracts in a high abundance. A list of 56 proteins that exclusively copurified with MOS6-3xHA-SII in at least two of three independent biological experiments is shown in Table 3.1. Proteins were selected for further analyses based on following criteria: i) prediction of subcellular localization in the nucleus and/or cytoplasm, 
ii) transcription in rosette leaf tissue and iii) indication for involvement in nucleocytoplasmic transport.

Table 3.1 Proteins that exclusively co-purified with MOS6-3xHA-SII. Proteins listed here were identified in at least two of three independent experiments. Identified proteins that were absent in control samples are sorted according to total number of peptide-spectrum matches (PSMs) across the three experiments. Twoweek-old plants expressing MOS6-3xHA-SII in the mos6-1 background were infected with $\mathrm{H}$. a. NOCO2 and leaf material for affinity purification was harvested $8 \mathrm{dpi}$ (three-week-old plant material). Proteins that were chosen for further analysis and MOS6 are highlighted in bold/underlined.

\begin{tabular}{|c|c|c|c|c|c|c|c|c|c|c|c|c|c|c|c|c|}
\hline \multirow[b]{2}{*}{ Accession } & \multirow[b]{2}{*}{ Description } & \multicolumn{5}{|c|}{ Experiment 1} & \multicolumn{5}{|c|}{ Experiment 2} & \multicolumn{5}{|c|}{ Experiment 3} \\
\hline & & 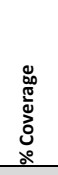 & 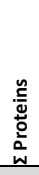 & 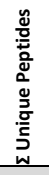 & $\begin{array}{l}\tilde{o} \\
\frac{0}{0} \\
\frac{0}{0} \\
\frac{0}{w}\end{array}$ & $\sum_{\substack{n \\
\omega}}^{n}$ & 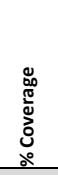 & 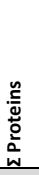 & 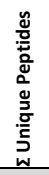 & 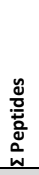 & $\sum_{\omega=}^{n}$ & 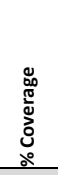 & 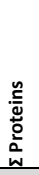 & 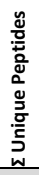 & 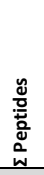 & $\sum_{\substack{n \\
\omega}}^{n}$ \\
\hline AT4G02150 & IMP- $\alpha 3 /$ MOS6 & 52,5 & 9 & 20 & 30 & 1215 & 26,2 & 3 & 13 & 14 & 60 & 40,3 & 1 & 16 & 19 & 154 \\
\hline AT4G17330 & G2484-1 protein & 27,5 & 1 & 13 & 56 & 191 & 16,5 & 3 & 27 & 27 & 38 & 16,1 & 1 & 24 & 24 & 90 \\
\hline AT5G46070 & $\begin{array}{l}\text { Guanylate-binding family } \\
\text { protein }\end{array}$ & 53,4 & 2 & 26 & 71 & 235 & 7,4 & 2 & 7 & 7 & 9 & 19,0 & 1 & 19 & 19 & 42 \\
\hline АТЗG08943 & IMPß, putative & 34,6 & 2 & 22 & 30 & 190 & 19,6 & 1 & 16 & 16 & 36 & 23,2 & 1 & 16 & 16 & 49 \\
\hline AT1G52360 & Coatomer, beta' subunit & 32,5 & 2 & 4 & 33 & 138 & 11,9 & 3 & 2 & 10 & 36 & 6,1 & 6 & 3 & 5 & 8 \\
\hline АТЗG09630 & Ribosomal protein L4/L1 family & 53,2 & 11 & 5 & 26 & 75 & 12,8 & 2 & 5 & 5 & 5 & 40,2 & 1 & 7 & 16 & 99 \\
\hline AT1G64790 & ILITYHIA & 24,8 & 2 & 15 & 67 & 164 & & & & & & 3,3 & 2 & 8 & 8 & 12 \\
\hline AT1G04820 & tubulin alpha- 4 chain & 37,8 & 3 & 3 & 19 & 122 & & & & & & 29,8 & 2 & 3 & 9 & 48 \\
\hline АТ3G18780 & actin 2 & 42,6 & 2 & 1 & 18 & 153 & & & & & & 14,8 & 3 & 2 & 4 & 16 \\
\hline AT5G02500 & heat shock $70 \mathrm{kDa}$ protein $1 / 8$ & & & & & & 37,2 & 3 & 3 & 21 & 69 & 34,6 & 1 & 6 & 19 & 95 \\
\hline AT5G53480 & KPNB1/IMP-B2 & 26,2 & 1 & 19 & 19 & 64 & 22,0 & 2 & 17 & 17 & 38 & 18,7 & 1 & 14 & 14 & 45 \\
\hline AT1G79990 & structural molecules & 32,8 & 3 & 5 & 32 & 100 & 8,6 & 4 & 3 & 7 & 15 & 7,9 & 3 & 3 & 6 & 11 \\
\hline AT4G28470 & $\begin{array}{l}26 \mathrm{~S} \text { proteasome regulatory } \\
\text { subunit S2 1B }\end{array}$ & 35,9 & 1 & 2 & 30 & 98 & 12,2 & 2 & 3 & 10 & 12 & 12,5 & 1 & 2 & 9 & 11 \\
\hline AT2G28290 & $\begin{array}{l}\text { Nucleoside triphosphate } \\
\text { hydrolases superfamily protein }\end{array}$ & 20,0 & 12 & 1 & 68 & 104 & & & & & & 1,6 & 3 & 4 & 4 & 8 \\
\hline AT3G54760 & $\begin{array}{l}\text { dentin sialophosphoprotein- } \\
\text { related }\end{array}$ & 40,7 & 2 & 15 & 28 & 91 & 17,9 & 2 & 10 & 10 & 14 & 4,9 & 1 & 2 & 2 & 3 \\
\hline АТЗG10650 & NUP1/NUP136 & 32,0 & 1 & 11 & 43 & 93 & & & & & & 6,5 & 1 & 6 & 6 & 11 \\
\hline AT4G29060 & $\begin{array}{l}\text { elongation factor Ts family } \\
\text { protein }\end{array}$ & & & & & & 32,0 & 6 & 27 & 27 & 87 & 11,0 & 1 & 7 & 7 & 14 \\
\hline AT5G56010 & heat shock protein $81-3$ & 45,5 & 5 & 9 & 43 & 89 & & & & & & 8,4 & 4 & 5 & 5 & 9 \\
\hline AT1G14850 & NUP155 & 22,5 & 1 & 6 & 31 & 52 & & & & & & 25,4 & 2 & 2 & 9 & 40 \\
\hline AT1G47900 & $\begin{array}{l}\text { Plant protein of unknown } \\
\text { function (DUF869) }\end{array}$ & 34,4 & 2 & 1 & 42 & 76 & & & & & & 5,6 & 2 & 4 & 4 & 7 \\
\hline AT1G67140 & HEAT repeat-containing protein & 18,7 & 3 & 6 & 39 & 80 & & & & & & 1,4 & 3 & 2 & 2 & 2 \\
\hline AT5G22770 & alpha-adaptin & 32,1 & 2 & 1 & 36 & 75 & & & & & & 6,3 & 2 & 5 & 5 & 7 \\
\hline
\end{tabular}




\begin{tabular}{|c|c|c|c|c|c|c|c|c|c|c|c|c|c|c|c|c|}
\hline AT3G55220 & $\begin{array}{l}\text { Polyadenylation specificity } \\
\text { factor A subunit protein }\end{array}$ & 25,5 & 1 & 8 & 30 & 75 & 3,1 & 1 & 3 & 3 & 3 & 2,7 & 1 & 2 & 2 & 2 \\
\hline AT2G47940 & DEGP protease 2 & 27,6 & 2 & 7 & 23 & 70 & 3,6 & 2 & 2 & 2 & 2 & 7,6 & 2 & 4 & 4 & 6 \\
\hline AT1G52380 & NUP50 & 40,5 & 1 & 13 & 20 & 65 & 32,3 & 1 & 10 & 10 & 11 & & & & & \\
\hline AT2G16950 & TRN1 & 26,4 & 2 & 8 & 27 & 59 & 12,9 & 4 & 11 & 11 & 17 & & & & & \\
\hline AT3G62310 & RNA helicase family protein & 31,8 & 1 & 1 & 26 & 69 & & & & & & 7,6 & 1 & 4 & 4 & 6 \\
\hline AT3G57890 & $\begin{array}{l}\text { Tubulin binding cofactor } \mathrm{C} \\
\text { domain-containing protein }\end{array}$ & 35,0 & 4 & 9 & 23 & 69 & & & & & & 5,2 & 2 & 2 & 2 & 3 \\
\hline AT2G18940 & $\begin{array}{l}\text { Tetratricopeptide repeat (TPR)- } \\
\text { like superfamily protein }\end{array}$ & 33,5 & 1 & 1 & 29 & 69 & & & & & & 3,2 & 1 & 2 & 2 & 2 \\
\hline AT4G31490 & coatomer subunit beta- 2 & & & & & & 18,7 & 4 & 17 & 17 & 58 & 9,5 & 1 & 1 & 9 & 13 \\
\hline AT1G21630 & $\begin{array}{l}\text { Calcium-binding EF hand family } \\
\text { protein }\end{array}$ & 23,7 & 2 & 1 & 30 & 64 & 3,6 & 3 & 3 & 3 & 3 & & & & & \\
\hline AT3G22520 & unknown protein & 25,5 & 1 & 1 & 18 & 39 & 3,8 & 1 & 2 & 2 & 2 & 22,8 & 1 & 11 & 11 & 25 \\
\hline AT4G34430 & DNA-binding family protein & 32,6 & 3 & 1 & 30 & 60 & & & & & & 3,9 & 3 & 3 & 3 & 5 \\
\hline AT1G48900 & $\begin{array}{l}\text { Signal recognition particle, } \\
\text { SRP54 subunit protein }\end{array}$ & 56,6 & 3 & 2 & 29 & 53 & & & & & & 18,3 & 2 & 6 & 6 & 11 \\
\hline AT5G51070 & Clp ATPase & 25,1 & 1 & 1 & 21 & 48 & 3,9 & 1 & 2 & 3 & 3 & 3,9 & 1 & 2 & 3 & 13 \\
\hline AT5G64270 & splicing factor, putative & 20,7 & 1 & 1 & 30 & 53 & & & & & & 3,0 & 1 & 3 & 3 & 5 \\
\hline AT2G34040 & Apoptosis inhibitory protein 5 & 33,8 & 2 & 1 & 22 & 47 & & & & & & 7,7 & 2 & 3 & 3 & 5 \\
\hline AT1G18450 & actin-related protein 4 & 33,1 & 2 & 2 & 15 & 40 & & & & & & 11,8 & 1 & 4 & 4 & 6 \\
\hline AT3G09200 & $\begin{array}{l}\text { Ribosomal protein L10 family } \\
\text { protein }\end{array}$ & 28,8 & 4 & 5 & 10 & 22 & & & & & & 25,1 & 2 & 7 & 7 & 23 \\
\hline AT5G13680 & IKI3 family protein & 21,1 & 1 & 1 & 27 & 40 & & & & & & 3,6 & 1 & 4 & 4 & 5 \\
\hline AT1G54920 & unknown protein & 17,6 & 3 & 5 & 16 & 36 & & & & & & 3,3 & 3 & 2 & 2 & 6 \\
\hline AT5G55230 & $\begin{array}{l}\text { microtubule-associated } \\
\text { proteins } 65-1\end{array}$ & 22,2 & 2 & 2 & 14 & 40 & & & & & & 3,8 & 2 & 2 & 2 & 2 \\
\hline AT3G42170 & $\begin{array}{l}\text { BED zinc finger domain- } \\
\text { containing protein }\end{array}$ & & & & & & 10,6 & 2 & 6 & 6 & 28 & 12,4 & 1 & 6 & 6 & 13 \\
\hline AT1G20370 & $\begin{array}{l}\text { Pseudouridine synthase family } \\
\text { protein }\end{array}$ & 32,2 & 3 & 2 & 19 & 33 & & & & & & 7,0 & 6 & 3 & 3 & 5 \\
\hline AT5G24350 & uncharacterized protein & & & & & & 5,0 & 2 & 10 & 10 & 19 & 5,7 & 2 & 11 & 11 & 17 \\
\hline AT1G27750 & nucleic acid binding & 19,2 & 1 & 1 & 20 & 29 & & & & & & 3,3 & 1 & 3 & 3 & 5 \\
\hline AT5G09390 & CD2-binding protein-related & 30,4 & 2 & 4 & 12 & 31 & & & & & & 10,9 & 2 & 3 & 3 & 3 \\
\hline AT3G22990 & $\begin{array}{l}\text { ARM repeat superfamily } \\
\text { protein }\end{array}$ & 19,8 & 1 & 1 & 12 & 31 & & & & & & 6,5 & 1 & 2 & 2 & 2 \\
\hline AT5G43960 & NTF2 & 26,9 & 2 & 3 & 8 & 28 & 9,0 & 2 & 3 & 3 & 3 & 7,4 & 2 & 2 & 2 & 2 \\
\hline AT2G25010 & $\begin{array}{l}\text { Aminotransferase-like family } \\
\text { protein }\end{array}$ & 23,4 & 1 & 1 & 14 & 23 & & & & & & 11,6 & 1 & 5 & 5 & 9 \\
\hline AT3G03630 & cysteine synthase 26 & 24,5 & 1 & 1 & 9 & 21 & & & & & & 6,2 & 1 & 2 & 2 & 4 \\
\hline AT5G40200 & DegP protease 9 & 18,9 & 1 & 1 & 11 & 16 & & & & & & 6,6 & 1 & 4 & 4 & 7 \\
\hline AT1G04170 & $\begin{array}{l}\text { eukaryotic translation initiation } \\
\text { factor } 2 \text { gamma subunit }\end{array}$ & 25,0 & 3 & 2 & 14 & 20 & & & & & & 6,2 & 1 & 2 & 2 & 2 \\
\hline AT3G24430 & ATP binding & 30,1 & 1 & 1 & 13 & 17 & & & & & & 4,5 & 1 & 2 & 2 & 4 \\
\hline AT1G30470 & $\begin{array}{l}\text { SIT4 phosphatase-associated- } \\
\text { like protein }\end{array}$ & & & & & & 12,7 & 4 & 8 & 8 & 14 & 5,1 & 3 & 2 & 2 & 2 \\
\hline AT4G38225 & unknown protein & 15,9 & 3 & 1 & 4 & 6 & & & & & & 10,1 & 3 & 2 & 2 & 2 \\
\hline
\end{tabular}


Similar to the evaluation of candidate MOS6-interactors from in silico analyses (3.2.1) predicted subcellular localization and rosette leaf expression were analyzed by use of bioinformatics tools (SUBA3: Heazlewood et al., 2007; Tanz et al., 2013; Heazlewood et al., 2005, Yloc+: Briesemeister et al., 2010a, 2010b, eFP-browser: Winter et al., 2007, Genevestigator: Hruz et al., 2008). Among the 56 proteins that exclusively co-purified with MOS6-3xHA-SII (Table 3.1), 4 karyopherins and 3 nucleoporins were selected for further analysis (Table 3.2).

Peptides corresponding to two IMP- $\beta$ proteins were found in high abundance. IMP- $\beta$ s are possibly the most frequent interaction partners of MOS6 because translocation through the nuclear pore complex is mediated only when the IBB domain of the cargo-bound IMP- $\alpha$ bridges the interaction with IMP- $\beta$. Therefore, interaction of the IMP- $\alpha 3$ homolog MOS 6 with one or more IMP- $\beta$ isoforms was expected. Both IMP- $\beta$ S (KPNB1/IMP- $\beta 2$ and a putative IMP- $\beta$ protein named IMP- $\beta$ _a in this work) were selected for further characterization based on their involvement in nuclear transport. Additionally, a protein very similar to IMP- $\beta$ _a was also included in further experiments (named IMP- $\beta$ _b). Other karyopherins selected for further analysis are NUCLEAR TRANSPORT FACTOR 2 (NTF2) and TRANSPORTIN 1 (TRN1). NTF2 proteins bind to both RanGDP and FxFG repeat-containing nucleoporins and single-stranded RNAs (Bhattacharya and Steward, 2002; Ribbeck et al., 1998; Quimby et al., 2001). TRN1 is involved in the nuclear import of the RNA-binding protein GRP7 (Ziemienowicz et al., 2003). Interestingly, in addition to regulation of response to cold and other environmental stresses, GRP7 plays a role in plant innate immunity (Lee et al., 2012). Three nucleoporins (NUPs) were identified as MOS6 interaction partners: NUP1/NUP136, NUP50 and NUP155 (Table 3.2). NUP1/NUP136 is involved in regulating nuclear pore morphology and mRNA export (Tamura and Hara-Nishimura, 2011). NUP50 was found to interact with IMP- $\alpha 1,2,3,4,5$ and 6, Ran1, NUP155 and LAZARUS 5 (LAZ5, Tamura and Hara-Nishimura, 2011; Tamura et al., 2010). LAZ5 is a TIR-class NB-LRR R protein with sequence similarity to RPS4, a TIRNB-LRR R protein conferring resistance to Pst DC3000 expressing AvrRPS4 and LAZ5 is required for manifestation of auto-immune phenotypes in the lesion-mimic mutant acd11 (Palma et al., 2010). Whereas NUP50 and NUP1/NUP136 are nuclear FG-NUPs of the basket, NUP155 is located in the inner ring of the NPC (Grossmann et al., 2012). 
In summary, a total of thirteen MOS6-interaction candidates were chosen for further analysis from the in silico approach (3.2.1) and the in planta affinity purification experiments. These thirteen candidates are listed in Table 3.2 according to their functional category: nucleoporins, karyopherins, defense-related transcription factors and putative defense related proteins of the TIR-NBS-LRR family.

Table 3.2 MOS6 interaction candidates selected for further analysis. MOS6-interaction candidates were selected based on the presence of a NLS and/or predicted nuclear localization and their expression in rosette leaves. For further details see text. Candidates are listed according to their functional category. nuc $=$ nucleus, $c y t=$ cytosol, mem $=$ membrane, n.i. $=$ no information available.

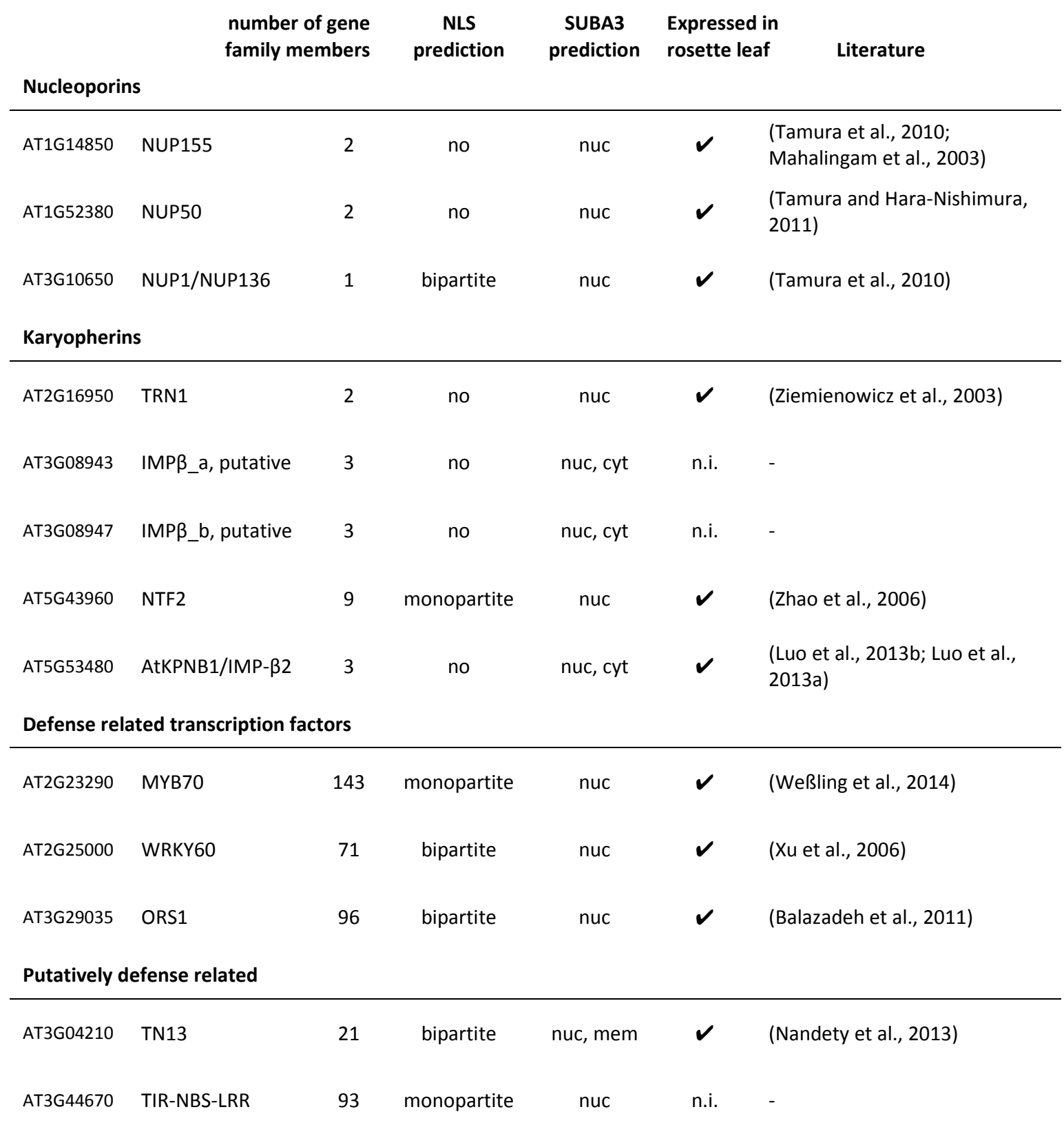




\subsubsection{Validation of MOS6 interactions via Agrobacterium-mediated transient expression in N. benthamiana and Co-immunoprecipitation}

The well-established Agrobacterium-mediated transient expression system in Nicotiana benthamiana was utilized to validate interaction of the thirteen selected candidates (Table 3.2) with MOS6. In addition, the transient expression system was employed to test whether the closest homolog of MOS6, IMP- $\alpha 6$ (Figure 3.3), also interacts with these candidates. For this purpose genomic sequences (ATG to Stop) were amplified from Col-0 gDNA. In the case of TRN1, the coding sequence was amplified from Col-0 cDNA. All candidates were cloned into expression vectors for generation of cCFP-tagged fusion proteins. cCFP-tagged fusion proteins were transiently co-expressed in $\mathrm{N}$. benthamiana under control of the $35 \mathrm{~S}$ promoter together with $35 \mathrm{~S}$ promoter driven MOS6-3xHA-SII or IMP- $\alpha 6-3 \times \mathrm{HA}-\mathrm{SII}$, respectively. A construct expressing a tandem YFP-YFP was used as negative control to monitor possible binding of 3xHA-SII-tagged MOS6 or IMP- $\alpha 6$ to YFP. This was done because YFP and CCFP are highly similar proteins that only differ in two amino acids (Zhang et al., 2002; Lippincott-Schwartz and Patterson, 2003). Two days after Agrobacterium infiltration into $N$. benthamiana leaves, leaf tissues were harvested and used for Co-immunoprecipitation (CoIP). ColPs were carried out three times in independent biological experiments using GFP-Trap ${ }^{\circledR}$ coupled to magnetic particles (Chromotec). GFP-Trap ${ }^{\circledR}$ specifically binds GFP and its highly similar derivatives such as cCFP and YFP. To monitor the presence of fusion proteins after transient expression, total protein extracts were generated from input fractions of ColP experiments and probed with aGFP (for cCFP-tagged candidate fusion proteins) or aHA (for MOS6-3xHA-SII and

Figure 3.17 on page 86: Interaction of candidates with MOS6 but not with IMP- $\alpha 6$ could be verified. MOS6-3xHA-SII (A) or its closest homolog IMP- $\alpha 6-3 \times \mathrm{HA}-\mathrm{SII}$ (B) were transiently co-expressed with the indicated CCFP-tagged candidate MOS6-interactors in N. benthamiana. 48h post infiltration the candidatecCFP proteins were immunoprecipitated using GFP-Trap ${ }^{\circledR}$ magnetic particles (immunoprecipitate). Coimmunoprecipitation of MOS6-3xHA-SII (A) or IMP- $\alpha 6-3 x H A-S I I$ (B) was detected by aHA immunoblots. Experiments were repeated three times and representative results from these experiments are summarized in this figure. For simplification, representative mock and YFP-YFP controls are shown at the left. YFP-YFP was used as negative control to monitor possible binding of 3xHA-SII-tagged MOS6 or IMP- $\alpha 6$ to YFP which is highly similar to CCFP (Lippincott-Schwartz and Patterson, 2003; Zhang et al., 2002). The top two panels shows total protein extracts (input) and the bottom two panels show aGFP-immunoprecipitates probed with $\alpha$ GFP or $\alpha H A$. Proteins were separated on $10 \%$ SDS polyacrylamide gels and blotted on nitrocellulose membranes. Membranes were probed with aGFP or aHA antibodies. Protein amounts were monitored by Ponceau S (PonS) staining of the membrane. All samples were co-infiltrated with a third Agrobacterium strain carrying the p19 gene of tomato bushy stunt virus (TBSV), that prevents the onset of posttranscriptional gene silencing in the infiltrated tissues to allow high level of transient expression (Voinnet et al., 2003). mock = Agrobacterium carrying p19 alone, $g=$ genomic, $c=$ coding sequence. 
A

\begin{tabular}{cccc} 
cCFP-tagged & & \\
\hline & Karyopherins & $\begin{array}{c}\text { Transcription } \\
\text { factors }\end{array}$ & $\begin{array}{c}\text { TIR-NBS } \\
\text { proteins }\end{array}$ \\
Nucleoporins & &
\end{tabular}
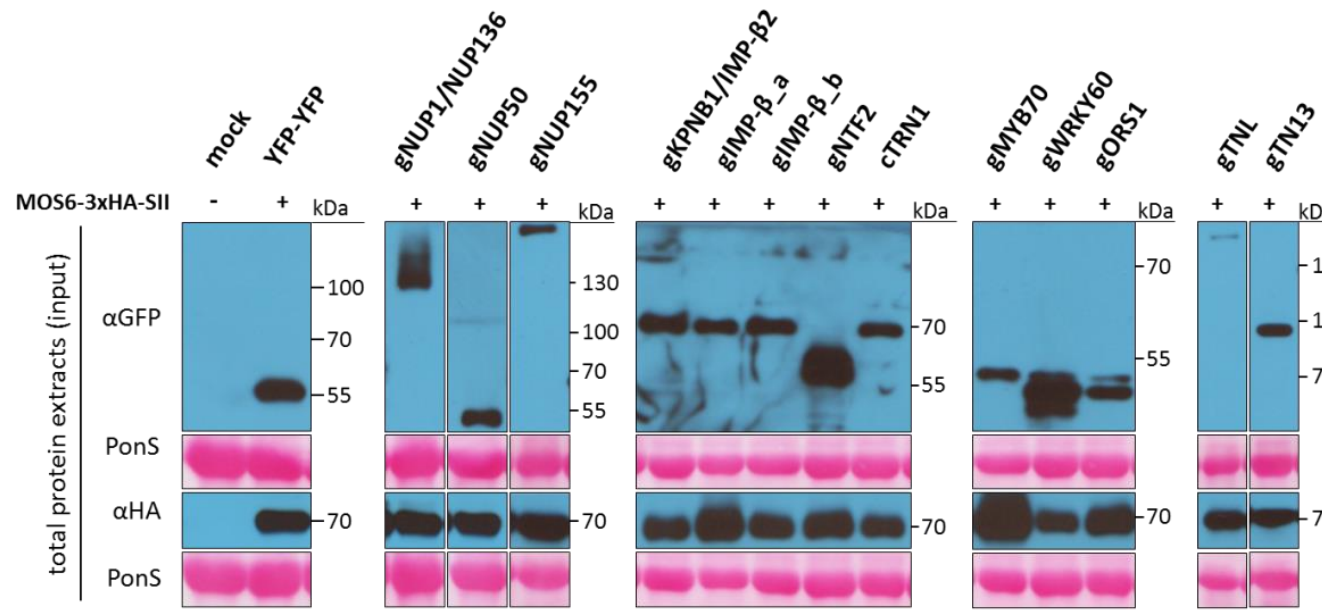

$++\quad+\mathrm{kDa}$
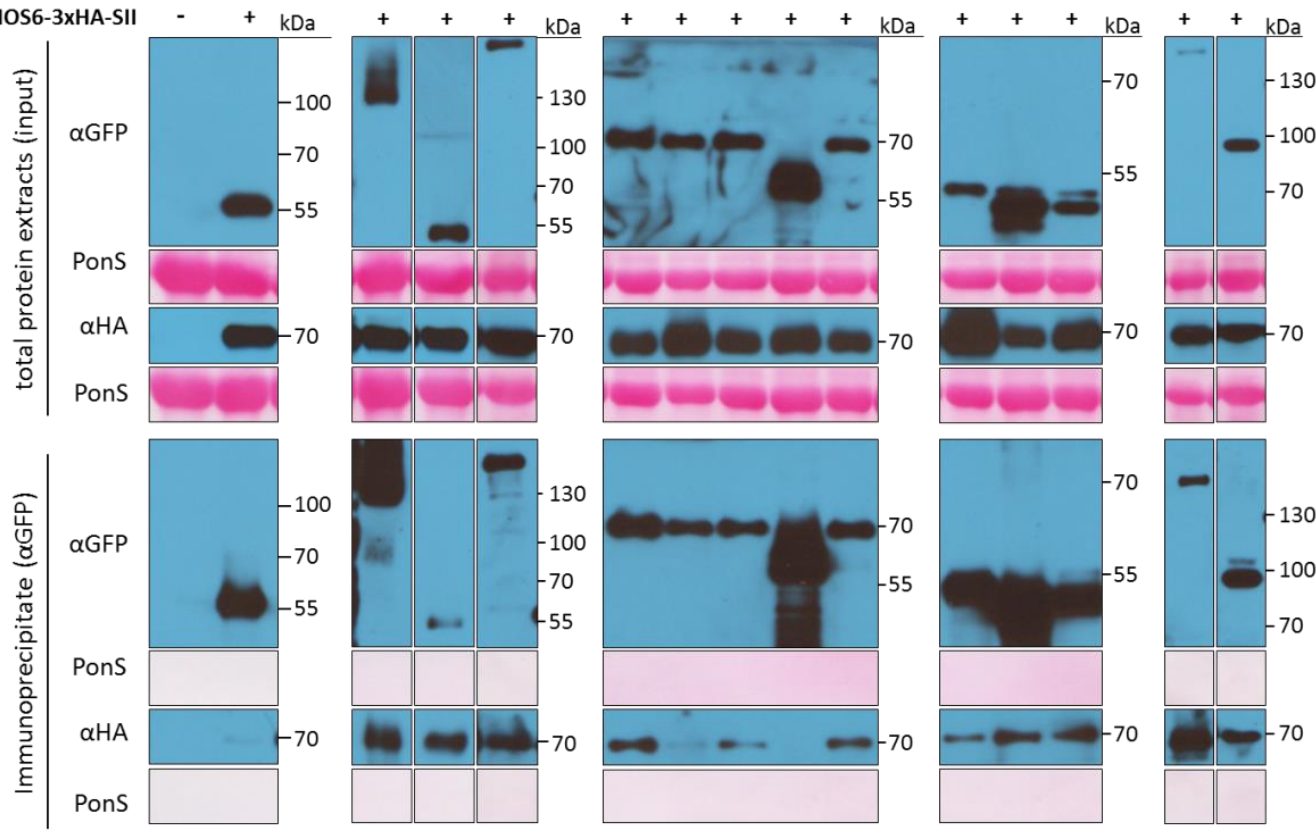

B

cCFP-tagged
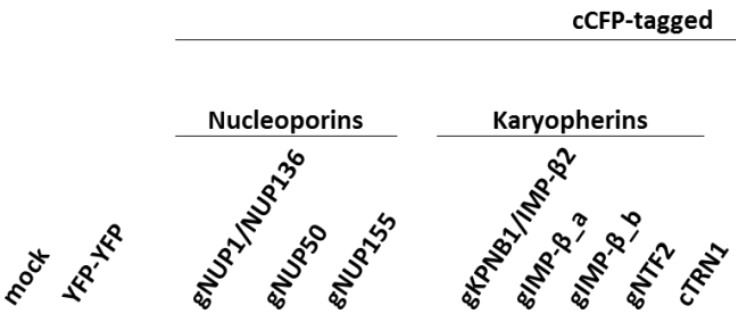

Transcription

TIR-NBS

IMP- $\alpha 6-3 \times$ HA-SII -
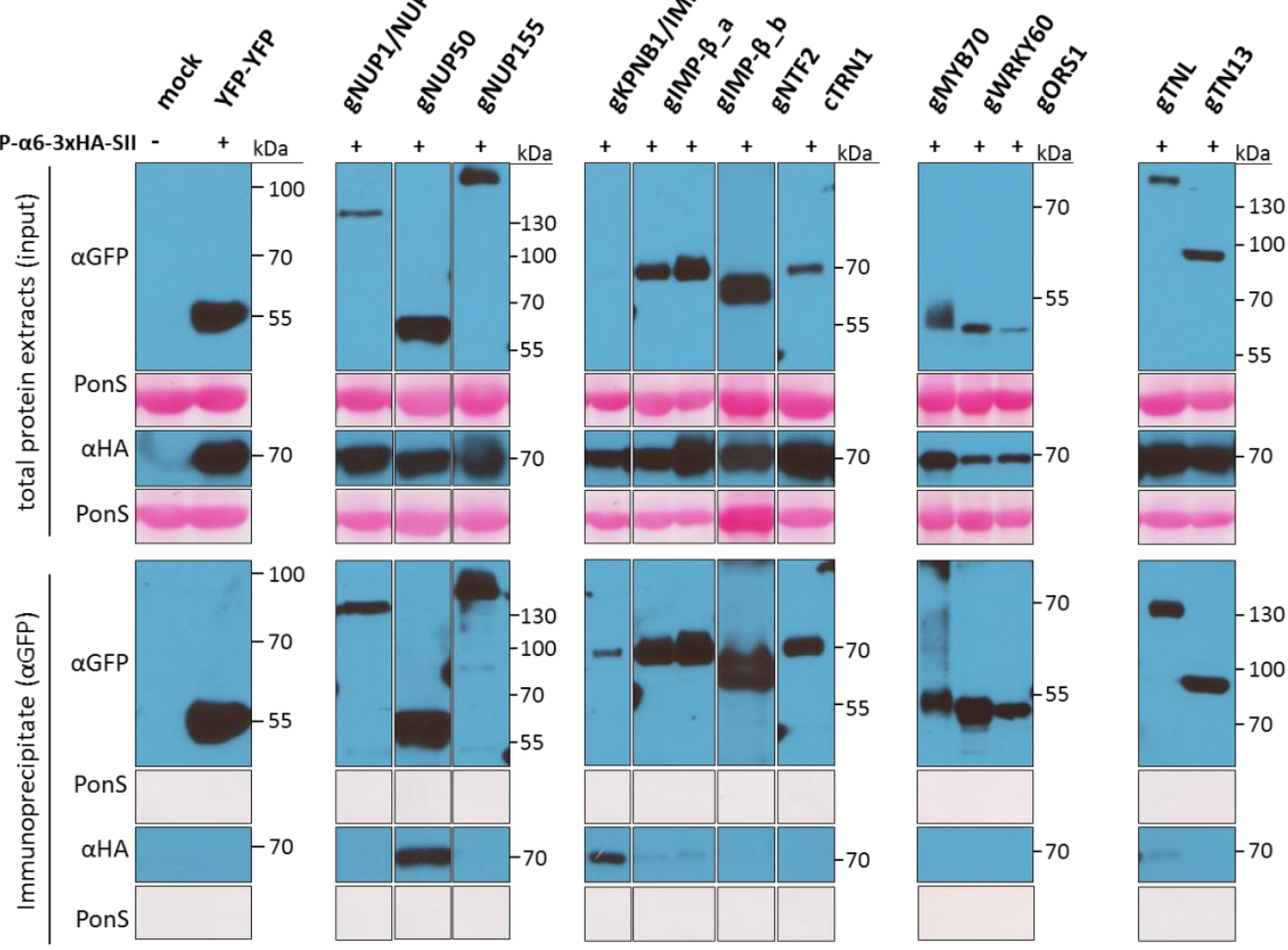
IMP- $\alpha 6-3 \times \mathrm{HA}-\mathrm{SII}$ ) in immunoblot analyses (Figure 3.17, top panels). Analysis of immunoprecipitated samples by aGFP immunoblot was used to monitor efficient purification of candidate-cCFP fusion proteins from transiently expressing N. benthamiana leaf tissue. Detection of protein bands corresponding either to MOS63xHA-SII or IMP- $\alpha 6-3 \times H A-S I I$ with $\alpha \mathrm{HA}$ was used to reveal co-immunoprecipitation with cCFP-tagged candidates (Figure 3.17, bottom panels).

MOS6-3xHA-SII successfully co-immunoprecipitated with all fusion proteins tested here, except NTF2-cCFP (Figure 3.17 A). Very weak interaction with MOS6 was detected with one of the putative IMP- $\beta$ homologues, IMP- $\beta$ _a. NUP50-cCFP and KPNB1/IMP- $\beta 2-c C F P \quad$ co-immunoprecipitated IMP- $\alpha 6-3 \times H A-S I I$ (Figure 3.17 B). Additionally, for both putative IMP- $\beta$ homologues and the TNL-fusion protein faint IMP- $\alpha 6-3 \times \mathrm{HA}-\mathrm{SII}$ containing bands were detected in the immunoprecipitates via $\alpha \mathrm{HA}$ western blot. The co-expressed YFP-YFP fusion protein served as a negative control and no protein bands corresponding to MOS6-3xHA-SII or IMP- $\alpha 6-3 \times \mathrm{HA}-\mathrm{SII}$ were visible in these samples, although YFP-YFP could efficiently be immunoprecipitated.

Taken together, these ColP results confirmed that NUP155, NUP50, NUP1/NUP136, TRN1, IMP- $\beta$ _b putative, AtKPNB1/IMP- $\beta 2$, MYB70, WRKY60, AT3G29035/ORS1, TNL and TN13 interact with MOS6 in planta. NTF2 did not interact with MOS6 and IMP- $\beta$ _a showed very weak interaction. For the closest MOS6 homolog, IMP$\alpha 6$, only interactions with NUP50, AtKPNB1/IMP- $\beta 2$, both IMP- $\beta$ like proteins and the TNL-type protein could be shown. The interaction with both IMP- $\beta$ like and the TNL-type protein appeared to be rather weak. This suggests that MOS6 has both selective and partially overlapping functions with its closest homolog, IMP- $\alpha 6$, in nuclear protein import, transport complex formation with its IMP- $\beta$ co-receptor and possibly its route through the NPC.

\subsubsection{Reverse genetic analysis of candidate MOS6 interactors in pathogen defense}

To assess the involvement of MOS6-interactors in plant immunity, reverse-genetic analyses were conducted. T-DNA insertion mutants of MOS6-interactor candidates (Table 3.2) were obtained from the European Arabidopsis Stock Centre (Scholl et al., 2000) and homozygous lines were isolated via PCR-based genotyping for further analysis. For 
A
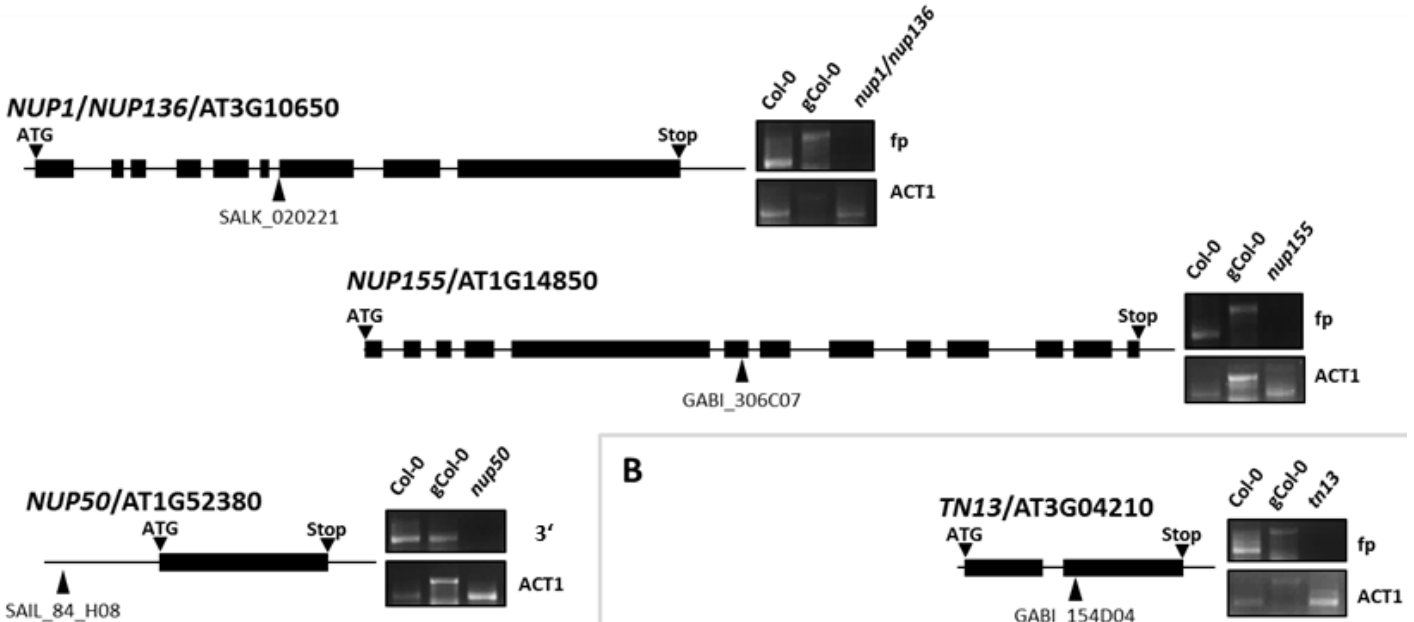

C
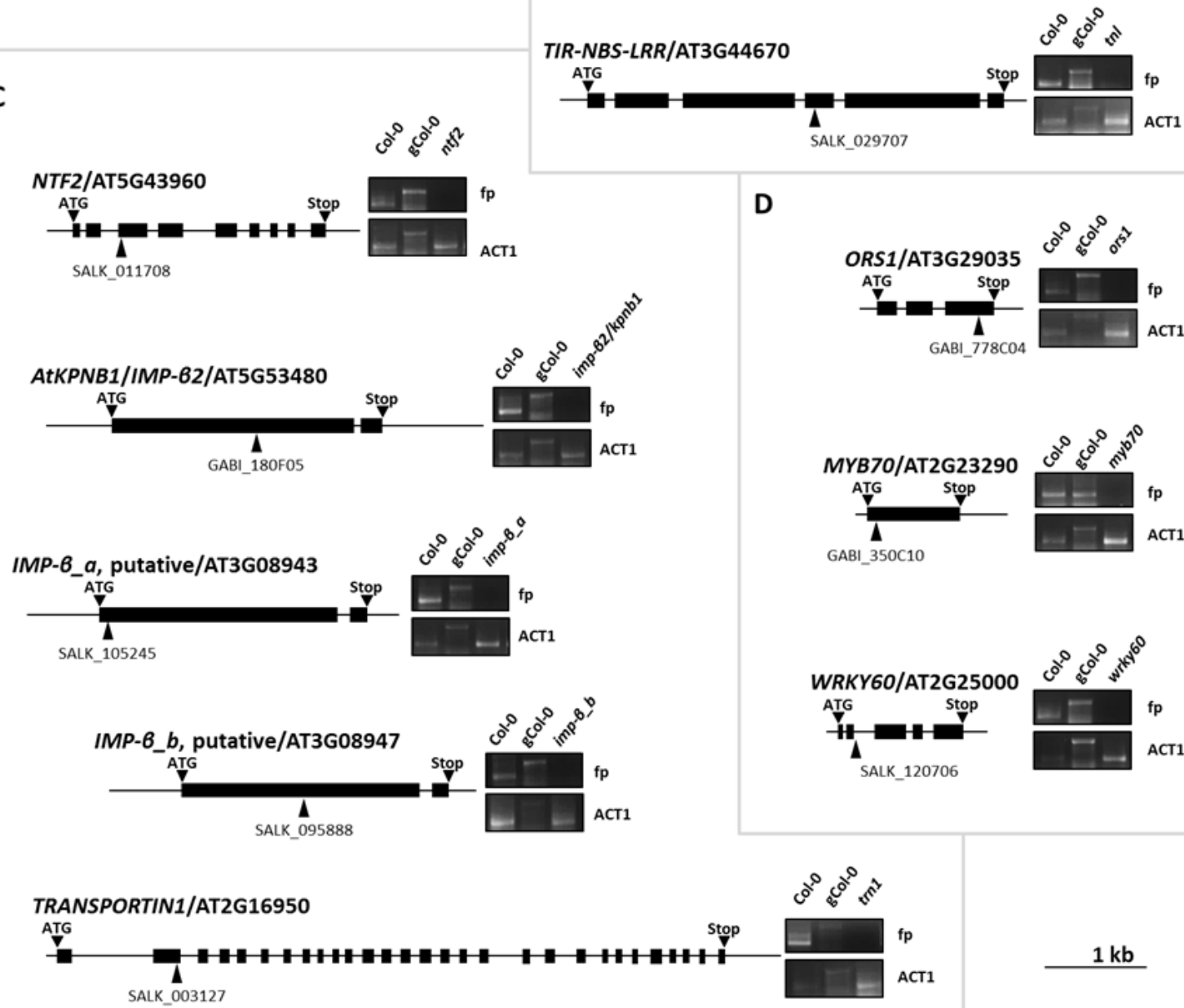

$1 \mathrm{~kb}$

Figure 3.18 Schematic structures of genes encoding candidate MOS6 interactors. A) Nucleoporins. B) TIRNBS domain containing proteins. C) Karyopherins. D) Transcription factors. Exons are represented as black boxes, introns as solid lines. Start and Stop codons are labeled as ATG or Stop above the gene structures. Positions of T-DNA insertions are indicated with triangles below the gene structures. Semi-quantitative RT-PCRs for the respective genes are shown next to the gene structures. Col-0 was used as wild-type control. gCol-0 (genomic Col-0 DNA) was used as control for genomic contamination. Flanking primers (fp) were used to amplify fragments from cDNA, confirming disruption of functional transcripts. Primer combinations were designed to be located in exons and span at least one intron of the tested gene to monitor potential contamination by genomic DNA based on the size of PCR-fragments. This was not possible for Nup50 and primers align in the single exon $3^{\prime}$ of the T-DNA. PCR products were analyzed by agarose gel electrophoresis and ethidium bromide staining. 
WRKY60, the previously published line SALK_120706 was used (Chen et al., 2010). The schematic gene structures of MOS6-interactors and the position of T-DNA insertions are depicted in Figure 3.18. Initially, two independent T-DNA insertion lines for each candidate gene were ordered if available. Homozygous lines were tested for disruption of functional transcripts via RT-PCR using cDNA-specific primers flanking the T-DNA insertion sites. Of these, only the lines with no residual transcripts detectable in RT-PCR were subsequently chosen for further functional analyses.

\subsubsection{A T-DNA insertion in the TIR-NBS gene TN13 is more susceptible to Pst DC3000 ( $\triangle$ AvrPto/AvrPtoB) but does not suppress the snc1 growth phenotype}

Loss of MOS6 results in enhanced susceptibility against the mildly virulent Pseudomonas strain Pst DC3000 ( $\triangle$ AvrPto/AvrPtoB, Figure 3.2). To analyze the genetic requirement of the candidate MOS6 interactors in plant immunity, the whole set of mutants depicted in Figure 3.18 was inoculated with this Pst strain. The mos6-1 mutant served as control for increased susceptibility and the eds1-2 mutant (Col eds1-2) was used as hyper-susceptible control. Resistance against Pst DC3000 ( $\triangle$ AvrPto/AvrPtoB) is significantly compromised in mos6-1, but not in any candidate mutant except for tn13 (Figure 3.19 A and B) that shows enhanced susceptibility against this mildly virulent Pst strain to an extent comparable with mos6-1. These results suggest that the in planta MOS6 interactor TN13, a TIR-NBS protein, is involved in basal resistance against Pst DC3000 ( $\triangle$ AvrPto/AvrPtoB).

Since TIR-NBS domain containing proteins are known to be involved in R protein mediated resistance, the involvement of TN13 and TNL in this process was assessed. The respective T-DNA insertion lines were tested with the avirulent $H$. $a$. isolates EMWA1 and CALA2 that are recognized by the TIR-NB-LRR R proteins RPP4 and RPP2, respectively, in Col-0. No enhanced susceptibility of $t n l$ and $t n 13$ mutants could be detected (Figure 3.19 C and D).

Mutations in MOS6 suppress the auto-immune growth phenotype and morphology of snc1 plants (Figure 3.1). To test whether the MOS6 in planta interactor TN13 also plays a role in snc1-mediated auto-immunity, the tn13 T-DNA insertion line was crossed with snc1 to generate the snc1 tn13 double mutant. Figure 3.19 E shows that the 
A

B
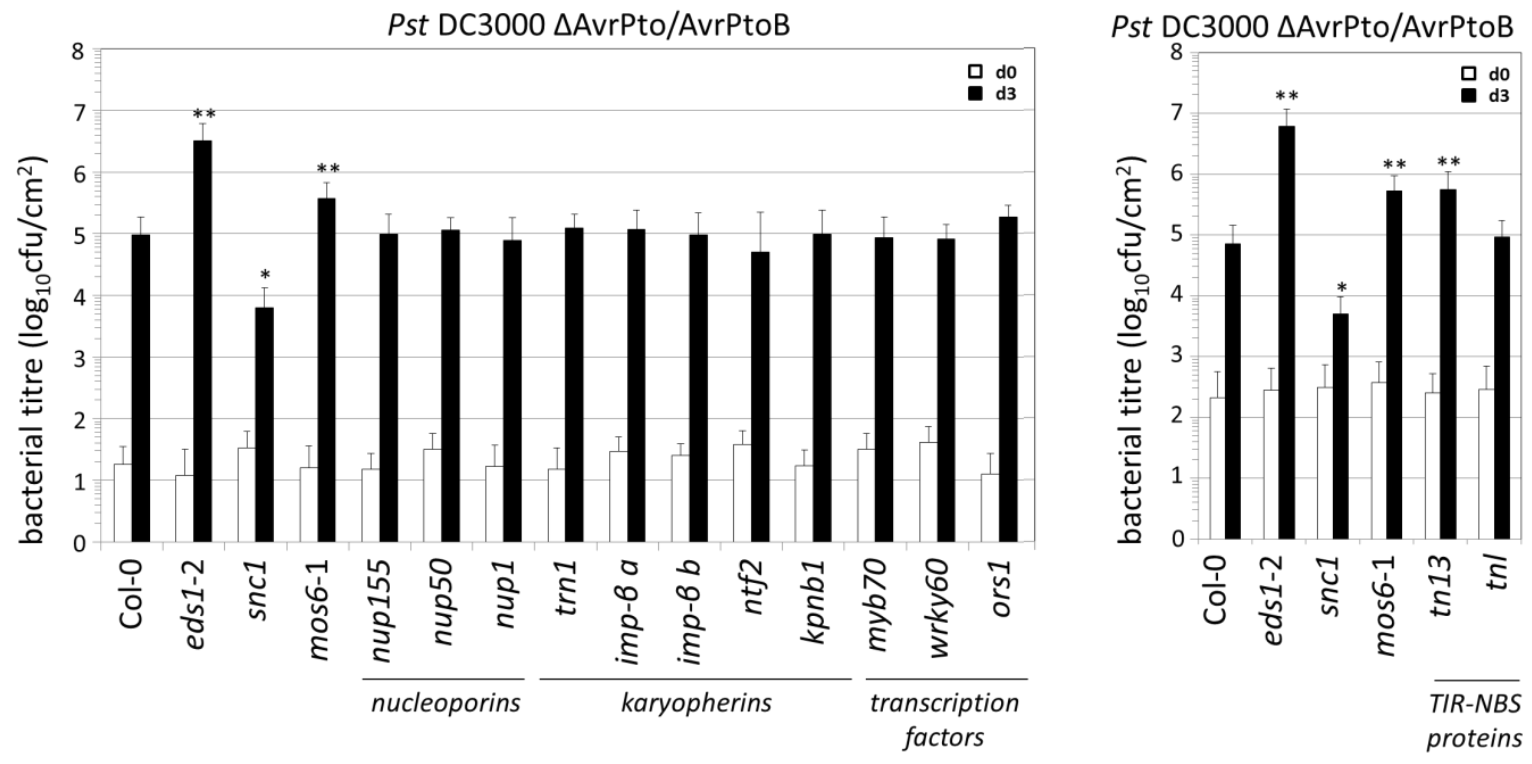

C

D

$\mathbf{E}$
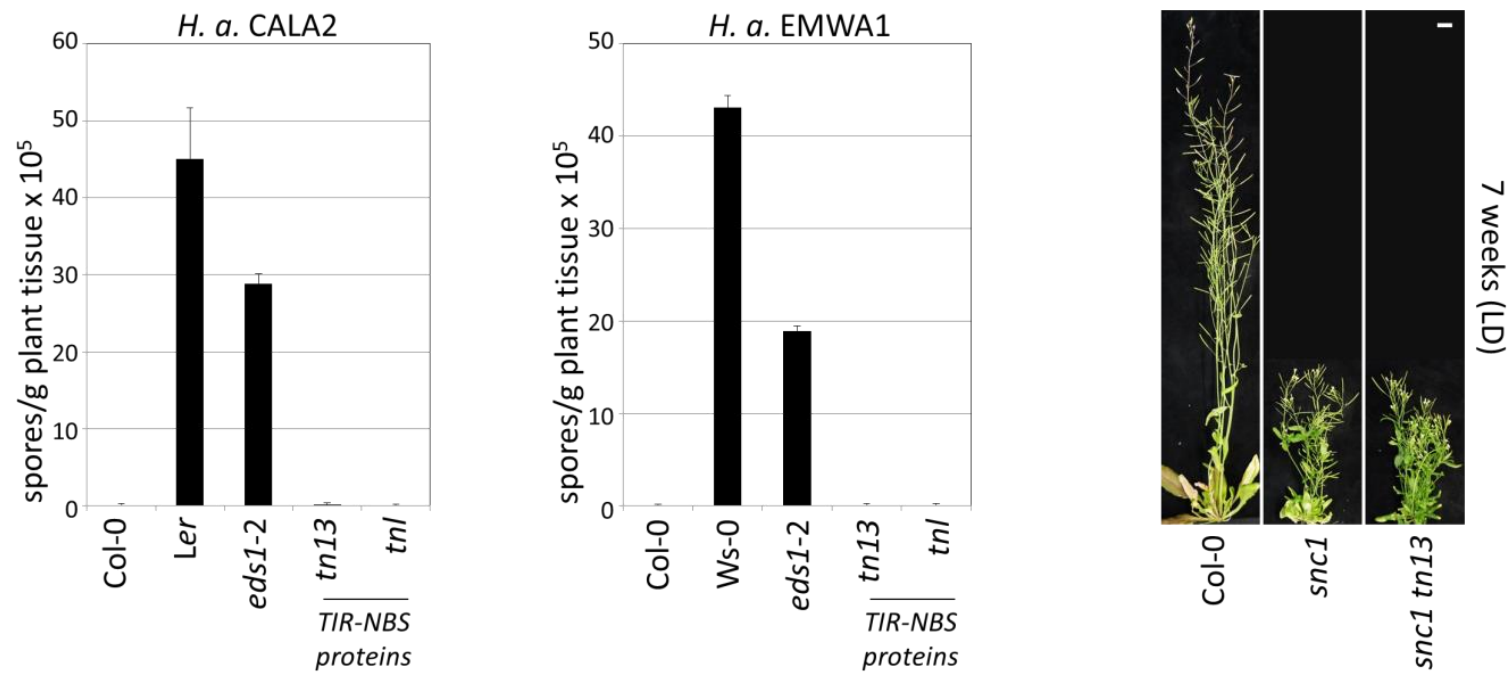

Figure 3.19 A T-DNA insertion in the TIR-NBS gene TN13 shows enhanced susceptibility against Pst DC3000 ( $\triangle$ AvrPto/AvrPtoB) comparable with mos6-1 but does not suppress snc1-related growth inhibition. A) Growth of Pst DC3000 ( $\triangle$ AvrPto/AvrPtoB) on nucleoporin, karyopherin and transcription factor candidate T-DNA lines. B) Growth of Pst DC3000 ( $\triangle$ AvrPto/AvrPtoB) on TIR-NBS domain containing candidat T-DNA lines. The leaves of four-week-old plants were vacuum-infiltrated with a bacterial suspension of $1 \times 10^{5} \mathrm{cfu} / \mathrm{mL}$. To quantify bacterial growth, leaf discs within the inoculated areas were taken immediately (d0) and three days after infection (d3). Bars represent means from two replicate samplings for $\mathrm{d0}$ (white bars) and nine replicate samplings for $d_{3}$ (black bars). Error bars show standard deviation and asterisks indicate statistical significance (t-test for pairwise comparison between wild-type and mutant, $* \mathrm{p}<0.05, * * \mathrm{p}<0.01$ ). snc1 and eds1 (Col eds1-2) are resistant and hyper-susceptible controls, respectively. $\mathrm{Cfu}=$ colony-forming units. The experiments were repeated three times with similar results. C) Growth of the avirulent $H$. $a$. isolates CALA2 and D) EMWA1 that are recognized in Col-0 by RPP2 and RPP4, respectively. Ler (lacking functional RPP2) and Ws-0 (lacking functional RPP4) were used as susceptible wild-type ecotypes for the respective $H$. a. isolate. E) Growth phenotype of snc1 tn13 double mutant. Plants were grown parallel on soil for seven weeks under long day (LD) conditions. Scale bar $=1 \mathrm{~cm}$. 
snc1 tn13 double mutant plants are indistinguishable from the snc1 single mutant. Together, these data demonstrate that the T-DNA insertion in the gene encoding for the MOS6 in planta interactor TN13 results in enhanced disease susceptibility against Pst with reduced effector repertoire but does not have an obvious impact on snc1-related growth inhibition.

\subsubsection{TN13-cCFP localizes in the ER in N. benthamiana}

The results presented under 3.2.4 and 3.2.5.1 show that the TIR-NBS protein TN13 is an in planta interactor of the IMP- $\alpha$ MOS6 and required for full resistance against the bacterial pathogen Pst DC3000 ( $\triangle$ AvrPto/AvrPtoB). The $T N 13$ gene is located head-to-tail next to AT3G04220, encoding a predicted TNL protein (Figure 3.20 A). This resembles the situation of two TNL R genes, RRS1 and RPS4, that are genomically linked head-to-head (Narusaka et al., 2009). To assess the presence of intrinsic functional protein modules in TN13, the InterProScan5 protein domain prediction was used (http://www.ebi.ac.uk/ Tools/pfa/iprscan5/, Zdobnov and Apweiler, 2001; Goujon et al., 2010). In addition to the TIR and NBS domains, a N-terminal hydrophobic transmembrane helix was predicted that might be involved in membrane insertion (Figure $3.20 \mathrm{~B}$ ). Interestingly, two bipartite NLS that could mediate interaction with MOS6 were predicted by the NLS-mapper online-tool. (http://nls-mapper.iab.keio.ac.jp/ cgi-bin/ NLS_Mapper_form.cgi, Kosugi et al., 2009b). Figure 3.20 (B) shows a schematic representation of the predicted protein domain structure of TN13. Using the PROSPER tool for in silico prediction of protease cleavage sites (https://prosper.erc.monash.edu.au, Song et al., 2012) revealed numerous putative cleavage sites for cysteine-, metallo- and serine proteases in the TN13 primary amino acid sequence including the region between the predicted trans membrane and TIR domains. Possibly, this suggests that membrane-bound TN13 might be cleaved and subsequently released from an endomembrane compartment.

In order to investigate the subcellular localization of TN13, the TN13-cCFP fusion protein constructs that was also used to validate the interaction with MOS6 in planta by ColP-analysis (Fig. 3.17) was expressed transiently in $N$. benthamiana. Subsequent confocal laser scanning microscopy (CLSM) showed a reticulate, network-like location 
A

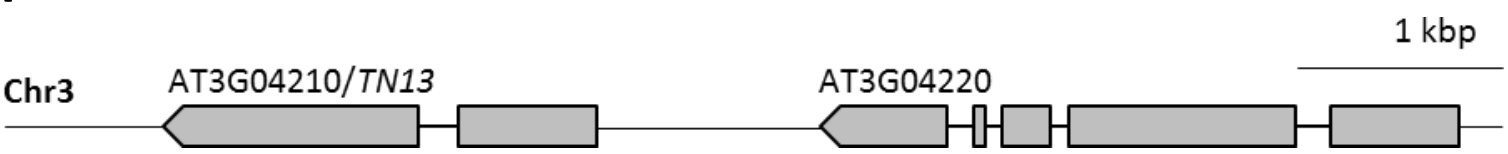

B

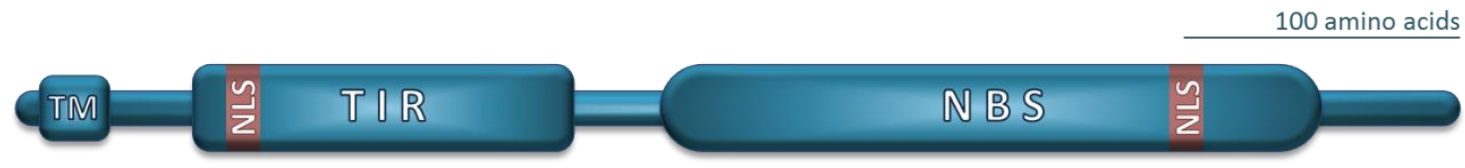

C

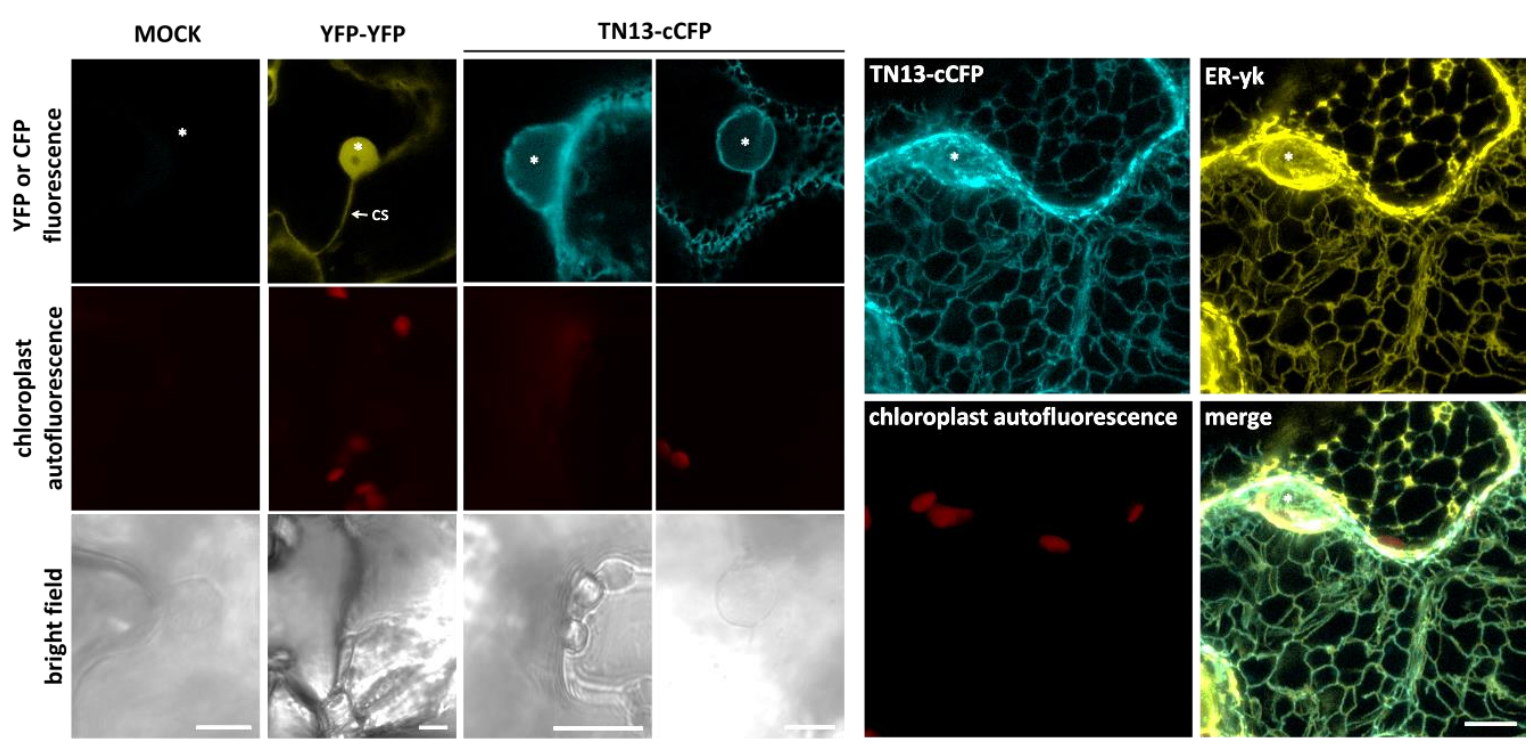

Figure 3.20 TN13-cCFP localizes in the endoplasmic reticulum in N. benthamiana. A) Schematic diagram of AT3G04210/TN13 and AT3G04220. The genes are arranged in a head-to-tail orientation on Arabidopsis chromosome 3 (Chr3). Exons are indicated by grey boxes, introns are indicated as lines. B) Schematic representation of predicted protein domain structure of TN13. Domains were predicted with InterProScan5 (http://www.ebi.ac.uk/Tools/pfa/iprscan5/, Zdobnov and Apweiler, 2001; Goujon et al., 2010), NLS were predicted with NLS-mapper (http://nls-mapper.iab.keio.ac.jp/cgi-bin/ NLS_Mapper_form.cgi, Kosugi et al., 2009b). $\mathrm{TM}=$ transmembrane domain, $\mathrm{TIR}=$ Toll/interleukin-1 receptor homology domain, NBS = nucleotide binding site, NLS = bipartite nuclear localization signal. C) Transient expression of genomic AT3G04210/TN13 fused to CCFP (TN13-CCFP) under control of the 355 promoter in $N$. benthamiana was analyzed by confocal fluorescence microscopy. Comparison of TN13-cCFP fluorescence with mock ( $A$. tumefaciens GV3101 pMP19RK p19 strain) and tandem mYFP (YFP-YFP) fluorescence. Upper row shows fluorescence signals of the indicated fusion proteins (blue and yellow). Middle row shows chloroplast autofluorescence (red). Bottom row shows bright field images. Asterisks mark nuclei, cs = cytoplasmic strand, scale bar $=10 \mu \mathrm{m}$. D) TN13-cCFP fluorescence is shown in blue and fluorescence of a co-expressed ERmarker protein fused to YFP (ER-yk, (Nelson et al., 2007) is shown in yellow. Chloroplast autofluorescence is shown in red. Asterisk indicates position of the nucleus. Scale bar $=10 \mu \mathrm{m}$. 
pattern in addition to signal surrounding the nucleus, suggesting a potential localization at the nuclear envelope and the ER (endoplasmic reticulum, Figure $3.20 \mathrm{C}$ ). To validate this hypothesis, an established ER-marker (ER-yk; Nelson et al., 2007) was co-expressed with TN13-cCFP and CLSM analysis was conducted. TN13-cCFP co-localized with the ER-yk marker protein when transiently expressed in $N$. benthamiana (Figure $3.20 \mathrm{D}$ ). The localization of TN13 to the ER is consistent with the predicted hydrophobic domain at its $\mathrm{N}$-terminus (Figure $3.20 \mathrm{~B}$ ). Interestingly, TN13 shares $60 \%$ identity on amino acid level with RPP1-WsA (supplementary Figure S1) that also contains a stretch of hydrophobic amino acids at its $\mathrm{N}$-terminus that directs the protein into $\mathrm{ER}$ and Golgi membranes (Weaver et al., 2006). 


\section{Discussion}

This work focuses on the analysis of IMPORTIN- $\alpha$ (IMP- $\alpha$ ) nuclear transport receptors (NTRs) in Arabidopsis innate immunity. One of the nine IMP- $\alpha$ paralogs present in the Arabidopsis genome encodes for MOS6/IMP-a3. MOS (MODIFIERS OF SNC1) genes have been identified in a forward genetic screen for suppressors of auto-immune responses and related growth inhibition caused by a mutation in the TIR-NB-LRR (TNL)-type $R$ gene variant snc1 (suppressor of npr1-1, constitutive 1, Johnson et al., 2012; Zhang et al., 2003). Intriguingly, several MOS genes encode components of the nuclear pore complex (NPC) and nucleocytoplasmic transport machinery, revealing the importance of this fundamental cellular process for plant immunity and constitutive resistance activated in snc1 (Cheng et al., 2009; Germain et al., 2010; Monaghan et al., 2010; Palma et al., 2005; Wiermer et al., 2010; Xu et al., 2012). Palma et al. (2005) demonstrated a role for MOS6 in basal plant immunity against the virulent oomycete Hyaloperonospora arabidopsidis (H. a.) isolate NOCO2. The higher susceptibility of mos6 single mutant alleles towards the bacterial pathogen Pseudomonas syringae pv. tomato (Pst) DC3000 ( $\Delta$ AvrPto/AvrPtoB) presented here further corroborates the specific involvement of MOS6 in basal resistance (Figures 3.2 and 3.9, Wirthmueller et al., 2015). Together, the findings that MOS6 is genetically required for basal resistance and snc1-mediated auto-immunity substantiate the importance of MOS6 in plant defense (Figures 3.2, 3.7, 3.8 and 3.9).

\subsection{Selective roles of Arabidopsis IMP- $\alpha$ proteins in plant growth and defense}

Potential functional redundancies within the nuclear import receptor family in plant defense signaling were addressed in the first part of this study (3.1). T-DNA insertion mutants for the nine IMP- $\alpha$ family members were isolated for reverse-genetic analyses. The responses of the imp- $\alpha$ single, as well as double and triple mutants towards Pst DC3000 ( $\triangle$ AvrPto/AvrPtoB) were tested. An involvement of IMP- $\alpha$ s other than MOS6 in basal immunity against this pathogen could not be detected (Figure 3.9). In addition, only mutations in MOS6 but in none of the other IMP- $\alpha$ s suppressed the stunted growth 
morphology of the snc1 auto-immune mutant, reinforcing the idea of MOS6 substrate specificity (Figure 3.10). Interestingly, analyses of the imp- $\alpha$ single, double and triple mutant growth phenotypes revealed partially redundant functions of IMP- $\alpha 1, I M P-\alpha 2$ and MOS6 for regular plant growth (Figure 3.12). These results imply contributions of MOS6 in plant growth additionally to its functions in immunity and will be evaluated and discussed in the following chapters.

\subsubsection{Regulation of IMP- $\alpha$ expression and function}

The size expansion of the IMP- $\alpha$ gene family during eukaryotic evolution raises questions about redundancy and functional specialization of these nuclear transport receptors. One possibility to regulate and adjust protein functions to the particular requirements of a given tissue, developmental stage or external stimulus is temporally or spatially distinct gene expression (Schmid et al., 2005; Yamada et al., 2003). Accordingly, tissue-specific expression patterns have been reported for mammalian IMP- $\alpha$ paralogs (Köhler et al., 1997; Tsuji et al., 1997; Yasuhara et al., 2007; Hogarth et al., 2006). In silico analysis of the Genevestigator database showed that MOS6, IMP- $\alpha 1,2,4,6$ and 9 were ubiquitously transcribed in unchallenged plants (Figure 3.4, https://www. genevestigator.com; Hruz et al., 2008). In addition, mRNA levels of these IMP- $\alpha$ s were higher in rosette leaves compared to IMP- $\alpha 5,7$ and 8. High levels of MOS6 and IMP- $\alpha 6$ mRNAs were also found in the shoot apex.

The overlapping expression of six IMP- $\alpha$ genes in Arabidopsis leaves implies partially redundant functions of these paralogs. This scenario is supported by the strong conservation of residues contributing to the NLS-binding site in MOS6 and IMP- $\alpha 1,2,4$ and 6, suggesting overlapping NLS-substrate specificities (Wirthmueller et al., 2013, 2015). The NLS-binding site is less conserved in IMP- $\alpha 9$ which might imply different functions for this IMP- $\alpha$ (Wirthmueller et al., 2013, 2015). Nevertheless, given the similarities in the NLS-binding sites and expression profiles of IMP- $\alpha 1,2,4,6$ and MOS6, it is intriguing that genetic knock-out of a single IMP- $\alpha$ gene can lead to mutant phenotypes. For instance, Bhattacharjee et al. (2008) reported lower A. tumefaciens transformation rates in root tissue of Arabidopsis imp- $\alpha 4$ mutants. IMP- $\alpha 4$ has the highest expression level in roots compared to the other IMP-as (Figure 3.4). Expression of 
several importin-a paralogs under control of the tissue non-specific 355 promoter in imp- $\alpha 4$ complemented the reduced transformation rates (Bhattacharjee et al., 2008). This finding suggests that tissue-specific expression levels of IMP- $\alpha$ s can determine their contribution to nuclear transport (Wirthmueller et al., 2015; Bhattacharjee et al., 2008).

Interestingly, gene expression of IMP- $\alpha$ family members was not significantly altered after challenge with diverse pathogens (e.g. Pst and $H$. a.) or treatment with bacterial or oomycete elicitors in any of the datasets available via the Genevestigator or the Bar Expression Browser (Toufighi et al., 2005; Hruz et al., 2008). In support of this, $I M P-\alpha$ gene transcription was not induced in the snc1 auto-immune mutant that accumulates high levels of the plant defense hormone salicylic acid (SA, Figure 3.6, Li et al., 2001). This suggests, consistent with the constitutively high transcription of MOS6, $I M P-\alpha 1,2,4,6$ and 9 in leaf tissue, that expression of this Arabidopsis IMP- $\alpha$ s subset is not regulated by stimulus-induced variations in gene transcription.

Post-translational modifications emerge to be involved in regulation of IMP- $\alpha$ protein function. Several reports show post-translational modification by acetylation and phosphorylation of IMP- $\alpha$ proteins in yeast and mammals (Azuma et al., 1995; Bannister et al., 2000; Wang et al., 2004; Zou et al., 2008). Specific acetylation of a G/SK -motif in human IMP- $\alpha 1$ and 7 by the acetylase CBP (CREB-binding protein) was found to enhance the affinity of the IBB domain to IMP- $\beta$ (Bannister et al., 2000). Phosphorylation by the upstream regulator AMPK (5'-AMP-activated protein kinase, human) is discussed to increase affinity of the major NLS-binding pocket for a certain NLS (Zou et al., 2008). Combination of acetylation with additional phosphorylation in IMP- $\alpha 1$ was demonstrated to be required for enhanced AMPK-triggered nuclear transport of HuR (human antigen R, Wang et al., 2004). Therefore, post-translational modifications on specific IMP- $\alpha$ proteins possibly allow to regulate preferential association and subsequently nuclear transport of certain cargo proteins (Pumroy and Cingolani, 2015). However, post-translational modifications have not been demonstrated for Arabidopsis IMP- $\alpha$ paralogs. It would be interesting to investigate whether the function of Arabidopsis IMP- $\alpha$ s expressed in the same tissue is also regulated by specific acetylation and/or phosphorylation and whether this affects selective nuclear transport of defense regulators in plant immunity. 


\subsubsection{MOS6 is selectively required for plant defense}

The genetic requirement for MOS6 in defense against H. a. NOCO2 and Pst DC3000 ( $\triangle$ AvrPto/AvrPtoB, Figures 3.8 and 3.9) together with the finding that only mutations in MOS6 but not in any other IMP- $\alpha$ gene suppress the snc1 phenotype (Figure 3.10), implies specialized functions of this nuclear transport receptor in plant defense. Nevertheless, it should be noted that mos6 only partially suppresses snc1-related stunted growth and enhanced resistance (Figures 3.1 and 3.10; Palma et al., 2005). Therefore, a role of other IMP- $\alpha$ s in snc1-mediated auto-immunity and basal resistance cannot be entirely excluded, also because for some IMP- $\alpha$ genes only T-DNA lines with insertions late in the gene were available (Figure 3.5). This includes the closest MOS6 homolog IMP- $\alpha 6$. By using semiquantitative RT-PCR analysis, no full-length transcript for imp- $\alpha$ mutants was detected (Figure 3.5). However, the possible production of partial transcripts in imp- $\alpha$ mutants with late insertions in the gene cannot be excluded. Partial transcripts might lead to the translation of truncated proteins and thus these T-DNA lines may not represent functional-null mutants. In the imp- $\alpha 6$ T-DNA line for example, the T-DNA inserted in the region coding for the C-terminal CAS-binding domain (Figures 3.3 and 3.5). Therefore, if a truncated IMP- $\alpha 6$ protein was produced, this protein would possibly lack a functional CAS domain. This domain mediates the interaction between IMP-as and the exportin CAS in the nucleus for cargo-release and transport of IMP- $\alpha$ back to the cytoplasm (Kutay et al., 1997; Conti and Kuriyan, 2000; Goldfarb et al., 2004; Haasen and Merkle, 2002). Consistent with this, a mutation or partial deletion of the CAS domain was shown to result in retention of human IMP- $\alpha 2$ (RCH1) in the nucleus (Herold et al., 1998). Therefore, a hypothetical IMP- $\alpha 6$ protein lacking a functional CAS domain would probably accumulate inside the nucleus. Consequently, this would reduce or abolish IMP- $\alpha 6$ mediated nuclear transport. Nevertheless, it is possible that such truncated IMP- $\alpha 6$ protein may be sufficiently active for manifestation of the snc1-associated growth phenotype in the snc1 imp- $\alpha 6$ double mutant. This could explain why unlike for mos 6 , no effect of the imp- $\alpha 6$ mutation in snc1-mediated growth suppression was observed (Figure 3.10). Nevertheless, the reduced growth phenotype of double and triple mutants containing imp- $\alpha 1$ suggests that combined mutations in more than one imp- $\alpha$ could be necessary for development of a pronounced phenotype (Figures 3.11 and 3.12, 4.1.3). 
Since loss of MOS6 only partially suppresses the snc1-mediated growth phenotype, mos6 imp- $\alpha 6$ and other higher order mutants between closely related IMP- $\alpha$ family members should be combined with the snc1 mutant to further analyze redundant roles of IMP- $\alpha$ s in the snc1-mediated phenotypes. Also, mos 6 imp- $\alpha 6$ double mutants should be tested to assess whether a stronger susceptibility phenotype can be obtained by the loss of both, MOS6 and IMP- $\alpha 6$ compared to mos6 single mutants. However, testing the IMP- $\alpha$ triple mutants (that contain mos6-4) with Pst DC3000 ( $\triangle$ AvrPto/AvrPtoB) did not show enhanced susceptibility towards this pathogens when compared to mos6-1 single mutants (Figure 3.14). This suggests that MOS6 does not function redundantly with the tested IMP- $\alpha$ s in defense against Pst DC3000 ( $\triangle$ AvrPto/AvrPtoB) and substantiates the idea that MOS6 is specifically required for basal defense reactions.

Another possibility for nuclear transport factors that function redundantly with IMP- $\alpha$ s are IMP- $\beta$ proteins. The classical nuclear import mechanism involves both, IMP- $\alpha$ and IMP- $\beta$ (Meier and Somers, 2011). However, IMP- $\beta$ family proteins were also shown to directly bind to cargo proteins and mediate nuclear import independently of IMP-aS (Ziemienowicz et al., 2003; Jakel and Görlich, 1998; Lam et al., 1999; Lee et al., 2006; Lee et al., 2003; Nagoshi and Yoneda, 2001; Palmeri and Malim, 1999; Zehorai and Seger, 2014). Redundant functions between such NTRs and MOS6 could also be responsible for the fact that mos6 only partially suppresses the stunted growth of snc1. Interestingly, several IMP- $\beta$ family proteins were found to interact with MOS6 in the in planta affinity purification approach (3.2, Figure 3.17). Double mutants of these MOS6 interactors with snc1 are currently generated to answer the question whether loss of these NTRs influences the snc1-mediated growth phenotype.

\subsubsection{IMP- $\alpha 1, I M P-\alpha 2$ and MOS6 have partially redundant functions in plant growth regulation}

Plant growth of the imp- $\alpha 1$ imp- $\alpha 2$ and imp- $\alpha 1 \operatorname{mos} 6$ double mutants and the triple mutant line imp- $\alpha 1$ imp- $\alpha 2$ mos6-4 is reduced (Figure 3.11 and 3.12) whereas loss of $i m p-\alpha 1$ alone is not is sufficient for growth reduction in comparison to wild-type plants (Figure 3.7). These findings indicate partially redundant roles of IMP- $\alpha 1, I M P-\alpha 2$ and MOS6 in plant growth, suggesting overlapping functions of these IMP-as in import of 
cargo proteins involved in plant growth regulation. Together with the finding that loss of nucleoporins can cause growth and developmental defects such as early flowering time or root elongation, the growth phenotype of imp- $\alpha 1$ imp- $\alpha 2$ mos6-4 underlines the important role for components of the nucleocytoplasmic transport machinery for proper plant development (Parry et al., 2006; Parry, 2014; Ferrández-Ayela et al., 2013; Wiermer et al., 2012). However, no further increase in susceptibility against Pst DC3000 ( $\triangle$ AvrPto/AvrPtoB) could be shown for the growth-retarded triple imp- $\alpha 1$ imp- $\alpha 2$ mos6-4 mutant compared to the mos6-1 single mutant (Figure 3.14). Therefore, these IMP-as do not have overlapping functions in defense against the mildly virulent Pst strain DC3000 ( $\triangle$ AvrPto/AvrPtoB). This suggests divergent roles of the different IMP-as in plant development and immunity, although MOS6 appears to be involved in both processes.

Loss of IMP- $\alpha 1, I M P-\alpha 2$, and MOS6 in the triple mutant probably results in reduction of the absolute amount of cellular IMP- $\alpha$ protein, since no compensatory transcriptional upregulation of remaining IMP- $\alpha$ s was detected (Figure 3.13). This deficiency of IMP- $\alpha$ proteins in the cells might lead to reduced cargo/IMP- $\alpha$ transport complex formation. It was reported that the NLS-cargo/NTR ratio is important for efficient nucleocytoplasmic transport (Riddick and Macara, 2005; Hodel et al., 2006; Timney et al., 2006). Reduction of the amount of IMP- $\alpha$ proteins available for nuclear transport in a specific tissue could consequently lead to reduced import rates of cargo proteins. These circumstances would in turn affect tissue development if translocation of crucial regulatory factors was reduced. It remains to be analyzed how loss of IMP-as leads to retardation of plant growth and whether IMP- $\alpha 1$, IMP- $\alpha 2$ and/or MOS6 import specific yet unknown cargo proteins involved in plant growth regulation. Expression of fusion constructs of $I M P-\alpha 1$ and $I M P-\alpha 2$ to the $3 \times$ HA-SII-tag in transgenic plants and subsequent affinity purification approaches might help answer these questions.

$I M P-\alpha 1, I M P-\alpha 2$ and IMP- $\alpha 4$ are the three most highly expressed IMP- $\alpha$ s in rosette leaves (Figure 3.4). The idea of potential redundancy between IMP- $\alpha 1$, IMP- $\alpha 2$ and IMP- $\alpha 4$ is supported by the strong conservation of residues contributing to the NLSbinding site of these proteins (Wirthmueller et al., 2013, 2015). Therefore, the generation

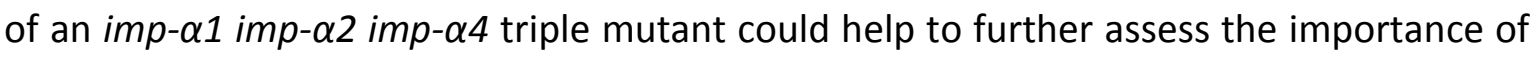
these three IMP-as in nuclear transport for plant growth regulation. 


\subsection{Identification and characterization of MOS6 cargo proteins and interaction partners}

To understand the molecular function of MOS6 in plant immunity, MOS6 cargo proteins and interaction partners were identified in the second part of this work (3.2). For this purpose, two independent approaches were adopted. The Plant-Pathogen Immune Network (PPIN-1, Mukhtar et al., 2011) was analyzed in silico for putative immune-related interaction partners of MOS6 that were identified via high-throughput yeast two-hybrid screens. In addition, an affinity purification approach aimed at the identification of MOS6 interacting proteins in planta after pathogen challenge with $\mathrm{H}$. a. NOCO2 was conducted. From the candidate interactors identified in both approaches, components of the nucleocytoplasmic transport machinery (i.e. nucleoporins and karyopherins), transcription factors and members of the TIR-NBS family were selected for further functional analyses. To independently verify binding of the selected candidate proteins to MOS6, co-immunoprecipitation (CoIP) after Agrobacterium-mediated transient expression analyses in $N$. benthamiana were conducted. Importantly, several of the candidate interactors co-immunoprecipitated MOS6 but not its closest homolog IMP- $\alpha 6$ (Figure 3.17). Reverse genetic analysis of candidate MOS6 interactors was carried out to assess their potential involvement in plant immunity. These experiments uncovered an impairment in basal resistance against Pst DC3000 ( $\triangle$ AvrPto/AvrPtoB) for a T-DNA insertion in TN13, encoding a TIR-NBS (TN) class protein (Figure $3.19 \mathrm{~B}$ ). Confocal laser scanning microscopy after transient expression of cCFP-tagged TN13 in N. benthamiana revealed localization of this MOS6-interactor to the endoplasmic reticulum (Figure 3.20). The findings summarized above will be evaluated and discussed in the following.

\subsubsection{Exclusive and redundant functions of MOS6 and its closest homolog IMP- $\alpha 6$ in nuclear transport complex formation}

After evaluation of the two data sets based on the criteria specified under 3.2.1 and 3.2.3, thirteen candidates were selected for further analysis (Table 3.2). From the PPIN-1 network analysis, three transcription factors and two TIR-NBS-domain containing proteins were chosen. From the in planta affinity purification approach three nucleoporins and 
five karyopherins were selected. In planta interaction of the thirteen candidate MOS6 cargo proteins and interaction partners was re-evaluated via ColP. For this, Agrobacterium-mediated transient co-expression of cCFP-tagged candidates and 3xHA-SII-tagged MOS6 was carried out in Nicotiana benthamiana. To assess whether the selected candidates also interact with the closest homolog of MOS6, IMP-a6, precipitation of IMP- $\alpha 6-3 \times \mathrm{HA}-\mathrm{SII}$ was also tested. Five of the putative MOS6 interacting proteins were able to precipitate IMP- $\alpha 6$ as well. These are NUP50, KPNB1/IMP- $\beta 2$, both putative IMP- $\beta$ proteins ( $a$ and $b$ ) and the TNL protein (Figure 3.17). The interaction between IMP- $\alpha 6$ and both putative IMP- $\beta$ proteins and the TNL protein was at the detection limit of this assay, suggesting weak interactions.

The identification of proteins that selectively interact with MOS6 and proteins that interact with both IMP- $\alpha 6$ and MOS6 suggests exclusive as well as redundant functions for MOS6 and its closest homolog IMP- $\alpha 6$ in nuclear import. Wirthmueller et al (2015) showed that in addition to the protein levels of IMP- $\alpha$ s in a given tissue, the binding affinity of a certain NLS to a specific IMP- $\alpha$ is an important factor for the formation of cargo-NLS/IMP- $\alpha$ transport complexes. Small sequence variations in the cargo-NLS and/or the IMP- $\alpha$ NLS binding sites are therefore of functional relevance for distinct transport pathways (Wirthmueller et al., 2015; Quensel et al., 2004). Interestingly, predominantly proteins of the nuclear transport machinery that do not contain predicted NLS motifs were found to interact with IMP- $\alpha 6$ with the exception of the TNL protein. Conceivably, unique features in the NLS-sequences of MOS6-inteactors and/or the MOS6-NLS binding sites might be responsible for preferential binding to MOS6. Comparison and functional analyses of the NLS-sequences of proteins that only precipitated MOS6 in the ColP experiments might give further insights in specific NLS sequence-requirements for binding to MOS6 and not to IMP- $\alpha 6$.

\subsubsection{NUP1/NUP136 and NUP155 selectively interact with MOS6 while NUP50 interacts with both, MOS6 and IMP- $\alpha 6$}

Several nuclear pore complex proteins (nucleoporins) have previously been shown to be required for Arabidopsis innate immunity (i.e. MOS7/NUP288, NUP160, SEH1, Cheng et 
al., 2009; Wiermer et al., 2010; Roth and Wiermer, 2012) or plant responses to symbiotic microbes (i.e. NUP133, NUP85, NENA, Kanamori et al., 2006; Saito et al., 2007; Groth et al., 2010). The nucleoporins NUP50, NUP1/NUP136 and NUP155 that were identified in the MOS6 affinity-purification, however, have not previously been described to be involved in plant-microbe interactions and were therefore selected for further analysis.

The CoIP analysis of NUP50-cCFP showed interaction of this nucleoporin with both MOS6-3xHA-SII and IMP- $\alpha 6-3 \times$ HA-SII (Figure 3.17). NUP50 is encoded by AT1G52380 and its C-terminal part shows $46 \%$ similarity to the corresponding region of human NUP50 (Tamura et al., 2010). NUP50 contains a RanBP1 domain for direct binding to Ran-GTP and belongs to the FG nucleoporins (Tamura et al., 2010). The Arabidopsis genome encodes one additional ortholog of NUP50 (Table 3.2). Localization to the nucleoplasm and to the basket on the nuclear site of the NPC was reported for NUP50 proteins in Arabidopsis and other eukaryotes (Lindsay et al., 2002; Tamura et al., 2010; Guan et al., 2000; Tamura and Hara-Nishimura, 2013). Interactions of NUP50 with IMP- $\alpha 1$, IMP- $\alpha 2$, MOS6, IMP- $\alpha 4$, IMP- $\alpha 5, I M P-\alpha 6$ and Ran were shown previously in a proteomic approach aiming to identify the composition of the Arabidopsis NPC (Tamura et al., 2010). Because of its interaction with IMP- $\alpha$ proteins and Ran, NUP50 is discussed to possibly function in regulation of nucleocytoplasmic transport rather than forming a part of the NPC (Tamura et al., 2010). This assumption is consistent with findings from the animal field where NUP50 was shown to displace cargo proteins from IMP- $\alpha$ (mouse Kap60p, Matsuura and Stewart, 2005). The NUP50 N-terminal domain was demonstrated to compete with a canonical cargo-NLS sequence for binding to an IMP- $\alpha /$ IMP- $\beta$ complex, resulting in accelerated NLS release in the terminal stages of nuclear import (Matsuura and Stewart, 2005). Arabidopsis NUP50 does not contain a predicted NLS motif (Table 3.2). Therefore, precipitation of both MOS6 and IMP- $\alpha 6$ by NUP50 might support the scenario of functional interaction for acceleration of NLS-release by an active displacement mechanism in Arabidopsis (Matsuura and Stewart, 2005; Gilchrist et al., 2002). When Pst DC3000 ( $\triangle$ AvrPto/AvrPtoB) was used to test the involvement of NUP50 in Arabidopsis immunity no aberrant phenotype of a nup50 T-DNA insertion line was uncovered (Figure 3.19). This indicates that NUP50 is not involved in defense against Pst DC3000 ( $\triangle$ AvrPto/AvrPtoB) and rather plays a mechanistic role in plant nucleocytoplasmic 
transport as pointed out above. Alternatively, NUP50 might have redundant functions with its putative ortholog (Table 3.2).

Two other nucleoporins were investigated in the ColP analyses. Both, NUP1/NUP136-CCFP and NUP155-cCFP precipitated MOS6-3xHA-SII but not IMP- $\alpha 6-3 \times$ HA-SII. NUP1/NUP136, like NUP50, belongs to the group of nuclear FG nucleoporins of the NPC basket, whereas NUP155 belongs to the inner ring/NUP93 sub-complex (Figures 1.2 and 4.1, Tamura and Hara-Nishimura, 2013). NUP1/NUP136 (NUP153 in vertebrates) was found to be mobile on the nuclear envelope and to dynamically interact with the NPC (Tamura et al., 2010) where it anchors the Arabidopsis homolog of the yeast TREX-2 mRNA export complex (Lu et al., 2010). Tamura et al., (2010) could show in a proteomic approach that NUP1/NUP136 interacts with NUP155, IMP- $\alpha 1$, IMP- $\alpha 2$, MOS6 and KPNB1/IMP- $\beta 2$. The presence of FG repeats in NUP1/NUP136 and its localization to the NPC basket suggest a requirement for this nucleoporin in active transport through the NPC (Tamura et al., 2010; Tamura and Hara-Nishimura, 2013). Analysis of nup1/nup136 mutants revealed that NUP1/NUP136 is involved in regulating nucleus morphology and mRNA export from the nucleus. Lack of NUP1/NUP136 function leads to developmental defects such as early flowering and a reduced number of rosette leaves in mutant plants (Tamura and Hara-Nishimura, 2011; Tamura et al., 2010; Lu et al., 2010). However, loss of NUP1/NUP136 had no effect on resistance against Pst DC3000 ( $\triangle$ AvrPto/AvrPtoB, Figure 3.19). These observations support the idea that NUP1/NUP136 has a general function in plant nucleocytoplasmic transport, regulation of nuclear morphology and mRNA export rather than a specialized role in plant disease resistance. Unlike NUP50 and NUP155, NUP1/NUP136 contains a predicted NLS, which makes it a potential NLS-cargo candidate (Table 3.2). Hence, MOS6 could be responsible for import of NUP1/NUP136 into the nucleus after cytoplasmic biosynthesis of the protein. MOS6mediated nuclear import of NUP1/NUP136 may therefore be the reason for efficient precipitation of MOS6 by this nucleoporin in addition to an interaction necessary for nuclear transport complex translocation through the NPC. Whether MOS6 directly interacts with NUPs or whether this interaction is mediated by IMP- $\beta$ co-receptors cannot be deduced from the ColP experiments. Notably, different members of the IMP- $\beta$ family 
were identified as MOS6 interactors and could serve to mediate interaction with nucleoporins (Figure 3.17, 4.2.1.2).

NUP155 is part of the inner ring of the NPC and its transcription is 1.4 fold upregulated in response to infection with the virulent $H$. $a$. isolate AHCO (Mahalingam et al., 2003; Tamura et al., 2010). Interestingly, NUP155-cCFP only co-precipitated MOS6-3xHA-SII but not IMP- $66-3 x H A-S I I$ (Figure 3.17). However, an involvement of the analyzed nucleoporins in resistance against Pst DC3000 ( $\triangle$ AvrPto/AvrPtoB) was not detected (Figure 3.19). These results indicate that the interactions of MOS6 with NUP50, NUP1/NUP136 and NUP155 possibly represent a general need for nucleocytoplasmic transport rather than a mechanism involved in biotic stress responses. Also, putative orthologs might act redundantly with NUPs analyzed in this study (Table 3.2). The weak (1.4-fold) upregulation of NUP155 expression in response to infection with H. a. AHCO could therefore reflect the general need for nuclear trafficking in plant defense rather than a direct involvement in defense regulation.

Only one of the NUPs analyzed in this work interacts with both, MOS6 and IMP- $\alpha 6$ (Figure 3.17), showing that MOS6 has selective as well as partially overlapping functions with its closest homolog, IMP-a6. Differences between MOS6 and IMP- $\alpha 6$ interactions and ultimately differences in their biological functions could be rooted in nuclear protein import, transport complex formation with the IMP- $\beta$ co-receptors and/or their route through the NPC in which selective interactions with different NUPs might play a role.

\subsubsection{MOS6 and IMP- $\alpha 6$ interact with karyopherins of the IMP- $\beta$ family}

Five soluble proteins implicated in nucleocytoplasmic protein transport were among the MOS6 interacting candidates that were selected for further analysis (Table 3.2). AtKPNB1/IMP- $\beta 2$ interacted with both MOS6 and IMP- $\alpha 6$ after transient expression in N. benthamiana (Figure 3.17). This protein was one of the most abundant interactors of MOS6 in the in planta affinity purification experiments (Table 3.1). The interaction of MOS6 with an IMP- $\beta$ co-receptor was expected due to the cooperative function of both proteins in nuclear import (Figure 1.2, Stewart, 2007b; Meier and Somers, 2011). Therefore, presence of IMP- $\beta$ served as proof-of-concept for this experiment. 
AtKPNB1/IMP- $\beta 2$ is the Arabidopsis homolog of human KPNB1 (Luo et al., 2013a). Interestingly, human KPNB1 was shown to interact with nucleoporins and to directly bind and transport cargo substrates such as histones and ribosomal proteins into the nucleus without the aid of an IMP- $\alpha$ protein (Conti et al., 2006; Merkle, 2011; Jakel and Görlich, 1998; Takizawa et al., 1999). In contrast to recent findings where IMP- $\alpha 6$ but not MOS6 did interact with AtKPNB1 in yeast two hybrid assays (Luo et al., 2013a), the ColP analysis presented in this work revealed that MOS6 is able to interact with this protein in planta (Table 3.1, Figure 3.17). Therefore, the number of IMP- $\alpha$ proteins interacting with this particular IMP- $\beta$ homolog could be extended. AtKPNB1/IMP-B2 is expressed in various organs and tissues (Luo et al., 2013a). These observations suggest that this IMP- $\beta$ protein is generally rather than selectively involved in nuclear transport processes. The finding that KPNB1 interacts with several IMP- $\alpha$ s including MOS6 and IMP- $\alpha 6$ likely represents the general requirement of this IMP- $\beta$ for nuclear protein import in Arabidopsis. Consistent with this, loss of KPNB1 in Arabidopsis leads to various defects such as delayed plant development under normal growth conditions and increased sensitivity to abscisic acid (Luo et al., 2013a). When tested with Pst DC3000 ( $\triangle$ AvrPto/AvrPtoB), the kpnb1 mutant did not show an aberrant phenotype (Figure 3.19). Therefore, AtKPNB1/IMP- $\beta 2$ is probably not the only MOS6 co-receptor in nuclear import, which is consistent with the identification of other IMP- $\beta$ like proteins in the MOS6 affinity-purification (Table 3.1).

An additional putative IMP- $\beta$ protein identified in the MOS6 affinity-purification is AT3G08943/IMP-B_a and the genomically linked AT3G08947/IMP-B_b encodes a very similar protein. Because functions in nuclear import have not yet been demonstrated, these two proteins were named IMP- $\beta$, putative $-a$ and $-b$, respectively. The two putative IMP- $\beta$ proteins both contain an importin- $\beta \mathrm{N}$-terminal domain and a HEAT repeat domain. The HEAT repeat domain is implicated in binding to the IBB domain of IMP- $\alpha$ proteins and the interaction with nucleoporins (Cingolani et al., 1999; Bayliss et al., 2000). The characteristic importin- $\beta \mathrm{N}$-terminal domain is involved in the interaction with Ran (Cingolani et al., 1999; Bayliss et al., 2000). Interestingly, both proteins were able to weakly precipitate IMP- $\alpha 6-3 x \mathrm{HA}-\mathrm{SII}$ (Figure 3.17). MOS6-3xHA-SII weakly interacted with IMP- $\beta$ _a whereas interaction with IMP- $\beta \_b$ was considerably stronger. These observations suggest that IMP- $\alpha 6$ and MOS6 have selective binding capacities for 
different IMP- $\beta$ (or IMP- $\beta$-like) co-receptors. The interaction of IMP- $\alpha$ with IMP- $\beta$ typically occurs via the auto-inhibitory IBB domain of IMP- $\alpha$ (Cingolani et al., 1999). The IBB domains of MOS6 and IMP- $\alpha 6$ share $83 \%$ sequence identity on amino acid level (Wirthmueller et al., 2013). It might be possible that small differences in the IBB domains account for differential binding to other karyopherins. Therefore, preferential interaction of IMP- $\alpha$ s with certain nuclear transport factors might represent an additional level in the regulation of nucleocytoplasmic transport.

The IMP- $\beta$-like proteins TRANSPORTIN 1 (TRN1) and NUCLEAR TRANSPORT FACTOR 2 (NTF2) were identified as MOS6-3XHA-SII interactors by affinity-purification in Arabidopsis (3.2.3). TRN1 proteins mediate nuclear import of cargo proteins that contain a non-canonical M9 NLS defined by a glycine-rich amino acid motif without involvement of IMP- $\alpha$ (Michael et al., 1995; Bogerd et al., 1999; Pollard et al., 1996; Lee et al., 2006; Marfori et al., 2011). Arabidopsis TRN1 mediates nuclear import of the RNA-binding protein GRP7 in digitonin-permeabilized HeLa cells without contribution of Arabidopsis IMP- $\alpha$ proteins (Ziemienowicz et al., 2003). Interestingly, the TRN1-cargo GRP7 selectively binds FLS2 and EFR transcripts and this function is targeted by the Pst type III effector HopU1 to promote disease (Ziemienowicz et al., 2003; Nicaise et al., 2013). However, an involvement of TNR1 in immunity against Pst DC3000 ( $\triangle$ AvrPto/AvrPtoB) could not be observed by analysis of a trn1 T-DNA insertion line (Figure 3.19). This suggests that either the role of TRN1 in GRP7 mediated transport is not crucial for immunity against Pst DC3000 ( $\triangle$ AvrPto/AvrPtoB) or that TRN1 works redundantly with an ortholog (Table 3.2) and/or other karyopherins in GRP7 nuclear import. In contrast to the finding that TRN1 proteins do not require IMP- $\alpha$ for nuclear import (Pollard et al., 1996; Marfori et al., 2011), in planta ColP experiments revealed an interaction of MOS6 with TRN1 (Figure 3.17). TRN1 does not contain a predicted NLS (Table 3.2), suggesting that it is not an IMP- $\alpha$ cargo protein. Therefore, TRN1 and MOS6 might act cooperatively in nuclear transport. A possible scenario for the association of MOS6 and TRN1 involves cooperation of these proteins for efficient nuclear import of GRP7. GRP7 binds FLS2 and EFR transcripts in the nucleus for export to the cytosol and subsequent FLS2 and EFR protein biosynthesis (Nicaise et al., 2013). It can therefore be hypothesized that reduced nuclear import of GRP7 in mos6 mutants might lead to reduced nuclear GRP7 levels available for 
export of FLS2 and EFR transcripts. This would in turn affect protein levels of the PRRs FLS2 and EFR. Reduced levels of these PRRs would consequently lead to reduced PTI activation after treatment with bacterial pathogens (Bauer et al., 2001; Zipfel et al., 2004; Zipfel et al., 2006). The interaction between TRN1 and MOS6 demonstrated in this work is intriguing, but it remains to be shown whether TRN1 and MOS6 operate cooperatively in GRP7 nuclear import.

Similar to TRN1, it was shown that NTF2 is able to mediate nuclear import of cargo proteins independently from IMP- $\alpha$. One prominent cargo of NTF2 is Ran-GDP and interaction of NTF2 with both, FG repeat-containing nucleoporins and single-stranded RNA was reported (Bhattacharya and Steward, 2002; Ribbeck et al., 1998). Interestingly, Drosophila melanogaster NTF2 is also required for nuclear transport of NF-KB transcription factors (Bhattacharya and Steward, 2002). Since direct binding of NTF2 to NF- $\kappa B$ has not been shown, it was suggested that NTF2 indirectly regulates the function of NTRs by controlling the nucleocytoplasmic Ran gradient (Bhattacharya and Steward, 2002). By association of NTF2 to nucleoporins, interaction with nuclear transport receptors that travel through the NPC is conceivable (Bhattacharya and Steward, 2002). Therefore, binding of NTF2 to MOS6 suggests a conjunction of NTF2/Ran complexes and nuclear import complexes at the NPC. However, interaction of NTF2 with MOS6 or IMP- $\alpha 6$ could not be confirmed after transient expression in $N$. benthamiana (Figure 3.17). This could be due to the heterologous expression system in N. benthamiana, where putative mediators for an interaction between MOS6 and/or IMP- $\alpha 6$ and NTF2 might not be present. An involvement in immunity against Pst DC3000 ( $\triangle$ AvrPto/AvrPtoB) could not be observed by use of an ntf2 T-DNA insertion line (Figure 3.19), suggesting that NTF2 is either not required for plant immunity or works redundantly with other NTF2 proteins or karyopherins.

The data summarized above suggest that selective interactions of MOS6 and other IMP-as with various co-receptors as for example IMP- $\beta$ s, TRN1 or NTF2 could represent different routes through the NPC that might be required for modulation of specific plant responses. Differential routes of nuclear import complexes through the NPC could involve selective interaction with specific nucleoporins. This is further supported by the finding that MOS6 and IMP- $\alpha 6$ interact with different subsets of nucleoporins (4.2.1.1). 


\subsubsection{MYB70, ORS1 and WRKY60 interact with MOS6 but not with IMP- $\alpha 6$}

All three transcription factors (MYB70, ORS1 and WRKY60) that were selected for further analysis from the PPIN-1 database co-immunoprecipitated MOS6-3xHA-SII but not IMP- $\alpha 6-3 \times \mathrm{HA}-\mathrm{SII}$ in N. benthamiana (Figure 3.17). These results are consistent with data from the yeast two hybrid assays of the PPIN-1 network (Mukhtar et al., 2011). In this work, altered susceptibility towards Pst DC3000 ( $\triangle$ AvrPto/AvrPtoB) was not observed for the myb70 T-DNA line (Figure 3.19). The function of MOS6 in basal responses towards Pst DC3000 ( $\triangle$ AvrPto/AvrPtoB) infection is therefore probably independent of MYB70. However, interestingly, MYB70 is targeted by various $H$. $a$. effectors and loss of MYB70 renders Arabidopsis more susceptible to H. a. NOCO2 (Weßling et al., 2014; Mukhtar et al., 2011). This suggests a central role for MYB70 in basal defense against this virulent oomycete. MOS6 is also involved in basal resistance against this pathogen (Palma et al., 2005), and both proteins interact in planta (Figure 3.17). Therefore, it is tempting to speculate that MOS6 mediates nuclear transport of MYB70 for basal defense against $H$. $a$. NOCO2. However, whether MOS6 influences nuclear localization of MYB70 remains to be assessed.

The MOS6-interacting NAC transcription factor ORS1 (ORESARA1 SISTER1) was found to regulate senescence in Arabidopsis and its transcription is strongly induced by $\mathrm{H}_{2} \mathrm{O}_{2}$ treatment (Balazadeh et al., 2011; Matallana-Ramirez et al., 2013). Loss of ORS1 function in the ors1 T-DNA line did not result in altered susceptibility against Pst DC3000 ( $\triangle$ AvrPto/AvrPtoB, Figure 3.19). Notably, the expression of WRKY4O was upregulated upon nuclear localization of ORS1 (Balazadeh et al., 2011) which suggests that ORS1 is involved in regulating WRKY4O gene expression. Interestingly, in addition to ORS1, WRKY60-cCFP also co-precipitated MOS6-3xHA-SII but not IMP- $\alpha 6-3 x H A-S I I$ (Figure 3.17). WRKY60 co-operates with WRKY18 and WRKY40 in plant defense regulation (Chen et al., 2010; $\mathrm{Xu}$ et al., 2006). Loss of WRKY60 has no effect on resistance against virulent Pst DC3000 and virulent powdery mildew pathogens (Xu et al., 2006). This coincides with the finding that susceptibility to Pst DC3000 ( $\triangle$ AvrPto/AvrPtoB) was not altered in the wrky60 single mutant (Figure 3.17). The wrky18 wrky60 and wrky18 wrky40 double mutants and the wrky18 wrky40 wrky60 triple mutant, however, are more resistant to Pst DC3000 and more susceptible to the necrotrophic pathogen Botrytis cinerea than 
wild-type plants (Xu et al., 2006). Additionally, wrky18 wrky40 is more resistant to Golovinomyces orontii (Shen et al., 2007). These findings demonstrate partially redundant roles for the three WRKY TFs in immunity towards biotrophic and necrotrophic pathogens. It would be interesting to test whether MOS6 also interacts with WRKY18 and WRKY40. However, the opposite phenotypes of mos6 mutants (more susceptible towards Pst DC3000 ( $\triangle$ AvrPto/AvrPtoB)) and the wrky18 wrky40 wrky60 triple mutant (more resistant towards Pst DC3000) imply that MOS6-mediated nuclear transport is either dispensable for nuclear localization of these WRKY TFs or that other IMP-as act redundantly with MOS6 in nuclear import of WRKY18, WRKY40 and WRKY60.

In addition to their role in plant defense, WRKY18, WRKY40 and WRKY60 act as repressors of abscisic acid (ABA) signaling (Liu et al., 2012). Interestingly, high levels of ABA relocate WRKY40, and probably WRKY18 and WRKY60 as well, from the nucleus to the cytoplasm to release inhibition of ABA-responsive genes (Shang et al., 2010). This is accomplished by interaction of WRKY40 with the chloroplast envelope ABA receptor (the magnesium-protophorphyrin IX chelatase H subunit, Shang et al., 2010). These data further underline the importance of dynamic nuclear-cytoplasmic localization of WRKY transcription factors. Another link between ABA-responses and disease resistance is represented by the finding that ABA deficiency leads to accumulation of the TIR-NB-LRR R proteins SNC1 and RPS4 in the nucleus (Mang et al., 2012). Whether MOS6-dependent nuclear transport of SNC1 and RPS4 is involved in these processes is an interesting question to pursue.

The suppression of snc1-mediated phenotypes by mutations in MOS6 (Figure 3.1, Palma et al., 2005) suggests a role for MOS6 in nuclear transport of auto-active snc1. However, SNC1 was not identified as MOS6 interaction partner in the affinity-purification approach. This might be due to the fact that wild-type SNC1 but not the auto-active snc1 variant were present in the transgenic mos6-1 line expressing MOS6-3xHA-SII. The amino acid substitution that leads to the snc1 phenotype is located in the linker region between the NBS and LRR domains and possibly alters snc1 protein conformation (Zhang et al., 2003). Interestingly, the snc1 mutation is located in close proximity to a predicted NLS and NES. Therefore, it is conceivable that the constitutively active conformation might lead to enhanced nuclear import of snc1 by MOS6. Consistent with this scenario, it was 
shown that snc1 needs to accumulate in the nucleus for activation of auto-immunity (Cheng et al., 2009). To test whether MOS6 is able to bind the auto-active snc1 variant, affinity purification could be executed with the transgenic lines expressing MOS6-3xHA-SII in snc1 mos6-1 (Figure 3.15). Notably, these lines have been shown to express functional 3xHA-SIl-tagged MOS6 by reconstitution of the growth phenotype back to snc1 morphology (3.2.2, Figure 3.15). This will allow purifying MOS6 cargo proteins and interaction partners in the snc1 auto-immune background that shows constitutive activation of defense responses. This may yield further information on MOS6-mediated nuclear transport in TNL-mediated immunity.

Auto-immunity in snc1 fully depends on the defense regulator EDS1, but like SNC1, EDS1 was not found in MOS6 affinity purifications from $H$. a. NOCO2 infected samples. This could be due to relatively weak nuclear accumulation of EDS1 in basal defense responses compared to TNL-mediated resistance or snc1 auto-immunity (García et al., 2010). Consequently, nuclear import rates of EDS1 might have been too low to detect EDS1 in mass spectrometric analyses after MOS6 affinity purification. To tackle the problem of detecting low-abundant or weakly interacting NLS-cargo substrates, transgenic lines should be generated that express $\triangle$ IBB-MOS6-3xHA-SII (MOS6 without its IBB domain) in mos6-1 or snc1 mos6-1 background. It was shown previously that mutation or deletion of the IBB domain responsible for interaction with IMP- $\beta$ leads to accumulation of IMP- $\alpha$ proteins in the cytoplasm (Görlich et al., 1996; Zannini et al., 2003). Cytoplasmic retention subsequently inhibits cargo-release because of the spatial separation from nuclear localized Ran-GTP (Görlich et al., 1996; Zannini et al., 2003). Accordingly, the advantage of $\triangle$ IBB-MOS6-3xHA-SII expressing lines is the cytoplasmic retention/accumulation of MOS6/cargo complexes. Such lines would provide a useful tool to enhance the efficiency of future MOS6 affinity purification experiments.

\subsubsection{MOS6 but not its closest homolog IMP- $\alpha 6$ interacts with the TIR-NBS protein TN13 which is involved in plant innate immunity}

The Arabidopsis genome contains a large number of TIR-domain encoding genes (estimations range from 82 to 93 genes, Sun et al., 2014; Meyers, 2003; Yang et al., 2008). 
Typically, TIR-NB-LRR family proteins function in ETI as immune receptors that indirectly or directly recognize pathogenic effector proteins. Signals from TNLS converge on the lipase-like protein EDS1 (Aarts et al., 1998; García et al., 2010).

Two members of the TIR-NBS-domain family of defense related proteins were analyzed in this study: a not yet characterized TIR-NBS-LRR (TNL) protein and TIR-NBS 13 (TN13, Table 3.2). TN13 is lacking a C-terminal LRR protein domain. Therefore, it belongs to the group of Arabidopsis TIR-NBS (TN) proteins (Nandety et al., 2013; Meyers et al., 2002). Both proteins co-precipitated MOS6-3xHA-SII (Figure 3.17). Interestingly TNL interacted with IMP- $\alpha 6-3 \times \mathrm{HA}-\mathrm{SII}$ after transient expression in $N$. benthamiana (Figure 3.17), suggesting redundant functions in TNL-nuclear transport for MOS6 and IMP- $\alpha 6$. TN13 selectively interacted with MOS6 in ColP analyses, reinforcing the idea of MOS6substrate specificity. Blast searches revealed that TNL shares $80 \%$ identity on amino acid level with RPP1-WsB (RECOGNITION OF PERONOSPORA PARASITICA1 from Arabidopsis accession Wassilewskija, Altschul et al., 1990). For TN13 60 \% identity with RPP1-WsA was detected (supplementary Figure S1). RPP1 confers resistance to different $H$. $a$. isolates in Arabidopsis accession Ws-0 through direct binding of the cognate effector ATR1 via its LRR repeat domain (Rehmany et al., 2005; Botella et al., 1998; Krasileva et al., 2010; Steinbrenner et al., 2015). Effector triggered immunity of Col-0 against the $H$. $a$. isolates CALA2 and EMWA1 is mediated by the TNLS RPP4 and RPP2, respectively (Botella et al., 1998; Caillaud et al., 2012b). However, the $t n l$ and $t n 13$ mutant lines did not show altered resistance towards these avirulent oomycetes (Figure 3.19), indicating that TNL and TN13 are not required for RPP2 and RPP4 mediated immunity. To assess their involvement in basal resistance, susceptibility towards Pst DC3000 ( $\triangle$ AvrPto/AvrPtoB) was analyzed. Bacterial proliferation was not altered by loss of TNL (Figure 3.19). In contrast to the $t n I$ mutant, the T-DNA insertion mutant of the TN13 gene was more susceptible against Pst DC3000 ( $\triangle$ AvrPto/AvrPtoB, Figure 3.19). Notably, a similar phenotype was demonstrated for mos6 mutants (Figure 3.2). Together with the finding that TN13 interacts with MOS6 in planta these results suggest collaborative roles of MOS6 and TN13 in basal plant immunity. To address the question whether both proteins function together in plant defense, double mos 6 tn13 mutants should be generated for gene interaction analysis. 


\subsection{Possible roles for the TIR-NBS protein TN13 in plant defense signaling}

In addition to TIR-NB-LRR (TNL), TIR-X (TX) and TIR-NBS (TN) proteins were described that either contain various domains (TX) or only the NBS-domain in addition to the TIR-domain (TN, Meyers et al., 2002; Nandety et al., 2013). Arabidopsis TN proteins are suggested to function as adaptor proteins in plant defense signaling similar to MyD88 (MYELOID DIFFERENTIATION PRIMARY RESPONSE GENE 88) and MyD88-adapter-like proteins in mammalian and Drosophila immune responses (Horng and Medzhitov, 2001; Medzhitov et al., 1998; Meyers et al., 2002). Interestingly, the Arabidopsis TN protein TN2 was found to directly interact with the exocyst complex subunit EXO70B1 which mediates vesicle exocytosis (Zhao et al., 2015). Since exo70b1 mutants show enhanced resistance against Pst DC3000, virulent oomycetes and powdery mildews, it was suggested that TN2 functions as a guard for EXO70B1 (Zhao et al., 2015; Stegmann et al., 2012). Although effector targeting to EXO70B1 has not been shown, it is tempting to speculate that guarding of proteins involved in PTI is a function executed by TN proteins (Zhao et al., 2015). Nandety et al. (2013) demonstrated effector binding to various TN proteins by yeast two hybrid analyses. Interestingly, the MOS6-interactor TN13 was shown to interact with the Pst DC3000 effector HopY and nematode effector Rbp001 (Nandety et al., 2013). This suggests a hypothetical role for TN13 as an effector target which is consistent with its involvement in basal immunity against Pst DC3000 ( $\triangle$ AvrPto/AvrPtoB, Figure 3.19).

Certain TN proteins were shown to induce EDS1-dependent HR responses upon transient expression in N. benthamiana and this was also shown for truncated TNL proteins that only contained TIR and NBS domains (Nandety et al., 2013; Weaver et al., 2006; Swiderski et al., 2009). This effect was not observed upon transient expression of TN13-CCFP, suggesting that expression of TN13 alone is not sufficient to trigger cell death in $N$. benthamiana. Overexpression of TN13 in Col-0 did not lead to altered immune responses upon challenge with Pst DC3000 nor to aberrant plant growth phenotypes (Nandety et al., 2013). A genetic requirement of TN13 for growth-retardation in the TIR-NB-LRR auto-immune mutant snc1 that accumulates high levels of SA was not observed (Figure 3.19). Interestingly, TN13 gene expression is ten-fold increased at 4 and $52 \mathrm{~h}$ after SA treatment suggesting an involvement of TN13 in SA-dependent defense pathways (Nandety et al., 2013). 
The Arabidopsis genome contains genetically linked pairs of $T N$ and TNL genes which are discussed to be cooperatively required for defense responses in plants (Eitas and Dangl, 2010; Meyers et al., 2002; Zbierzak et al., 2013). Interestingly, the TN13 gene (encoded by AT3G04210) is located head-to-tail next to AT3G04220, encoding a predicted TNL protein (Figure $3.20 \mathrm{~A}$ ). This resembles the situation of two TNL R genes, RRS1 and RPS4, that are genomically linked head-to-head (Narusaka et al., 2009). Recently, direct interaction of the TIR domains of RPS4 and RRS1, individually and as a heterodimeric complex was revealed (Williams et al., 2014). Also, binding of the effectors AvrRps4 and PopP2 to the RPS4/RRS1 complex and RRS1 alone was demonstrated (Williams et al., 2014). In addition to TIR-NB-LRR domains, RRS1 contains a WRKY domain that negatively regulates disease resistance signaling (Noutoshi et al., 2005). Consistent with the findings that nucleotide-binding by RPS4 is required for function of the RPS4/RRS1 complex and that RRS1 seems to be the prime effector target, it was suggested that RPS4 guards RRS1 (Nishimura and Dangl, 2014; Williams et al., 2014). Similarly, the rice CNL pairs RGA4/5, $\mathrm{Pi} 5-1 / 2$ and Pik-1/2 are encoded by genes linked tail-to-tail and co-operate in immunity against Magnaporthe oryzae (Ashikawa et al., 2008; Cesari et al., 2013; Lee et al., 2009; Okuyama et al., 2011; Yuan et al., 2011; Zhai et al., 2011). These data raise the question whether TN13 is part of a TN/TNL pair together with AT3G04220. The finding that TN13 binds to a Pst effector (HopY, Nandety et al., 2013) suggests that TN13 either directly recognizes this effector or that it is an effector-target and guarded by AT3G04220.

Typically, TNL R protein activation leads to ETI, but TN13 was found to be required for basal immunity against Pst DC3000 ( $\triangle$ AvrPto/AvrPtoB, Figure 3.19). Therefore, it is tempting to speculate that TN13 is involved in a defense mechanism comparable to MLA10-mediated de-repression of PTI in barley (Shen et al., 2007). Recognition of the Blumeria graminis effector $\mathrm{Avr}_{\mathrm{A} 10}$ by the barley CC-NB-LRR (CNL) R protein MLA10 leads to $A v r_{A 10}$-dependent association between MLA10 and WRKY1/2 in the nucleus to de-repress PAMP-triggered basal defense (Shen et al., 2007). Hence, Shen et al., describe a mechanistic link between ETI and PTI represented through the interference with WRKY PTI-repression by association with NB-LRR proteins (Shen et al., 2007). Interestingly, barley WRKY1 and WRKY2 are homologs of Arabidopsis WRKY18 and WRKY40 (Shen et al., 2007). It is conceivable, to postulate that TN13 may mediate "weak ETI" as part of the 
basal defense response (against Pst DC3000 ( $\triangle$ AvrPto/AvrPtoB)) as has been suggested by Jones and Dangl (2006). Thomma et al. (2011) argue that the definitions used to distinguish between PAMP- and effector triggered immunity become blurred the more knowledge about the underlying mechanisms of plant defense is gained. They suggest that some evolutionarily ancient effectors that are present in different pathogen species and contribute to pathogenicity might act as PAMPs (Thomma et al., 2011). The function of the TN13 associated effector HopY has not yet been elucidated (Marín et al., 2013; O'Brien et al., 2011; Baltrus et al., 2011; Marín et al., 2013). It would be interesting to analyze whether the interaction of TN13 with HopY plays a role in plant defense and whether the TNL protein AT3G04220 is involved in this process. A simplified hypothetical model of how TN13 might be activated by HopY is summarized in Figure 4.1.

\subsubsection{The TIR-NBS protein TN13 localizes to the endoplasmic reticulum when expressed transiently in $\mathbf{N}$. benthamiana}

Diverse sub-cellular localizations have been found for TN and TX family members, such as the nucleus, cytoplasm and plasma membrane, suggesting different functions for these proteins (Nandety et al., 2013). Interestingly, TN13-cCFP was found to localize to the endoplasmic reticulum (ER) and nuclear envelope (NE) when transiently expressed in N. benthamiana although it contains two predicted bipartite NLS motifs (Figure 3.20). TN13 localization to the ER that is continuous with the NE can be explained by the presence of a hydrophobic peptide at its $\mathrm{N}$-terminus that might be responsible for membrane insertion (Figure 3.20 B) similar to what was shown for RPP1-WsA (Weaver et al., 2006). TN13 was identified as an interactor of MOS6 (Figure 3.17), and since MOS6 localizes to the cytoplasm and the nucleus, interaction between both proteins probably takes place in either or both of these subcellular compartments (Palma et al., 2005; Mukhtar et al., 2011). However, no obvious nuclear accumulation of TN13 was observed after transient expression in N. benthamiana leaves (Figure 3.20 C and D). This raises the question whether nuclear accumulation of TN13 is stimulus dependent (Figure 4.1). Interaction with Pst expressing the HopY effector could be an example for such a stimulus (Nandety et al., 2013). It is important to note that the transient localization studies of TN13-cCFP in N. benthamiana were conducted in the absence of MOS6. Therefore, an 
important question that remains to be assessed is whether Agrobacterium-mediated transient co-expression together with MOS6 leads to nuclear localization of TN13-cCFP.

During pathogen infection the host plant's endomembrane trafficking is reorganized for secretion of defense proteins into the apoplast (Wang et al., 2005; Teh and Hofius, 2014). NLRs that locate to endomembrane compartments such as the ER or the Golgi system possibly play a role in sensing perturbations caused by pathogenic effectors (Takemoto et al., 2012; Qi et al., 2012). Intriguingly, in Linum usitatissimum (flax), two TNLs were found to localize to the Golgi system and the tonoplast, respectively (Takemoto et al., 2012). These TNLs have been demonstrated to recognize specific rust fungal effectors (Takemoto et al., 2012). Additional TNLs that localize to the ER or other endomembranes and activate ETI upon cognate effector recognition in Arabidopsis are RPS4 and RPP1-WsA (Takemoto et al., 2012; Weaver et al., 2006; Krasileva et al., 2010; Steinbrenner et al., 2012; Gassmann et al., 1999; Wirthmueller et al., 2007; Deslandes et al., 2003). RPS4 contains a NLS and nuclear localization of RPS4 is necessary for AvrRps4-triggered immunity (Wirthmueller et al., 2007). Recently, EDS1 was identified as effector target that associates with RPS4 at endomembranes and RPS4/EDS1 complexes were shown to mediate different defense branches dependent on localization either to the nucleus or the cytosol (Heidrich et al., 2011; Bhattacharjee et al., 2011). RPP1-WsA was shown to contain a hydrophobic peptide at its $\mathrm{N}$-terminus that directs the protein into ER and Golgi membranes (Weaver et al., 2006). As mentioned above, TN13 shares $60 \%$ identity on amino acid level with RPP1-WsA (supplementary Figure S1) and also contains a stretch of hydrophobic amino acids at its $\mathrm{N}$-terminus (Figure $3.20 \mathrm{~B}$ ).

These examples highlight the endomembrane system as site for dynamic $R$ protein signaling. Together with the notion that some TN and TNL genes constitute genomic pairs that are required for defense responses and the interaction of TN13 with the HopY effector and MOS6 (Figure 3.17), a hypothetical model for the function and subcellular localization dynamics of TN13 is presented in Figure 4.1 (Eitas and Dangl, 2010; Meyers et al., 2002; Griebel et al., 2014; Nandety et al., 2013).

From the ColP experiments it can be deduced that TN13 and MOS6 interact in unstressed N. benthamiana leaves upon Agrobacterium-mediated transient expression (Figure 3.17). Since TN13 localizes to the ER in this tissue (Figure 3.20), interaction with 
MOS6 can only take place at the cytoplasmic side of the ER membrane. Therefore, MOS6 could associate with the predicted C-terminal bipartite NLS of TN13 (Figure 3.20 B). This hypothesized interaction of MOS6 and TN13 might represent a preformed nuclear import complex that is sequestered at the ER (Figure 4.1). Pathogen attack might trigger release of such a complex from the ER membrane by proteolytic cleavage mediated by interaction with a hypothetical protease. Release of TN13 from the ER membrane would

A

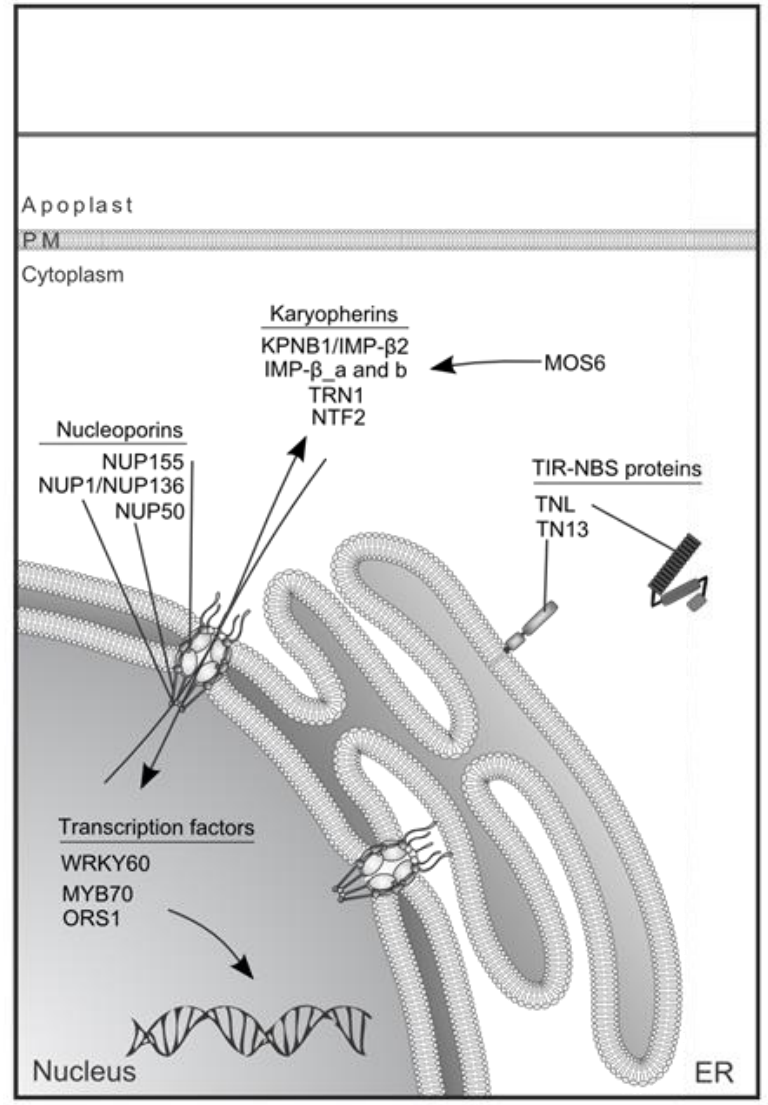

B

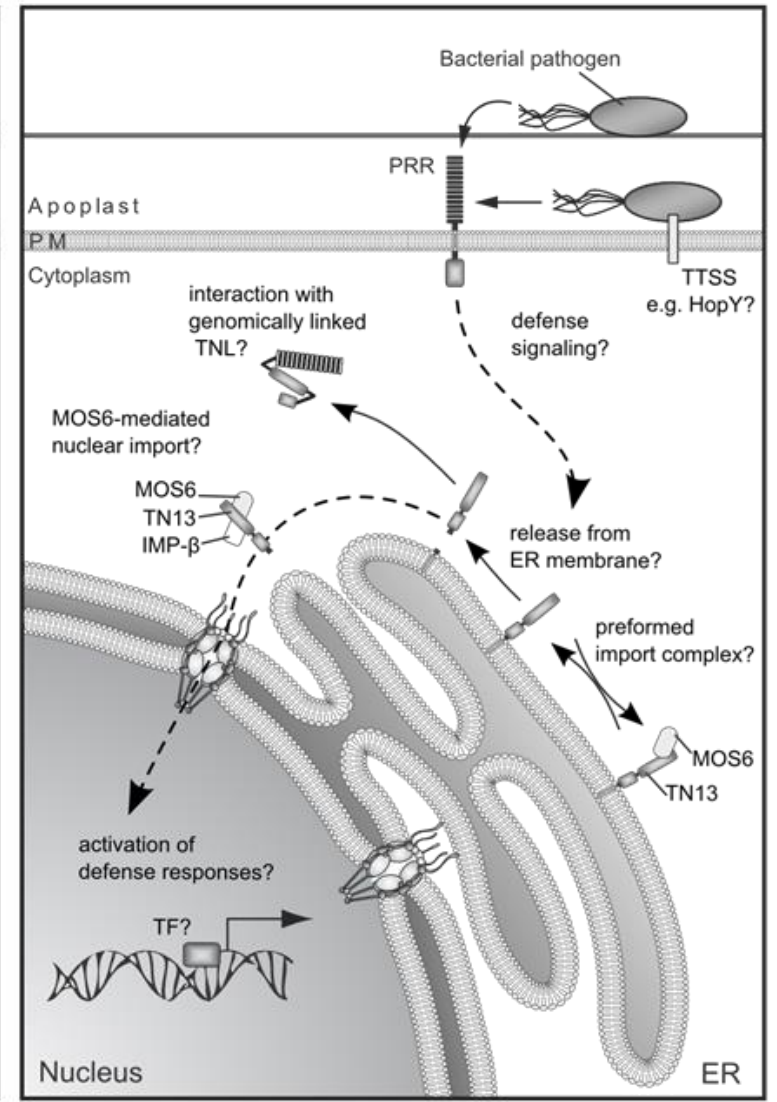

Figure 4.1 Simplified, hypothetical model summarizing the cellular localization of identified MOS6 interactors and the association of MOS6 and TN13 in plant immunity. A) Predicted localization of identified MOS6 interactors in unchallenged cells. The MOS6 interactors characterized in this study are grouped into karyopherins, nucleoporins, transcription factors and TIR-NBS proteins (Table 3.2). The TIRNBS protein TN13 localizes to the ER in uninfected cells (Figure 3.20). B) Hypothetical model for nuclear translocation of TN13 in basal immunity. TN13 localizes to the ER in unstressed cells and might associate with MOS6 in a preformed import complex via a NLS motif at its C-terminus. Pathogen attack might trigger release of TN13 from the ER-membrane by proteolytic cleavage by a hypothetical protease and thus release of TN13 from the ER membrane. Cytosolic TN13 could be imported into the nucleus by MOS6 and association of IMP- $\beta$. The formation of a preformed import complex provides the possibility of rapid stimulus-induced nuclear localization. In the nucleus, putative activation of defense responses that are required for maintaining the basal resistance layer to Pst DC3000 ( $\triangle$ AvrPto/AvrPtoB) might occur. The genomically linked TIR-NB-LRR (TNL) protein might associate with TN13 in the cytosol and/or at the ER membrane. It is also conceivable that this TNL protein is transported into the nucleus as well and guards TN13 since TN13 was shown to associate with the Pseudomonas effector HopY (Nandety et al., 2013). 
allow access of MOS6 to a second putative NLS in TN13 located at the N-terminus which might accelerate nuclear transport.

In order to assess whether this model holds true and TN13 undergoes a pathogeninduced re-localization from the ER to the nucleus in Arabidopsis, stable transgenic tn13 plants expressing TN13-cCFP are currently generated. Also, expression of TN13-cCFP in the mos6 mutant background will help to further elucidate subcellular localization dynamics of TN13 in response to pathogen challenge and its dependency on MOS6 for nuclear transport.

\subsection{Outlook}

The findings presented in this study revealed preferential binding of MOS6 to the TIR-NBS protein TN13. TN13 localizes to the ER when transiently expressed in N. benthamiana and is required for basal resistance against Pst DC3000 ( $\triangle$ AvrPto/AvrPtoB).

To further analyze the involvement of TN13 in plant immunity, the tn13 T-DNA insertion mutant should be inoculated with avirulent strains of the bacterial pathogen Pseudomonas syringae. This will allow to directly test the requirement of TN13 in $R$ gene mediated resistance against these pathogens. The TNL gene AT3G04220 is genomically linked with $T N 13$, suggesting cooperative functions in plant immunity. The genetic requirement of AT3G04220 in plant disease resistance should be assessed by use of respective T-DNA insertion mutants.

Stable transgenic Arabidopsis tn13 plants expressing TN13-cCFP should provide a powerful tool to analyze the subcellular localization dynamics of TN13 in response to pathogen attack. This will test the hypothesis that TN13 relocates from the ER to the nucleus upon pathogen induction. If this model holds true, stable expression of TN13cCFP in mos6 tn13 double mutant plants would allow investigating the requirement of MOS6 for TN13 nuclear localization upon pathogen challenge.

Finally, stable transgenic plants expressing MOS6-3xHA-SII in the snc1 autoimmune mutant background as well as lines stably expressing $\triangle \mathrm{IBB}-\mathrm{MOS6}-3 \times \mathrm{HA}-\mathrm{SII}$ might be powerful tools to identify additional and potentially low-abundant/low-affinity cargo proteins of MOS6 that are involved in nucleocytoplasmic defense signaling. 


\section{References}

Aarts, N., Metz, M., Holub, E., Staskawicz, B.J., Daniels, M.J., and Parker, J.E. (1998). Different requirements for EDS1 and NDR1 by disease resistance genes define at least two $\mathrm{R}$ gene-mediated signaling pathways in Arabidopsis. Proc Natl Acad Sci U S A 95 (17): 10306-10311.

Alber, F., Dokudovskaya, S., Veenhoff, L.M., Zhang, W., Kipper, J., Devos, D., Suprapto, A., Karni-Schmidt, O., Williams, R., Chait, B.T., Sali, A., and Rout, M.P. (2007). The molecular architecture of the nuclear pore complex. Nature 450 (7170): 695-701.

Alcázar, R., and Parker, J.E. (2011). The impact of temperature on balancing immune responsiveness and growth in Arabidopsis. Trends in plant science 16 (12): 666-675.

Alonso, J.M., Stepanova, A.N., Leisse, T.J., Kim, C.J., Chen, H., Shinn, P., Stevenson, D.K., Zimmerman, J., Barajas, P., Cheuk, R., Gadrinab, C., Heller, C., Jeske, A., Koesema, E., Meyers, C.C., Parker, H., Prednis, L., Ansari, Y., Choy, N., Deen, H., Geralt, M., Hazari, N., Hom, E., Karnes, M., Mulholland, C., Ndubaku, R., Schmidt, I., Guzman, P., Aguilar-Henonin, L., Schmid, M., Weigel, D., Carter, D.E., Marchand, T., Risseeuw, E., Brogden, D., Zeko, A., Crosby, W.L., Berry, C.C., and Ecker, J.R. (2003). Genome-wide insertional mutagenesis of Arabidopsis thaliana. Science 301 (5633): 653-657.

Altschul, S.F., Gish, W., Miller, W., Myers, E.W., and Lipman, D.J. (1990). Basic local alignment search tool. J Mol Biol 215 (3): 403-410.

Arabidopsis Interactome Mapping Consortium (2011). Evidence for network evolution in an Arabidopsis interactome map. Science 333 (6042): 601-607.

Ashikawa, I., Hayashi, N., Yamane, H., Kanamori, H., Wu, J., Matsumoto, T., Ono, K., and Yano, M. (2008). Two adjacent nucleotide-binding site-leucine-rich repeat class genes are required to confer Pikmspecific rice blast resistance. Genetics 180 (4): 2267-2276.

Azuma, Y., Tabb, M.M., Vu, L., and Nomura, M. (1995). Isolation of a yeast protein kinase that is activated by the protein encoded by SRP1 (Srp1p) and phosphorylates Srp1p complexed with nuclear localization signal peptides. Proc Natl Acad Sci U S A 92 (11): 5159-5163.

Bai, X., Correa, V.R., Toruño, T.Y., Ammar, E.-D., Kamoun, S., and Hogenhout, S.A. (2009). AY-WB phytoplasma secretes a protein that targets plant cell nuclei. Mol Plant Microbe Interact. 22 (1): $18-30$.

Balazadeh, S., Kwasniewski, M., Caldana, C., Mehrnia, M., Zanor, M.I., Xue, G.P., and Mueller-Roeber, B. (2011). ORS1, an $\mathrm{H}_{2} \mathrm{O}_{2}$-responsive NAC transcription factor, controls senescence in Arabidopsis thaliana. Molecular plant 4 (2): 346-360.

Ballas, N., and Citovsky, v. (1997). Nuclear localization signal binding protein from Arabidopsis mediates nuclear import of Agrobacterium VirD2 protein. Proc Natl Acad Sci U S A 94 (20): 10723-10728.

Ballesteros, M.L., Bolle, C., Lois, L.M., Moore, J.M., Vielle-Calzada, J.P., Grossniklaus, U., and Chua, N.H. (2001). LAF1, a MYB transcription activator for phytochrome A signaling. Genes Dev 15 (19): 26132625.

Baltrus, D.A., Nishimura, M.T., Romanchuk, A., Chang, J.H., Mukhtar, M.S., Cherkis, K., Roach, J., Grant, S.R., Jones, C.D., and Dangl, J.L. (2011). Dynamic evolution of pathogenicity revealed by sequencing and comparative genomics of 19 Pseudomonas syringae isolates. PLoS pathogens 7 (7): e1002132.

Bannister, A.J., Miska, E.A., Gorlich, D., and Kouzarides, T. (2000). Acetylation of importin-alpha nuclear import factors by CBP/p300. Curr Biol 10 (8): 467-470.

Bartsch, M., Gobbato, E., Bednarek, P., Debey, S., Schultze, J.L., Bautor, J., and Parker, J.E. (2006). Salicylic acid-independent ENHANCED DISEASE SUSCEPTIBILITY1 signaling in Arabidopsis immunity and cell death is regulated by the monooxygenase FMO1 and the Nudix hydrolase NUDT7. The Plant cell 18 (4): 1038-1051.

Bauer, Z., Gómez-Gómez, L., Boller, T., and Felix, G. (2001). Sensitivity of different ecotypes and mutants of Arabidopsis thaliana toward the bacterial elicitor flagellin correlates with the presence of receptorbinding sites. The Journal of biological chemistry 276 (49): 45669-45676.

Bayliss, R., Littlewood, T., and Stewart, M. (2000). Structural basis for the interaction between FxFG nucleoporin repeats and importin-beta in nuclear trafficking. Cell 102 (1): 99-108.

Bhattacharjee, S., Halane, M.K., Kim, S.H., and Gassmann, W. (2011). Pathogen effectors target Arabidopsis EDS1 and alter its interactions with immune regulators. Science 334 (6061): 1405-1408.

Bhattacharjee, S., Lee, L.-Y., Oltmanns, H., Cao, H., Veena, Cuperus, J., and Gelvin, S.B. (2008). IMPa-4, an Arabidopsis importin alpha isoform, is preferentially involved in agrobacterium-mediated plant transformation. Plant Cell 20 (10): 2661-2680. 
Bhattacharya, A., and Steward, R. (2002). The Drosophila homolog of NTF-2, the nuclear transport factor-2, is essential for immune response. EMBO Rep 3 (4): 378-383.

Birkenbihl, R.P., Diezel, C., and Somssich, I.E. (2012). Arabidopsis WRKY33 is a key transcriptional regulator of hormonal and metabolic responses toward Botrytis cinerea infection. Plant physiology 159 (1): $266-$ 285.

Boch, J., and Bonas, U. (2010). Xanthomonas AvrBs3 family-type III effectors: discovery and function. Annual review of phytopathology 48: 419-436.

Bogerd, H.P., Benson, R.E., Truant, R., Herold, A., Phingbodhipakkiya, M., and Cullen, B.R. (1999). Definition of a consensus transportin-specific nucleocytoplasmic transport signal. J Biol Chem 274 (14): 9771-9777.

Boller, T., and Felix, G. (2009). A renaissance of elicitors: perception of microbe-associated molecular patterns and danger signals by pattern-recognition receptors. Annual review of plant biology 60: 379406.

Boller, T., and He, S.Y. (2009). Innate immunity in plants: An arms race between pattern recognition receptors in plants and effectors in microbial pathogens. Science 324 (5928): 742-744.

Botella, M.A., Parker, J.E., Frost, L.N., Bittner-Eddy, P.D., Beynon, J.L., Daniels, M.J., Holub, E.B., and Jones, J.D. (1998). Three genes of the Arabidopsis RPP1 complex resistance locus recognize distinct Peronospora parasitica avirulence determinants. Plant Cell 10 (11): 1847-1860.

Briesemeister, S., Rahnenführer, J., and Kohlbacher, O. (2010a). Going from where to why--interpretable prediction of protein subcellular localization. Bioinformatics (Oxford, England) 26 (9): 1232-1238.

Briesemeister, S., Rahnenführer, J., and Kohlbacher, O. (2010b). YLoc--an interpretable web server for predicting subcellular localization. Nucleic acids research 38 (Web Server issue): W497-502.

Burch-Smith, T.M., Schiff, M., Caplan, J.L., Tsao, J., Czymmek, K., and Dinesh-Kumar, S.P. (2007). A novel role for the TIR domain in association with pathogen-derived elicitors. PLoS Biol 5 (3): e68.

Caillaud, M.-C., Piquerez, Sophie J.M., Fabro, G., Steinbrenner, J., Ishaque, N., Beynon, J., and Jones, J.D.G. (2012a). Subcellular localization of the Hpa RxLR effector repertoire identifies a tonoplastassociated protein HaRxL17 that confers enhanced plant susceptibility. Plant J 69 (2): 252-265.

Caillaud, M.-C., Wirthmueller, L., Fabro, G., Piquerez, S.J.M., Asai, S., Ishaque, N., and Jones, J.D.G. (2012b). Mechanisms of nuclear suppression of host immunity by effectors from the Arabidopsis downy mildew pathogen Hyaloperonospora arabidopsidis (Hpa). Cold Spring Harbor symposia on quantitative biology 77: 285-293.

Cao, H., Bowling, S.A., Gordon, A.S., and Dong, X. (1994). Characterization of an Arabidopsis Mutant That Is Nonresponsive to Inducers of Systemic Acquired Resistance. Plant Cell 6 (11): 1583-1592.

Capelson, M., and Hetzer, M.W. (2009). The role of nuclear pores in gene regulation, development and disease. EMBO reports 10 (7): 697-705.

Caplan, J., Padmanabhan, M., and Dinesh-Kumar, S.P. (2008a). Plant NB-LRR immune receptors: from recognition to transcriptional reprogramming. Cell Host Microbe 3 (3): 126-135.

Caplan, J.L., Mamillapalli, P., Burch-Smith, T.M., Czymmek, K., and Dinesh-Kumar, S.P. (2008b). Chloroplastic protein NRIP1 mediates innate immune receptor recognition of a viral effector. Cell 132 (3): 449-462.

Cesari, S., Thilliez, G., Ribot, C., Chalvon, V., Michel, C., Jauneau, A., Rivas, S., Alaux, L., Kanzaki, H., Okuyama, Y., Morel, J.-B., Fournier, E., Tharreau, D., Terauchi, R., and Kroj, T. (2013). The rice resistance protein pair RGA4/RGA5 recognizes the Magnaporthe oryzae effectors AVR-Pia and AVR1CO39 by direct binding. The Plant cell 25 (4): 1463-1481.

Chang, C.-W., Couñago, R.M., Williams, S.J., Boden, M., and Kobe, B. (2013). The distribution of different classes of nuclear localization signals (NLSs) in diverse organisms and the utilization of the minor NLSbinding site inplantnuclear import factor importin- $\alpha$. Plant signaling \& behavior 8 (10).

Chen, H., Lai, Z., Shi, J., Xiao, Y., Chen, Z., and Xu, X. (2010). Roles of arabidopsis WRKY18, WRKY40 and WRKY60 transcription factors in plant responses to abscisic acid and abiotic stress. BMC plant biology 10: 281.

Cheng, Y.T., Germain, H., Wiermer, M., Bi, D., Xu, F., García, A.V., Wirthmueller, L., Després, C., Parker, J.E., Zhang, Y., and Li, X. (2009). Nuclear pore complex component MOS7/Nup88 is required for innate immunity and nuclear accumulation of defense regulators in Arabidopsis. Plant Cell 21 (8): 2503-2516.

Chisholm, S.T., Coaker, G., Day, B., and Staskawicz, B.J. (2006). Host-microbe interactions: shaping the evolution of the plant immune response. Cell 124 (4): 803-814.

Cingolani, G., Petosa, C., Weis, K., and Müller, C.W. (1999). Structure of importin-beta bound to the IBB domain of importin-alpha. Nature 399 (6733): 221-229. 
Clough, S.J., and Bent, A.F. (1998). Floral dip: a simplified method for Agrobacterium-mediated transformation of Arabidopsis thaliana. Plant J 16 (6): 735-743.

Conti, E., and Kuriyan, J. (2000). Crystallographic analysis of the specific yet versatile recognition of distinct nuclear localization signals by karyopherin alpha. Structure 8 (3): 329-338.

Conti, E., Muller, C.W., and Stewart, M. (2006). Karyopherin flexibility in nucleocytoplasmic transport. Curr Opin Struct Biol 16 (2): 237-244.

Cook, A., Bono, F., Jinek, M., and Conti, E. (2007). Structural biology of nucleocytoplasmic transport. Annu Rev Biochem 76: 647-671.

Cressman, D.E., O'Connor, W.J., Greer, S.F., Zhu, X.S., and Ting, J.P. (2001). Mechanisms of nuclear import and export that control the subcellular localization of class II transactivator. J Immunol 167 (7): 36263634.

Cronshaw, J.M., Krutchinsky, A.N., Zhang, W., Chait, B.T., and Matunis, M.J. (2002). Proteomic analysis of the mammalian nuclear pore complex. J Cell Biol 158 (5): 915-927.

Dangl, J.L., Horvath, D.M., and Staskawicz, B.J. (2013). Pivoting the plant immune system from dissection to deployment. Science (New York, N.Y.) 341 (6147): 746-751.

Dangl, J.L., and Jones, J.D.G. (2001). Plant pathogens and integrated defence responses to infection. Nature 411 (6839): 826-833.

Deslandes, L., Olivier, J., Peeters, N., Feng, D.X., Khounlotham, M., Boucher, C., Somssich, I., Genin, S., and Marco, Y. (2003). Physical interaction between RRS1-R, a protein conferring resistance to bacterial wilt, and PopP2, a type III effector targeted to the plant nucleus. Proc Natl Acad Sci U S A 100 (13): 8024-8029.

Deslandes, L., Olivier, J., Theulieres, F., Hirsch, J., Feng, D.X., Bittner-Eddy, P., Beynon, J., and Marco, Y. (2002). Resistance to Ralstonia solanacearum in Arabidopsis thaliana is conferred by the recessive RRS1-R gene, a member of a novel family of resistance genes. Proc Natl Acad Sci U S A 99 (4): 24042409.

Després, C., Chubak, C., Rochon, A., Clark, R., Bethune, T., Desveaux, D., and Fobert, P.R. (2003). The Arabidopsis NPR1 Disease Resistance Protein Is a Novel Cofactor That Confers Redox Regulation of DNA Binding Activity to the Basic Domain/Leucine Zipper Transcription Factor TGA1. Plant Cell 15 (9): 21812191.

Dodds, P.N., Lawrence, G.J., Catanzariti, A.-M., Teh, T., Wang, C.-I.A., Ayliffe, M.A., Kobe, B., and Ellis, J.G. (2006). Direct protein interaction underlies gene-for-gene specificity and coevolution of the flax resistance genes and flax rust avirulence genes. Proc Natl Acad Sci U S A 103 (23): 8888-8893.

Dodds, P.N., and Rathjen, J.P. (2010). Plant immunity: towards an integrated view of plant-pathogen interactions. Nature reviews. Genetics 11 (8): 539-548.

Dong, J., Chen, C., and Chen, Z. (2003). Expression profiles of the Arabidopsis WRKY gene superfamily during plant defense response. Plant Mol Biol 51 (1): 21-37.

Dou, D., and Zhou, J.-M. (2012). Phytopathogen effectors subverting host immunity: different foes, similar battleground. Cell Host Microbe 12 (4): 484-495.

Dufu, K., Livingstone, M.J., Seebacher, J., Gygi, S.P., Wilson, S.A., and Reed, R. (2010). ATP is required for interactions between UAP56 and two conserved mRNA export proteins, Aly and CIP29, to assemble the TREX complex. Genes Dev 24 (18): 2043-2053.

Durrant, W.E., and Dong, X. (2004). Systemic acquired resistance. Annu Rev Phytopathol 42: 185-209.

Durrenberger, F., Crameri, A., Hohn, B., and Koukolikova-Nicola, Z. (1989). Covalently bound VirD2 protein of Agrobacterium tumefaciens protects the T-DNA from exonucleolytic degradation. Proc Natl Acad Sci U S A 86 (23): 9154-9158.

Eitas, T.K., and Dangl, J.L. (2010). NB-LRR proteins: pairs, pieces, perception, partners, and pathways. Curr Opin Plant Biol 13 (4): 472-477.

Eulgem, T., Rushton, P.J., Robatzek, S., and Somssich, I.E. (2000). The WRKY superfamily of plant transcription factors. Trends Plant Sci 5 (5): 199-206.

Eulgem, T., and Somssich, I.E. (2007). Networks of WRKY transcription factors in defense signaling. Curr Opin Plant Biol 10 (4): 366-371.

Fabre, E., Boelens, W.C., Wimmer, C., Mattaj, I.W., and Hurt, E.C. (1994). Nup145p is required for nuclear export of mRNA and binds homopolymeric RNA in vitro via a novel conserved motif. Cell 78 (2): 275289.

Fagerlund, R., Kinnunen, L., Kohler, M., Julkunen, I., and Melen, K. (2005). NF-\{kappa\}B is transported into the nucleus by importin $\alpha 3$ and importin $\alpha 4$. J Biol Chem 280 (16): 15942-15951. 
Fagerlund, R., Melen, K., Kinnunen, L., and Julkunen, I. (2002). Arginine/lysine-rich nuclear localization signals mediate interactions between dimeric STATs and importin alpha 5. J Biol Chem 277 (33): 3007230078.

Ferrández-Ayela, A., Alonso-Peral, M.M., Sánchez-García, A.B., Micol-Ponce, R., Pérez-Pérez, J.M., Micol, J.L., and Ponce, M.R. (2013). Arabidopsis TRANSCURVATA1 encodes NUP58, a component of the nucleopore central channel. PloS one 8 (6): e67661.

Feys, B.J., Wiermer, M., Bhat, R.A., Moisan, L.J., Medina-Escobar, N., Neu, C., Cabral, A., and Parker, J.E. (2005). Arabidopsis SENESCENCE-ASSOCIATED GENE101 stabilizes and signals within an ENHANCED DISEASE SUSCEPTIBILITY1 complex in plant innate immunity. Plant Cell 17 (9): 2601-2613.

Fiserova, J., Kiseleva, E., and Goldberg, M.W. (2009). Nuclear envelope and nuclear pore complex structure and organization in tobacco BY-2 cells. Plant J 59 (2): 243-255.

García, A.V., Blanvillain-Baufumé, S., Huibers, R.P., Wiermer, M., Li, G., Gobbato, E., Rietz, S., and Parker, J.E. (2010). Balanced nuclear and cytoplasmic activities of EDS1 are required for a complete plant innate immune response. PLoS Pathog. 6: e1000970.

García, A.V., and Parker, J.E. (2009). Heaven's Gate: nuclear accessibility and activities of plant immune regulators. Trends in plant science 14 (9): 479-487.

Gassmann, W., Hinsch, M.E., and Staskawicz, B.J. (1999). The Arabidopsis RPS4 bacterial-resistance gene is a member of the TIR-NBS-LRR family of disease-resistance genes. Plant J 20 (3): 265-277.

Gelvin, S.B. (2010). Plant proteins involved in Agrobacterium-mediated genetic transformation. Annu Rev Phytopathol 48: 45-68.

Germain, H., Qu, N., Cheng, Y.T., Lee, E., Huang, Y., Dong, O.X., Gannon, P., Huang, S., Ding, P., Li, Y., Sack, F., Zhang, Y., and Li, X. (2010). MOS11: a new component in the mRNA export pathway. PLoS Genet. 6 (12): e1001250.

Gilchrist, D., Mykytka, B., and Rexach, M. (2002). Accelerating the rate of disassembly of karyopherin.cargo complexes. J Biol Chem 277 (20): 18161-18172.

Goldberg, M.W., Wiese, C., Allen, T.D., and Wilson, K.L. (1997). Dimples, pores, star-rings, and thin rings on growing nuclear envelopes: evidence for structural intermediates in nuclear pore complex assembly. J Cell Sci 110 (Pt 4): 409-420.

Goldfarb, D.S., Corbett, A.H., Mason, D.A., Harreman, M.T., and Adam, S.A. (2004). Importin alpha: a multipurpose nuclear-transport receptor. Trends Cell Biol 14 (9): 505-514.

Gomez-Gomez, L., and Boller, T. (2000). FLS2: an LRR receptor-like kinase involved in the perception of the bacterial elicitor flagellin in Arabidopsis. Mol Cell 5 (6): 1003-1011.

Goritschnig, S., Weihmann, T., Zhang, Y., Fobert, P., McCourt, P., and Li, X. (2008). A novel role for protein farnesylation in plant innate immunity. Plant physiology 148 (1): 348-357.

Goritschnig, S., Zhang, Y., and Li, X. (2007). The ubiquitin pathway is required for innate immunity in Arabidopsis. Plant J. 49 (3): 540-551.

Görlich, D., Henklein, P., Laskey, R.A., and Hartmann, E. (1996). A 41 amino acid motif in importin-alpha confers binding to importin-beta and hence transit into the nucleus. EMBO J 15 (8): 1810-1817.

Görlich, D., and Kutay, U. (1999). Transport between the cell nucleus and the cytoplasm. Annu Rev Cell Dev Biol 15: 607-660.

Goujon, M., McWilliam, H., Li, W., Valentin, F., Squizzato, S., Paern, J., and Lopez, R. (2010). A new bioinformatics analysis tools framework at EMBL-EBI. Nucleic acids research $\mathbf{3 8}$ (Web Server issue): W695-9.

Griebel, T., Maekawa, T., and Parker, J.E. (2014). NOD-like receptor cooperativity in effector-triggered immunity. Trends in immunology 35 (11): 562-570.

Groth, M., Takeda, N., Perry, J., Uchida, H., Dräxl, S., Brachmann, A., Sato, S., Tabata, S., Kawaguchi, M., Wang, T.L., and Parniske, M. (2010). NENA, a Lotus japonicus homolog of Sec13, is required for rhizodermal infection by arbuscular mycorrhiza fungi and rhizobia but dispensable for cortical endosymbiotic development. The Plant cell 22 (7): 2509-2526.

Guan, T., Kehlenbach, R.H., Schirmer, E.C., Kehlenbach, A., Fan, F., Clurman, B.E., Arnheim, N., and Gerace, L. (2000). Nup50, a Nucleoplasmically Oriented Nucleoporin with a Role in Nuclear Protein Export. Molecular and cellular biology 20 (15): 5619-5630.

Haasen, D., Kohler, C., Neuhaus, G., and Merkle, T. (1999). Nuclear export of proteins in plants: AtXPO1 is the export receptor for leucine-rich nuclear export signals in Arabidopsis thaliana. Plant J 20 (6): 695705.

Haasen, D., and Merkle, T. (2002). Characterization of an Arabidopsis thaliana Homologue of the Nuclear Export Receptor CAS by its Interaction with Importin $\alpha$. Plant biol 4 (4): 432-439. 
Hall, M.N., Hereford, L., and Herskowitz, I. (1984). Targeting of E. coli beta-galactosidase to the nucleus in yeast. Cell 36 (4): 1057-1065.

Harreman, M.T., Cohen, P.E., Hodel, M.R., Truscott, G.J., Corbett, A.H., and Hodel, A.E. (2003). Characterization of the auto-inhibitory sequence within the $\mathrm{N}$-terminal domain of importin alpha. J Biol Chem 278 (24): 21361-21369.

He, P., Shan, L., Lin, N.-C., Martin, G.B., Kemmerling, B., Nürnberger, T., and Sheen, J. (2006). Specific bacterial suppressors of MAMP signaling upstream of MAPKKK in Arabidopsis innate immunity. Cell 125 (3): 563-575.

He, S., Huang, K., Zhang, X., Yu, X., Huang, P., and An, C. (2011). The LSD1-type zinc finger motifs of Pisum sativa LSD1 are a novel nuclear localization signal and interact with importin alpha. PloS one 6 (7): e22131.

Heath, M.C. (2000). Nonhost resistance and nonspecific plant defenses. Curr Opin Plant Biol 3 (4): 315-319.

Heazlewood, J.L., Tonti-Filippini, J., Verboom, R.E., and Millar, A.H. (2005). Combining experimental and predicted datasets for determination of the subcellular location of proteins in Arabidopsis. Plant Physiol 139 (2): 598-609.

Heazlewood, J.L., Verboom, R.E., Tonti-Filippini, J., Small, I., and Millar, A.H. (2007). SUBA: the Arabidopsis Subcellular Database. Nucleic Acids Res 35 (Database issue): D213-8.

Heidrich, K., Wirthmueller, L., Tasset, C., Pouzet, C., Deslandes, L., and Parker, J.E. (2011). Arabidopsis EDS1 connects pathogen effector recognition to cell compartment-specific immune responses. Science (New York, N.Y.) 334 (6061): 1401-1404.

Hemetsberger, C., Herrberger, C., Zechmann, B., Hillmer, M., and Doehlemann, G. (2012). The Ustilago maydis effector Pep1 suppresses plant immunity by inhibition of host peroxidase activity. PLoS Pathog. 8 (5): e1002684.

Herold, A., Truant, R., Wiegand, H., and Cullen, B.R. (1998). Determination of the functional domain organization of the importin alpha nuclear import factor. J Cell Biol 143 (2): 309-318.

Hicks, G.R., Smith, H.M., Shieh, M., and Raikhel, N.V. (1995). Three classes of nuclear import signals bind to plant nuclei. Plant Physiol 107 (4): 1055-1058.

Hillebrand, M.; Gersting, S. W.; Lotz-Havla, A. S.; Schäfer, A.; Rosewich, H.; Valerius, O.; Muntau A. C.; and Gärtner J. (2012). Identification of a new fatty acid synthesis-transport machinery at the peroxisomal membrane. J Biol Chem 287 (1): 210-221.

Hodel, A.E., Harreman, M.T., Pulliam, K.F., Harben, M.E., Holmes, J.S., Hodel, M.R., Berland, K.M., and Corbett, A.H. (2006). Nuclear localization signal receptor affinity correlates with in vivo localization in Saccharomyces cerevisiae. J Biol Chem 281 (33): 23545-23556.

Hoelz, A., Debler, E.W., and Blobel, G. (2011). The structure of the nuclear pore complex. Annual review of biochemistry 80: 613-643.

Hogarth, C.A., Calanni, S., Jans, D.A., and Loveland, K.L. (2006). Importin alpha mRNAs have distinct expression profiles during spermatogenesis. Dev Dyn 235 (1): 253-262.

Holub, Beynon, and Crute (1994). Phenotypic and Genotypic Characterization of Interactions between Isolates of Peronospora parasitica and Accessions of Arabidopsis thaliana. Mol. Plant Microbe Interact. 7: 223-239.

Horng, T., and Medzhitov, R. (2001). Drosophila MyD88 is an adapter in the Toll signaling pathway. Proc Natl Acad Sci U S A 98 (22): 12654-12658.

House, C., Roth, C., Hunt, J., and Kover, P.X. (2010). Paternal effects in Arabidopsis indicate that offspring can influence their own size. Proc. Biol. Sci. 277 (1695): 2885-2893.

Howard, E.A., Zupan, J.R., Citovsky, V., and Zambryski, P.C. (1992). The VirD2 protein of A. tumefaciens contains a C-terminal bipartite nuclear localization signal: implications for nuclear uptake of DNA in plant cells. Cell 68 (1): 109-118.

Hruz, T., Laule, O., Szabo, G., Wessendorp, F., Bleuler, S., Oertle, L., Widmayer, P., Gruissem, W., and Zimmermann, P. (2008). Genevestigator v3: a reference expression database for the meta-analysis of transcriptomes. Advances in bioinformatics 2008: 420747.

Hu, J., Wang, F., Yuan, Y., Zhu, X., Wang, Y., Zhang, Y., Kou, Z., Wang, S., and Gao, S. (2010). Novel importin-alpha family member Kpna7 is required for normal fertility and fecundity in the mouse. The Journal of biological chemistry 285 (43): 33113-33122.

Huang, T.T., Kudo, N., Yoshida, M., and Miyamoto, S. (2000). A nuclear export signal in the N-terminal regulatory domain of IkappaBalpha controls cytoplasmic localization of inactive NFkappaB/IkappaBalpha complexes. Proc Natl Acad Sci U S A 97 (3): 1014-1019.

Inoue H., Nojima H. and Okayama H. (1990). High efficiency transformation of Escherichia coli with plasmids. Gene 96: 23-28. 
Jakel, S., and Görlich, D. (1998). Importin beta, transportin, RanBP5 and RanBP7 mediate nuclear import of ribosomal proteins in mammalian cells. EMBO J 17 (15): 4491-4502.

Johnson, Dong, O.X., Huang, Y., and Li, X. (2012). A rolling stone gathers no moss, but resistant plants must gather their moses. Cold Spring Harb. Symp. Quant. Biol. 77: 259-268.

Johnson, C., van Antwerp, D., and Hope, T.J. (1999). An N-terminal nuclear export signal is required for the nucleocytoplasmic shuttling of IkappaBalpha. EMBO J 18 (23): 6682-6693.

Jones, J.D., and Dangl, J.L. (2006). The plant immune system. Nature 444 (7117): 323-329.

Jung, C., Seo, J.S., Han, S.W., Koo, Y.J., Kim, C.H., Song, S.I., Nahm, B.H., Choi, Y.D., and Cheong, J.-J. (2008). Overexpression of AtMYB44 enhances stomatal closure to confer abiotic stress tolerance in transgenic Arabidopsis. Plant Physiol 146 (2): 623-635.

Kaminaka, H., Nake, C., Epple, P., Dittgen, J., Schutze, K., Chaban, C., Holt, Ben F 3rd, Merkle, T., Schafer, E., Harter, K., and Dangl, J.L. (2006). bZIP10-LSD1 antagonism modulates basal defense and cell death in Arabidopsis following infection. EMBO J 25 (18): 4400-4411.

Kanamori, N., Madsen, L.H., Radutoiu, S., Frantescu, M., Quistgaard, Esben M H, Miwa, H., Downie, J.A., James, E.K., Felle, H.H., Haaning, L.L., Jensen, T.H., Sato, S., Nakamura, Y., Tabata, S., Sandal, N., and Stougaard, J. (2006). A nucleoporin is required for induction of Ca2+ spiking in legume nodule development and essential for rhizobial and fungal symbiosis. Proc Natl Acad Sci U S A 103 (2): 359364.

Kanneganti, T.-D., Bai, X., Tsai, C.-W., Win, J., Meulia, T., Goodin, M., Kamoun, S., and Hogenhout, S.A. (2007a). A functional genetic assay for nuclear trafficking in plants. Plant J 50 (1): 149-158.

Kanneganti, T.-D., Lamkanfi, M., and Nunez, G. (2007b). Intracellular NOD-like receptors in host defense and disease. Immunity 27 (4): 549-559.

Kearse, M., Moir, R., Wilson, A., Stones-Havas, S., Cheung, M., Sturrock, S., Buxton, S., Cooper, A., Markowitz, S., Duran, C., Thierer, T., Ashton, B., Meintjes, P., and Drummond, A. (2012). Geneious Basic: an integrated and extendable desktop software platform for the organization and analysis of sequence data. Bioinformatics (Oxford, England) 28 (12): 1647-1649.

Kelley, J.B., Talley, A.M., Spencer, A., Gioeli, D., and Paschal, B.M. (2010). Karyopherin alpha7 (KPNA7), a divergent member of the importin alpha family of nuclear import receptors. BMC cell biology 11: 63.

Kinkema, M., Fan, W., and Dong, X. (2000). Nuclear localization of NPR1 is required for activation of PR gene expression. Plant Cell 12 (12): 2339-2350.

Kiseleva, E., Rutherford, S., Cotter, L.M., Allen, T.D., and Goldberg, M.W. (2001). Steps of nuclear pore complex disassembly and reassembly during mitosis in early Drosophila embryos. J Cell Sci 114 (Pt 20): 3607-3618.

Kleinboelting, N., Huep, G., Kloetgen, A., Viehoever, P., and Weisshaar, B. (2012). GABI-Kat SimpleSearch: new features of the Arabidopsis thaliana T-DNA mutant database. Nucleic acids research $\mathbf{4 0}$ (Database issue): D1211-5.

Kobe, B. (1999). Autoinhibition by an internal nuclear localization signal revealed by the crystal structure of mammalian importin alpha. Nat Struct Biol 6 (4): 388-397.

Köhler, M., Ansieau, S., Prehn, S., Leutz, A., Haller, H., and Hartmann, E. (1997). Cloning of two novel human importin-alpha subunits and analysis of the expression pattern of the importin-alpha protein family. FEBS letters 417 (1): 104-108.

Köhler, M., Speck, C., Christiansen, M., Bischoff, F.R., Prehn, S., Haller, H., Görlich, D., and Hartmann, E. (1999). Evidence for Distinct Substrate Specificities of Importin a Family Members in Nuclear Protein Import. Mol Cell Biol 19 (11): 7782-7791.

Koncz, C., and Schell, J. (1986). The promoter of TL-DNA gene 5 controls the tissue-specific expression of chimaeric genes carried by a novel type of Agrobacterium binary vector. Molec Gen Genet 204 (3): 383396.

Kosugi, S., Hasebe, M., Entani, T., Takayama, S., Tomita, M., and Yanagawa, H. (2008). Design of peptide inhibitors for the importin alpha/beta nuclear import pathway by activity-based profiling. Chem Biol 15 (9): 940-949.

Kosugi, S., Hasebe, M., Matsumura, N., Takashima, H., Miyamoto-Sato, E., Tomita, M., and Yanagawa, H. (2009a). Six classes of nuclear localization signals specific to different binding grooves of importin alpha. J Biol Chem 284 (1): 478-485.

Kosugi, S., Hasebe, M., Tomita, M., and Yanagawa, H. (2009b). Systematic identification of cell cycledependent yeast nucleocytoplasmic shuttling proteins by prediction of composite motifs. Proc Natl Acad Sci U S A 106 (25): 10171-10176. 
Krasileva, K.V., Dahlbeck, D., and Staskawicz, B.J. (2010). Activation of an Arabidopsis resistance protein is specified by the in planta association of its leucine-rich repeat domain with the cognate oomycete effector. Plant Cell 22 (7): 2444-2458.

Krebs, J., Mueller-Roeber, B., and Ruzicic, S. (2010). A novel bipartite nuclear localization signal with an atypically long linker in DOF transcription factors. Journal of plant physiology 167 (7): 583-586.

Kutay, U., Bischoff, F.R., Kostka, S., Kraft, R., and Görlich, D. (1997). Export of importin alpha from the nucleus is mediated by a specific nuclear transport factor. Cell 90 (6): 1061-1071.

La Cour, T., Gupta, R., Rapacki, K., Skriver, K., Poulsen, F.M., and Brunak, S. (2003). NESbase version 1.0: a database of nuclear export signals. Nucleic Acids Res 31 (1): 393-396.

Lam, M.H., Briggs, L.J., Hu, W., Martin, T.J., Gillespie, M.T., and Jans, D.A. (1999). Importin beta recognizes parathyroid hormone-related protein with high affinity and mediates its nuclear import in the absence of importin alpha. J Biol Chem 274 (11): 7391-7398.

Lee, B.J., Cansizoglu, A.E., Suel, K.E., Louis, T.H., Zhang, Z., and Chook, Y.M. (2006). Rules for nuclear localization sequence recognition by karyopherin beta 2. Cell 126 (3): 543-558.

Lee, H.J., Kim, J.S., Yoo, S.J., Kang, E.Y., Han, S.H., Yang, K.-Y., Kim, Y.C., McSpadden Gardener, B., and Kang, H. (2012). Different roles of glycine-rich RNA-binding protein7 in plant defense against Pectobacterium carotovorum, Botrytis cinerea, and tobacco mosaic viruses. Plant Physiol Biochem 60: 46-52.

Lee, S.J., Sekimoto, T., Yamashita, E., Nagoshi, E., Nakagawa, A., Imamoto, N., Yoshimura, M., Sakai, H., Chong, K.T., Tsukihara, T., and Yoneda, Y. (2003). The structure of importin-beta bound to SREBP-2: nuclear import of a transcription factor. Science 302 (5650): 1571-1575.

Lee, S.-K., Song, M.-Y., Seo, Y.-S., Kim, H.-K., Ko, S., Cao, P.-J., Suh, J.-P., Yi, G., Roh, J.-H., Lee, S., An, G., Hahn, T.-R., Wang, G.-L., Ronald, P., and Jeon, J.-S. (2009). Rice Pi5-mediated resistance to Magnaporthe oryzae requires the presence of two coiled-coil-nucleotide-binding-leucine-rich repeat genes. Genetics 181 (4): 1627-1638.

Li, X., Clarke, J.D., Zhang, Y., and Dong, X. (2001). Activation of an EDS1-mediated R-gene pathway in the snc1 mutant leads to constitutive, NPR1-independent pathogen resistance. Mol. Plant Microbe Interact. 14 (10): 1131-1139.

Li, Y., Tessaro, M.J., Li, X., and Zhang, Y. (2010). Regulation of the expression of plant resistance gene SNC1 by a protein with a conserved BAT2 domain. Plant Physiol. 153 (3): 1425-1434.

Lim, C.P., and Cao, X. (2006). Structure, function, and regulation of STAT proteins. Mol Biosyst 2 (11): 536550.

Lin, N.-C., and Martin, G.B. (2005). An avrPto/avrPtoB mutant of Pseudomonas syringae pv. tomato DC3000 does not elicit Pto-mediated resistance and is less virulent on tomato. Mol Plant Microbe Interact 18 (1): 43-51.

Lindsay, M.E., Plafker, K., Smith, A.E., Clurman, B.E., and Macara, I.G. (2002). Npap60/Nup50 Is a Tri-Stable Switch that Stimulates Importin- $\alpha: \beta-M e d i a t e d ~ N u c l e a r$ Protein Import. Cell 110 (3): 349-360.

Lippincott-Schwartz, J., and Patterson, G.H. (2003). Development and use of fluorescent protein markers in living cells. Science (New York, N.Y.) 300 (5616): 87-91.

Liu, W.J., Wang, X.J., Mokhonov, V.V., Shi, P.-Y., Randall, R., and Khromykh, A.A. (2005). Inhibition of interferon signaling by the New York 99 strain and Kunjin subtype of West Nile virus involves blockage of STAT1 and STAT2 activation by nonstructural proteins. J Virol 79 (3): 1934-1942.

Liu, Z.-Q., Yan, L., Wu, Z., Mei, C., Lu, K., Yu, Y.-T., Liang, S., Zhang, X.-F., Wang, X.-F., and Zhang, D.-P. (2012). Cooperation of three WRKY-domain transcription factors WRKY18, WRKY40, and WRKY60 in repressing two ABA-responsive genes $A B I 4$ and ABI5 in Arabidopsis. Journal of experimental botany 63 (18): 6371-6392.

Long, J.C., and Caceres, J.F. (2009). The SR protein family of splicing factors: master regulators of gene expression. The Biochemical journal 417 (1): 15-27.

Lu, Q., Tang, X., Tian, G., Wang, F., Liu, K., Nguyen, V., Kohalmi, S.E., Keller, W.A., Tsang, Edward W T, Harada, J.J., Rothstein, S.J., and Cui, Y. (2010). Arabidopsis homolog of the yeast TREX-2 mRNA export complex: components and anchoring nucleoporin. Plant J 61 (2): 259-270.

Lukhovitskaya, N.I., Cowan, G.H., Vetukuri, R.R., Tilsner, J., Torrance, L., and Savenkov, E.I. (2015). Importin-alpha mediated nucleolar localisation of potato mop-top virus TGB1 protein facilitates virus systemic movement whereas TGB1 self-interaction is required for cell-to-cell movement in Nicotiana benthamiana. Plant Physiol.

Luo, Y., Wang, Z., Ji, H., Fang, H., Wang, S., Tian, L., and Li, X. (2013a). An Arabidopsis homolog of importin $\beta 1$ is required for ABA response and drought tolerance. Plant J 75 (3): 377-389. 
Luo, Y., Wang, Z., Tian, L., and Li, X. (2013b). The function of importin $\beta 1$ is conserved in eukaryotes but the substrates may vary in organisms. Plant signaling \& behavior 8 (8).

Mackey, D., Holt, B.F., Wiig, A., and Dangl, J.L. (2002). RIN4 Interacts with Pseudomonas syringae Type III Effector Molecules and Is Required for RPM1-Mediated Resistance in Arabidopsis. Cell 108 (6): 743754.

Maekawa, T., Cheng, W., Spiridon, L.N., Töller, A., Lukasik, E., Saijo, Y., Liu, P., Shen, Q.-H., Micluta, M.A., Somssich, I.E., Takken, Frank L W, Petrescu, A.-J., Chai, J., and Schulze-Lefert, P. (2011). Coiled-coil domain-dependent homodimerization of intracellular barley immune receptors defines a minimal functional module for triggering cell death. Cell host \& microbe 9 (3): 187-199.

Mahalingam, R., Gomez-Buitrago, A., Eckardt, N., Shah, N., Guevara-Garcia, A., Day, P., Raina, R., and Fedoroff, N.V. (2003). Characterizing the stress/defense transcriptome of Arabidopsis. Genome Biol 4 (3): R20.

Malek, S., Chen, Y., Huxford, T., and Ghosh, G. (2001). IkappaBbeta, but not IkappaBalpha, functions as a classical cytoplasmic inhibitor of NF-kappaB dimers by masking both NF-kappaB nuclear localization sequences in resting cells. J Biol Chem 276 (48): 45225-45235.

Mang, H.-G., Qian, W., Zhu, Y., Qian, J., Kang, H.-G., Klessig, D.F., and Hua, J. (2012). Abscisic acid deficiency antagonizes high-temperature inhibition of disease resistance through enhancing nuclear accumulation of resistance proteins SNC1 and RPS4 in Arabidopsis. Plant Cell 24 (3): 1271-1284.

Marfori, M., Lonhienne, T.G., Forwood, J.K., and Kobe, B. (2012). Structural basis of high-affinity nuclear localization signal interactions with importin-alpha. Traffic 13 (4): 532-548.

Marfori, M., Mynott, A., Ellis, J.J., Mehdi, A.M., Saunders, Neil F W, Curmi, P.M., Forwood, J.K., Boden, M., and Kobe, B. (2011). Molecular basis for specificity of nuclear import and prediction of nuclear localization. Biochim Biophys Acta 1813 (9): 1562-1577.

Marín, M., Thallmair, V., and Ott, T. (2013). The intrinsically disordered N-terminal region of AtREM1.3 remorin protein mediates protein-protein interactions. The Journal of biological chemistry 287 (47): 39982-39991.

Matallana-Ramirez, L.P., Rauf, M., Farage-Barhom, S., Dortay, H., Xue, G.-P., Dröge-Laser, W., Lers, A., Balazadeh, S., and Mueller-Roeber, B. (2013). NAC transcription factor ORE1 and senescence-induced BIFUNCTIONAL NUCLEASE1 (BFN1) constitute a regulatory cascade in Arabidopsis. Molecular plant 6 (5): 1438-1452.

Matsuura, Y., and Stewart, M. (2004). Structural basis for the assembly of a nuclear export complex. Nature 432 (7019): 872-877.

Matsuura, Y., and Stewart, M. (2005). Nup50/Npap60 function in nuclear protein import complex disassembly and importin recycling. The EMBO journal 24 (21): 3681-3689.

Maul, G.G. (1977). The nuclear and the cytoplasmic pore complex: structure, dynamics, distribution, and evolution. Int Rev Cytol Suppl (6): 75-186.

Medzhitov, R., Preston-Hurlburt, P., Kopp, E., Stadlen, A., Chen, C., Ghosh, S., and Janeway, C.A. (1998). MyD88 Is an Adaptor Protein in the hToll/IL-1 Receptor Family Signaling Pathways. Molecular Cell 2 (2): 253-258.

Meier, I. (2007). Composition of the plant nuclear envelope: theme and variations. J Exp Bot 58 (1): 27-34.

Meier, I., and Somers, D.E. (2011). Regulation of nucleocytoplasmic trafficking in plants. Current opinion in plant biology 14 (5): 538-546.

Meissner, T.B., Li, A., Liu, Y.-J., Gagnon, E., and Kobayashi, K.S. (2012a). The nucleotide-binding domain of NLRC5 is critical for nuclear import and transactivation activity. Biochem Biophys Res Commun 418 (4): 786-791.

Meissner, T.B., Liu, Y.-J., Lee, K.-H., Li, A., Biswas, A., van Eggermond, Marja C J A, van den Elsen, Peter J, and Kobayashi, K.S. (2012b). NLRC5 cooperates with the RFX transcription factor complex to induce MHC class I gene expression. J Immunol 188 (10): 4951-4958.

Melen, K., Fagerlund, R., Franke, J., Kohler, M., Kinnunen, L., and Julkunen, I. (2003). Importin alpha nuclear localization signal binding sites for STAT1, STAT2, and influenza A virus nucleoprotein. The Journal of biological chemistry 278 (30): 28193-28200.

Melen, K., Kinnunen, L., and Julkunen, I. (2001). Arginine/lysine-rich structural element is involved in interferon-induced nuclear import of STATs. J Biol Chem 276 (19): 16447-16455.

Merkle, T. (2001). Nuclear import and export of proteins in plants: a tool for the regulation of signalling. Planta 213 (4): 499-517.

Merkle, T. (2011). Nucleo-cytoplasmic transport of proteins and RNA in plants. Plant Cell Rep 30 (2): 153176. 
Meyers, B.C. (2003). Genome-Wide Analysis of NBS-LRR-Encoding Genes in Arabidopsis. THE PLANT CELL ONLINE 15 (4): 809-834.

Meyers, B.C., Morgante, M., and Michelmore, R.W. (2002). TIR-X and TIR-NBS proteins: two new families related to disease resistance TIR-NBS-LRR proteins encoded in Arabidopsis and other plant genomes. The Plant Journal 32 (1): 77-92.

Michael, W.M., Choi, M., and Dreyfuss, G. (1995). A nuclear export signal in hnRNP A1: a signal-mediated, temperature-dependent nuclear protein export pathway. Cell 83 (3): 415-422.

Miya, A., Albert, P., Shinya, T., Desaki, Y., Ichimura, K., Shirasu, K., Narusaka, Y., Kawakami, N., Kaku, H., and Shibuya, N. (2007). CERK1, a LysM receptor kinase, is essential for chitin elicitor signaling in Arabidopsis. Proc Natl Acad Sci U S A 104 (49): 19613-19618.

Miyamoto, Y., Imamoto, N., Sekimoto, T., Tachibana, T., Seki, T., Tada, S., Enomoto, T., and Yoneda, Y. (1997). Differential modes of nuclear localization signal (NLS) recognition by three distinct classes of NLS receptors. J Biol Chem 272 (42): 26375-26381.

Monaghan, J., Xu, F., Xu, S., Zhang, Y., and Li, X. (2010). Two putative RNA-binding proteins function with unequal genetic redundancy in the MOS4-associated complex. Plant Physiol. 154 (4): 1783-1793.

Mou, Z., Fan, W., and Dong, X. (2003). Inducers of plant systemic acquired resistance regulate NPR1 function through redox changes. Cell 113 (7): 935-944.

Mukhtar, M.S., Carvunis, A.-R., Dreze, M., Epple, P., Steinbrenner, J., Moore, J., Tasan, M., Galli, M., Hao, T., Nishimura, M.T., Pevzner, S.J., Donovan, S.E., Ghamsari, L., Santhanam, B., Romero, V., Poulin, M.M., Gebreab, F., Gutierrez, B.J., Tam, S., Monachello, D., Boxem, M., Harbort, C.J., McDonald, N., Gai, L., Chen, H., He, Y., Vandenhaute, J., Roth, F.P., Hill, D.E., Ecker, J.R., Vidal, M., Beynon, J., Braun, P., and Dangl, J.L. (2011). Independently evolved virulence effectors converge onto hubs in a plant immune system network. Science (New York, N.Y.) 333 (6042): 596-601.

Mülhardt, C. (2009). Der Experimentator: Molekularbiologie/Genomics (Heidelberg: Spektrum Akademischer Verlag).

Murashige, T., and Skoog, F. (1962). A Revised Medium for Rapid Growth and Bio Assays with Tobacco Tissue Cultures. Physiol Plant 15 (3): 473-497.

Nadler, S.G., Tritschler, D., Haffar, O.K., Blake, J., Bruce, A.G., and Cleaveland, J.S. (1997). Differential expression and sequence-specific interaction of karyopherin alpha with nuclear localization sequences. J Biol Chem 272 (7): 4310-4315.

Nagoshi, E., and Yoneda, Y. (2001). Dimerization of sterol regulatory element-binding protein 2 via the helix-loop-helix-leucine zipper domain is a prerequisite for its nuclear localization mediated by importin beta. Mol Cell Biol 21 (8): 2779-2789.

Nandety, R.S., Caplan, J.L., Cavanaugh, K., Perroud, B., Wroblewski, T., Michelmore, R.W., and Meyers, B.C. (2013). The role of TIR-NBS and TIR-X proteins in plant basal defense responses. Plant physiology 162 (3): 1459-1472.

Narusaka, M., Shirasu, K., Noutoshi, Y., Kubo, Y., Shiraishi, T., Iwabuchi, M., and Narusaka, Y. (2009). RRS1 and RPS4 provide a dual Resistance-gene system against fungal and bacterial pathogens. Plant J 60 (2): 218-226.

Ndunguru, J., Taylor, N.J., Yadav, J., Aly, H., Legg, J.P., Aveling, T., Thompson, G., and Fauquet, C.M. (2005). Application of FTA technology for sampling, recovery and molecular characterization of viral pathogens and virus-derived transgenes from plant tissues. Virology journal 2: 45.

Nelson, B.K., Cai, X., and Nebenführ, A. (2007). A multicolored set of in vivo organelle markers for colocalization studies in Arabidopsis and other plants. Plant J 51 (6): 1126-1136.

Neumann, N., Lundin, D., and Poole, A.M. (2010). Comparative genomic evidence for a complete nuclear pore complex in the last eukaryotic common ancestor. PloS one 5 (10): e13241.

Nicaise, V., Joe, A., Jeong, B.-r., Korneli, C., Boutrot, F., Westedt, I., Staiger, D., Alfano, J.R., and Zipfel, C. (2013). Pseudomonas HopU1 modulates plant immune receptor levels by blocking the interaction of their mRNAs with GRP7. The EMBO journal 32 (5): 701-712.

Nishimura, M.T., and Dangl, J.L. (2014). Plant science. Paired plant immune receptors. Science (New York, N.Y.) 344 (6181): 267-268.

Noutoshi, Y., Ito, T., Seki, M., Nakashita, H., Yoshida, S., Marco, Y., Shirasu, K., and Shinozaki, K. (2005). A single amino acid insertion in the WRKY domain of the Arabidopsis TIR-NBS-LRR-WRKY-type disease resistance protein SLH1 (sensitive to low humidity 1 ) causes activation of defense responses and hypersensitive cell death. Plant J 43 (6): 873-888.

Nürnberger, T., and Brunner, F. (2002). Innate immunity in plants and animals: emerging parallels between the recognition of general elicitors and pathogen-associated molecular patterns. Curr Opin Plant Biol 5 (4): 318-324. 
O'Brien, H.E., Thakur, S., and Guttman, D.S. (2011). Evolution of plant pathogenesis in Pseudomonas syringae: a genomics perspective. Annual review of phytopathology 49: 269-289.

Okuyama, Y., Kanzaki, H., Abe, A., Yoshida, K., Tamiru, M., Saitoh, H., Fujibe, T., Matsumura, H., Shenton, M., Galam, D.C., Undan, J., Ito, A., Sone, T., and Terauchi, R. (2011). A multifaceted genomics approach allows the isolation of the rice Pia-blast resistance gene consisting of two adjacent NBS-LRR protein genes. Plant J 66 (3): 467-479.

Ouyang, S., Zhu, W., Hamilton, J., Lin, H., Campbell, M., Childs, K., Thibaud-Nissen, F., Malek, R.L., Lee, Y., Zheng, L., Orvis, J., Haas, B., Wortman, J., and Buell, C.R. (2007). The TIGR Rice Genome Annotation Resource: improvements and new features. Nucleic acids research 35 (Database issue): D883-7.

Palma, K., Zhang, Y., and Li, X. (2005). An importin alpha homolog, MOS6, plays an important role in plant innate immunity. Curr. Biol. 15 (12): 1129-1135.

Palmeri, D., and Malim, M.H. (1999). Importin beta can mediate the nuclear import of an arginine-rich nuclear localization signal in the absence of importin alpha. Mol Cell Biol 19 (2): 1218-1225.

Panstruga, R., and Dodds, P.N. (2009). Terrific protein traffic: the mystery of effector protein delivery by filamentous plant pathogens. Science (New York, N.Y.) 324 (5928): 748-750.

Park, C.-J., and Ronald, P.C. (2012). Cleavage and nuclear localization of the rice XA21 immune receptor. Nature communications 3: 920.

Parker, J.E., Szabo, V., Staskawicz, B.J., Lister, C., Dean, C., Daniels, M.J., and Jones, J. (1993). Phenotypic characterization and molecular mapping of the Arabidopsis thaliana locus RPP5, determining disease resistance to Peronospora parasitica. Plant J 4 (5): 821-831.

Parry, G. (2014). Components of the Arabidopsis nuclear pore complex play multiple diverse roles in control of plant growth. Journal of experimental botany 65 (20): 6057-6067.

Parry, G., Ward, S., Cernac, A., Dharmasiri, S., and Estelle, M. (2006). The Arabidopsis SUPPRESSOR OF AUXIN RESISTANCE proteins are nucleoporins with an important role in hormone signaling and development. Plant Cell 18 (7): 1590-1603.

Pemberton, L.F., and Paschal, B.M. (2005). Mechanisms of receptor-mediated nuclear import and nuclear export. Traffic 6 (3): 187-198.

Petre, B., and Kamoun, S. (2014). How do filamentous pathogens deliver effector proteins into plant cells? PLoS biology 12 (2): e1001801.

Petutschnig, E.K., Jones, Alexandra M E, Serazetdinova, L., Lipka, U., and Lipka, V. (2010). The lysin motif receptor-like kinase (LysM-RLK) CERK1 is a major chitin-binding protein in Arabidopsis thaliana and subject to chitin-induced phosphorylation. The Journal of biological chemistry 285 (37): 28902-28911.

Pitzschke, A., and Hirt, H. (2010). New insights into an old story: Agrobacterium-induced tumour formation in plants by plant transformation. EMBO J 29 (6): 1021-1032.

Pollard, V.W., Michael, W.M., Nakielny, S., Siomi, M.C., Wang, F., and Dreyfuss, G. (1996). A novel receptor-mediated nuclear protein import pathway. Cell 86 (6): 985-994.

Pumroy, R.A., and Cingolani, G. (2015). Diversification of importin- $\alpha$ isoforms in cellular trafficking and disease states. The Biochemical journal 466 (1): 13-28.

Qi, D., DeYoung, B.J., and Innes, R.W. (2012). Structure-function analysis of the coiled-coil and leucine-rich repeat domains of the RPS5 disease resistance protein. Plant Physiol 158 (4): 1819-1832.

Quensel, C., Friedrich, B., Sommer, T., Hartmann, E., and Kohler, M. (2004). In vivo analysis of importin alpha proteins reveals cellular proliferation inhibition and substrate specificity. Molecular and cellular biology 24 (23): 10246-10255.

Quimby, B.B., Leung, S.W., Bayliss, R., Harreman, M.T., Thirumala, G., Stewart, M., and Corbett, A.H. (2001). Functional analysis of the hydrophobic patch on nuclear transport factor 2 involved in interactions with the nuclear pore in vivo. J Biol Chem 276 (42): 38820-38829.

Ratan, R., Mason, D.A., Sinnot, B., Goldfarb, D.S., and Fleming, R.J. (2008). Drosophila importin alpha1 performs paralog-specific functions essential for gametogenesis. Genetics 178 (2): 839-850.

Rehmany, A.P., Gordon, A., Rose, L.E., Allen, R.L., Armstrong, M.R., Whisson, S.C., Kamoun, S., Tyler, B.M., Birch, Paul R J, and Beynon, J.L. (2005). Differential recognition of highly divergent downy mildew avirulence gene alleles by RPP1 resistance genes from two Arabidopsis lines. The Plant cell 17 (6): 1839-1850.

Reichelt, R. (1990). Correlation between structure and mass distribution of the nuclear pore complex and of distinct pore complex components. The Journal of Cell Biology 110 (4): 883-894.

Ribbeck, K., Lipowsky, G., Kent, H.M., Stewart, M., and Görlich, D. (1998). NTF2 mediates nuclear import of Ran. EMBO J 17 (22): 6587-6598.

Riddick, G., and Macara, I.G. (2005). A systems analysis of importin-\{alpha\}-\{beta\} mediated nuclear protein import. J Cell Biol 168 (7): 1027-1038. 
Rivas, S., and Deslandes, L. (2013). Nuclear components and dynamics during plant innate immunity. Frontiers in plant science 4: 481.

Ronald, P.C., and Beutler, B. (2010). Plant and animal sensors of conserved microbial signatures. Science (New York, N.Y.) 330 (6007): 1061-1064.

Roth, C., and Wiermer, M. (2012). Nucleoporins Nup160 and Seh1 are required for disease resistance in Arabidopsis. Plant Signal Behav 7 (10): 1212-1214.

Roth, P., Xylourgidis, N., Sabri, N., Uv, A., Fornerod, M., and Samakovlis, C. (2003). The Drosophila nucleoporin DNup88 localizes DNup214 and CRM1 on the nuclear envelope and attenuates NESmediated nuclear export. The Journal of Cell Biology 163 (4): 701-706.

Rout, M.P. (1993). Isolation of the yeast nuclear pore complex. The Journal of Cell Biology 123 (4): 771-783.

Ryan, K.J., and Wente, S.R. (2000). The nuclear pore complex: a protein machine bridging the nucleus and cytoplasm. Curr Opin Cell Biol 12 (3): 361-371.

Sacco, M.A., Mansoor, S., and Moffett, P. (2007). A RanGAP protein physically interacts with the NB-LRR protein Rx, and is required for Rx-mediated viral resistance. Plant J 52 (1): 82-93.

Saito, K., Yoshikawa, M., Yano, K., Miwa, H., Uchida, H., Asamizu, E., Sato, S., Tabata, S., ImaizumiAnraku, H., Umehara, Y., Kouchi, H., Murooka, Y., Szczyglowski, K., Downie, J.A., Parniske, M., Hayashi, M., and Kawaguchi, M. (2007). NUCLEOPORIN85 is required for calcium spiking, fungal and bacterial symbioses, and seed production in Lotus japonicus. Plant Cell 19 (2): 610-624.

Schmid, M., Davison, T.S., Henz, S.R., Pape, U.J., Demar, M., Vingron, M., Schölkopf, B., Weigel, D., and Lohmann, J.U. (2005). A gene expression map of Arabidopsis thaliana development. Nature genetics 37 (5): 501-506.

Scholl, R.L., May, S.T., and Ware, D.H. (2000). Seed and molecular resources for Arabidopsis. Plant physiology 124 (4): 1477-1480.

Schön, M., Töller, A., Diezel, C., Roth, C., Westphal, L., Wiermer, M., and Somssich, I.E. (2013). Analyses of wrky18 wrky40 plants reveal critical roles of SA/EDS1 signaling and indole-glucosinolate biosynthesis for Golovinomyces orontii resistance and a loss-of resistance towards Pseudomonas syringae pv. tomato AvrRPS4. Mol. Plant Microbe Interact. 26 (7): 758-767.

Schornack, S., van Damme, M., Bozkurt, T.O., Cano, L.M., Smoker, M., Thines, M., Gaulin, E., Kamoun, S., and Huitema, E. (2010). Ancient class of translocated oomycete effectors targets the host nucleus. Proc Natl Acad Sci U S A 107 (40): 17421-17426.

Schwessinger, B., and Zipfel, C. (2008). News from the frontline: recent insights into PAMP-triggered immunity in plants. Current opinion in plant biology 11 (4): 389-395.

Shang, Y., Yan, L., Liu, Z.-Q., Cao, Z., Mei, C., Xin, Q., Wu, F.-Q., Wang, X.-F., Du, S.-Y., Jiang, T., Zhang, X.F., Zhao, R., Sun, H.-L., Liu, R., Yu, Y.-T., and Zhang, D.-P. (2010). The Mg-chelatase H subunit of Arabidopsis antagonizes a group of WRKY transcription repressors to relieve ABA-responsive genes of inhibition. The Plant cell 22 (6): 1909-1935.

Shen, Q.-H., Saijo, Y., Mauch, S., Biskup, C., Bieri, S., Keller, B., Seki, H., Ulker, B., Somssich, I.E., and Schulze-Lefert, P. (2007). Nuclear activity of MLA immune receptors links isolate-specific and basal disease-resistance responses. Science 315 (5815): 1098-1103.

Shevchenko, A., Wilm, M., Vorm, O., and Mann, M. (1996). Mass spectrometric sequencing of proteins silver-stained polyacrylamide gels. Analytical chemistry 68 (5): 850-858.

Shurvinton, C.E., Hodges, L., and Ream, W. (1992). A nuclear localization signal and the C-terminal omega sequence in the Agrobacterium tumefaciens VirD2 endonuclease are important for tumor formation. Proc Natl Acad Sci U S A 89 (24): 11837-11841.

Slootweg, E., Roosien, J., Spiridon, L.N., Petrescu, A.-J., Tameling, W., Joosten, M., Pomp, R., van Schaik, C., Dees, R., Borst, J.W., Smant, G., Schots, A., Bakker, J., and Goverse, A. (2010). Nucleocytoplasmic distribution is required for activation of resistance by the potato NB-LRR receptor Rx1 and is balanced by its functional domains. The Plant cell 22 (12): 4195-4215.

Smyth, D.R., Bowman, J.L., and Meyerowitz, E.M. (1990). Early flower development in Arabidopsis. The Plant cell 2 (8): 755-767.

Song, J., Tan, H., Perry, A.J., Akutsu, T., Webb, G.I., Whisstock, J.C., and Pike, R.N. (2012). PROSPER: an integrated feature-based tool for predicting protease substrate cleavage sites. PloS one 7 (11): e50300.

Song, W.-Y., Wang, G.-L., Chen, L.-L., Kim, H.-S., Pi, L.-Y., Holsten, T., Gardner, J., Wang, B., Zhai, W.-X., Zhu, L.-H., Fauquet, C., and Ronald, P. (1995). A Receptor Kinase-Like Protein Encoded by the Rice Disease Resistance Gene, Xa21. Science 270 (5243): 1804-1806.

Spilianakis, C., Papamatheakis, J., and Kretsovali, A. (2000). Acetylation by PCAF enhances CIITA nuclear accumulation and transactivation of major histocompatibility complex class II genes. Mol Cell Biol 20 (22): 8489-8498. 
Stade, K., Ford, C.S., Guthrie, C., and Weis, K. (1997). Exportin 1 (Crm1p) is an essential nuclear export factor. Cell 90 (6): 1041-1050.

Stade, K., Vogel, F., Schwienhorst, I., Meusser, B., Volkwein, C., Nentwig, B., Dohmen, R.J., and Sommer, T. (2002). A lack of SUMO conjugation affects cNLS-dependent nuclear protein import in yeast. J Biol Chem 277 (51): 49554-49561.

Stegmann, M., Anderson, R.G., Ichimura, K., Pecenkova, T., Reuter, P., Žársky, V., McDowell, J.M., Shirasu, K., and Trujillo, M. (2012). The ubiquitin ligase PUB22 targets a subunit of the exocyst complex required for PAMP-triggered responses in Arabidopsis. The Plant cell 24 (11): 4703-4716.

Steinbrenner, A.D., Goritschnig, S., Krasileva, K.V., Schreiber, K.J., and Staskawicz, B.J. (2012). Effector recognition and activation of the Arabidopsis thaliana NLR innate immune receptors. Cold Spring Harbor symposia on quantitative biology 77: 249-257.

Steinbrenner, A.D., Goritschnig, S., and Staskawicz, B.J. (2015). Recognition and Activation Domains Contribute to Allele-Specific Responses of an Arabidopsis NLR Receptor to an Oomycete Effector Protein. PLoS pathogens 11 (2): e1004665.

Stewart, M. (2007a). Molecular mechanism of the nuclear protein import cycle. Nat Rev Mol Cell Biol 8 (3): 195-208.

Stewart, M. (2007b). Molecular mechanism of the nuclear protein import cycle. Nat Rev Mol Cell Biol 8 (3): 195-208.

Strawn, L.A., Shen, T., Shulga, N., Goldfarb, D.S., and Wente, S.R. (2004). Minimal nuclear pore complexes define FG repeat domains essential for transport. Nat Cell Biol 6 (3): 197-206.

Sugio, A., MacLean, A.M., and Hogenhout, S.A. (2014). The small phytoplasma virulence effector SAP11 contains distinct domains required for nuclear targeting and CIN-TCP binding and destabilization. The New phytologist 202 (3): 838-848.

Sugiura, T., Sakurai, K., and Nagano, Y. (2007). Intracellular characterization of DDX39, a novel growthassociated RNA helicase. Exp Cell Res 313 (4): 782-790.

Sun, X., Pang, H., Li, M., Chen, J., and Hang, Y. (2014). Tracing the origin and evolution of plant TIRencoding genes. Gene 546 (2): 408-416.

Suntharalingam, M., and Wente, S.R. (2003). Peering through the PoreNuclear Pore Complex Structure, Assembly, and Function. Developmental Cell 4 (6): 775-789.

Swiderski, M.R., Birker, D., and Jones, J. (2009). The TIR domain of TIR-NB-LRR resistance proteins is a signaling domain involved in cell death induction. Mol Plant Microbe Interact 22 (2): 157-165.

Tada, Y., Spoel, S.H., Pajerowska-Mukhtar, K., Mou, Z., Song, J., Wang, C., Zuo, J., and Dong, X. (2008). Plant immunity requires conformational changes [corrected] of NPR1 via S-nitrosylation and thioredoxins. Science (New York, N.Y.) 321 (5891): 952-956.

Takemoto, D., Rafiqi, M., Hurley, U., Lawrence, G.J., Bernoux, M., Hardham, A.R., Ellis, J.G., Dodds, P.N., and Jones, D.A. (2012). N-terminal motifs in some plant disease resistance proteins function in membrane attachment and contribute to disease resistance. Mol Plant Microbe Interact 25 (3): $379-$ 392.

Takizawa, C.G., Weis, K., and Morgan, D.O. (1999). Ran-independent nuclear import of cyclin B1-Cdc2 by importin. Proceedings of the National Academy of Sciences 96 (14): 7938-7943.

Tameling, W., and Baulcombe, D. (2007). Physical association of the NB-LRR resistance protein Rx with a Ran GTPase-activating protein is required for extreme resistance to Potato virus X. Plant Cell 19 (5): 1682-1694.

Tameling, W., Nooijen, C., Ludwig, N., Boter, M., Slootweg, E., Goverse, A., Shirasu, K., and Joosten, Matthieu H A J (2010). RanGAP2 mediates nucleocytoplasmic partitioning of the NB-LRR immune receptor Rx in the Solanaceae, thereby dictating Rx function. The Plant cell 22 (12): 4176-4194.

Tamura, K., Dudley, J., Nei, M., and Kumar, S. (2007). MEGA4: Molecular Evolutionary Genetics Analysis (MEGA) software version 4.0. Molecular biology and evolution 24 (8): 1596-1599.

Tamura, K., Fukao, Y., Iwamoto, M., Haraguchi, T., and Hara-Nishimura, I. (2010). Identification and characterization of nuclear pore complex components in Arabidopsis thaliana. The Plant cell 22 (12): 4084-4097.

Tamura, K., and Hara-Nishimura, I. (2011). Involvement of the nuclear pore complex in morphology of the plant nucleus. Nucleus 2 (3): 168-172.

Tamura, K., and Hara-Nishimura, I. (2013). The molecular architecture of the plant nuclear pore complex. Journal of experimental botany 64 (4): 823-832.

Tanz, S.K., Castleden, I., Hooper, C.M., Vacher, M., Small, I., and Millar, H.A. (2013). SUBA3: a database for integrating experimentation and prediction to define the SUBcellular location of proteins in Arabidopsis. Nucleic Acids Res 41 (Database issue): D1185-91. 
Tasset, C., Bernoux, M., Jauneau, A., Pouzet, C., Brière, C., Kieffer-Jacquinod, S., Rivas, S., Marco, Y., and Deslandes, L. (2010). Autoacetylation of the Ralstonia solanacearum effector PopP2 targets a lysine residue essential for RRS1-R-mediated immunity in Arabidopsis. PLoS pathogens 6 (11): e1001202.

Teh, O.-K., and Hofius, D. (2014). Membrane trafficking and autophagy in pathogen-triggered cell death and immunity. Journal of experimental botany 65 (5): 1297-1312.

Terry, L.J., Shows, E.B., and Wente, S.R. (2007). Crossing the nuclear envelope: hierarchical regulation of nucleocytoplasmic transport. Science 318 (5855): 1412-1416.

Thomma, B., Nürnberger, T., and Joosten, Matthieu H A J (2011). Of PAMPs and effectors: the blurred PTIETI dichotomy. The Plant cell 23 (1): 4-15.

Timney, B.L., Tetenbaum-Novatt, J., Agate, D.S., Williams, R., Zhang, W., Chait, B.T., and Rout, M.P. (2006). Simple kinetic relationships and nonspecific competition govern nuclear import rates in vivo. J Cell Biol 175 (4): 579-593.

Torres, M. de, Mansfield, J.W., Grabov, N., Brown, I.R., Ammouneh, H., Tsiamis, G., Forsyth, A., Robatzek, S., Grant, M., and Boch, J. (2006). Pseudomonas syringae effector AvrPtoB suppresses basal defence in Arabidopsis. Plant J 47 (3): 368-382.

Toufighi, K., Brady, S.M., Austin, R., Ly, E., and Provart, N.J. (2005). The Botany Array Resource: eNortherns, Expression Angling, and promoter analyses. Plant J 43 (1): 153-163.

Tsuji, L., Takumi, T., Imamoto, N., and Yoneda, Y. (1997). Identification of novel homologues of mouse importin alpha, the alpha subunit of the nuclear pore-targeting complex, and their tissue-specific expression. FEBS letters 416 (1): 30-34.

Tsukaya, H., lokawa, Y., Kondo, M., and Ohba, H. (2005). Large-scale general collection of wild-plant DNA in Mustang, Nepal. Journal of plant research 118 (1): 57-60.

Ueda, H., Yamaguchi, Y., and Sano, H. (2006). Direct interaction between the tobacco mosaic virus helicase domain and the ATP-bound resistance protein, $\mathrm{N}$ factor during the hypersensitive response in tobacco plants. Plant Mol Biol 61 (1-2): 31-45.

Uv, A.E., Roth, P., Xylourgidis, N., Wickberg, A., Cantera, R., and Samakovlis, C. (2000). members only encodes a Drosophila nucleoporin required for rel protein import and immune response activation. Genes Dev 14 (15): 1945-1957.

Van Der Biezen, Erik A., and Jones, J. (1998). Plant disease-resistance proteins and the gene-for-gene concept. Trends in Biochemical Sciences 23 (12): 454-456.

Vasu, S., Shah, S., Orjalo, A., Park, M., Fischer, W.H., and Forbes, D.J. (2001). Novel vertebrate nucleoporins Nup133 and Nup160 play a role in mRNA export. The Journal of Cell Biology 155 (3): 339354.

Veronese, P., Ruiz, M.T., Coca, M.A., Hernandez-Lopez, A., Lee, H., Ibeas, J.I., Damsz, B., Pardo, J.M., Hasegawa, P.M., Bressan, R.A., and Narasimhan, M.L. (2003). In Defense against Pathogens. Both Plant Sentinels and Foot Soldiers Need to Know the Enemy. Plant Physiol 131 (4): 1580-1590.

Voinnet, O., Rivas, S., Mestre, P., and Baulcombe, D. (2003). An enhanced transient expression system in plants based on suppression of gene silencing by the p19 protein of tomato bushy stunt virus. Plant J 33 (5): 949-956.

Wagner, S., Stuttmann, J., Rietz, S., Guerois, R., Brunstein, E., Bautor, J., Niefind, K., and Parker, J.E. (2013). Structural basis for signaling by exclusive EDS1 heteromeric complexes with SAG101 or PAD4 in plant innate immunity. Cell Host Microbe 14 (6): 619-630.

Wang, D., Weaver, N.D., Kesarwani, M., and Dong, X. (2005). Induction of protein secretory pathway is required for systemic acquired resistance. Science 308 (5724): 1036-1040.

Wang, R., and Brattain, M.G. (2007). The maximal size of protein to diffuse through the nuclear pore is larger than 60kDa. FEBS Lett 581 (17): 3164-3170.

Wang, W., Yang, X., Kawai, T., López de Silanes, Isabel, Mazan-Mamczarz, K., Chen, P., Chook, Y.M., Quensel, C., Köhler, M., and Gorospe, M. (2004). AMP-activated protein kinase-regulated phosphorylation and acetylation of importin alpha1: involvement in the nuclear import of RNA-binding protein HuR. The Journal of biological chemistry 279 (46): 48376-48388.

Weaver, L., Swiderski, M.R., Li, Y., and Jones, J. (2006). The Arabidopsis thaliana TIR-NB-LRR R-protein, RPP1A; protein localization and constitutive activation of defence by truncated alleles in tobacco and Arabidopsis. Plant J 47 (6): 829-840.

Weinthal, D.M., Barash, I., Tzfira, T., Gaba, V., Teper, D., Sessa, G., and Manulis-Sasson, S. (2011). Characterization of nuclear localization signals in the type III effectors HsvG and HsvB of the gallforming bacterium Pantoea agglomerans. Microbiology (Reading, England) 157 (Pt 5): 1500-1508.

Weßling, R., Epple, P., Altmann, S., He, Y., Yang, L., Henz, S.R., McDonald, N., Wiley, K., Bader, K.C., Gläßer, C., Mukhtar, M.S., Haigis, S., Ghamsari, L., Stephens, A.E., Ecker, J.R., Vidal, M., Jones, J D G, 
Mayer, Klaus F X, Ver Loren van Themaat, Emiel, Weigel, D., Schulze-Lefert, P., Dangl, J.L., Panstruga, R., and Braun, P. (2014). Convergent targeting of a common host protein-network by pathogen effectors from three kingdoms of life. Cell Host Microbe 16 (3): 364-375.

Whitham, S., Dinesh-Kumar, S.P., Choi, D., Hehl, R., Corr, C., and Baker, B. (1994). The product of the tobacco mosaic virus resistance gene N: Similarity to toll and the interleukin-1 receptor. Cell 78 (6): 1101-1115.

Wiermer, M., Cheng, Y.T., Imkampe, J., Li, M., Wang, D., Lipka, V., and Li, X. (2012). Putative members of the Arabidopsis Nup107-160 nuclear pore sub-complex contribute to pathogen defense. Plant J. 70 (5): 796-808.

Wiermer, M., Germain, H., Cheng, Y.T., García, A.V., Parker, J.E., and Li, X. (2010). Nucleoporin MOS7/Nup88 contributes to plant immunity and nuclear accumulation of defense regulators. Nucleus 1 (4): 332-336.

Wiermer, M., Palma, K., Zhang, Y., and Li, X. (2007). Should I stay or should I go? Nucleocytoplasmic trafficking in plant innate immunity. Cell. Microbiol. 9 (8): 1880-1890.

Williams, S.J., Sohn, K.H., Wan, L., Bernoux, M., Sarris, P.F., Segonzac, C., Ve, T., Ma, Y., Saucet, S.B., Ericsson, D.J., Casey, L.W., Lonhienne, T., Winzor, D.J., Zhang, X., Coerdt, A., Parker, J.E., Dodds, P.N., Kobe, B., and Jones, Jonathan D G (2014). Structural basis for assembly and function of a heterodimeric plant immune receptor. Science 344 (6181): 299-303.

Winey, M., Yarar, D., Giddings, T H Jr, and Mastronarde, D.N. (1997). Nuclear pore complex number and distribution throughout the Saccharomyces cerevisiae cell cycle by three-dimensional reconstruction from electron micrographs of nuclear envelopes. Mol Biol Cell 8 (11): 2119-2132.

Winter, D., Vinegar, B., Nahal, H., Ammar, R., Wilson, G.V., and Provart, N.J. (2007). An \"Electronic Fluorescent Pictograph\" browser for exploring and analyzing large-scale biological data sets. PloS one 2 (8): e718.

Wirthmueller, L., Roth, C., Banfield, M.J., and Wiermer, M. (2013). Hop-on hop-off: importin- $\alpha$-guided tours to the nucleus in innate immune signaling. Front Plant Sci 4: 149.

Wirthmueller, L., Roth, C., Fabro, G., Caillaud, M.-C., Rallapalli, G., Asai, S., Sklenar, J., Jones, Alexandra M E, Wiermer, M., Jones, J D G, and Banfield, M.J. (2015). Probing formation of cargo/importin- $\alpha$ transport complexes in plant cells using a pathogen effector. Plant J.

Wirthmueller, L., Zhang, Y., Jones, J D G, and Parker, J.E. (2007). Nuclear accumulation of the Arabidopsis immune receptor RPS4 is necessary for triggering EDS1-dependent defense. Curr Biol 17 (23): 20232029.

Witte, C.-P., Noël, L.D., Gielbert, J., Parker, J.E., and Romeis, T. (2004). Rapid one-step protein purification from plant material using the eight-amino acid Strepll epitope. Plant molecular biology 55 (1): 135-147.

Xu, F., Cheng, Y.T., Kapos, P., Huang, Y., and Li, X. (2014). P-loop-dependent NLR SNC1 can oligomerize and activate immunity in the nucleus. Mol Plant 7 (12): 1801-1804.

Xu, F., Xu, S., Wiermer, M., Zhang, Y., and Li, X. (2012). The cyclin L homolog MOS12 and the MOS4associated complex are required for the proper splicing of plant resistance genes. Plant J. 70 (6): $916-$ 928.

Xu, S., Zhang, Z., Jing, B., Gannon, P., Ding, J., Xu, F., Li, X., and Zhang, Y. (2011). Transportin-SR is required for proper splicing of resistance genes and plant immunity. PLoS Genet. 7 (6): e1002159.

Xu, X., Chen, C., Fan, B., and Chen, Z. (2006). Physical and functional interactions between pathogeninduced Arabidopsis WRKY18, WRKY40, and WRKY60 transcription factors. The Plant cell 18 (5): 13101326.

Xu, X.M., Meulia, T., and Meier, I. (2007). Anchorage of plant RanGAP to the nuclear envelope involves novel nuclear-pore-associated proteins. Curr Biol 17 (13): 1157-1163.

Yamada, K., Lim, J., Dale, J.M., Chen, H., Shinn, P., Palm, C.J., Southwick, A.M., Wu, H.C., Kim, C., Nguyen, M., Pham, P., Cheuk, R., Karlin-Newmann, G., Liu, S.X., Lam, B., Sakano, H., Wu, T., Yu, G., Miranda, M., Quach, H.L., Tripp, M., Chang, C.H., Lee, J.M., Toriumi, M., Chan, Marie M H, Tang, C.C., Onodera, C.S., Deng, J.M., Akiyama, K., Ansari, Y., Arakawa, T., Banh, J., Banno, F., Bowser, L., Brooks, S., Carninci, P., Chao, Q., Choy, N., Enju, A., Goldsmith, A.D., Gurjal, M., Hansen, N.F., Hayashizaki, Y., Johnson-Hopson, C., Hsuan, V.W., lida, K., Karnes, M., Khan, S., Koesema, E., Ishida, J., Jiang, P.X., Jones, T., Kawai, J., Kamiya, A., Meyers, C., Nakajima, M., Narusaka, M., Seki, M., Sakurai, T., Satou, M., Tamse, R., Vaysberg, M., Wallender, E.K., Wong, C., Yamamura, Y., Yuan, S., Shinozaki, K., Davis, R.W., Theologis, A., and Ecker, J.R. (2003). Empirical analysis of transcriptional activity in the Arabidopsis genome. Science (New York, N.Y.) 302 (5646): 842-846.

Yang, S., Zhang, X., Yue, J.-X., Tian, D., and Chen, J.-Q. (2008). Recent duplications dominate NBS-encoding gene expansion in two woody species. Molecular genetics and genomics MGG 280 (3): 187-198. 
Yasuhara, N., Shibazaki, N., Tanaka, S., Nagai, M., Kamikawa, Y., Oe, S., Asally, M., Kamachi, Y., Kondoh, H., and Yoneda, Y. (2007). Triggering neural differentiation of ES cells by subtype switching of importinalpha. Nature cell biology 9 (1): 72-79.

Yu, D., Chen, C., and Chen, Z. (2001). Evidence for an important role of WRKY DNA binding proteins in the regulation of NPR1 gene expression. Plant Cell 13 (7): 1527-1540.

Yuan, B., Zhai, C., Wang, W., Zeng, X., Xu, X., Hu, H., Lin, F., Wang, L., and Pan, Q. (2011). The Pik-p resistance to Magnaporthe oryzae in rice is mediated by a pair of closely linked CC-NBS-LRR genes. TAG. Theoretical and applied genetics. Theoretische und angewandte Genetik 122 (5): 1017-1028.

Zannini, L., Lecis, D., Lisanti, S., Benetti, R., Buscemi, G., Schneider, C., and Delia, D. (2003). Karyopherinalpha2 protein interacts with Chk2 and contributes to its nuclear import. The Journal of biological chemistry 278 (43): 42346-42351.

Zbierzak, A.M., Porfirova, S., Griebel, T., Melzer, M., Parker, J.E., and Dörmann, P. (2013). A TIR-NBS protein encoded by Arabidopsis Chilling Sensitive 1 (CHS1) limits chloroplast damage and cell death at low temperature. Plant J 75 (4): 539-552.

Zdobnov, E.M., and Apweiler, R. (2001). InterProScan - an integration platform for the signaturerecognition methods in InterPro. Bioinformatics 17 (9): 847-848.

Zehorai, E., and Seger, R. (2014). Beta-like importins mediate the nuclear translocation of mitogenactivated protein kinases. Molecular and cellular biology 34 (2): 259-270.

Zhai, C., Lin, F., Dong, Z., He, X., Yuan, B., Zeng, X., Wang, L., and Pan, Q. (2011). The isolation and characterization of Pik, a rice blast resistance gene which emerged after rice domestication. The New phytologist 189 (1): 321-334.

Zhang, J., Campbell, R.E., Ting, A.Y., and Tsien, R.Y. (2002). Creating new fluorescent probes for cell biology. Nature reviews. Molecular cell biology 3 (12): 906-918.

Zhang, Y., Cheng, Y.T., Bi, D., Palma, K., and Li, X. (2005). MOS2, a protein containing G-patch and KOW motifs, is essential for innate immunity in Arabidopsis thaliana. Curr. Biol. 15 (21): 1936-1942.

Zhang, Y., Fan, W., Kinkema, M., Li, X., and Dong, X. (1999). Interaction of NPR1 with basic leucine zipper protein transcription factors that bind sequences required for salicylic acid induction of the PR-1 gene. Proc Natl Acad Sci U S A 96 (11): 6523-6528.

Zhang, Y., Goritschnig, S., Dong, X., and Li, X. (2003). A gain-of-function mutation in a plant disease resistance gene leads to constitutive activation of downstream signal transduction pathways in suppressor of npr1-1, constitutive 1. Plant Cell 15 (11): 2636-2646.

Zhang, Y., and Li, X. (2005). A putative nucleoporin 96 Is required for both basal defense and constitutive resistance responses mediated by suppressor of npr1-1,constitutive 1. Plant Cell 17 (4): 1306-1316.

Zhao, Q., Leung, S., Corbett, A.H., and Meier, I. (2006). Identification and characterization of the Arabidopsis orthologs of nuclear transport factor 2, the nuclear import factor of ran. Plant Physiol 140 (3): 869-878.

Zhao, T., Rui, L., Li, J., Nishimura, M.T., Vogel, J.P., Liu, N., Liu, S., Zhao, Y., Dangl, J.L., and Tang, D. (2015). A Truncated NLR Protein, TIR-NBS2, Is Required for Activated Defense Responses in the exo70B1 Mutant. PLoS genetics 11 (1): e1004945.

Zheng, Z., Qamar, S.A., Chen, Z., and Mengiste, T. (2006). Arabidopsis WRKY33 transcription factor is required for resistance to necrotrophic fungal pathogens. Plant J 48 (4): 592-605.

Zhu, Z., Xu, F., Zhang, Y., Cheng, Y.T., Wiermer, M., Li, X., and Zhang, Y. (2010). Arabidopsis resistance protein SNC1 activates immune responses through association with a transcriptional corepressor. Proc. Natl. Acad. Sci. U.S.A. 107 (31): 13960-13965.

Ziemienowicz, A., Haasen, D., Staiger, D., and Merkle, T. (2003). Arabidopsis transportin1 is the nuclear import receptor for the circadian clock-regulated RNA-binding protein AtGRP7. Plant molecular biology 53 (1-2): 201-212.

Zipfel, C., Kunze, G., Chinchilla, D., Caniard, A., Jones, J D G, Boller, T., and Felix, G. (2006). Perception of the bacterial PAMP EF-Tu by the receptor EFR restricts Agrobacterium-mediated transformation. Cell 125 (4): 749-760.

Zipfel, C., Robatzek, S., Navarro, L., Oakeley, E.J., Jones, J D G, Felix, G., and Boller, T. (2004). Bacterial disease resistance in Arabidopsis through flagellin perception. Nature 428 (6984): 764-767.

Zou, T., Liu, L., Rao, J.N., Marasa, B.S., Chen, J., Xiao, L., Zhou, H., Gorospe, M., and Wang, J.-Y. (2008). Polyamines modulate the subcellular localization of RNA-binding protein HuR through AMP-activated protein kinase-regulated phosphorylation and acetylation of importin alpha1. The Biochemical journal 409 (2): 389-398. 


\section{Supplemental material}

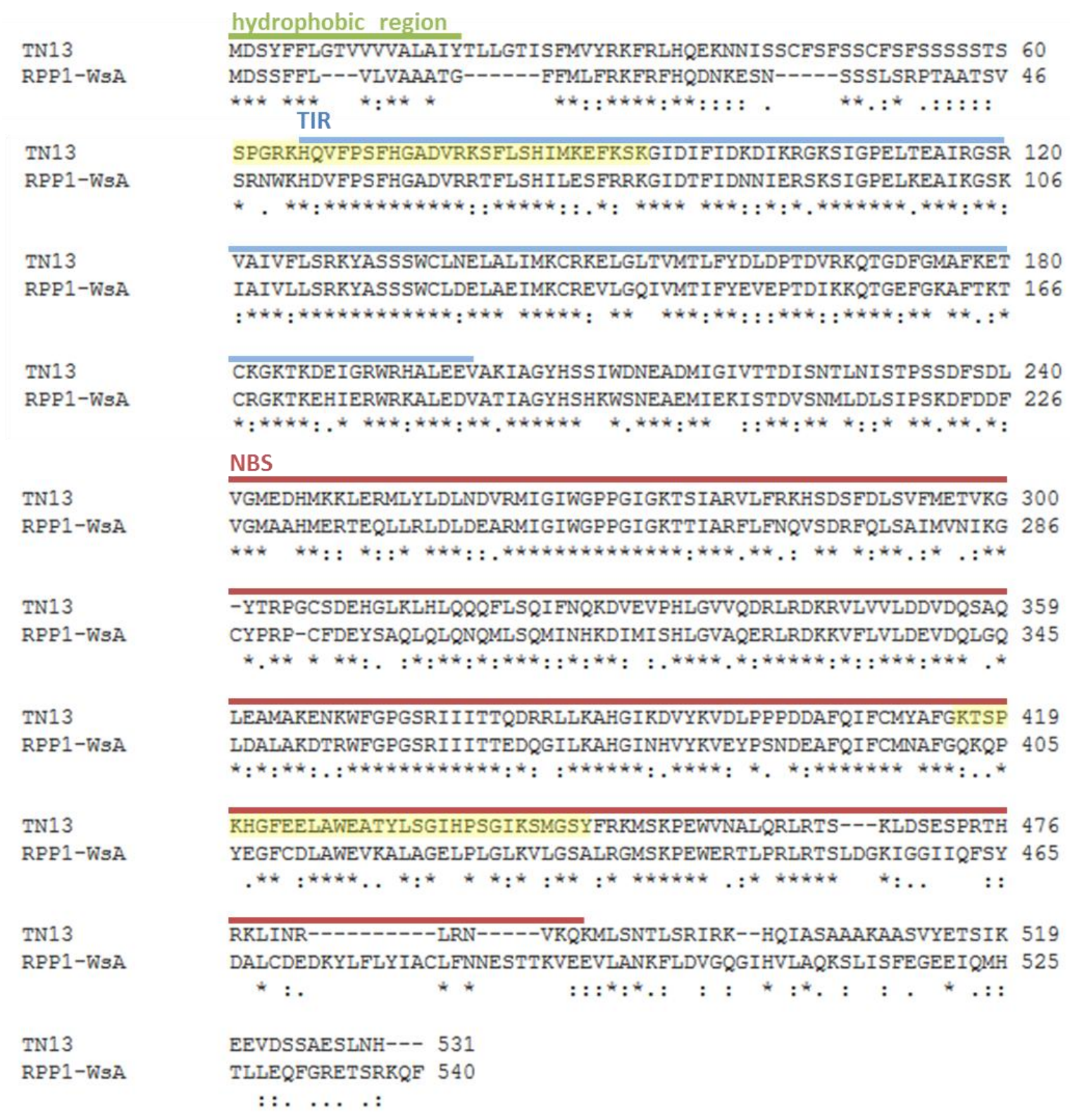

Figure S1 Amino acid sequence comparison of TN13 and RPP1-WsA. The full-length amino acid sequence of TN13 was aligned to N-terminal sequence of RPP1-WSA (amino acids 1 - 540) containing the TIR and NBS domains with ClustalW2 (http://www.ebi.ac.uk/Tools/msa/clustalw2/; Larkin et al., 2007). N-terminal hydrophobic region depicted in green, location of predicted TIR and NBS domains in blue and red, respectively. Yellow areas indicate amino acids that are predicted to contribute to bipartite NLS binding sites in TN13. Consensus symbols are depicted according to ClustalW2 formate: asterisks indicate positions which have a single, fully conserved residue. Colons indicate conservation between groups of strongly similar properties (scoring $>0.5$ in the Gonnet PAM 250 matrix). Periods indicates conservation between groups of weakly similar properties (scoring $=<0.5$ in the Gonnet PAM 250 matrix, Larkin et al., 2007). 


\section{Danksagung}

Ich möchte mich ganz herzlich bei allen bedanken, die mich in den letzten Jahren bei der Arbeit an meiner Dissertation unterstützt haben.

Allen voran möchte ich Dr. Marcel Wiermer danken, der mir dieses interessante Thema zur Verfügung gestellt und mir die Freiheit gegeben hat, das Projekt nach eigenen Vorstellungen mitzugestalten. Darüber hinaus möchte ich mich bei ihm für die freundschaftliche Atmosphäre, seine ständige Hilfe, Diskussionsbereitschaft und konstruktive Kritik bedanken, die zum Gelingen der vorliegenden Arbeit, der Posterpräsentationen und vieler Vorträge beigetragen haben.

Meinem Erstprüfer Prof. Dr. Volker Lipka danke ich für die Möglichkeit meine Arbeit in seiner Abteilung anfertigen zu dürfen. Durch seine unvoreingenommene und objektive Art hat er mich stets sehr unterstützt und den regen Austausch von Ideen und Gedanken in der Arbeitsgruppe gefördert.

PD Dr. Thomas Teichmann, möchte ich ebenfalls herzlich für die Übernahme des Korreferates dieser Arbeit und die Hilfe bei zahlreichen großen und kleinen Problemen danken.

Bei Prof. Dr. Christiane Gatz, Prof. Dr. Cynthia Gleason, Prof. Dr. Andrea Polle und Prof. Dr. Ivo Feußner bedanke ich mich für die Bereitschaft zusammen mit meinen Thesis Komitee meine Prüfungskommission zu bilden.

Prof. Dr. Gerhard Braus und vor allem Dr. Oliver Valerius danke ich für die Durchführung der MS-Analysen und die Hilfe bei der Auswertung der Ergebnisse.

Den technischen Assistentinnen Kathi, Ludmilla, Melanie, Gaby, Ronny und Sabine danke ich für ihre zuverlässige und gewissenhafte Hilfe im Laboralltag und darüber hinaus.

Feli, Susanne und Herrn Wedemeyer möchte ich für die Hilfe, die über die Bereitstellung von hunderten Schalen gestopfter Töpfe hinaus ging, danken.

Allen aktuellen und ehemaligen Mitgliedern der Arbeitsgruppe Lipka danke ich für die ständige Hilfsbereitschaft, die freundschaftliche Arbeitsatmosphäre und die vielen Geburtstags- und Weihnachtsfeiern, Ein- und Ausstände und all das. Vielen Dank!

Danke Alex, Karin, Yvonne und vor allem Marcel für das Korrekturlesen.

Ein besonderes Dankeschön geht an Melanie! Ohne ihre Hilfe und Freundschaft hätte ich die Arbeit, die zu dieser Dissertation geführt hat kaum bewältigen können. 
Alex, Karin, Yvi und Johanna gilt mein deutlicher Dank: Wir haben getanzt, haben geweint, haben gelacht und hatten eine wirklich, wirklich, wirklich gute Zeit.

Zu großem Dank bin ich meinen Eltern, Geschwistern und Großeltern verpflichtet, die mich in jeglicher Hinsicht unterstützt und somit das Gelingen dieser Arbeit ermöglicht haben. Danke Oma und Hanna für die vielen aufbauenden und motivierenden Gespräche, Telefonate und das stunden- und tagelange Daumendrücken! 
